DOE/BC--95/5/SP

Distribution Category UC-122 \& 125

\title{
OIL PROGRAM IMPLEMENTATION PLAN
}

FY $1996-2000$

April 1995

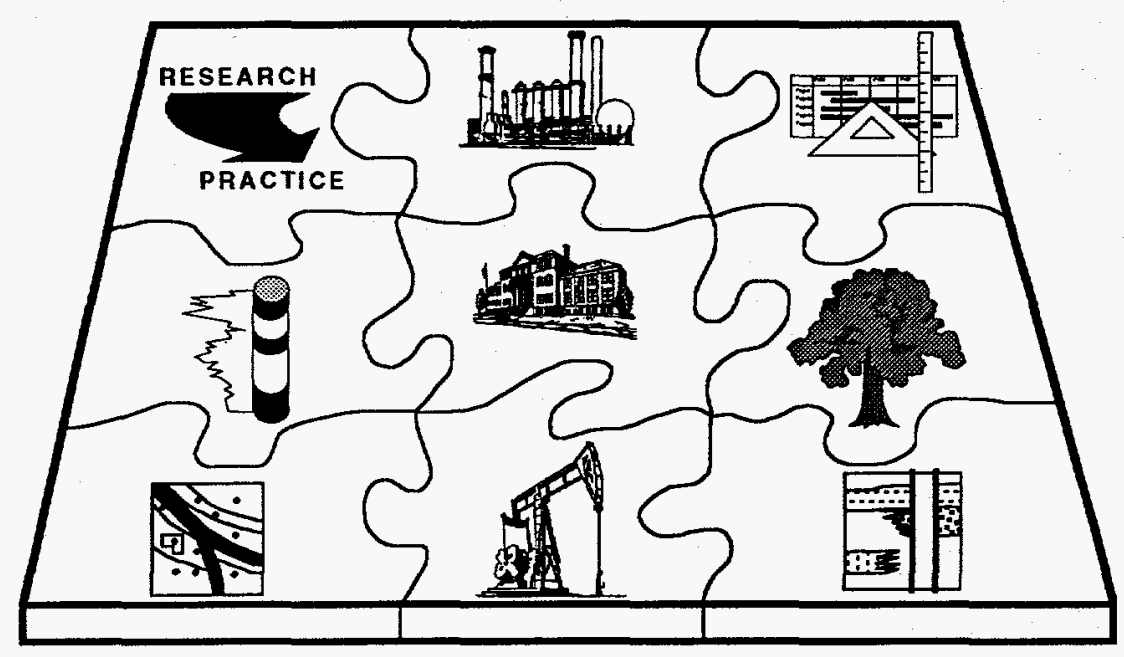

Prepared for

U.S. Department of Energy

Assistant Secretary for Fossil Energy

Bartlesville Project Office

P.O. Box 1398

Bartlesville, OK 74005

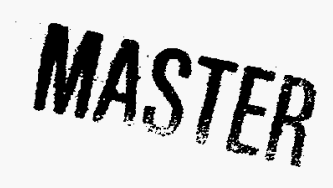

DISTRIBUTION OF THIS DOCUMENT IS UNLMITED

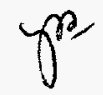





\section{DISCLAIMER}

This report was prepared as an account of work sponsored by an agency of the United States Government. Neither the United States Government nor any agency thereof, nor any of their employees, make any warranty, express or implied, or assumes any legal liability or responsibility for the accuracy, completeness, or usefulness of any information, apparatus, product, or process disclosed, or represents that its use would not infringe privately owned rights. Reference herein to any specific commercial product, process, or service by trade name, trademark, manufacturer, or otherwise does not necessarily constitute or imply its endorsement, recommendation, or favoring by the United States Government or any agency thereof. The views and opinions of authors expressed herein do not necessarily state or reflect those of the United States Government or any agency thereof. 


\section{DISCLAIMER}

Portions of this document may be illegible in electronic image products. Images are produced from the best available original document. 


\section{FOREWORD}

This document reaffirms the U.S. Department of Energy (DOE) Office of Fossil Energy commitment to implement the National Oil Research Program in a way to maximize assurance of energy security, economic growth, environmental protection, jobs, improved economic competitiveness, and improved U.S. balance of trade. Components of the program are designed to meet the roles indicated by Congress in the Energy Policy Act of 1992, the President in the Domestic Natural Gas and Oil Initiative, and the Secretary of Energy's Fueling a Competitive Economy Strategic Plan, April of 1994. Although this implementation plan describes DOE's planned actions for FY 1996-2000, the strategic directions and research activities are extensions of current activities in FY 1995.

The DOE Bartlesville Project Office (BPO) and its management and operations contractor has the ultimate responsibility to implement the $\mathrm{Na}$ tional Oil Program. While there is a significant amount of research conducted at the National Institute for Petroleum and Energy Research (NIPER) in Bartlesville, Oklahoma, other research activities and funding are directed to industry partnerships, cost-shared projects, universities, national laboratories, and private consultants.

There are two sections and an appendix in this document. Section 1 is background information that guided its formulation and a summary of the Oil Program Implementation Plan. This summary includes mission statements, major program drivers, oil issues and trends, budget issues, customers/stakeholders, technology transfer, measures of program effectiveness, and benefits. Section 2 contains more detailed program descriptions for the eight technical areas and the NIPER infrastructure. Each description contains an overview of the program, descriptions on main areas, a discussion of stakeholders, impacts, planned budget projections, projected schedules with Gantt charts, and measures of effectiveness. The appendix is a summary of comments from industry on an earlier draft of the plan. Although changes were made in response to the comments, many of the suggestions will be used as guidance for the FY 1997-2001 plan.

Nine committees contributed to this plan, one for each technical area and an infrastructure committee. Each committee was chaired by the Bartlesville Project Office or Metairie Site Office manager in charge of the program area. Committee membership included the Fossil Energy Headquarters manager, NIPER managers working in the technical area, representatives from other federal agencies (United States Geological Survey, Minerals Management Service), representatives from other DOE offices (i.e., Energy Information Agency, Naval Petroleum Reserve \#3), and outside subject area experts. These committees met in a series of meetings during April 1994 in Bartlesville. 


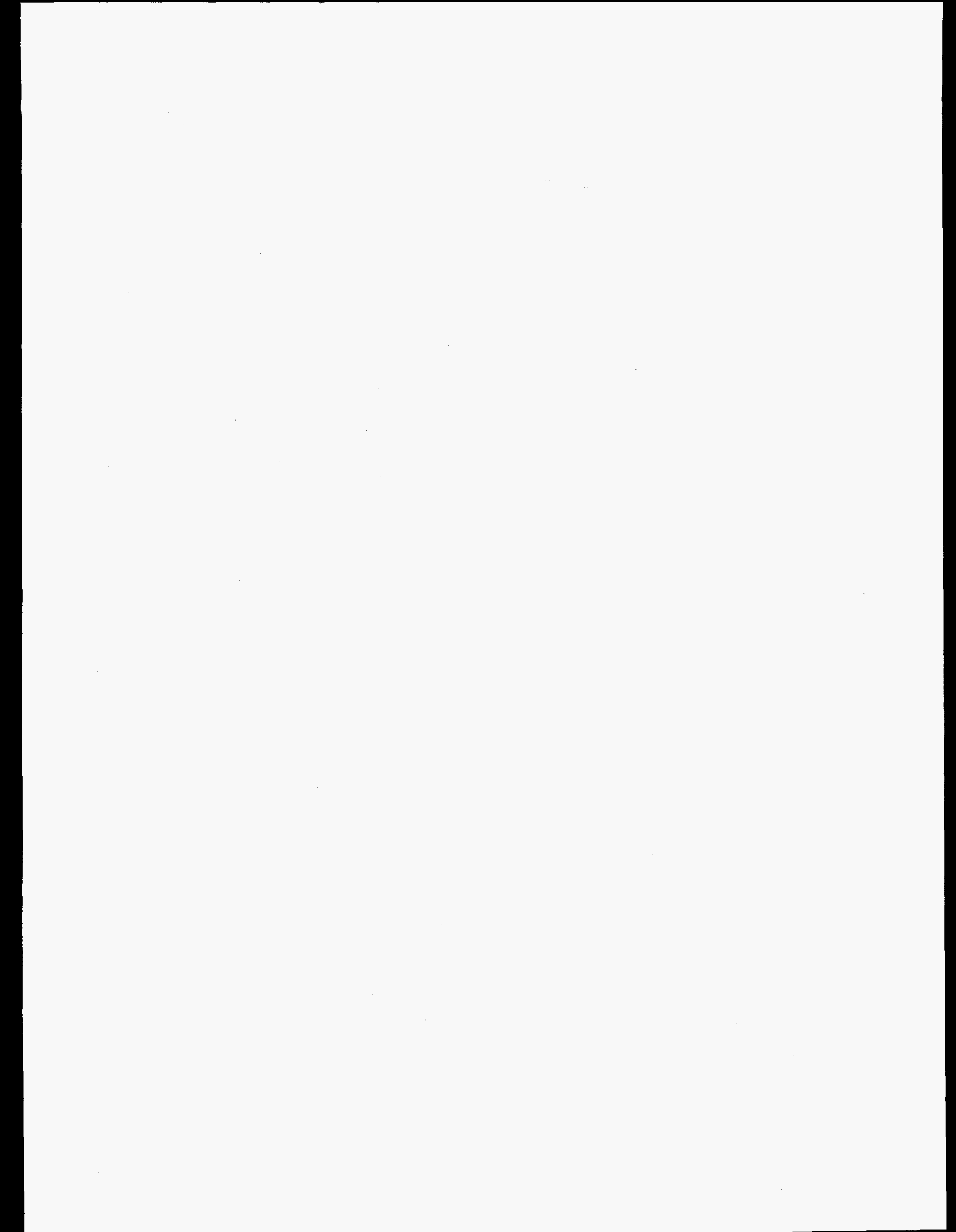




\section{CONTENTS}

\section{SECTION 1}

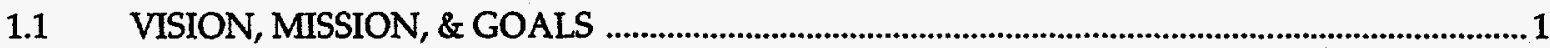

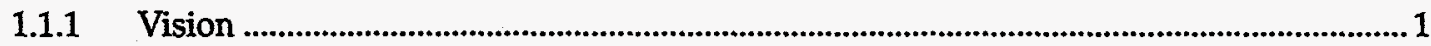

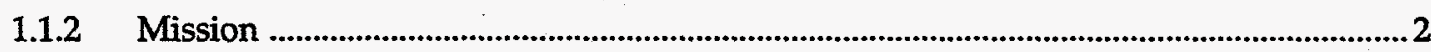

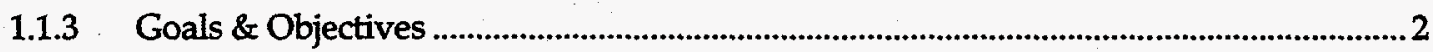

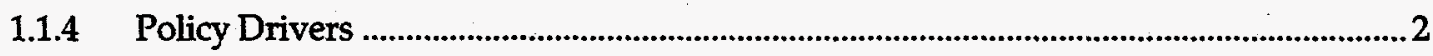

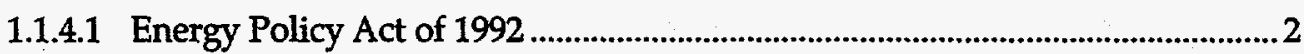

1.1.4.2 Domestic Natural Gas \& Oil Initiative .............................................................

1.1.4.3 DOE Strategic Plan ......................................................................................3

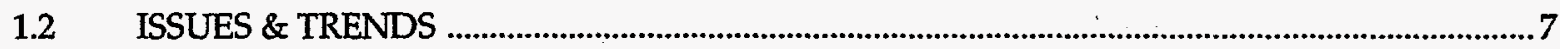

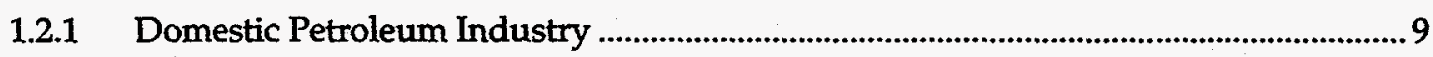

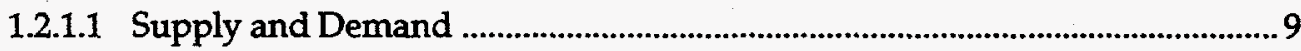

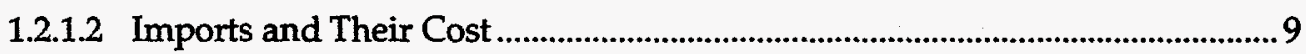

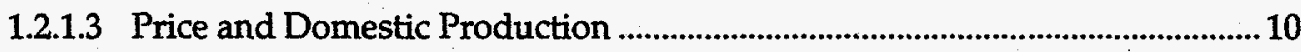

1.2.1.4 Marginal Wells and Abandonment ...............................................................10

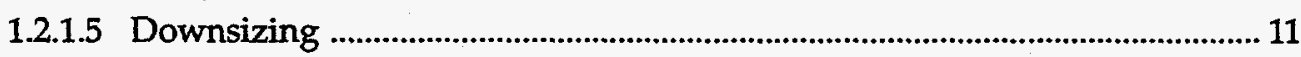

1.2.1.6 Exploration and Drilling ............................................................................. 11

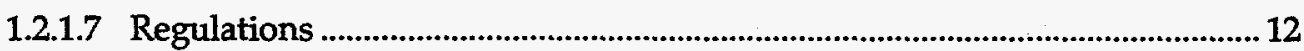

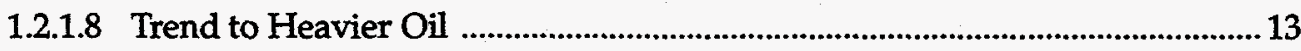

1.2.1.9 World Oil Market Volatility ..........................................................................13

1.2.1.10 Declining Industry R\&D Expenditures ..................................................... 13

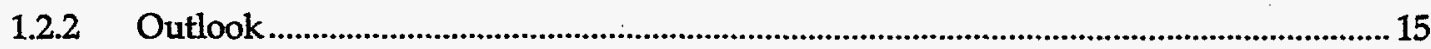

1.2.2.1 Demand, Price, and Production .................................................................. 15

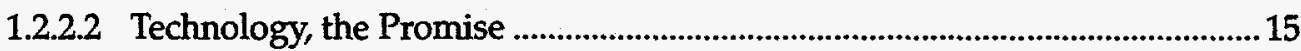

1.3 DOE'S EVOLVING ROLE IN OIL TECHNOLOGY

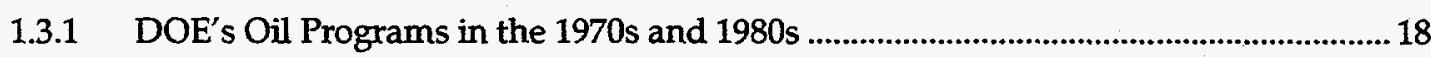

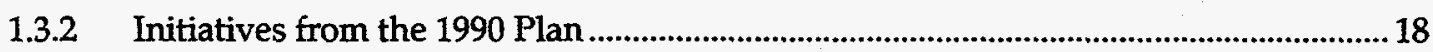

1.3.3 Initiatives from the FY 1996-2000 Plans .................................................................... 19

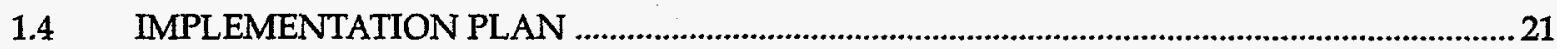

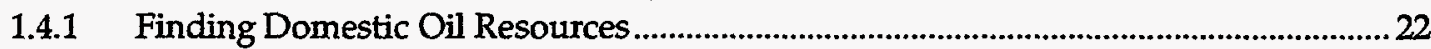

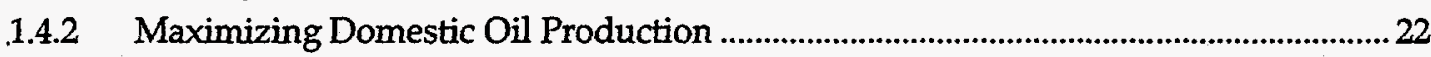

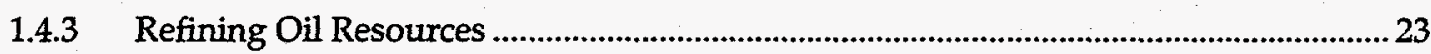

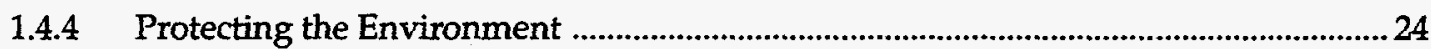

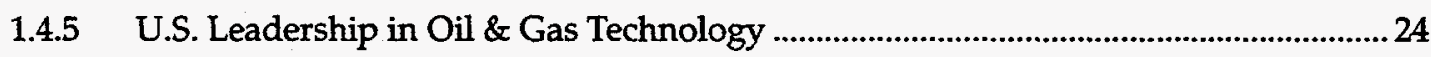

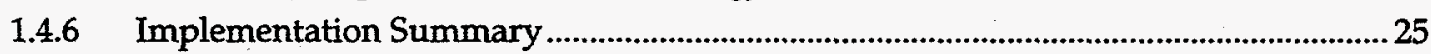




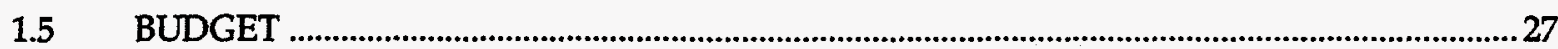

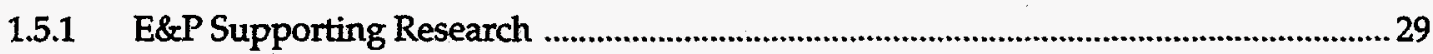

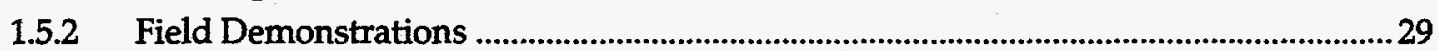

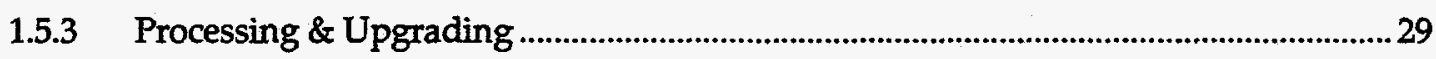

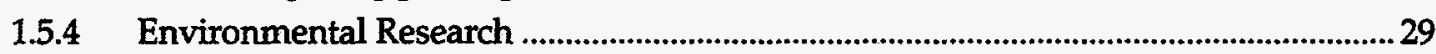

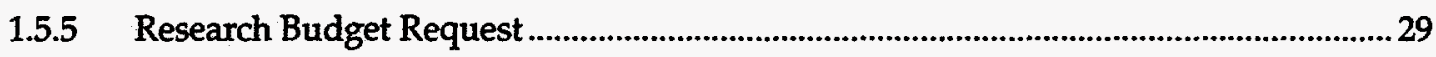

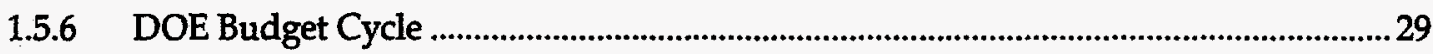

1.6 IMPROVING INDUSTRY \& STAKEHOLDER ACCEPTANCE

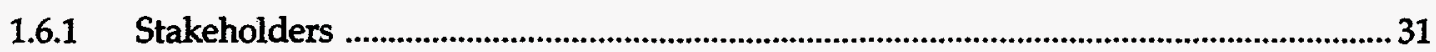

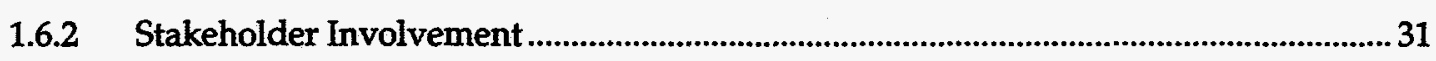

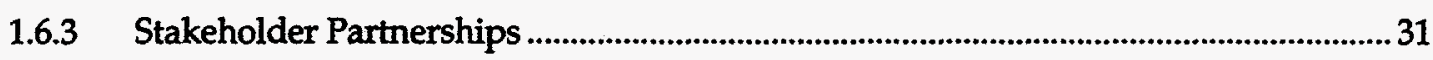

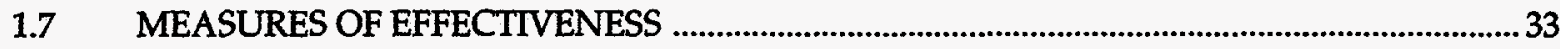

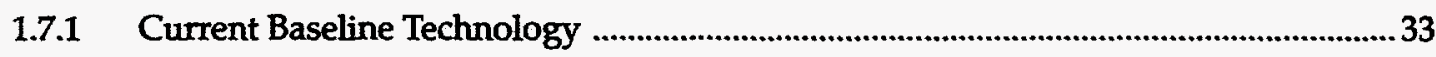

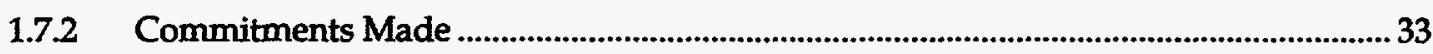

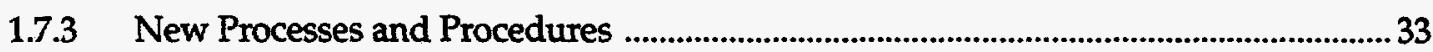

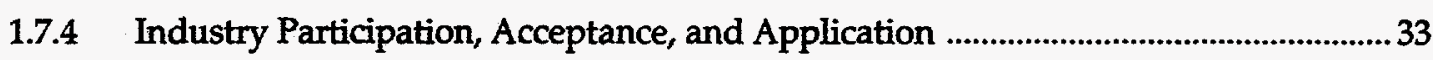

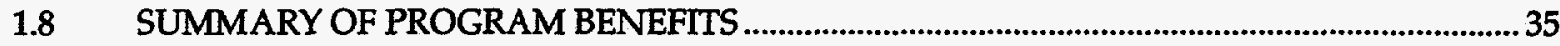

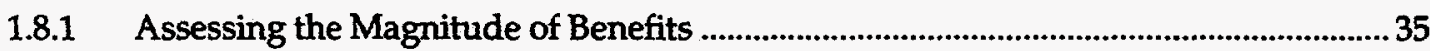

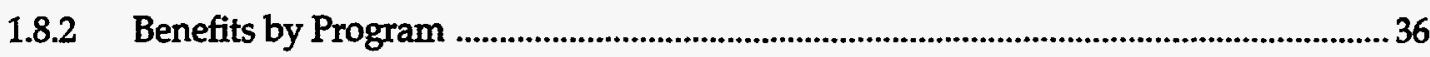

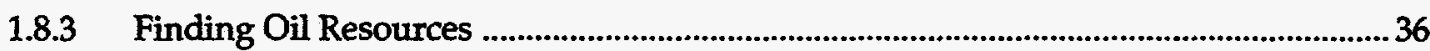

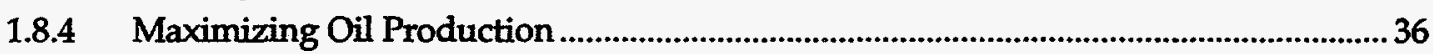

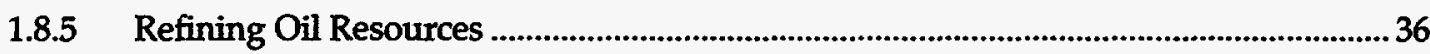

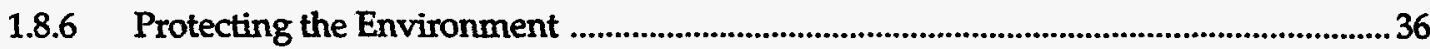

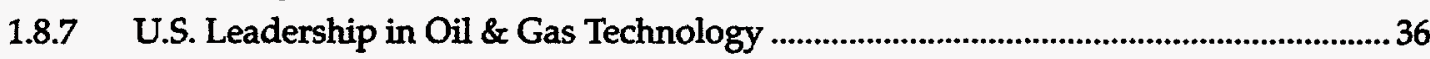

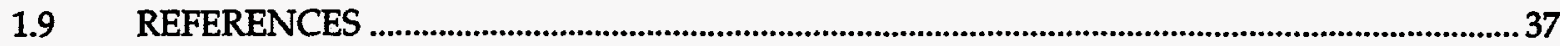

\section{SECTION 2}

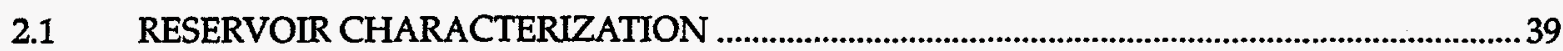

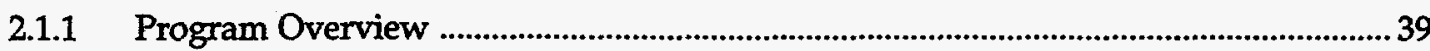

2.1.1.1 Goals and Objectives .....................................................................................4

2.1.1.2 Geoscientific Measurement .......................................................................42

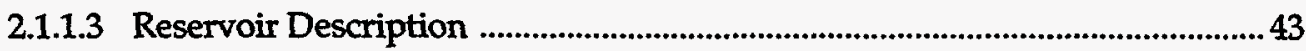

2.1.1.4 Reservoir Modeling and Simulation..................................................................43 43

2.1.1.5 Advanced Computational Technology Initiative ..........................................44

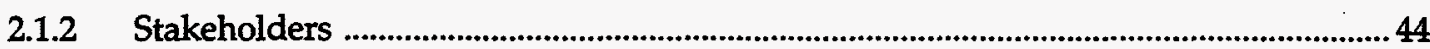

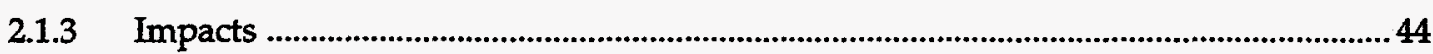

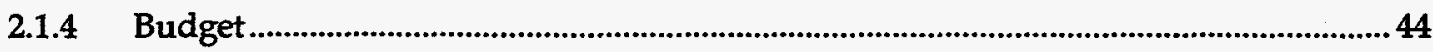

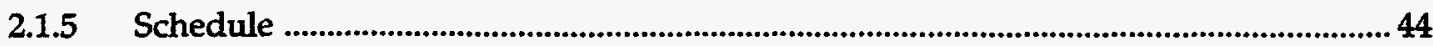

2.1.6 Measures of Effectiveness .....................................................................................4 


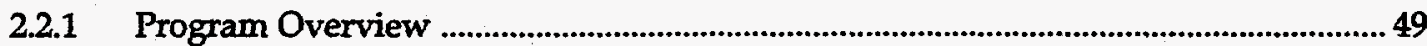

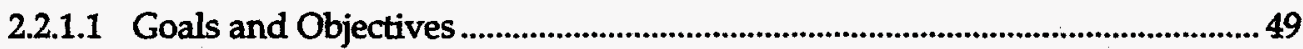

2.2.1.2 Improved Oil Recovery (IOR) ..........................................................................5 50

2.2.1.3 Advanced Oil Recovery (AOR) …...................................................................51

2.2.1.4 Field Pilots .........................................................................................................53

2.2.1.5 Simulation of Extraction Processes ….........................................................54

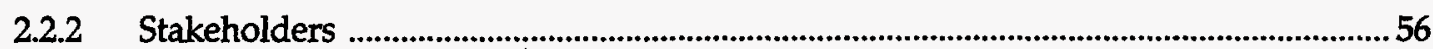

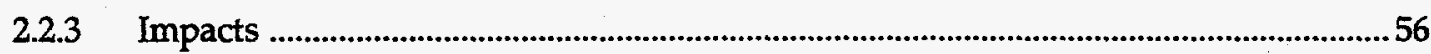

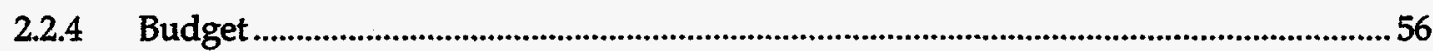

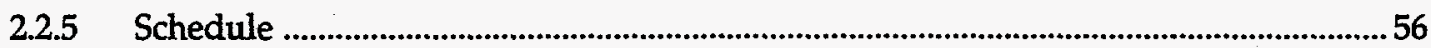

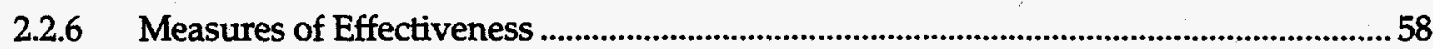

2.3 EXPLORATION, DRILLING, AND RISK-BASED DECISION MANAGEMENT ...................63

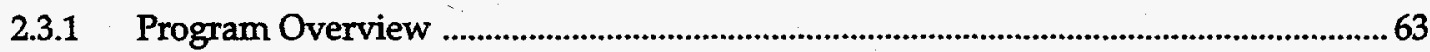

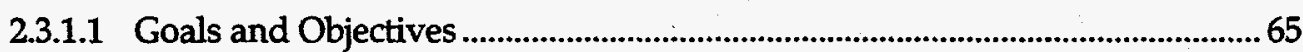

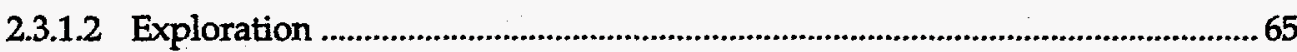

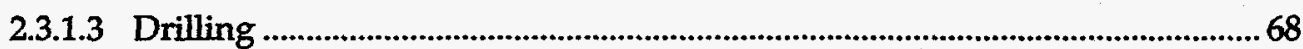

2.3.1.4 Risk-Based Decision Management ..............................................................71

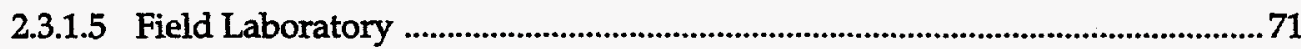

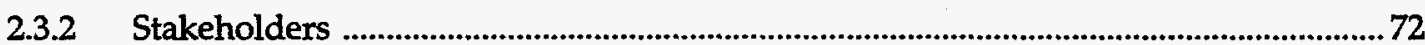

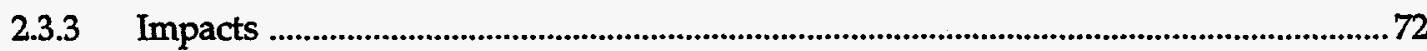

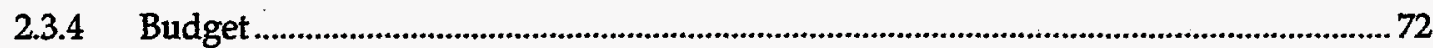

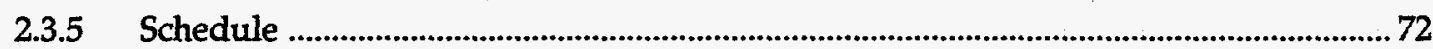

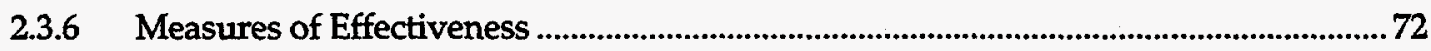

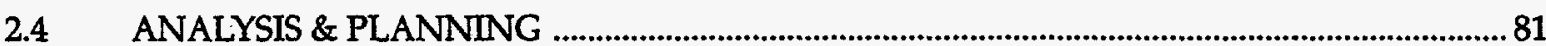

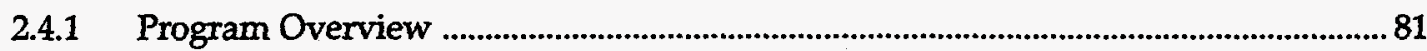

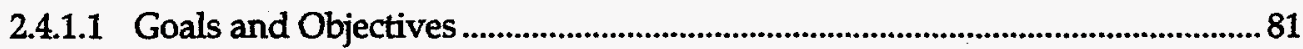

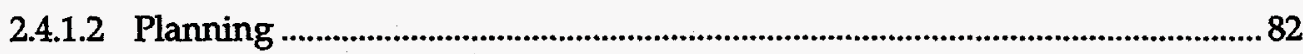

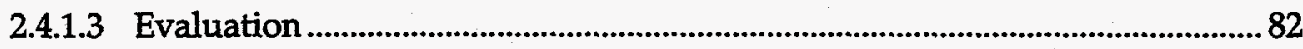

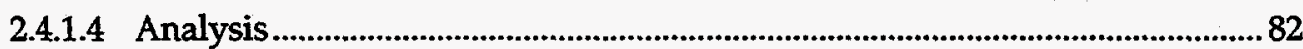

2.4.1.5 Quality Assurance ............................................................................................. 84

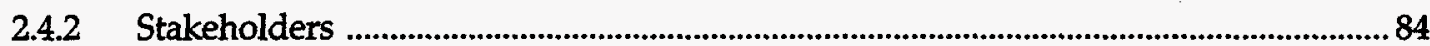

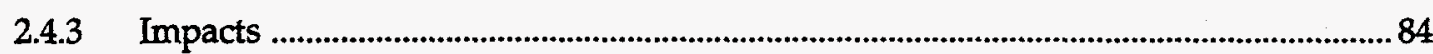

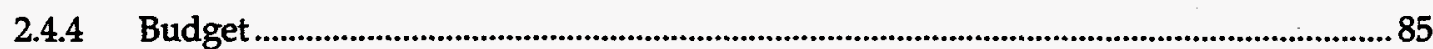

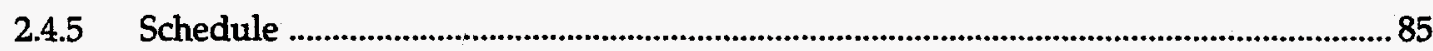

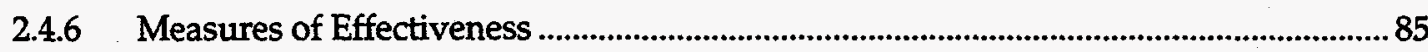

2.5 TECHNOLOGY TRANSFER

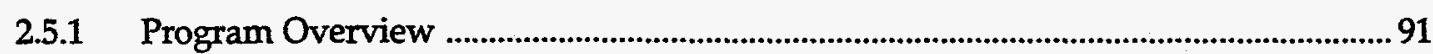

2.5.1.1 Oil Program Information Support ..............................................................91

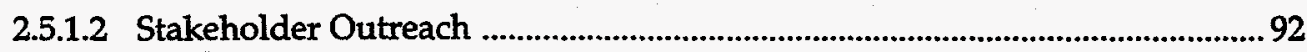

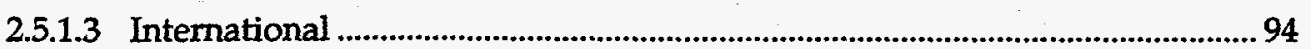


2.5.1.4 Educational Efforts

2.5.1.5 Work for Others, CRADAs, and Licensing ................................................... 95

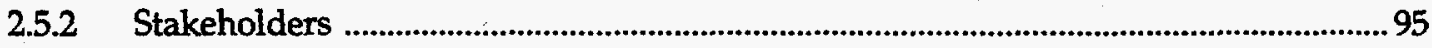

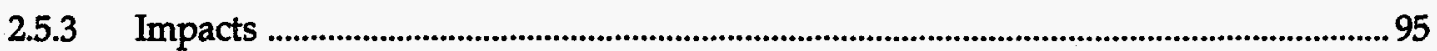

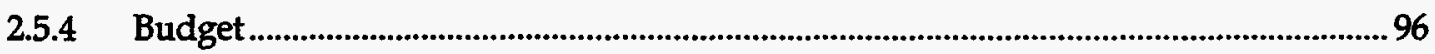

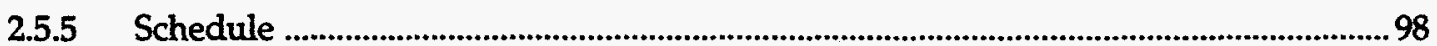

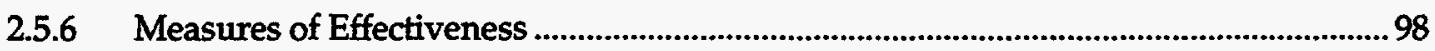

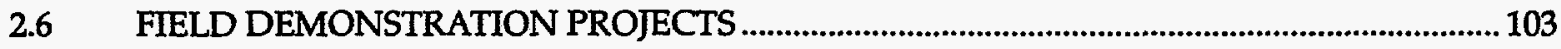

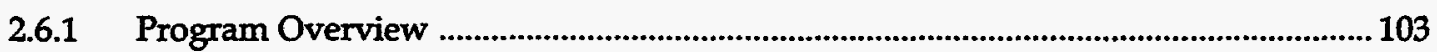

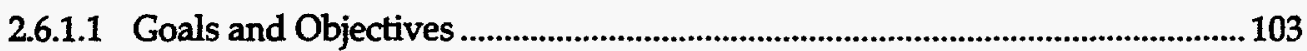

2.6.1.2 Near-term and Mid-term Technologies for Class Demonstrations ............. 104

2.6.1.3 Advanced Class Work ................................................................................ 104

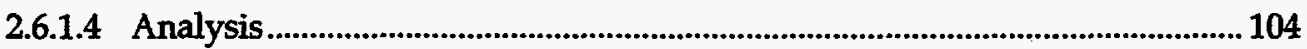

2.6.1.5 Assist Independents with Urgent Production Constraints .......................... 106

2.6.1.6 Reservoir Management Demonstrations ........................................................ 106

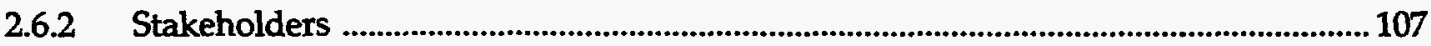

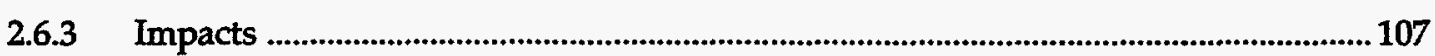

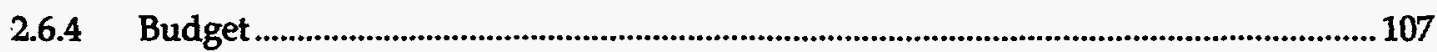

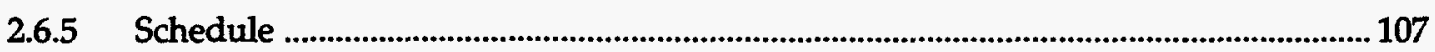

2.6.6 Measures of Effectiveness .............................................................................................. 107

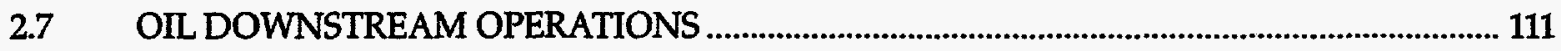

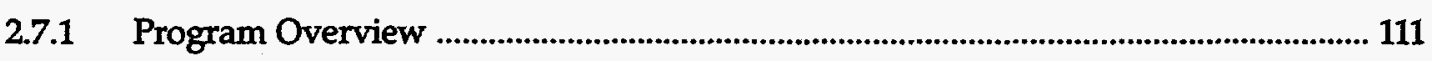

2.7.1.1 Situation Analysis ........................................................................................ 111

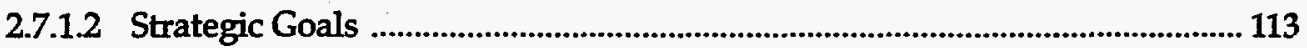

2.7.1.3 Implementation Strategies ...................................................................... 114

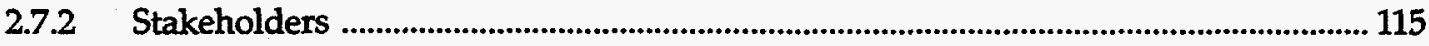

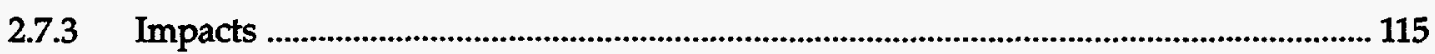

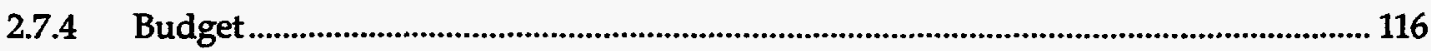

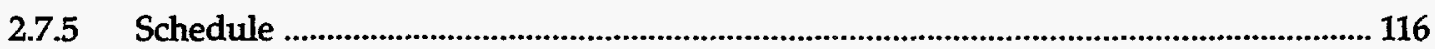

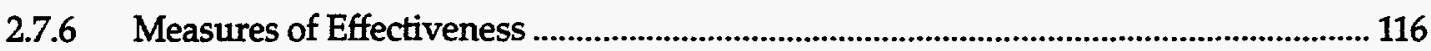

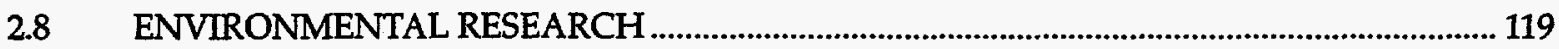

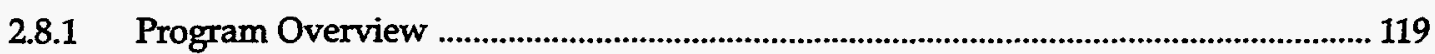

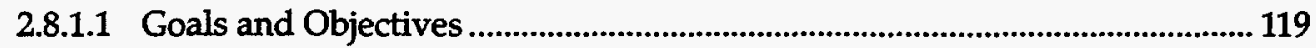

2.8.1.2 Area of Review Variance ............................................................................. 119

2.8.1.3 Streamlining Regulations .......................................................................120

2.8.1.4 Gulf of Mexico Discharges ....................................................................... 121

2.8.1.5 Environmental Outreach and Program Planning ....................................... 121

2.8.1.6 Environmental Technology Development .......................................................122

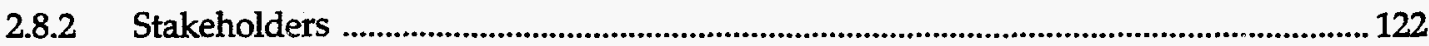

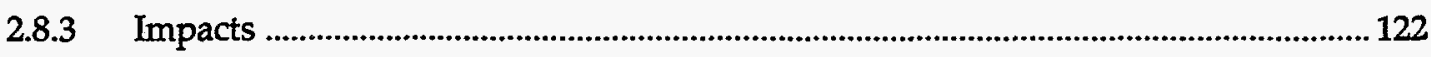

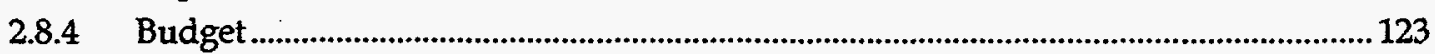




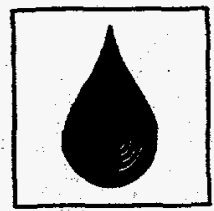

2.8.5 Schedule 123

2.8.6 Measures of Effectiveness ... 123

$2.9 \quad$ PROGRAM SUPPORT INFRASTRUCTURE …...................................................................... 127

2.9.1 Program Overview .............................................................................................. 127

2.9.1.1 Quality Assurance .................................................................................................. 127

2.9.1.2 Environment, Safety \& Health .....................................................................127

2.9.1.3 Facilities Management .................................................................................. 127

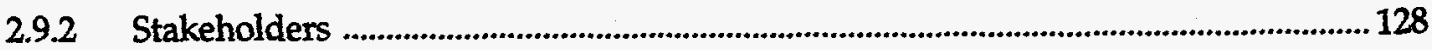

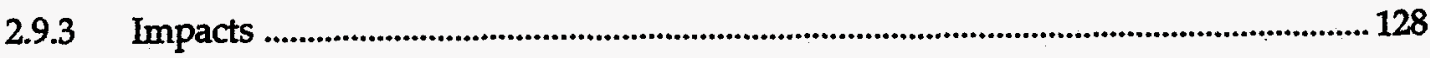

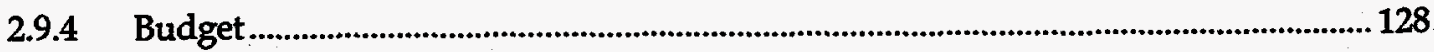

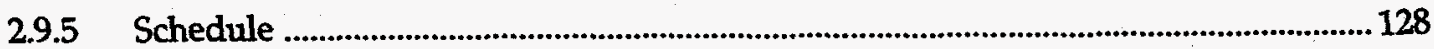

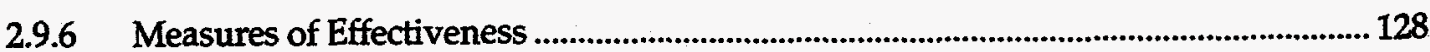

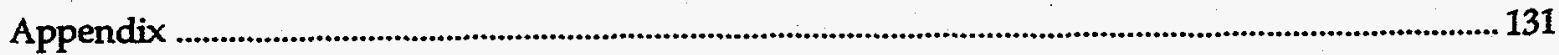




\section{TABLES}

1.1.1 EPACT Directives for the Oil Plan and Program 3

1.1.2 DNGOI Directives Addressed by the Oil Plan 4

1.1.3 DOE Strategic Plan Initiatives and Key Directives ....................................................................5

1.2.1 1993 Oil Production Rates in the Top Producing Countries ....................................................... 8

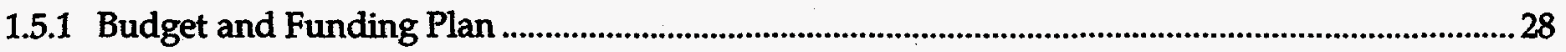

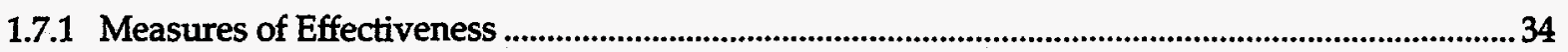

1.8.1 Oil Economy Expenditures and Employment by Sector ...........................................................35

2.1.1 Reservoir Characterization Drivers and Initiatives .............................................................40

2.1.2 Budget for Reservoir Characterization ................................................................................45

2.1.3 Measures of Effectiveness for Reservoir Characterization ........................................................48

2.2.1 Budget for Extraction Program ...........................................................................................................57

2.2.2 Measures of Effectiveness for the Extraction Research Program ................................................62

2.3.1 Budget for Exploration, Drilling, and Risk-Based Decision Management .................................. 73

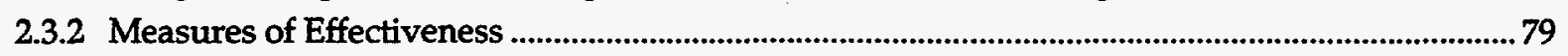

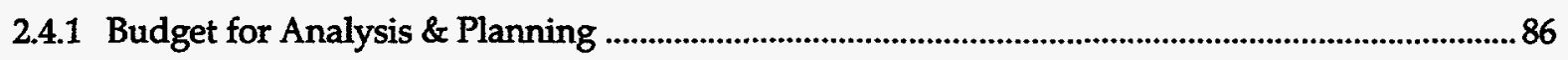

2.4.2 Measures of Effectiveness for the Analysis \& Planning Program ................................................ 89

2.5.1 Budget for Technology Transfer ........................................................................................................97

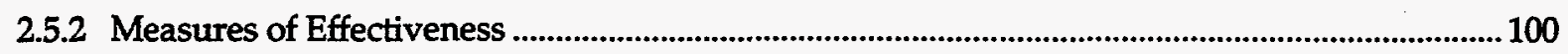

2.6.1 Budget Field Demonstration Program ............................................................................... 108

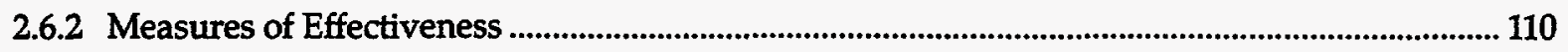

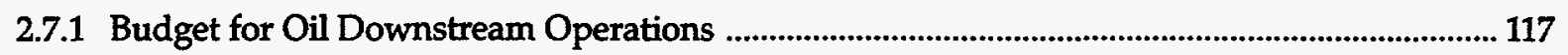

2.8.1 Budget for Environmental Research and Development Program ..............................................124

2.8.2 Measures of Effectiveness for the Environmental Research Program ....................................... 126

2.9.1 Measures of Effectiveness for Program Infrastructure .........................................................130 


\section{FIGURES}

1.2.1 U.S. Petroleum Industry Employment and Oil Production .......................................................7

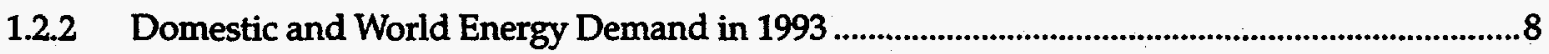

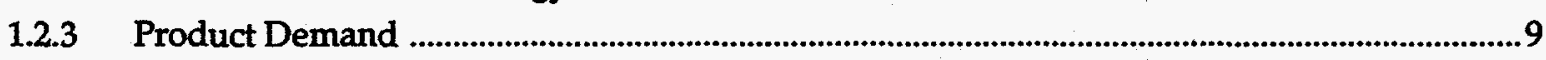

1.2.4 U.S. Oil Production and WTI Crude Oil Price in Constant 1993 Dollars ..................................10

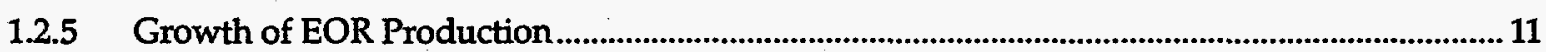

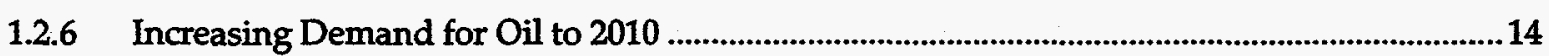

1.2.7 EIA Forecasts for U.S. Oil Production and Oil Prices to 2010. ................................................14

1.2.8 Estimates of Large Potential for Oil Reserve Additions ........................................................16

1.2.9 Impact of 1978 Tertiary Incentive Program on Implementing EOR .......................................16

1.3.1 Building a Successful Commercial Application-the Payoff for Technology .........................17

1.4.1 Relationship of Program Areas to Program Goals ...............................................................21

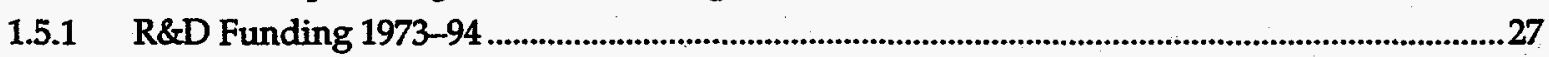

1.5.2 Relation of the Nine Program Areas to the Four Budget Areas ...........................................28

2.1.1 Steps in Characterizing a Reservoir ................................................................................41

2.1.2 Reservoir Characterization Program Work Breakdown Structure ........................................43

2.1.3 Reservoir Characterization Budget...................................................................................45

2.1.4 Key Activities and Timing for the Reservoir Characterization Program .................................46

2.2.1 Known Domestic Oil Resource as of 12/31/92 ..................................................................50

2.2.2 Extraction Research Program Work Breakdown Structure ........................................................51

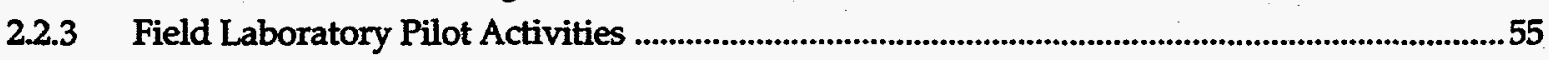

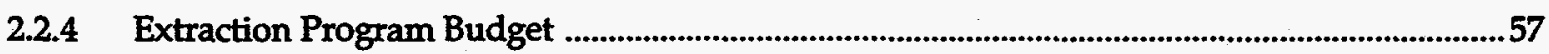

2.2.5 Key Activities and Timing for Improved Oil Recovery ......................................................59

2.2.6 Key Activities and Timing for Advanced Oil Recovery .......................................................60

2.2.7 Key Activities and Timing for Simulation Extraction Process ..................................................61

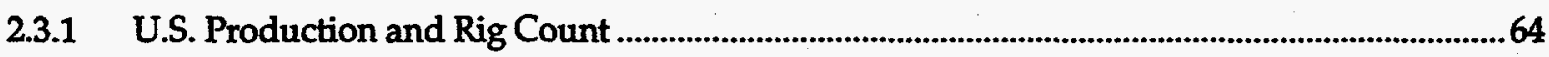

2.3.2 Exploration and Drilling Work Breakdown Structure .......................................................66

2.3.3 Workplan for Exploration Research ..............................................................................67

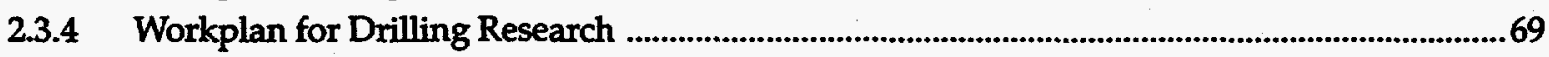

2.3.5 Workplan for Risk-Based Decision Management .................................................................70

2.3.6 Exploration, Drilling, and Risk-Based Decision Management Budget ..................................73

2.3.7 Key Activities and Timing for Exploration Research .............................................................75

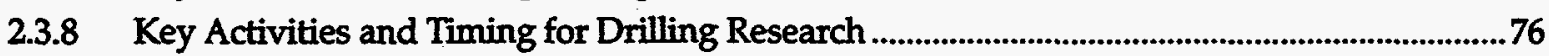

2.3.9 Key Activities and Timing for Risk-Based Decision Management ...........................................78

2.4.1 Analysis and Planning Work Breakdown Structure .............................................................8.

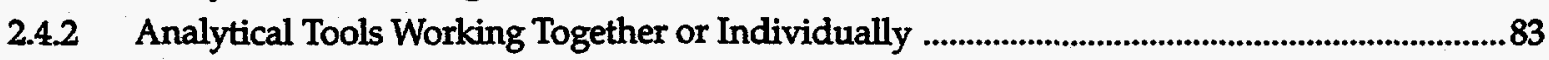

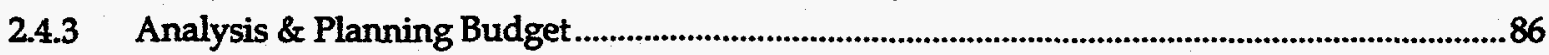

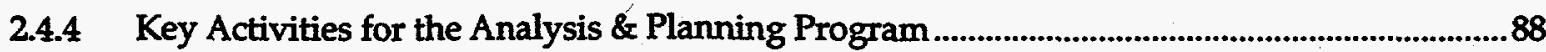


2.5.1 Technology Transfer Work Breakdown Structure .....................................................................92

2.5.2 Technology Transfer, the Pipeline to Key Stakeholders ..........................................................93

2.5.3 Technology Transfer Budget ...........................................................................................97

2.5.4 Key Activities and Timing for Technology Transfer ..........................................................99

2.6.1 Relationships Between Field Demonstration Projects and Other Oil Program Elements ... 105

2.6.2 Field Demonstration Work Breakdown Structure ............................................................... 105

2.6.3 Field Demonstration Program Budget ..............................................................................108

2.6.4 Key Activities and Timing for Field Demonstration Program ..............................................109

2.7.1 Cornerstones of Downstream Strategy ................................................................................. 114

2.7.2 Oil Downstream Operations Budget ...................................................................................... 117

2.7.3 Key Activities and Timing for Oil Downstream Operations ...............................................118

2.8.1 Environmental Research Program Work Breakdown Structure .............................................. 120

2.8.2 Environmental Research Budget............................................................................................124

2.8.3 Key Activities and Timing for Environmental Research and Development .........................125

2.9.1 Program Support Infrastructure Work Breakdown Structure ..............................................127

2.9.2 Key Activities and Timing for Program Support Infrastructure ..........................................129 


\section{ACRONYM LISTING}

ACTI Advanced Computational Technology Initiative

API American Petroleum Institute

AOR Advanced Oil Recovery

ASR

Advanced Secondary Recovery

AVO

Amplitude Variation with Offset

BPO Bartlesville Project Office

CRADA Cooperative Research and Development Agreements

DNGOI Domestic Natural Gas and Oil Initiative

DOE

Department of Energy

E\&P Exploration and Production

EERE Energy Efficiency and Renewable Energy

EIA

EOR

Energy Information Administration

EPA

Enhanced Oil Recovery

EPACT

Environmental Protection Agency

ES\&H

Energy Policy Act of 1992

FE

Environment, Safety and Health

FY

Fossil Energy

Fiscal Year

GOM Gulf of Mexico

GWPC Groundwater Protection Council

IEA

International Energy Agency

IOR

Improved Oil Recovery

METC Morgantown Energy Technology Center

MMS

Minerals Management Service

MSO

Metairie Site Office

NADET National Advanced Drilling and Energy Technology

NAFTA North American Free Trade Agreement

NIPER

National Institute for Petroleum and Energy Research

NORM

Naturally Occurring Radioactive Material

NPC

National Petroleum Council

NPR

Naval Petroleum Reserve 


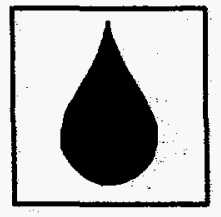

OMB Office of Management and Budget

QA Quality Assurance

R\&D Research and Development

SEMP Safety and Environmental Management Program

TIP Tertiary Incentive Program

TORIS Tertiary Oil Recovery Information System

TQM Total Quality Management

WTI West Texas Intermediate
ACRONYM LISTING

(continued) 


\section{EXECUTIVE SUMMARY}

The United States has led the world in oil production and refining for most of this century. Early development and use of innovative technologies by domestic oil companies resulted in indisputable technical dominance. Today the United States is considered a mature oil province where easily found, produced, and processed oil is rapidly being depleted. Although production is decreasing, the remaining domestic oil resource is large enough to maintain the United States as a top petroleum producer for the foreseeable future, if cost-effective technology and prudent energy policies are applied. Unfortunately, the domestic demand for cheap, abundant oil has risen over time to twice the production capability of the domestic oil industry. This leaves the country dependent on foreign oil, a situation that adversely affects the balance of trade and domestic jobs.

The United States leads the world in petroleum production and processing technologies, providing jobs for Americans throughout the world. Six of the top 10 petroleum-producing companies have headquarters in the United States. These integrated, high-technology companies are concentrating an increasing portion of their investment overseas in less mature oil provinces. Smaller, independent producers are increasingly producing oil from marginally economic wells. The crude oil deliveries to refineries have heavier API gravities, but the products required are lighter. At the same time, concern for the environment and increasingly complex regulatory processes have dramatically increased the cost of oil production and processing. Large and small producers and refineries struggle to comply with these regulations on a daily basis while the government must keep up with the escalating costs of monitoring and enforcement.
The goal of the Department of Energy's (DOE) Oil Program is to better manage our nation's oil resources by helping the industry more efficiently and effectively find, develop, and process oil into the desired energy products. The Oil Program Implementation Plan FY 1996-2000 (Oil Plan) describes the specific technical areas, goals, objectives, and funds required to meet policy goals set by the President, the Secretary of Energy, and Congress. The plan is diverse. It considers the appropriate short- and long-term role of the federal government in petroleum research, the realities facing major oil companies and small independent producers, and the potential impacts of implementing the planned research agenda.

\section{Vision, Mission, AND Goals}

The Oil Plan is based on the Domestic Natural Gas and Oil Initiative, the Energy Policy Act of 1992, and the Secretary of Energy's Fueling $a$ Competitive Economy Strategic Plan, April 1994. The vision for the year 2010 and beyond is for the United States to be a worldwide leader in the development, application, and export of sustainable, environmentally attractive, and economically competitive energy systems. The mission of the Oil Program is to stimulate the domestic oil industry to maximize the supply of domestically produced liquid fuels and to expand exports of oil-related technologies and services of the United States. This program seeks more efficient and economical methods to discover, produce, and refine oil while protecting the environment. Success will depend, in part, on explicit strategies that emphasize advances in American technology. Domestic cutting-edge technologies will ensure an expanding job base and technology export opportunities. 


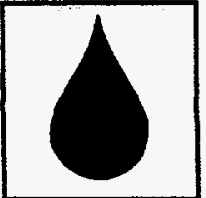

DOE's Oll Program

DOE recognizes the necessity of a strong and well-integrated oil program designed to address the broad goals of maintaining U.S. leadership in oil technologies and protecting the environment. Technological excellence will result in highly efficient and economical methods to discover, produce, and refine oil; to create jobs; and to reduce well abandonments. With these goals in mind, DOE has created a comprehensive program consisting of nine program areas: reservoir characterization; extraction research; exploration, drilling, and risk-based decision management; analysis and planning; technology transfer; field demonstration projects; oil downstream operations; environmental research; and program support infrastructure. The nine program areas work in a synergistic fashion to create an Oil Program that is extremely wellsuited to meeting DOE's mission and goals. Each program area is vital to the overall success of the Oil Program.

\section{Reservoir Characterization}

A major lesson learned in the application of enhanced oil recovery (EOR) and improved oil recovery (IOR) projects is that success depends on precise, accurate reservoir data. Reservoir characterization provides an understanding of reservoir architecture, reservoir geometry dimensions,

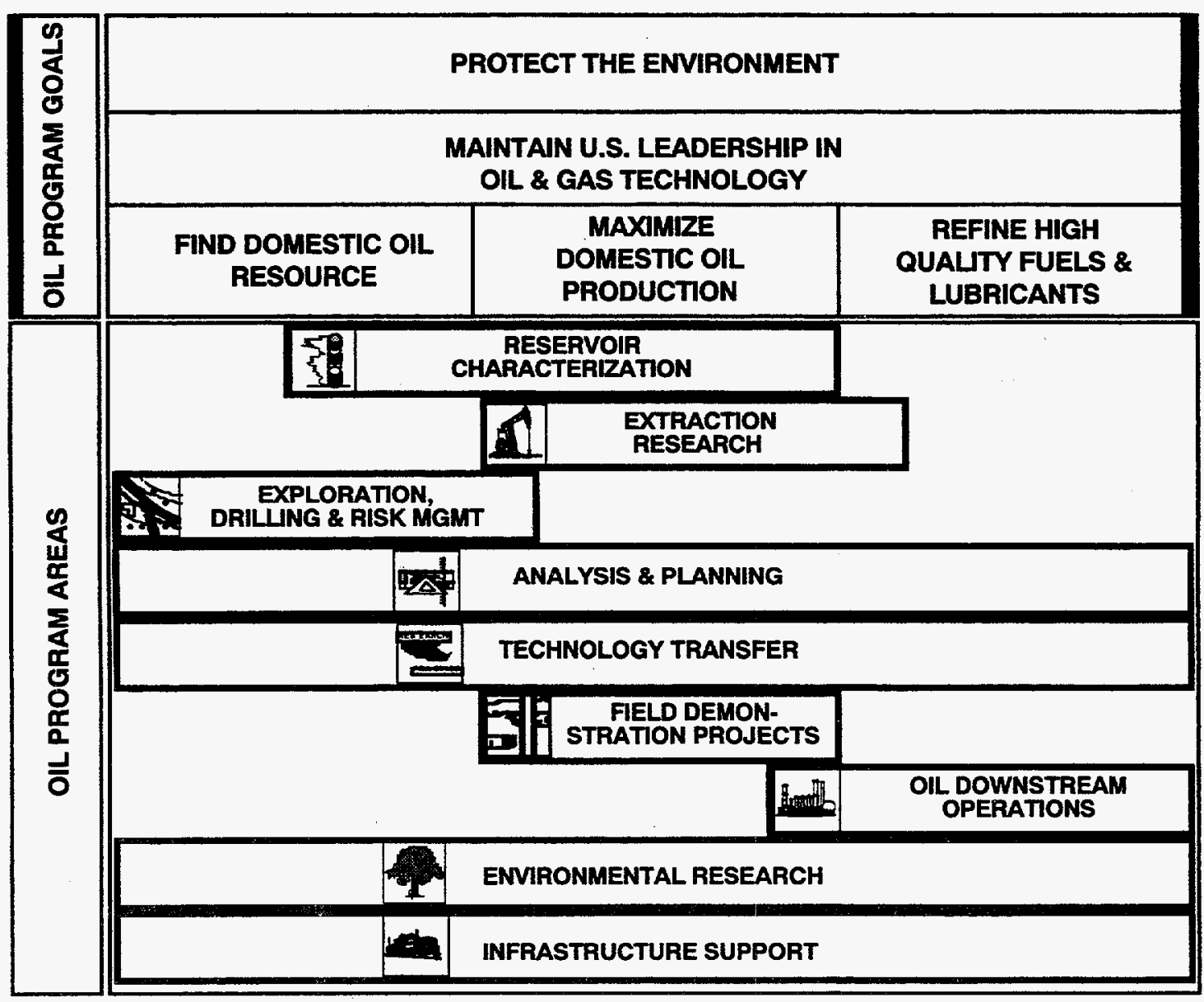


boundaries, fluid/rock properties, and fluid-flow characteristics within the reservoir. Properly conducted reservoir characterization programs strongly influence the economic and development success of an oil field by increasing the ultimate oil recovery and slowing the rate of field abandonment.

DOE's Reservoir Characterization Program is divided into four components: geoscientific measurement, interdisciplinary reservoir geometry description and related reservoir fluid flow, reservoir modeling and simulation, and Advanced Computational Technology Initiative (ACTI). (ACTI is part of a larger government/industry partnership to move defense technology from the national labs to other domestic applications.) Taken together, the four components will greatly increase the domestic producer's ability to successfully develop and manage reservoirs by stressing the vital importance of proper characterization and quantification. In addition, the Reservoir Characterization Program will increase much needed industry jobs, augment oil discovery and recovery, and reduce well abandonments.

\section{EXTRACTION RESEARCH}

Extraction Research is one of the cornerstones of DOE's Oil Program. Although significant advancements have been made over the last two decades, there is a huge amount of work yet to be done: roughly two-thirds of all discovered oil in the United States remains in the ground. DOE's Extraction Research Program has historically focused on basic, applied, and field EOR research. For fiscal years (FY) 1996-2000, a number of new needs and changing circumstances have been identified. The resultant program expands DOE's efforts toward wider application of existing technologies. Field pilot tests will be conducted to accelerate development of recovery technologies and transfer them to the petroleum industry. Computer models will be developed that will allow the industry-particularly small independents-to assess the merits of applying existing and new oil recovery technology from existing reservoirs. Each element of DOE's expanded
Extraction Research Program is interrelated. The multiple positive effects on the domestic oil industry will significantly contribute to the achievement of DOE's long-term goals.

\section{Exploration, Drilling, and Risk-Based Decision Management}

Unlike the Extraction Research Program, which seeks to recover already discovered oil, the Exploration, Drilling, and Risk-Based Decision Management Program is directed toward efficiently finding the estimated 33-70 billion undiscovered recoverable barrels of oil in the United States. This is a new research area for the Oil Program initiated in FY 1994 in response to the realization that the domestic oil exploration industry has changed drastically. Currently over $85 \%$ of all exploratory wells in the United States are drilled by independent producers. Given their large amount of exploratory activity, research tailored for the independent producer has not been emphasized. The Exploration, Drilling, and Risk-Based Decision Management Program is designed to reflect these dramatic changes in the oil-producing environment and respond to the unique needs of the independent producer.

\section{Analysis and Planning}

The Analysis and Planning Program is a crosscutting, tightly integrated network of functions that supports prudent, cost-effective management of all elements of the Oil Program. The area is staffed by experts from each research area, and its products reflect the perspective of the entire program. Four functions-planning, evaluation, analysis, and quality assurance-provide data, models, and expertise to the Analysis and Planning Program. Together, they provide DOE and its stakeholders with a wealth of highly tractable, state-of-the-art resources. These resources allow identification of the most beneficial areas of research to target as well as enabling assessment of alternative energy-related policies. All of the projects planned for FY 1996-2000 reflect DOE's strong emphasis on customer and stakeholder concerns. By conducting a major update and 
expansion of software tools for independents, developing a data repository for oilfield information, and implementing the new evaluation function, the Analysis and Planning Program will continue to realize one of its key goals: customer satisfaction.

\section{TECHNOLOgY TRANSFER}

The mission of the Technology Transfer Program is to convey efficiently and effectively the products of DOE's Oil Program to its customers and stakeholders. There is no doubt that this program is vital to realizing DOE's vision of technological excellence. Like the Analysis and Planning Program, the Technology Transfer Program is multifaceted and crosscutting. The success of this program depends on frequent communication with oil industry representatives-both majors and independents-and on a solid understanding of issues, needs, and trends. All of the planned activities are designed to facilitate better communication between DOE and its widely varied customer base in an aggressive effort to foster technological achievement.

\section{Field Demonstration Projects}

The Field Demonstration Program is a critical element of DOE's Oil Program because it focuses on the successful application of new technologies, or on making the idea a reality. Through cost-shared field demonstration projects, $\mathrm{DOE}$ is accelerating the application of numerous oilrelated recovery technologies. Communicating lessons learned is an integral part of each project. Additional research leverage is provided by evaluating the successes and failures of the field demonstration projects and including the findings in concurrent research programs. Industry awareness is further enhanced by communication from the Technology Transfer Program. The Field Demonstration Program will be expanded in FY 1996-2000 to address the special recovery constraints of offshore operations, conduct a reservoir management demonstration, and further Advanced Class Research. Advanced Class Research targets new problems and opportunities identified in previous demonstration projects.

\section{Oil Downstream Operations}

Domestic refineries are under new economic and technical pressures. The number of operating refineries in the United States has declined to 171 from over 300 in the $1970 \mathrm{~s}$. This portion of the Oil Program conducts research to help oil refineries comply with environmental regulations, prevent pollution, and upgrade heavy oil. The environmental compliance research will gather data and develop technologies in collaboration with refinery groups, industry, environmental groups, and federal, state, and local regulators. Pollution prevention research will help evaluate new and promising technologies to reduce specific pollutants, such as air emissions toxins, wastewater, refractory hydrocarbon residues, coke, and spent catalysts. Heavy oil upgrading research will develop fundamental chemical and thermodynamic data on heavy crude oil and residua while working with industry in partnerships to increase processing efficiencies of domestic heavy crude oils.

\section{Environmental Research}

Up to $24 \%$ of the domestic oil production capacity could be lost due to compliance costs as environmental regulations become more complex. At issue is the utility vs. costs of many of these regulations. Do they protect the environment? Can compliance costs be minimized without adversely affecting the environment? Research to facilitate cost-effective compliance and ensure that sound regulatory decisions are made by state, tribal, and federal government officials is one of the fundamental objectives of the Environmental Research Program. The planned projects range from supporting state governments in complying with forthcoming Environmental Protection Agency requirements 
under the Safe Water Drinking Act to providing regulators with data on produced water and sand discharges in the Gulf of Mexico.

\section{Program Support Infrastructure}

Although the Oil Program employs the national laboratories, universities, and other contractors, its principal site of operations is at the National Institute for Petroleum and Energy Research (NIPER). The mission of Program Support Infrastructure is to promote smooth operations by meeting (or exceeding) all environment, safety, and health requirements, quality assurance standards, and facilities management needs at this facility. The goal is to ensure that the Oil Program proceeds as planned and on schedule. Although Program Support Infrastructure is a nonprogram element, it provides an indispensable service to the Oil Program by fostering quality work in a conducive environment.

\section{BUDGET \& IMPACTS}

The planning budgets for FY 1996-2000 are modest in relation to the size of the oil industry. The annual cost is roughly equivalent to 1-1 $1 / 2$ days of the cost of oil imports each year. The Oil Plan is developed for an unconstrained budget that is bounded by the scope of goals set by Congress, the President, and the Secretary of Energy as well as the historic context of the Oil Program. This is the first step of the federal budgeting cycle and has not been approved for inclusion in the DOE's or the President's budget request.

Starting in FY 1996, the Oil Plan formalizes and expands the measurement of the effectiveness of the Oil Program in a new evaluation initiative. Each program area has identified measurable criteria to assess its success. This is a new initiative expected to result in improved response to stakeholders and an improved assessment of the impact the program has on the domestic industry.

\section{INDUSTRY INPUT}

DOE has a new emphasis on improving responsiveness to its stakeholders. During the planning process, inclusion of stakeholders from within the DOE and other federal agencies added new perspective to the program, reduced redundancy within the federal government, and identified areas for joint working efforts. Selected retired industry executives were included in several of the planning units. The final step of developing the plan consisted of reviews by a representative segment of the industry. The comments from these reviews are summarized in the appendix. Where possible, the comments and suggestions from this review were included in this report, and the remainder will be used as guidance for the FY 1997-2001 planning cycle.

\section{IN SUMMARY}

DOE envisions the United States as the world leader in developing, applying, and exporting sustainable, environmentally attractive, and economically competitive energy systems. By creating economical methods to discover, produce, and refine oil, we will reduce our dependency on foreign oil and vulnerability to supply disruptions. Our success will depend in a large part on strategies that emphasize advances in American petroleum technology and prudent energy policies. The Oil Plan reaffirms DOE's commitment to implement the Oil Program in a way that maximizes U.S. energy security, results in economic growth, protects the environment, creates jobs, and improves our ability to compete in the world marketplace. 


\subsection{VISION, MISSION, AND GOALS}

The Department of Energy's (DOE) Oil Program Implementation Plan for FY 1996-2000 (Oil Plan) is rooted in the President's Domestic Natural Gas and Oil Initiative (DNGOI), Congress's Energy Policy Act of 1992 (EPACT), the Secretary of Energy's Fueling a Competitive Economy Strategic Plan of April 1994, and the strategic goals of the Office of Fossil Energy. Vast amounts of energy are required to conduct the business of our nation and to maintain and expand the quality of life of the American people. To meet these requirements, the nation must have a variety of energy sources produced with minimal environmental impacts. Currently oil-based energy represents $41 \%$ of the country's primary energy usage (EIA 1994). While increased emphasis has been placed on conservation and renewable fuels, oil will be the largest source of primary energy well beyond 2010 (EIA 1994). Discovering, producing, and refining domestic oil have top priority because they are central to the American way of life. Jobs, technology, global competitiveness, and economic growth all depend on economical and plentiful sources of energy. And oil is the most important source.

\subsubsection{VISION}

The Secretary of Energy's vision for the year 2010 and beyond is for the United States to be a worldwide leader in the development, application, and export of sustainable, environmentally attractive, and economically competitive energy systems. A flexible, clean, efficient, and equitable system of energy supply and end use with minimal vulnerability to disruption is needed. The President's energy policy stresses "developing new ways to use energy sources we already have-including domestic gas and oil..."

The Oil Plan is based on a progressive vision for the U.S. petroleum industry to be the technology leader. Government-based projects will contribute to technology improvements and earlier and broader application of oil exploration, recovery, and refining technology. Through the combined efforts of the industry and DOE, the nation will continue to lead the world in efficiently bringing oil from the ground to its end use as energy. The results of these efforts will be shared by the domestic petroleum industry, the international sector, and ultimately by the consumer. The DOE-stakeholder partnership is a cornerstone of the program.

Greater recovery rates from both current and future discoveries will be achieved through reservoir characterization and drilling and extraction research. Practices causing reservoir damage during drilling and production will be corrected.

Exploration techniques will improve drilling success rates as a result of new joint research efforts between DOE, national laboratories, and industry. New fields and new productive horizons will be more easily distinguished and defined using the results of technical development.

Downstream processing, even with lower gravity crude and greater environmental restrictions, will reduce emissions and waste streams. Production of transportation fuels will increase, while adverse products such as residual fuel oil, residua, and coke will diminish. Refining costs 


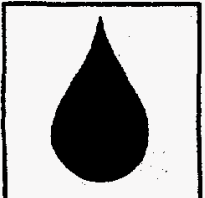

will be reduced as a result of more efficient technologies.

Environmental impacts will be mitigated. This, in conjunction with the DOE-stakeholder relationship, will result in more cost-effective environmental regulations.

\subsubsection{Goals \& ObJectives}

The goals of the Oil Plan are: (1) to increase the amount oil discovered, (2) to increase recovery of the oil that is already discovered, and (3) to improve yield of processing to obtain more refined, high-end products while protecting the environment.

This vision and the scope of the Oil Plan are rooted in policy directives and ambitions set forth by the President, the Congress, and the Secretary of Energy.

The mission is to stimulate the domestic oil
industry, to maximize the supply of
domestically produced liquid fuels and to
expand exports of oil related technologies
and services.

The objectives of the program are to design, to implement, and to monitor a comprehensive integrated oil program that will meet the Secretary's and President's priori-

ties. The program is designed to integrate the nation's crude oil-based liquid fuel needs with DOE, industry, and national laboratory capabilities using the disciplinary expertise and competency available.

The activities described in this plan will achieve DOE's mission through a cost-shared, participative approach combining DOE, national laboratory, and industry expertise.

\subsubsection{Policy Drivers}

The Oil Program is driven by the energy welfare of the nation, i.e., the need to maximize energy efficiency and to enhance available resources in the United States, and the need to expand business opportunities in the domestic oil industry. The program follows the guidance of three drivers: EPACT, DNGOI, and the DOE Strategic Plan.

even more critical as the domestic crude oil sup ply gets heavier and environmental regulations become more stringent. In the oil sector of the energy industry, discovering, producing, and refining more crude oil will be crucial if the Secretary's and the President's goals are to be met.

\subsubsection{Energy Policy Act of $\mathbf{1 9 9 2}$}

Congress' EPACT focuses on all areas of the energy-related industries. The goal outlined is to maximize energy efficiency and enhance 


\section{Table 1.1.1 EPACT Directives for the Oil Plan and Program}

\begin{tabular}{ll}
\hline \multicolumn{1}{c}{ EPACT } & \multicolumn{1}{c}{ Drivers for the Oil Plan } \\
\hline - Title XX Reduction of Oil & - Enhanced oil recovery studies \\
$\begin{array}{l}\text { Vulnerability Through } \\
\text { Supply and Conservation }\end{array}$ & - Environmental research \\
Research Development & Developing international markets for U. S. \\
& - Reducts \\
& - Field demonstration projects \\
& - Transfer of technology \\
Title XXII Energy and & - Integration of research and development \\
Economic Growth & - Support research and technical analysis \\
Title XXVI Indian Energy & - Promote energy resource development on tribal \\
Resources & lands-Native American tribe initiatives \\
\hline
\end{tabular}

resources available through near-term adoption by industry of improved reservoir evaluation and recovery techniques, and development and field demonstration of advanced recovery technology. Specific drivers for the Oil Plan are shown in Table 1.1.1.

\subsubsection{Domestic Natural Gas \& OIl INITIATIVE}

The goal of DNGOI, which was issued in December 1993, is to develop new and expanded opportunities in the domestic oil and gas industries through a climate of increasing domestic production and reducing dependence on foreign oil in three areas, e.g., promoting the advancement of oil and natural gas technologies, improving environmental technologies and practices, and improving government communication and decision making. The key drivers in DNGOI for the Oil Plan are summarized in Table 1.1.2.

\subsubsection{DOE Strategic Plan}

DOE, in partnership with our customers, is entrusted to contribute to the welfare of the nation by providing the technical information and scientific and educational foundation of the technology, policy, and institutional leadership necessary to achieve efficiency in energy use, diversity in energy sources, a more productive and competitive economy, improved environmental quality, and a secure national defense.

While using core competencies and considering the advice and thoughts of customers and stakeholders, DOE recognizes the need for new partnerships and the need to embrace continuous quality improvement. The Oil Plan considers these needs in four key areas as outlined in the Strategic Plan: industrial competitiveness, energy resources, science and technology, and environmental quality. Table 1.1 .3 outlines the four key areas of the Strategic Plan and the corresponding drivers for the Oil Plan. 
Table 1.1.2 DNGOI Directives Addressed by the Oil Plan

DNGOI Actions

- Promoting the advancement of natural gas and oil technologies

- Improving environmental technologies and practices

- Working to improve government communication and decision making

\section{Drivers for the Oil Plan}

- Expand industry-driven research and development (R\&D) for advanced oil recovery.

- Advance geologic basin analysis.

- Target a research program at specific, basic operating issues of producers.

- Stimulate development of a nationwide, regionally based oil technology transfer network.

- Advance technology testing, evaluation, and training.

- Establish field laboratory for field experiments, field pilots, operator training, and new technology demonstrations.

- Improve environmental compliance technologies and practices in upstream and downstream.

- Improve coordination and communication of environmental research between government, industry, and associations.

- Initiate environmental clearinghouse and assistance centers for independent operators.

- Work with other government agencies.

- Work with states on DNGOI.

- Increase oil production and environmental protection on Native American tribal lands. 


\section{Table 1.1.3 DOE Strategic Plan Initiatives and Key Directives}

\section{Strategic Initiative}

- Industrial competitivenesssustained long-term economic growth to create high wage jobs \& cleaner environments

- Energy resources-a flexible, clean, efficient, and definable system of energy supply with minimal vulnerability to disruption and economic costs

\section{Drivers for the Oil Plan}

- Development of resource efficiency, pollution prevention, renewable energy, and other clean technologies

- Development of integrated R\&D program plans with industry, including technology road maps

- Simplified access to DOE \& facilities by potential partners

- Making DOE facilities an integrated technical resource

- Improved efficiencies in energy supply, conversion, and utilization to reduce vulnerability to price and supply volatility

- Programs that establish U.S. as world leader in developing and deploying energy and environmental protection technologies and services throughout the world

- Exports of energy technologies \& services

- Diversity of supply to ensure reliable energy

- Promoting flexibility in energy sector

- Reduced adverse environmental impacts associated with energy production

- Excellence in basic \& applied science

- Full utilization of facilities-reduced unit costs

- Innovative funding for R\&D partnerships

- Flexibility in $R \& D$ programs

- Improved communications with stakeholders \& partnerships

- Added value through implementation of technology

- Good experiment design \& project management

- Risk-based decision making processes which augment technology with cost-savings to the industry and state and federal regulatory bodies

- Performance measure data for program planning evaluation and technology transfer 



\subsection{ISSUES \& TRENDS}

The President envisions an investment-driven economy capable of creating high-wage jobs. The contributions from the oil industry are important to meeting this vision for two reasons. First, the economic well-being of the American people depends heavily on the continuing availability of low-cost oil products. The domestic petroleum industry provides the American people with the lowest cost gasoline of any Organization for Economic Cooperation and Development (OECD) country. This is due to the combined efficiency of domestic oil producers and refiners, the distribution system, and the competitive world market for crude oil which is centered in the United States. Secondly, direct jobs within the oil industry are high technology, investment-driven, highwage jobs. In 1992 the average wage for an oil production worker was $22 \%$ above the average manufacturing laborer, and the average refinery worker's wage was $71 \%$ above the manufacturing equivalent (O\&GJ 1994). Unfortunately, the trends in employment as well as other measures have been negative for this important domestic

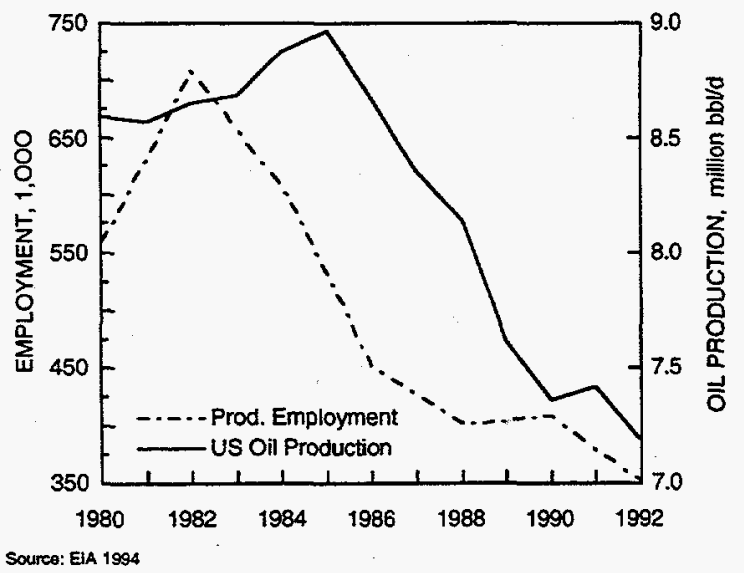

\section{Figure 1.2.1 U.S. Petroleum Industry Employment and Oil Production}

industry during the last decade (Fig. 1.2.1). Both employment and crude oil production are falling. The forecasts of the future are for more of the same-the only variable is the rate of decline. The federal government can affect this rate of decline with its policies and oil research products.

The United States is still one of the three large petroleum producers in the world, sharing this distinction with Russia and Saudi Arabia, as shown in Table 1.2.1. This country also has continued as the world leader in petroleum production and processing technologies, providing jobs for Americans throughout the world. Six of the top 10 petroleum-producing companies have headquarters in the United States (O\&GJ 1994). Unfortunately, this position of leadership in the competitive world is eroding. As global businesses, domestic-based petroleum companies are increasing investments, exploration, and research in other countries because of lower operating costs, better odds of finding large resources, and less stringent environmental regulations. This trend is expected to continue. Although the United States is seen as a mature oil province, industry continues investing in domestic exploration and development projects. Technological advances are frequently proven in the United States first and then exported. With a remaining discovered resource of 351 billion barrels after an expected $34 \%$ recovery (TORIS 1992) and the potential for discoveries of half again as much (Fisher 1992), this large domestic resource holds potential for today as well as future generations. The United States need not run out of oil, nor does its world-class producer status need to end any time soon. New ideas for discovering and producing oil more efficiently are being generated, and the federal research program is important to advancing ideas and reducing the risk of commercialization. 


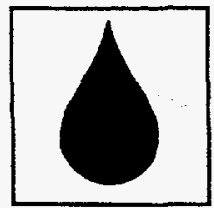

Table 1.2.1 1993 Oil Production Rates in the Top Producing Countries

\begin{tabular}{lcc}
\hline Country & $\begin{array}{c}\text { Crude Oil Production, } \\
\text { million bbl/d }\end{array}$ & $\begin{array}{c}\text { Crude, Condensates \& } \\
\text { NG }^{2} \text { Liquids, } \\
\text { million bbl/d }\end{array}$ \\
\hline United States & 6.7 & 8.6 \\
Saudi Arabia & 8.1 & 7.9 \\
Russia & 6.6 & 6.9 \\
Iran & 3.7 & 3.5 \\
Mexico & 2.8 & 3.2 \\
China & 2.9 & 2.9 \\
\hline 1EIA 1994 & & \\
2NG = Natural Gas & & \\
3World Oil 1994 & & \\
\hline
\end{tabular}

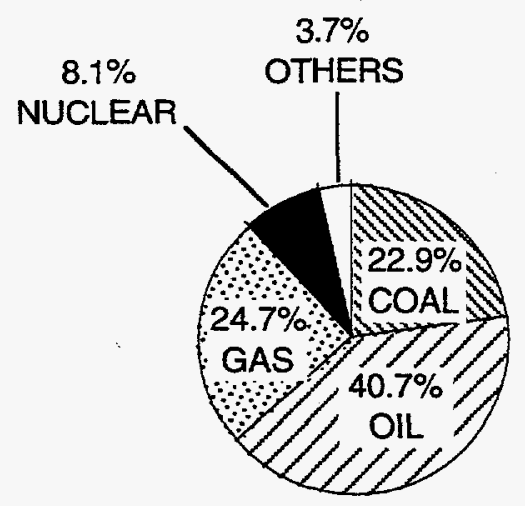

UNITED STATES ENERGY DEMAND 84 QUADS

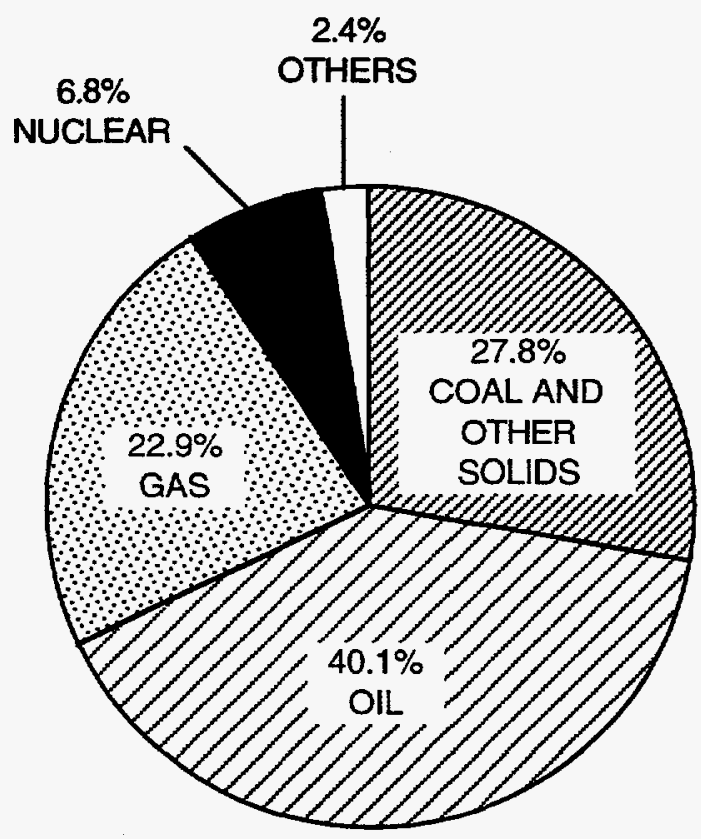

WORLD ENERGY DEMAND 331 QUADS

Source: EIA 1994, IEA 1994

Figure 1.2.2 Domestic and World Energy Demand in 1993 
Oil is important to the world as well as the domestic economy. The total energy usage for 1993 in the United States was 84 Quads (quadrillion British thermal units), or $25 \%$ of the world's use of energy (Fig. 1.2.2). Crude oil supplies $41 \%$ of the U.S. primary energy, and natural gas supplies another $25 \%$. Although natural gas usage is increasing in relative terms compared to oil and coal as well as in absolute terms, oil will continue to be the major source of primary energy in the United States well beyond 2010.

\subsubsection{Domestic Petroleum Industry}

\subsubsection{Supply ANd Demand}

The demand for petroleum parallels the health of the U.S. economy. Similar to the economy, oil consumption generally increased from 1982 until the 1989-91 recession (Fig. 1.2.3). Demand for oil dropped $8.4 \%$ from a peak usage in the first quarter of 1989 to a low of 16.3 million barrels/ day the second quarter of 1991. Since then, demand has increased by $9.2 \%$ through the first quarter of 1994, when demand averaged $17.8 \mathrm{mil}$ lion barrels/day (EIA 1994).

In 1993 the transportation sector of the United States economy was $97 \%$ dependent on oil derived energy and accounted for two-thirds of the consumption of oil products. While the total domestic demand for oil is up $6 \%$ since 1981, the demand for oil products in the transportation sector is up $18 \%$ (EIA 1994). Although natural gas might be a long-term alternative to oil in transportation, there is no significant shift to this or any other alternative. During the past 14-year period, motor gasoline demand has increased $12 \%$. The demand for residual fuel has fallen $57 \%$ during the same time, requiring changing refinery operations (EIA 1994). Refineries still run at $92 \%-95 \%$ efficiency despite the difficult shift in product mix.

The domestic supply of oil has not kept up with demand. In fact, it has dropped $20 \%$ while the demand for oil-derived products increased $7 \%$ since 1981. An increasing portion of the crude

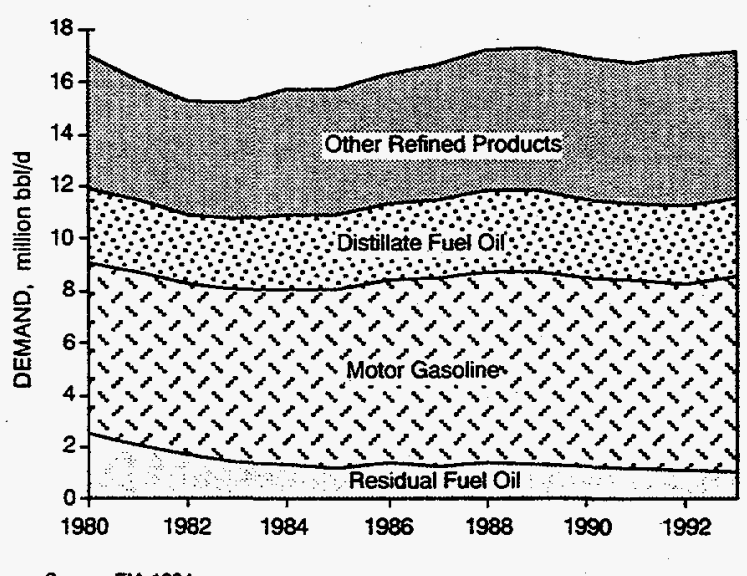

Source: ElA 1994

\section{Figure 1.2.3 Product Demand}

oil supply is imported-going from $35 \%$ in 1980 to $50 \%$ in March 1994. The increasing dependence on imported oil has negative impacts on the nation's security and the strength of the U.S. economy.

\subsubsection{IMPORTS AND THEIR COST}

In 1986 the cost of imported oil was approximately $\$ 35$ billion. It increased to $\$ 51$ billion in 1993. Oil imports averaged 7.8 million barrels/ day and another 1.6 million barrels/day equivalents of petroleum products during June 1994 (EIA 1994). At current prices, this contributes roughly $\$ 60$ billion/year to the trade deficit and a corresponding drain on the domestic economy. The cost of the imports is only part of the drain on the U.S. economy. Significant hidden and external costs justify an urgent response to these imports. If this imported oil and products were domestically produced and refined, domestic companies and their employees would pay an additional $\$ 4.5$ billion in taxes to state and local governments and another $\$ 8.8$ billion/year in federal taxes (TORIS 1994). If this production and refining could be done in the United States, it would generate 450,000 direct jobs. Direct wages would be around $\$ 12$ billion and another $\$ 12$ billion in wages from supporting industries (DOC 1992). A hidden cost for the military defense expenses is related to maintaining secure foreign sources and supply routes. External costs exist, 

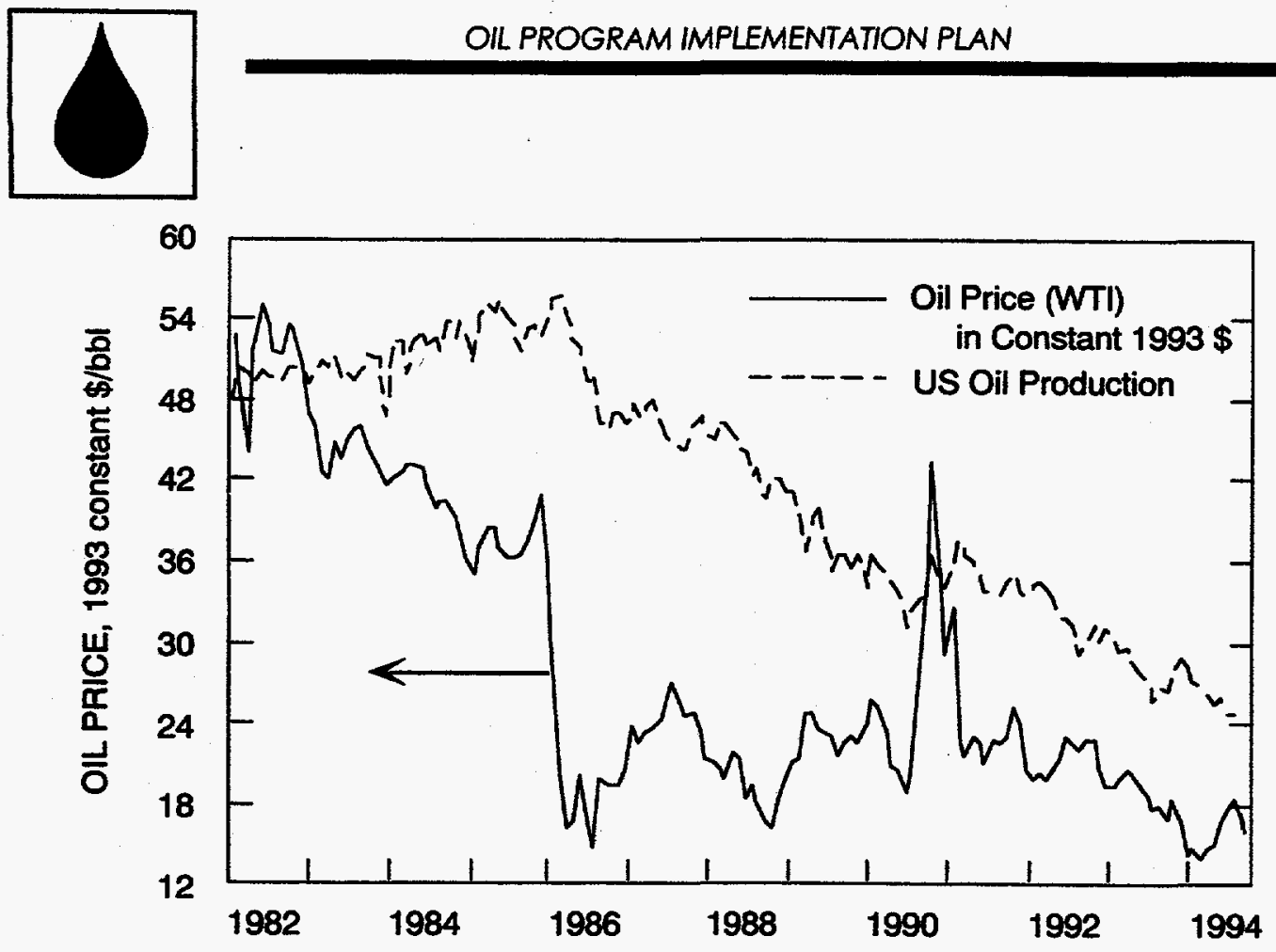

Source: EIA 1994; API 1994; O\&GJ 1994

\section{Figure 1.2.4 U.S. Oil Production and WTI Crude Oil Price in Constant 1993 Dollars}

such as environmental risk because of extra handling and distances traveled, but they are difficult to quantify.

\subsubsection{Price and Domestic Production}

The price of crude oil has frequently been volatile, but recently it has been more so. The spot market price of West Texas Intermediate (WTI) crude oil has varied widely (Fig. 1.2.4) from a brief high of $\$ 39 /$ barrel during the Persian Gulf War in 1991 to a low of $\$ 14 /$ barrel in 1994. (Note: average wellhead prices are roughly $20 \%$ less than the high-quality WTI benchmark) There is a strong link between price and domestic production that is evident in the historical production trends. When prices are expected to be stable or rising, decision makers are comfortable with committing to new projects. When prices are low, the domestic industry reduces costs by selling, shutting in, or abandoning marginally producing wells. High-cost producers (integrated major companies) are selling producing properties to independent producers with lower overhead, allowing resources to be extracted that might prematurely be abandoned. Although independents have a lower cost structure that extends the economic life of marginal and stripper wells, they frequently do not have the financial or the technical depth to implement new technologies that optimize recovery. A priority of past and current oil research programs has been to encourage development and application of advanced recovery technology to maximize recovery of the domestic oil resource. The success of these efforts is reflected in the continued growth of enhanced oil recovery (EOR) production to $10 \%$ of total domestic oil production in 1992 (Fig. 1.2.5). This significant production comes from the widespread application of steam to heavy oil in California, injection of gases in Alaska and the Permian Basin, and diverse application of advanced processes in numerous projects throughout the oil-producing states.

\subsubsection{Marginal Wells and Abandonment}

The worst case scenario for recovery of our national oil endowment is the premature loss of access. The owners of oil-producing properties 


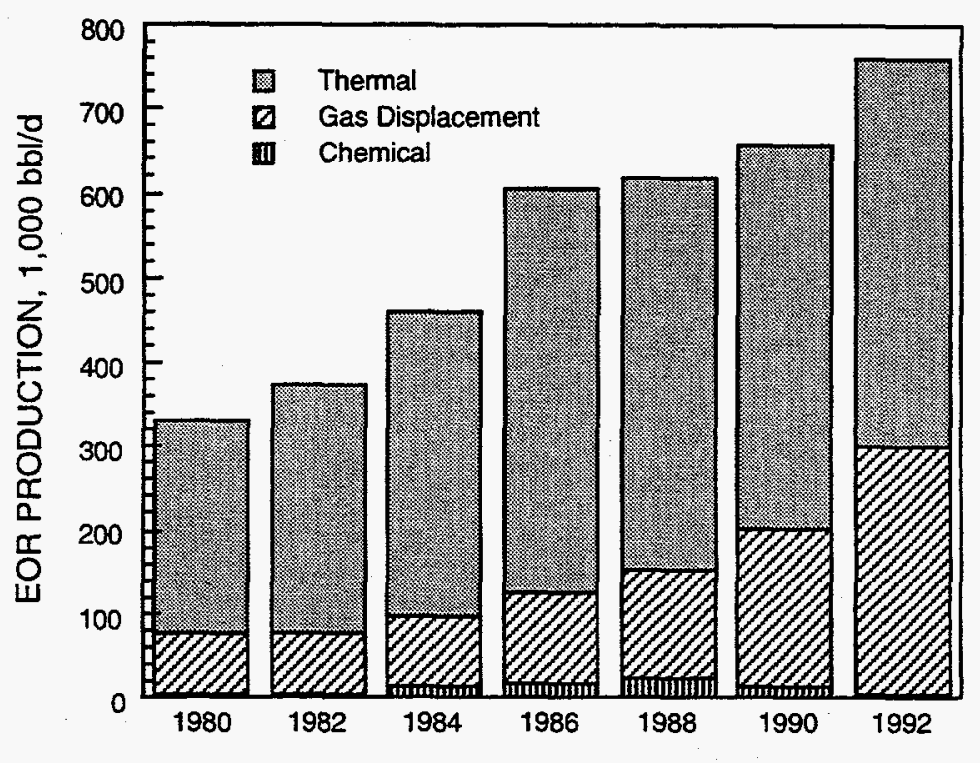

Source: O\&GJ 1992

Figure 1.2.5 Growth of EOR Production

are an extremely diverse and numerous group. Complex leasing arrangements are used to allow producers and owners to mutually benefit from the production of oil. If a group of leases were to expire, the economic hurdle to assemble these diverse participants and to redevelop the production infrastructure is likely to be higher than the profits from the remaining recoverable oil. As a mature oil province, the United States acquires approximately $22 \%$ of its production from marginal wells ( $<15$ barrels/day) (NPC 1994), and this production is in danger of being prematurely and permanently lost each time there is a temporary decrease in price. Wells have been plugged and abandoned at an increasing rate in recent years, with 13,400 abandoned in 1992 (up from 7,000 in 1980). As much as $80 \%$ of the known oil resource could be lost by 2010 if advanced recovery technologies are not implemented. It is difficult to measure at what price premature abandonment starts, yet a recent survey of independent producers found that new investments would occur at \$19-\$22/barrel (IPAA 1994), indicating that prolonged price movements below $\$ 19 /$ barrel could cause irreparable damage.

\subsubsection{Downsizing}

Jobs in the extraction sector of the industry dropped by $50 \%$ during the period 1982-92 (EIA 1994). During the spring and summer of 1994, most major petroleum companies initiated additional 3\%-10\% staff reductions. Many experienced, knowledgeable employees are being released and will never return to the industry, even if there were a shortage of knowledgeable labor. Companies are downsizing to be profitable and competitive at $\$ 14-\$ 16 /$ barrel. This is frequently accomplished at the expense of longterm research that would assure the United States a continued leadership role in petroleum technology.

\subsubsection{Exploration and Drilling}

The continuing low prices have developed the perception that oil prices will remain low or return to lower levels if they temporarily increase in the future. Decreasing investments for domestic exploration reflect this attitude. Wildcat drilling has decreased by $60 \%$ from its peak level in 


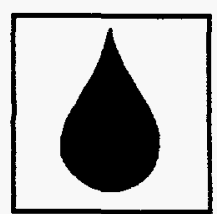

1981 (API). Development drilling has declined at a slightly lesser rate. Leasing and geophysical exploration expenditures have dropped dramatically. While seismic crew months dropped $83 \%$ in the period 1982-90, the miles of seismic line fell 46\% (SEG 1993). Technical and economic advances in tools used for exploration, such as 3-D seismic, may help improve finding rates. An advanced application of this technology allows analysis under salt deposits that resulted in an exciting discovery in the Gulf Coast and identified a new place to look for oil. Other technological improvements such as slimhole drilling, coiled tubing, measurement-while-drilling, and horizontal drilling all contribute to improved economics in the exploration and drilling area. These new developments combined with promising estimates of significant undiscovered oil are creating excitement in the industry.

\subsubsection{Regulations}

Concerns for improving the environment have led to new regulations imposed on the domestic exploration, producing, and processing industries at both the state and federal levels. Although some regulations produce the benefits of an improved environment, many of the increased regulatory demands add costs to operation with little perceptible environmental protection or improvement. The complexity of regulations often requires a specialist to interpret them and to help make proper filings for compliance. This is an obvious problem for a typical independent oil producer operating marginal wells with an average of less than 10 employees. Unfortunately, applying blanket standards that do not account for geological and operating realities often results in over- or underregulation that frustrates both conscientious operators and regulators. The rate of regulatory change has created an uncertain outlook for future financial liability. The cost and uncertainty of regulations are part of the reason for domestic-based production companies moving overseas. Stability and risk-based regulations would be well received by the industry. Keeping environmental impacts at a minimum level while simultaneously holding the cost of regulatory compliance down is a challenge facing industry. Environmental compliance is becoming increasingly costly and complex in the domestic oil industry. During the past 10 years, the cost of environmental compliance in the exploration and production sector alone has increased at a rate of 3\%-5\% per year. Compliance costs in 1990 were $\$ 2$ billion (Godec 1993).

In 1992 DOE did a study of future domestic oil supplies, concurrent with a similar National Petroleum Council study on natural gas supplies (NPC 1992). The assessment considered two environmental scenarios and two economic scenarios. For the period 1992-2010, strict environmental compliance requirements could result in a 32\% higher cost for new oil wells and a $43 \%$ increase in operating expenses. Crude oil production in the United States under the same regulatory scenario could decrease by as much as 620,000 barrels of oil per day by 2010 . A decrease in daily production from today's rates and a significant portion of the U.S. in-place oil reserves could be prematurely abandoned, eliminating accessibility to remaining oil that could be recovered with advanced extraction technologies. The oil industry, the government, and all other industry stakeholders need to work together to maintain a balanced environmental/ energy supply policy.

Regulations affecting the processing industry are even more confusing and onerous. Although advanced engine technologies have improved fuel efficiencies, the U.S. demand for liquid transportation fuels derived from oil will continue to increase. The Clean Air Act of 1990 has added new requirements and regulations to important environmental goals. Although the objectives are understood by all, the interpretation of the law into new regulations continues to be in flux. For example, a legal interpretation of the Clean Air Act and trade agreements allows a foreign processor to export lower quality products to the United States than our domestic refiners are allowed to sell. Another example of new 
regulations influx is the new requirements for renewable fuel content to meet reformulating goals. As with producers of crude oil, refiners and processors are being squeezed by increasingly stringent and costly regulation. In this uncertain environment, the economics of new refinery construction are poor. Efforts to upgrade old refineries are both economically and technologically challenging. A recent refinery study on the cost of regulations estimated expenditures of $\$ 150$ billion from 1991 to 2010 (NPC 1993). The number of U.S. refineries has decreased from more than 300 in the 1970 s to 171 in 1993 . We cannot now process enough crude to meet our demands. These few refiners were operating at $91.6 \%$ capacity for the first half of 1994 (EIA 1994). Refineries are at full capacity when running about $92 \%-95 \%$. With our production costs, we are unlikely to produce oil for export. If refining capacity continues to decline, we will further erode our balance of payments by the need to import more products, with attendant jobs, tax revenues, and profits going overseas.

\subsubsection{Trend to Heavier Oil}

A trend that affects the refiner is a domestic and worldwide trend toward heavier crude oils. From 1985 to 1992, the average gravity of oil processed by U.S. refiners decreased by $1^{\circ}$ API to $31^{\circ}$, and the sulfur content increased $0.3 \%$ to $1.2 \%$ (EIA 1994). This trend, which is expected to continue, challenges processors to produce more light-end products from a heavier crude base while reducing the heavy end residua and waste products.

Restrictions on the sale of Alaskan crude oil to foreign markets in the Pacific Rim puts this heavier crude into the same refineries that process the heavy California crudes from steam recovery projects. The market for both Alaskan oil and California heavy oil is constrained, resulting in especially low prices during a price decline. This decline causes production to be shut in or abandoned. Significant new offshore California heavy oil production will put additional price pressure on thermal enhanced oil recovery in the San Joaquin area of California.

\subsubsection{World Oil Market Volatility}

Worldwide oil supply and demand are closer now than any time since 1973. Growth in worldwide demand (particularly in areas such as Asia), lack of conservation efforts, and rapidly decreasing excess productive capacity contribute to a potentially volatile oil market. One recent estimate has idle production capacity at less than $2 \%$ if the Iraqi production is not considered. As noted earlier, there is little idle capacity in the domestic refining industry-virtually none if necessary downtime for maintenance is considered.

\subsubsection{DeCLining Industry R\&D EXPENDITURES}

The trend in industry research and development (R\&D) is difficult to gauge because a shift from basic and fundamental research to applied research and operating technical services is not directly reflected in $R \& D$ budgets. However, it will become obvious in 10-15 years by the lack of advances in technology. There has been a shift in focus from long-term to short-term research as part of the industry downsizing and the reengineering to focus only on critical near-term elements of the business. Research, development, and demonstration activity trends are in a downward spiral in the domestic oil industry. Historically, the oil-producing industry itself has defined needs and funded and carried out $R \& D$, whereas the government limited its participation to planning and funding long-range, high-risk $R \& D$ in recovery processes that industry would not perform.

Today's domestic oil industry, downsized and still shrinking, continues cutting $R \& D$ budgets and retiring its top technologists. Domestic major oil companies and service companies no longer devote large sums to long-term research. It is no longer an accepted certainty that the necessary $\mathrm{lab}$ and field-level research, commercialization, 

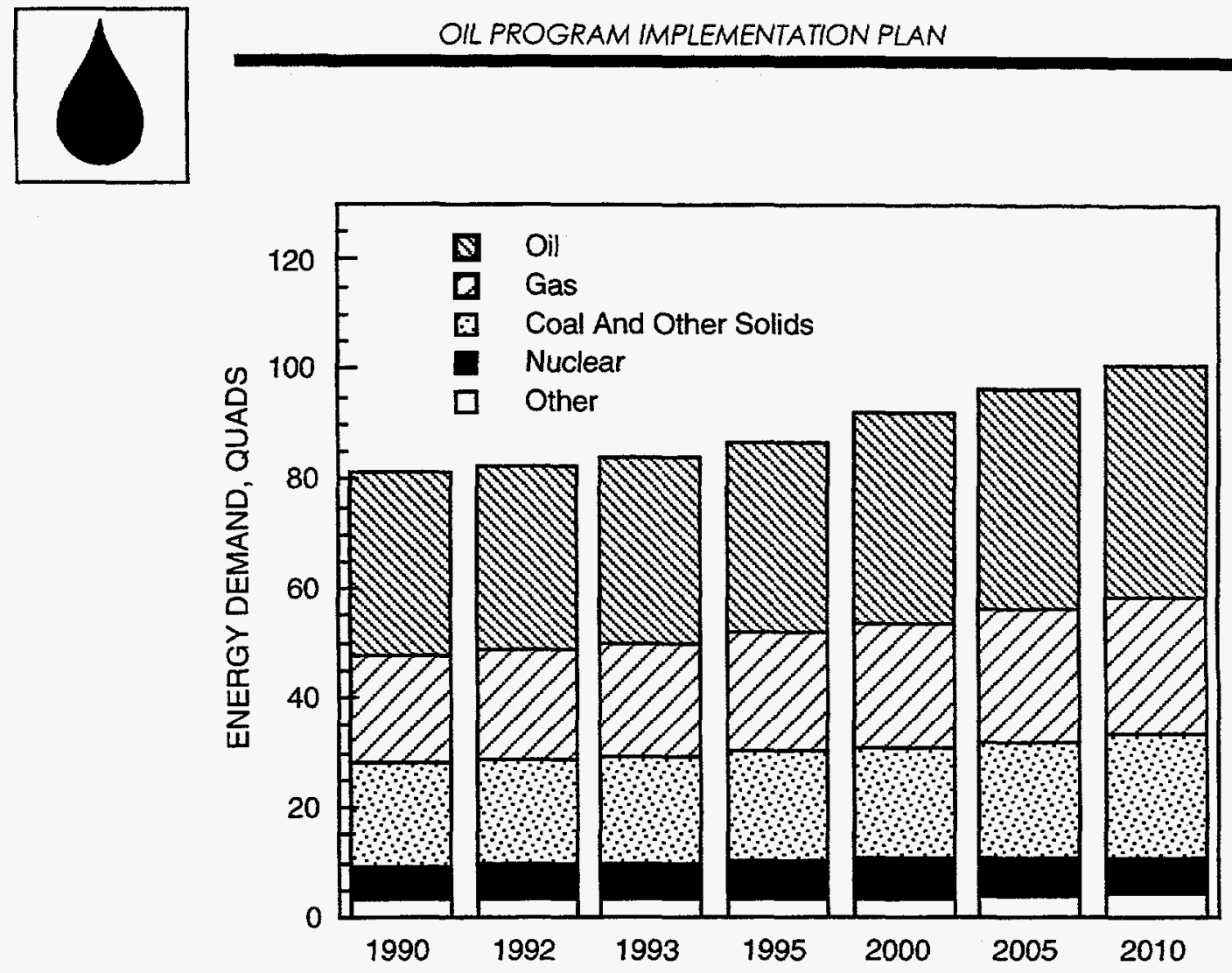

Source: EIA 1994

Figure 1.2.6 Increasing Demand for Oil to $\mathbf{2 0 1 0}$
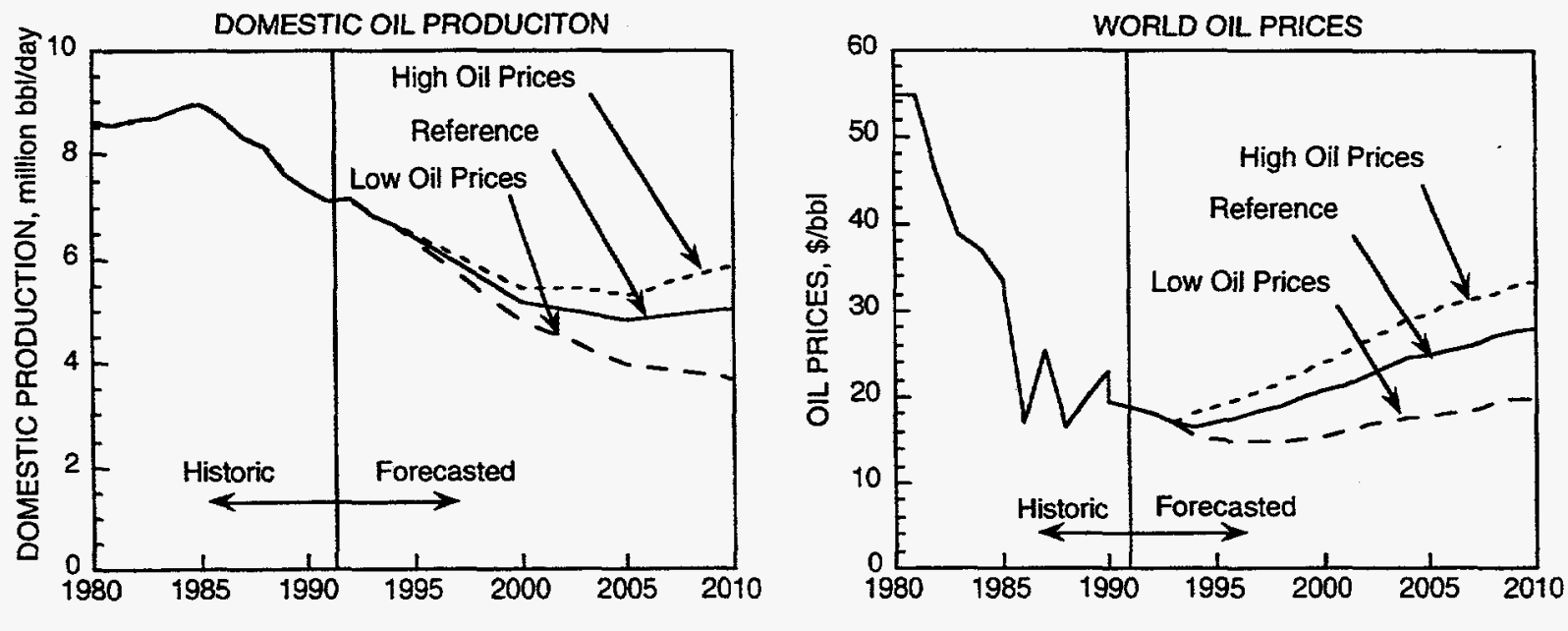

Source: EIA 1994

Figure 1.2.7 EIA Forecasts for U.S. Oil Production and Oil Prices to 2010 
and technology transfer will be performed without government encouragement or assistance.

The industry philosophy of short-term to midterm research with faster return on dollars expended is becoming the norm. As a result, the long-term research that often yields long-term benefits must be initiated by other means. The perceived success rate for $R \& D$ ideas needs to be high before industry will risk funding. This leaves a new willingness by industry to form partnerships with government and each other.

\subsubsection{OUTLOOK}

Energy usage will grow both domestically and worldwide. Both the Energy Information Agency (EIA) and the International Energy Agency (IEA) indicate that oil demand will increase but not as fast as total energy usage. A vast oil resource still remains in the United States. That resource can be lost to premature abandonment or it can help reduce imports and provide jobs.

\subsubsection{Demand, Price, and Production}

Oil will continue to be the largest source of primary energy beyond 2010. The use of natural gas will significantly increase also (Fig. 1.2.6). Forecasts for oil price vary from current levels to an increase to $\$ 30 /$ barrel in 2010 for WTI. EIA forecasts a high and low price track and an expected demand for the two extremes (Fig 1.2.7). The outlook for domestic oil production is a decline from a current 7 million barrels/day to 5 million barrels/day in 2000 and 2010 at the reference (expected) oil price. The gap between demand and domestic oil production will be met by imports. By EIA's forecast, imports will supply two-thirds of the oil demand by the turn of the century and more than three-fourths by 2010 . The cost will rise to between $\$ 100$ and $\$ 140$ billion/year for imports. Although this level of imports should cause concern for our economic well-being as well as our security, the potential world supply indicates continuation of low-cost energy from oil.

\subsubsection{Technology, the Promise}

The United States is endowed with an enormous oil resource. Nearly 160 billion barrels have been produced from this resource, and another $80-200$ billion barrels might yet be recovered (Fig. 1.2.8). Of this potential, 25 billion barrels are booked reserves that will be recovered under current economic and technology conditions. The remaining 55-175 billion barrels are a target for improved resource characterization, better recovery processes, active and improved exploration, expanded and improved drilling and completion, improved refining and processing, lower environmental impact, and improved economics. The Oil Program is directed toward encouraging, developing, and disseminating technology to U.S. explorationists, producers, and refiners to assure that we do not squander this heritage.

The federal government has had success in encouraging the oil industry to adopt advanced oil recovery technology and to share the experience. In 1978 the Tertiary Incentive Program (TIP) granted world oil pricing for certified EOR project production. Many of these projects resulted from joint ventures that unitized properties operated by both large and small producers. This incentive program caused implementation of advanced recovery technologies that started before or coincided with oil price increases rather than lagging as expected (Fig. 1.2.9). This boost was not temporary-35\%-40\% of current EOR production is from these TIP projects and their expansions. Many of the operators continued to file annual reports on the progress of these projects even though the reporting requirements were voluntary. This is one example of the industry's willingness to share experience with advanced production technology. 

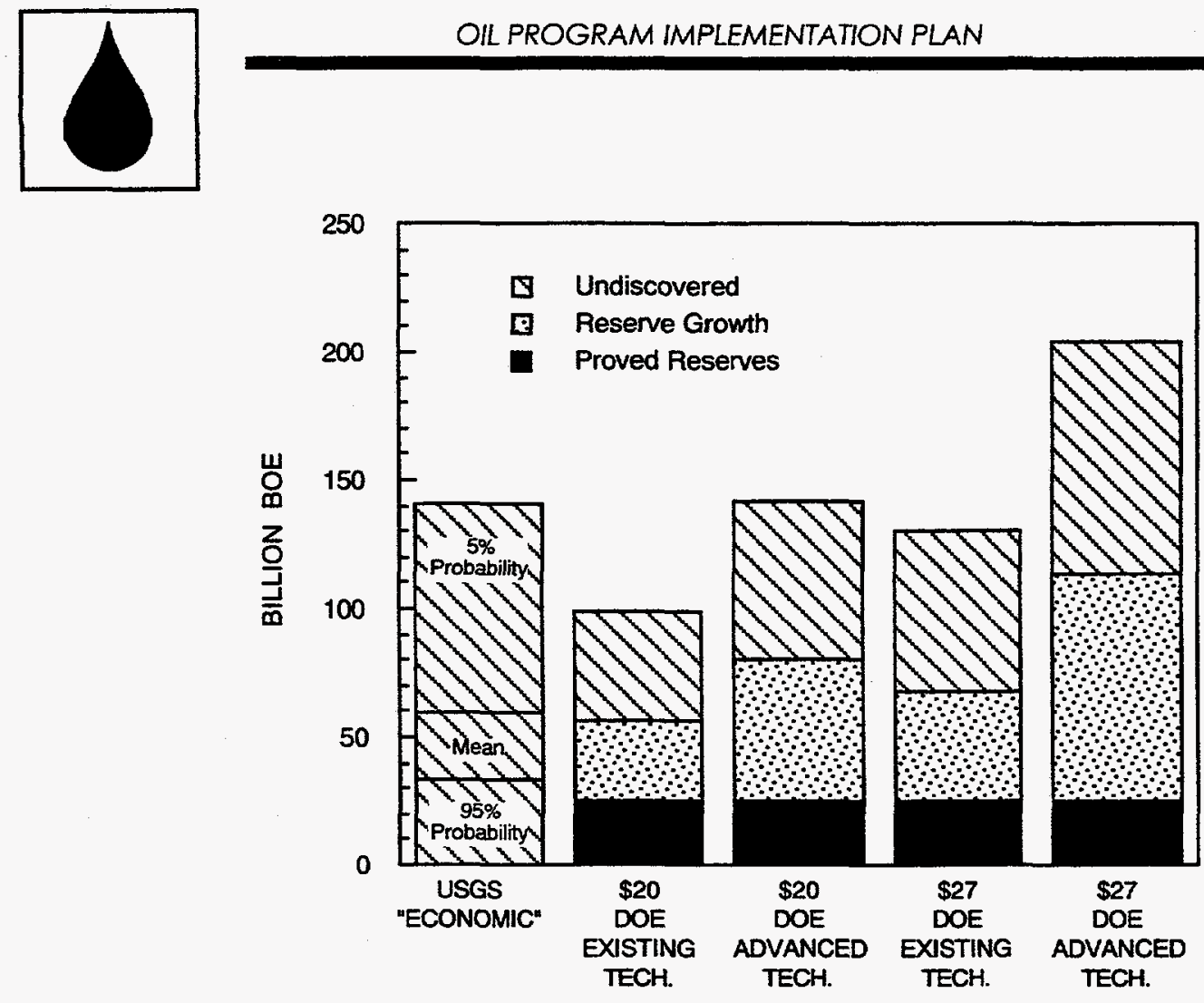

Source: Mast 1989, Fisher 1992

Figure 1.2.8 Estimates of Large Potential for Oil Reserve Additions
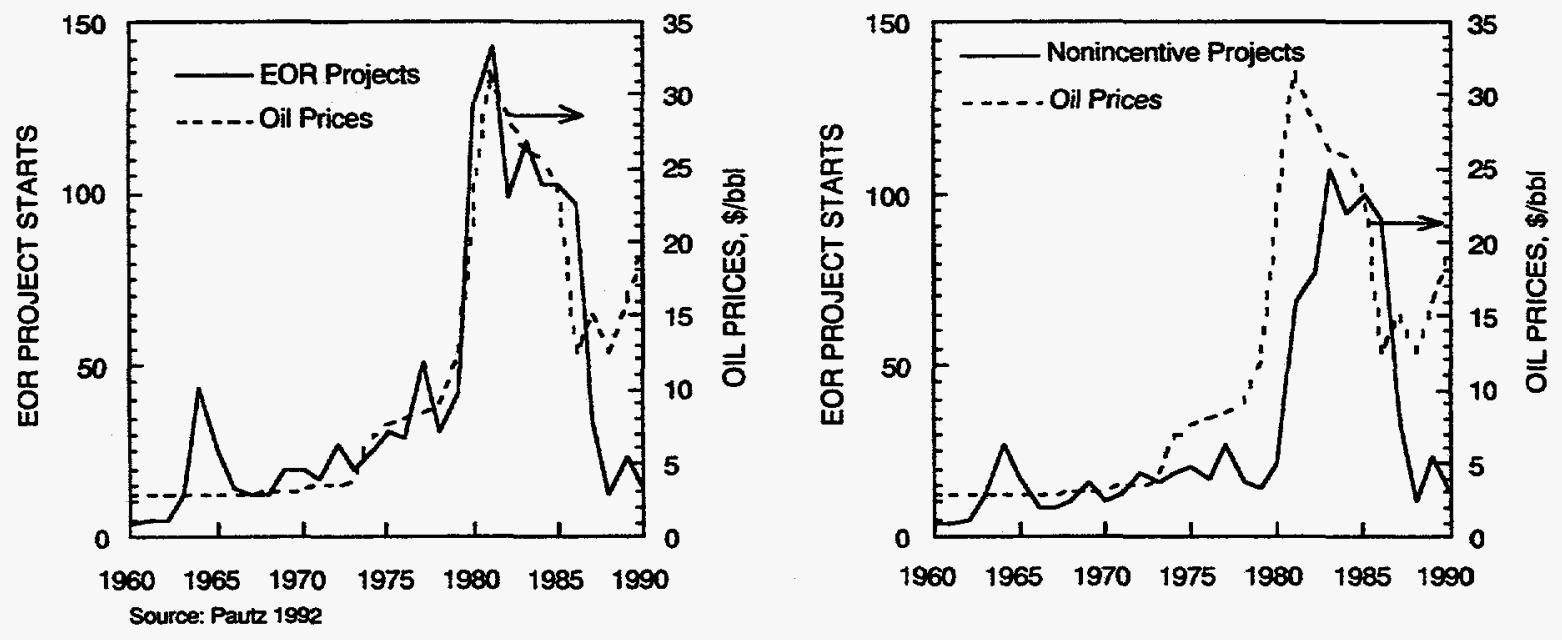

Figure 1.2.9 Impact of 1978 Tertiary Incentive Program on Implementing EOR 


\subsection{DOE'S EVOLVING ROLE IN OIL TECHNOLOGY}

The DOE investment in the Oil Program is small compared to the domestic capital expenditures of the petroleum industry. Therefore, it is a concern that this investment has a payoff. The payoff for the taxpayer is either a direct or indirect benefit. Direct benefits include lower energy costs, increased employment, and reduced risk of a major supply disruption. Indirect benefits from increased domestic oil production and the resulting decrease in imports include increased government revenues and ripple effects throughout the economy. This occurs when the Oil Program contributes to the development or implementation of commercial processes that either produce incremental oil from the domestic resource or yield additional refined products from each barrel of oil.

Since the Oil Program is small relative to the research needed to develop and implement an advanced oil recovery process, a new exploration tool, or a new refining process, the program makes incremental contributions to the development and implementation cycle that lead to commercial products. Figure 1.3.1 shows the building of an idea into a commercial application of technology. Almost anything can trigger an idea that can grow into a commercial payoff. Triggers can include problems, successes, and a technological breakthrough in a different industry. When an idea is identified, technical, economic, environmental, legal, and financial questions are generated-many of which cannot be answered without research and testing. Each unanswered question adds risk. Research attempts to reduce the critical risk elements to the point that an investor perceives the financial reward is attractive enough to overcome the perceived risk factors. Early laboratory and literature research is the least expensive to conduct, but it is also

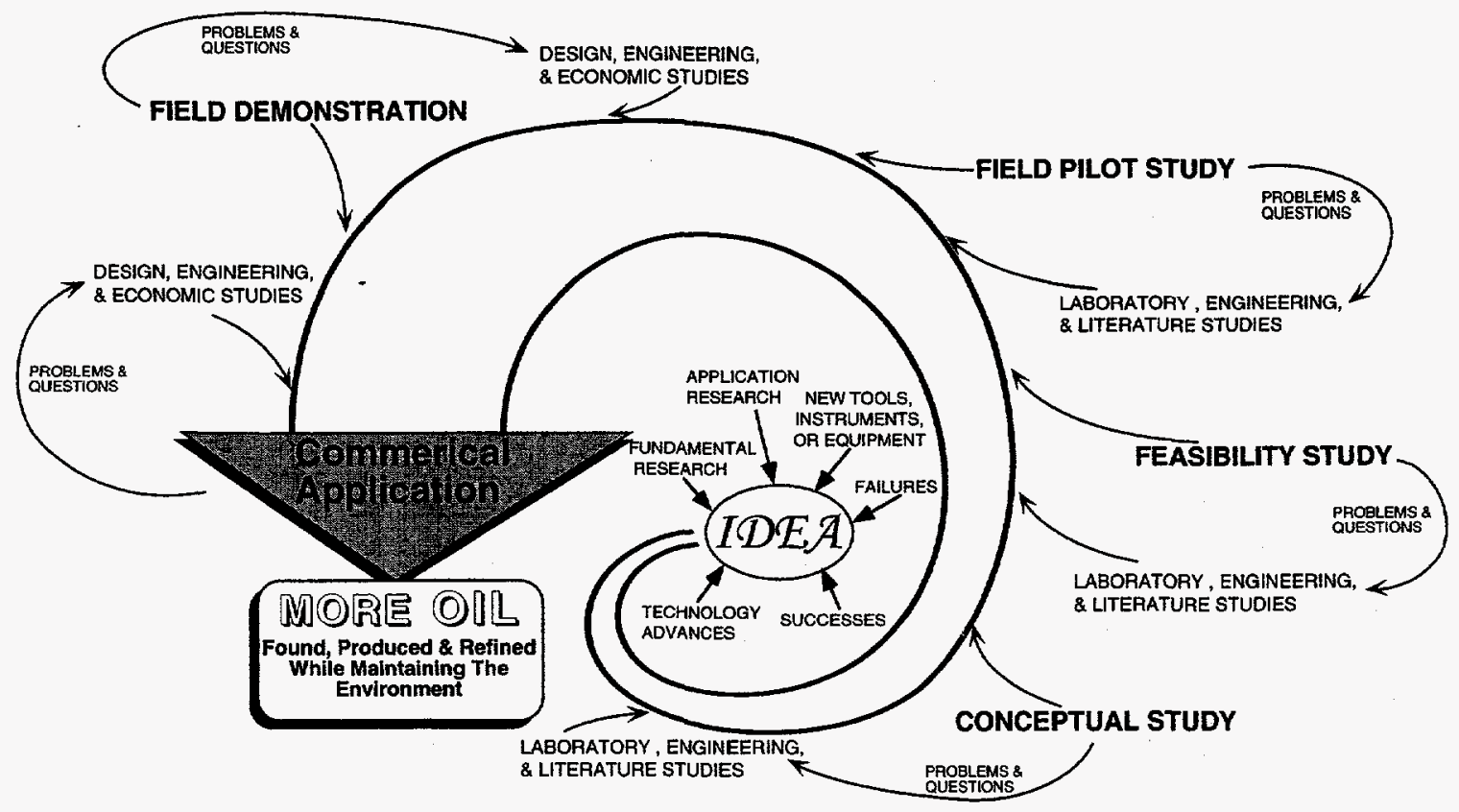

Figure 1.3.1 Building a Successful Commercial Application-the Payoff for Technology 


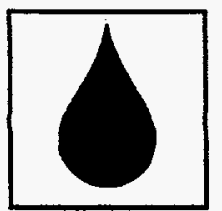

the furthest from the payoff promised at successful implementation. The path to final implementation is not straight. Development is an iterative process that requires going back to previous stages to make progress and numerous corrections before field application. The success rate for ideas is low-closer to $1 \%$ than $10 \%$. So research not only develops and refines ideas into successful application, it also eliminates noncommercial ideas from further consideration.

Government research can speed up this implementation process by conducting laboratory, literature, and engineering research as well as by disseminating information that might trigger ideas. Government can share the financial risk of early field and pilot tests that can jump steps in a normal implementation cycle. It can also develop and distribute tools for evaluating the potential of a line of research so that resources are targeted toward areas that have the biggest payoff. It can do background research that identifies true environmental risks. It can selectively target promising technologies that have long development times with potential payoffs for future generations. All of these have been a part of past oil research programs. In the competitive, market-driven U.S. economy, domestic industry and investors ultimately move the researched ideas into successful application.

\subsubsection{DOE's Oll Programs in the 1970s AND 1980s}

During the 1970 s a major thrust was to encourage implementation of EOR methods. A major portion of funding was for cost-shared EOR field tests with industry. These field tests generated a great deal of information and contributed greatly to the current appreciation of the formidable technical risk of advanced oil recovery (AOR) projects. They also demonstrated the government's ability to form partnerships with industry in projects to reduce the economic risk to participating companies while better defining technical risks. Results of these fields tests pointed to major areas of study, such as integrated reservoir characterization, that needed to be developed to reduce the technical risk in applying advanced recovery technologies.

During the late $1980 \mathrm{~s}$, an accelerating trend of well abandonments was recognized. If wells and leases are abandoned, the infrastructure and access to the remaining oil resource could be lost before the potential is realized. Although important advances have been made in oil recovery methods, the demonstration and application of the technology was not occurring at a rate that would affect abandonments.

\subsubsection{InItIATIVES fROM the 1990 PLAN}

In 1990 DOE published the Oil Research Program Implementation Plan. It focused on the goal of maximizing "the economic producibility of the domestic oil resource." The 1990 plan marked a significant redirection of DOE's Oil Program. Prior to the 1990 plan, the focus of the federal oil research program was to conduct long-term, high-risk research that maximized the ultimate recovery of the domestic resource. In most cases, this research was either not being done by industry, or it augmented industry's efforts. This strategy resulted in laboratory and computer research that advanced ideas and concepts of enhanced and improved oil recovery methods toward application in field pilot projects. This research was aimed at reducing the technical risk of field application but not the economic risk.

The 1990 plan marked a significant redirection of DOE's Oil Program based on recognition of the urgent need to facilitate rapid application of technology to preserve access to the domestic oil resource. The Reservoir Class Demonstration Program was the focusing feature of the 1990 Oil Research Program Implementation Plan. The R\&D program was oriented away from the longerterm, high-risk research that had been emphasized in previous years and toward development of technologies that could be applied in the near- and midterm. It also reimplemented partnership with industry to reduce the economic risk of accelerating field application of oil recovery technologies. 
In the 1990 plan, DOE estimates that up to 15 billion barrels of the estimated 351 billion barrels of remaining oil resource could be added to domestic oil reserves by near-term application of technologies that were available and proven. An additional 61 billion barrels of reserves could be added in the mid-term by applying currently identified advanced technologies. The remaining 275 billion barrels were the target for new technologies that had not yet been identified.

\subsubsection{INITIATIVES FROM THE FY 1996-2000 PLANS}

This Oil Plan builds on the strategies outlined in the 1990 plan. The approach for achieving these goals is based on targeting DOE's Oil Program efforts to develop and demonstrate the applicability of existing and advanced technologies.
New initiatives are targeted to address exploration of domestic basins, recovery from highpriority reservoir classes, Refinery of the Future, environmental constraints, changing feedstock and products, and better management of resources and waste. This plan includes a field demonstration program and a supporting program with targeted and discipline-oriented $R \& D$. Technology transfer is emphasized to ensure that technologies developed under DOE's programs will be applied widely by oil operators to achieve the goal of maximizing domestic production while protecting the environment. The plan also emphasizes the need to cooperate closely with independent operators, service companies, states, consultants, the academic community, and others to ensure that the program is targeted to develop and transfer technologies that will be applied widely. 


\subsection{IMPLEMENTATION PLAN}

DOE recognizes the necessity of a strong oil program designed to address the broad goals of assuring energy security, economic growth, environmental protection, jobs, improved economic competitiveness, and improvement in the U.S. balance of trade. Components of this plan are designed to meet the roles indicated by Congress in the Energy Policy Act of 1992 (EPACT), the President in the Domestic Natural Gas and Oil Initiative (DNGOI,) and the Secretary of Energy's Fueling a Competitive Economy Strategic Plan. The benefits of the Oil Plan will be seen in five areas:
- Improved exploration techniques to find domestic oil resources

- Improved technology to maximize domestic oil production

- Improved techniques to refine as much high quality fuel and lubricants as possible

- Assured protection of the environment

- Maintenance of U.S. leadership in oil and gas technology

The relationships between these five primary results of the Oil Plan and program areas contained in Section 2 are shown in Figure 1.4.1.

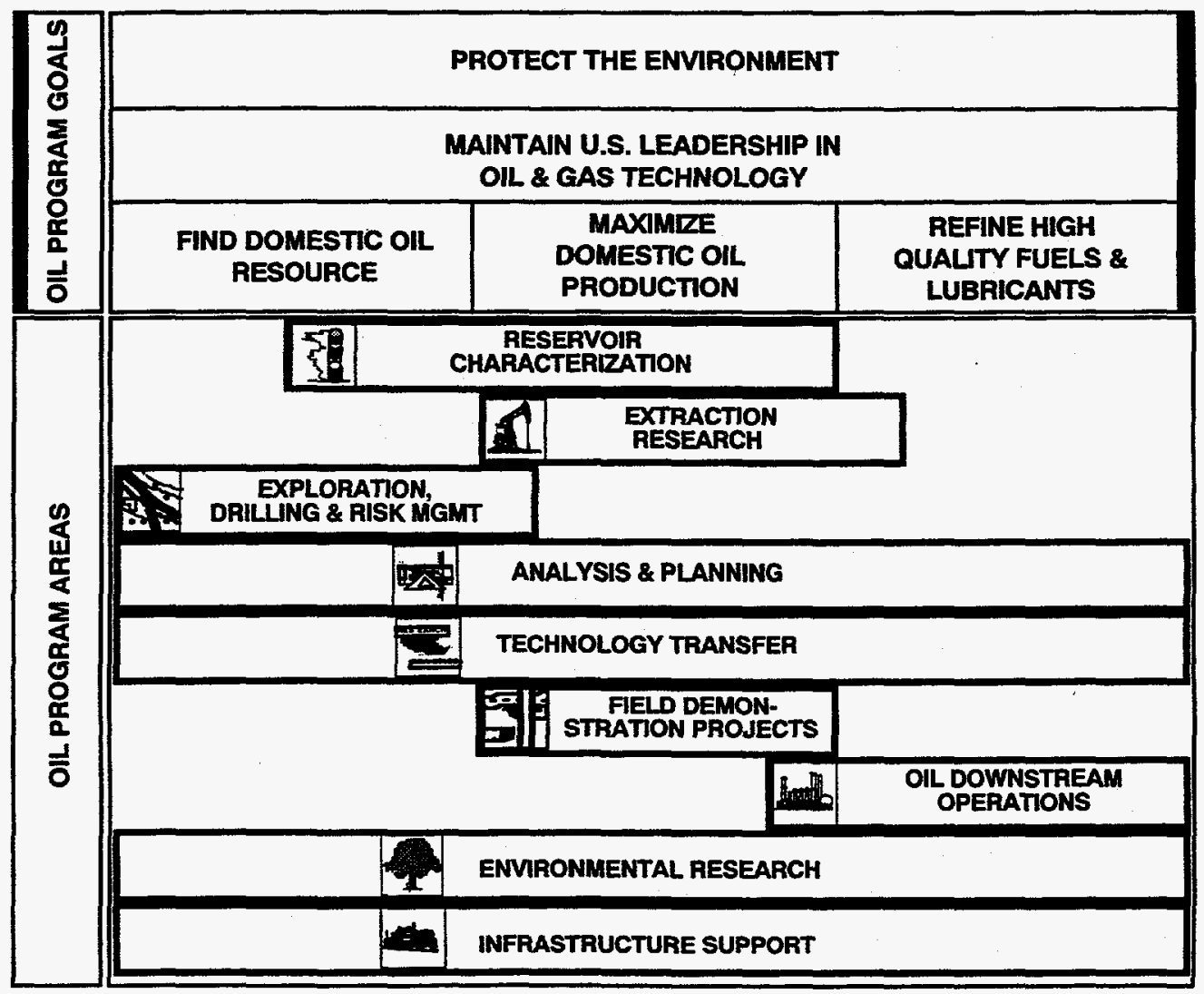

Figure 1.4.1 Relationship of Program Areas to Program Goals 


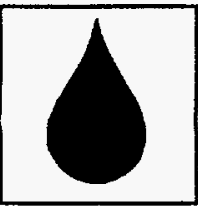

\subsubsection{Finding Domestic Oil Resources}

The undiscovered recoverable U.S. oil resource is estimated to be 33-70 billion barrels (Mast 1989). The majority of these resources will be found in small reservoirs located by exploratory wells drilled by independent operators. The Exploration, Drilling, and Risk-Based Decision Management Program will provide technical and informational support directed toward the efficient discovery of our remaining undiscovered oil resource. This program was begun in FY 1994, in response to the realization that the domestic oil exploration industry is changing. Currently over $85 \%$ of the exploratory wells drilled in the United States are drilled by independents. Independents drill almost all exploratory onshore wells in the lower 48 states. The Exploration, Drilling, and Risk-Based Decision Management Program is designed to reflect this change and is tailored to the independent.

Basin Analysis in High Potential Basins. This research will involve a multidisciplinary geoscience approach to basin analysis. Geologic, geophysical, geochemical, and engineering input will be coordinated using such tools as remote sensing and some of the new geophysical/ geochemical survey techniques, as well as computerized data management. The objective is to identify quickly and cost-effectively underexplored, high-potential regions and formations in basins of the United States. These efforts will be integrated with other government programs such as those at the United States Geological Survey (USGS), Minerals Management Service (MMS), and Morgantown Energy Technology Center (METC). Results will be distributed through seminars, workshops, and symposia.

Exploration in Mature Regions. This research will develop methodologies and techniques to explore untested formations within older producing fields in an environmentally safe manner.

Drilling and Completion Technology. The drilling research program is intended to develop improved, more cost-effective engineering methodologies and/or equipment. These are intended to optimize environmentally sound, operationally safe drilling and completion technologies. The work will encompass research on vertical, slant, horizontal, and slimhole wells.

Risk-based Decision Management Tools. This research effort will result in the development of an integrated state-of-the-art, risk-based decision management model using currently available operational data. This tool will help independent operators evaluate and minimize the risk associated with hydrocarbon exploration and drilling.

Establishment of a Field Laboratory. A new initiative of the Oil Plan is to establish a field laboratory on Native American lands. The initial phase is to select the site using evolving exploration techniques. Although this laboratory will initially test and demonstrate new exploration technologies, the site will be used as an integral part of developing and improving oil recovery processes, drilling, reservoir characterization, and environmental research as applicable to the reservoirs at this site. Field laboratories will accelerate development and demonstration of new technologies. The new field training and demonstration center at $\mathrm{Na}$ val Petroleum Reserve No. 3 (NPR\#3) will also be used. Since the characteristics of the reservoirs at these two sites are different, experiments and demonstrations for one site frequently would not be conducted at the other, and some experiments will require field sites other than these two.

\subsubsection{Maximizing Domestic Oll ProdLCTION}

The United States is at its lowest domestic oil production level in 24 years. Over one-half of U.S. oil is imported at a direct cost of about $\$ 1$ billion/week (EIA 1994). These grim statistics need to be balanced with a recognition that only one-third of the discovered original oil in place has been recovered. The remaining twothirds ( 351 billion barrels) of this oil cannot be economically produced at today's prices with today's 
technology (BPO 1992). It is the goal of the Reservoir Characterization Program, the Extraction Research Program, and the Field Demonstration Projects to provide improved technology and/or reduced operating costs to make more of this remaining target recoverable.

Reservoir Characterization Program. The Reservoir Characterization Program seeks to maximize oil recovery in an environmentally sound manner by providing an understanding of reservoir architecture, reservoir geometry dimensions, boundaries, fluid/rock properties, and fluid-flow characteristics within the reservoir. For example, enhancing the ability to define and describe fluid-flow paths and barriers to fluid movement within reservoirs can lead to more effective production and management strategies.

Extraction Research Program. The focus of the program is maximizing the recovery of the remaining 351 billion barrels of known oil in place. Historically, DOE oil research programs have concentrated on basic research and providing industry with monetary incentives for EOR programs. The Extraction Research Program described in this plan redirects DOE's efforts and has a goal of wider application of existing improved and advanced oil recovery (AOR). Field pilot tests and experiments will be implemented as a means of identifying and reducing the technical risks as well as demonstrating the benefits of technologies to the petroleum industry. These new initiatives will move technology closer to the payoff for the nation-successful commercial application of more effective oil recovery methods. Computer models will be developed that include improved oil recovery technology tailored for small and medium independent operators.

Examples of work include promoting extraction simulation by developing process models, reservoir models, economic models, and tracer models suitable for use by independent oil companies; developing improved oil recovery (IOR) methods that advance waterflooding, pressure maintenance, sweep improvement, completions/ stimulations, infill drilling, horizontal wells, and monitoring; and developing advanced oil recovery methods based on chemical flooding, gas flooding, microbial, thermal, and innovative methods.

Oil Field Demonstration Projects. DOE's reaction to an alarming trend of increased well and field abandonments in the late 1980s resulted in a new cost-shared program with industry. Developing recovery technology pays back the taxpayer only when the technology is implemented-reducing imports and employing Americans. A critical step in technology development is moving technology into wide acceptance and successful application by industry. DOE, through cost-shared field demonstration projects, accelerates the application of production technology. By prioritizing geologically based reservoir classes, projects target those reservoirs that have the most potential for improvement and are most at risk of abandonment. Benefits of this program are increased by intensive efforts to evaluate the results and to refine processes and methods, as well as by targeting communication toward operators in reservoirs having geological similarity. Twenty-four costshared projects in two classes have been awarded or initiated, and projects for a third class have been evaluated. New initiatives during the fiveyear plan leverage the lessons learned in the earlier field demonstrations and also target specific near-term technology payoffs to independent operators.

\subsubsection{Refining Oil Resources}

Domestic petroleum refineries will be the primary source of transportation and other fuels for decades to come. Global integration and high dependence on technology have been the hallmark of the refining industry. Because refined products move freely among countries and refinery processes are international in character, technological advances become available worldwide relatively quickly. Our domestic industry has led the rest of the world in technology developments and as a whole, remains the most 


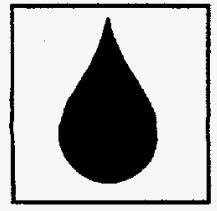

sophisticated. The number of refining processing sites declined to 171 at the close of 1993, down from more than 300 in the 1970s. The Oil Downstream Operations Program focuses on research to help the industry reduce refining costs, comply with environmental regulations, and meet increasingly strict environmentally driven fuel specifications, while dealing with the declining quality of the crude delivered to the refinery.

The three major components of the Oil Downstream Operations Program are environmental compliance, pollution prevention, and heavy oil upgrading. The environmental compliance component will develop environmental data and technologies in collaboration with a number of refinery groups, industry, environmental groups, and federal, state, and local regulators. The pollution prevention component will help evaluate new and promising technologies that reduce specific pollutants, such as air emissions toxins, wastewater, refractory hydrocarbon residues, coke, and spent catalysts. The heavy oil upgrading component will develop fundamental chemical and thermodynamic data on heavy crude oil and residua and work with industry to increase processing capacity of domestic heavy crude oils.

\subsubsection{Protecting the Environment}

The Environmental Research Program goals are to reduce environmental cost to operators while improving their environmental performance and to assure that sound regulatory decisions made by state, tribal, and federal government officials are based upon all available data. There are five principle components of the Environmental Research Program: Area of Review variance, streamlining regulations, Gulf of Mexico discharges, environmental technologies and practices, and environmental outreach and program planning.

Area of Review Variance. These projects will provide states with the capabilities to support the acquisition of variances to forthcoming Environmental Protection Agency requirements related to risk posed to groundwater from injection of produced water for disposal and enhanced oil recovery (EOR).

Streamlining Regulations. The goal of this area is to reduce costs to oil and gas operators by simplifying regulations without compromising environmental protection. One example of this streamlining is the Safety and Environmental Management Program (SEMP) alternative regulatory compliance demonstration. This work is a joint project of DOE, the Department of the Interior, and the offshore oil and gas industry. It will demonstrate the feasibility of voluntary SEMP plans for small operators on the Outer Continental Shelf as an alternative to new regulations.

Gulf of Mexico Discharges. This research will collect and analyze scientific data that affect regulatory decision making regarding producedwater and sand discharges in to the Gulf Coast. Examples of the type of data collected are organic, trace metals and naturally occurring radioactive material in water, sediment, and biota.

Environmental Technologies and Practices. This research involves environmental compliance technologies and practices to improve environmental performance and lowering cost for producers. Field demonstration of lower cost produced-water treatment technologies is a sample project.

\section{Environmental Outreach and Program} Planning. This project area is designed to conduct analysis of industry and environmental trends, to conduct environmental outreach efforts to oil and gas producers and regulators, and to support program management.

\subsubsection{U.S. LeADERSHIP IN OIL \& Gas TeChNOLOgY}

The domestic oil and gas industry has undergone a tremendous contraction since the peak boom years of 1981 and 1982. Almost all measures or indices of industry activity have shown 
dramatic downturns driven by low product prices. For example:

- Over 350,000 oil and gas extraction jobs have been lost since 1982 (EIA 1994). This amounts to almost a $50 \%$ decline.

- Annual domestic exploration and production expenditures have fallen by more that $\$ 20$ billion (O\&GJ 1994).

Outlooks and projections of product supply/ demand and prices show continued prices below $\$ 20 /$ barrel for the next few years (EIA 1994, IEA 1994). These changes have forced extensive cost containment and industry restructuring. Major oil and gas companies are leaving the United States by moving overseas where costs are lower, environmental laws are often less strict, and the chance of major finds is greater. Many of these companies are shedding their domestic oil and natural gas fields, which are being purchased by independents.

Change is also evident in the oil and gas research community. The industry domestic R\&D expenditures have been decreasing, and researchers have by necessity developed an emphasis on applied technology. More than ever, industry researchers are developing products that can contribute immediately to the bottom line. There is also an increased trend to participate in joint projects with other companies and government agencies to reduce risk and lower costs. These trends place an even greater importance on the efficacy of DOE's Oil Program. Many of the projects in the Oil Plan are designed to address these changes (e.g., the Field Demonstration Projects and Field Pilots). The Technology Transfer and Analysis and Planning Programs are critical components of the Oil Plan that first target research and then research conveys results to customers and stakeholders.

Technology Transfer Program. The Technology Transfer program is designed to deliver the products of the Oil Program to customers and stakeholders by providing support for dissemination of information, conducting stakeholder outreach, supporting international activities involving conferences and oil and gas technology centers, and offering and supporting educational efforts for enhanced science and technical education at all levels.

Analysis and Planning. The Analysis and Planning Program is designed to support prudent, cost-effective management of the Oil Program through four functions: planning, evaluation, analysis, and quality assurance. The planning function includes defining priorities, developing strategic and implementation plans, and establishing measures of effectiveness. The evaluation function is a new initiative in FY 1996. It encompasses developing and implementing monitoring systems, reporting relevant discrepancies, and collecting data to measure the program's effectiveness. The analysis function includes developing and maintaining a comprehensive analytical capability to provide information to internal and external stakeholders.

\subsubsection{IMPLEMENTATION SUMMARY}

The DOE Oil Plan presented here focuses on addressing the issues of importance to all Americans: maintaining high-paying jobs, secure and affordable transportation fuels, and American technological expertise. Section 2 provides more details of the individual program components. 



\subsection{BUDGET}

The Oil Plan is the first step of the federal budget process that will result in detailed program plans at the beginning of FY 1996. The projects defined will implement the goals of the President's Domestic Natural Gas and Oil Initiative (DNGOI), Congress' Energy Policy Act of 1992 (EPACT), and the Secretary of Energy's Fueling a Competitive Economy Strategic Plan. Budget values for FY 1994 and FY 1995 represent appropriated funding. Realistic expectations were the only limits placed on the amount of dollars available in the years FY 1996-2000. These planned budget levels have not been approved for inclusion in DOE's or the President's budget.

Over the past several years, the federal research and development $(R \& D)$ spending for the
Oil Program has been influenced by many factors. Funding increased in the late 1970s in response to oil supply disruptions (Fig. 1.5.1). During the early 1980 s, funding decreased when it became clear that major oil and gas companies had increased $R \& D$ funding and the world oil supply again exceeded demand at reduced oil prices. By the late 1980 s, concern about decreasing domestic oil production, increasing reliance on oil imports, increasing number of well abandonments, and smaller and more applied industry $R \& D$ efforts were reflected in increased federal funding.

There are four budget areas: Exploration and Production (E\&P) Supporting Research, Field Demonstrations, Environmental Research, and

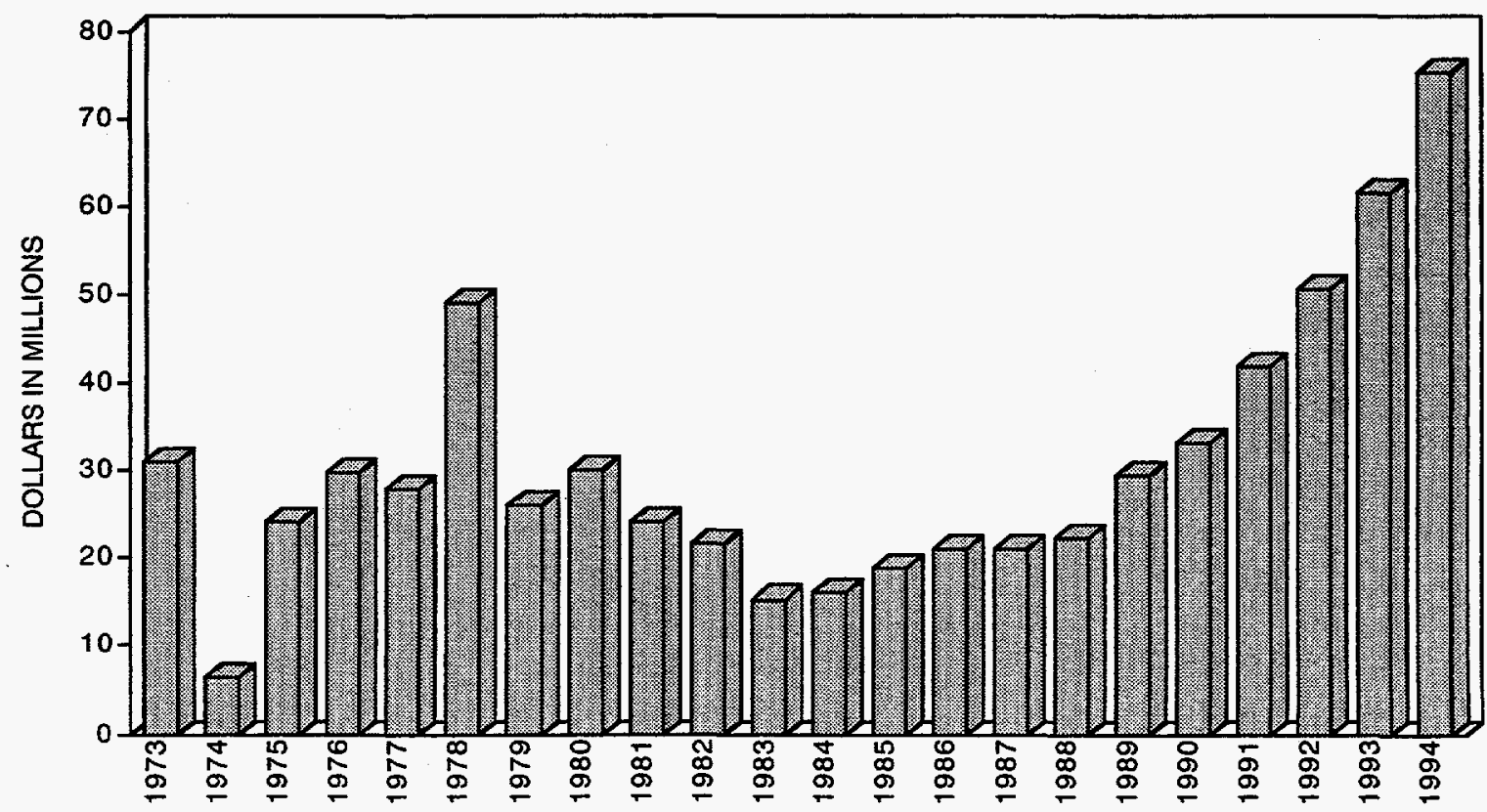

Figure1 1.5.1 R\&D Funding 1973-94 (in nominal or current dollars) 


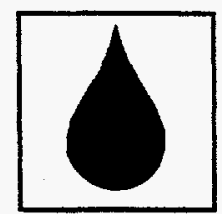

PROGRAM AREAS

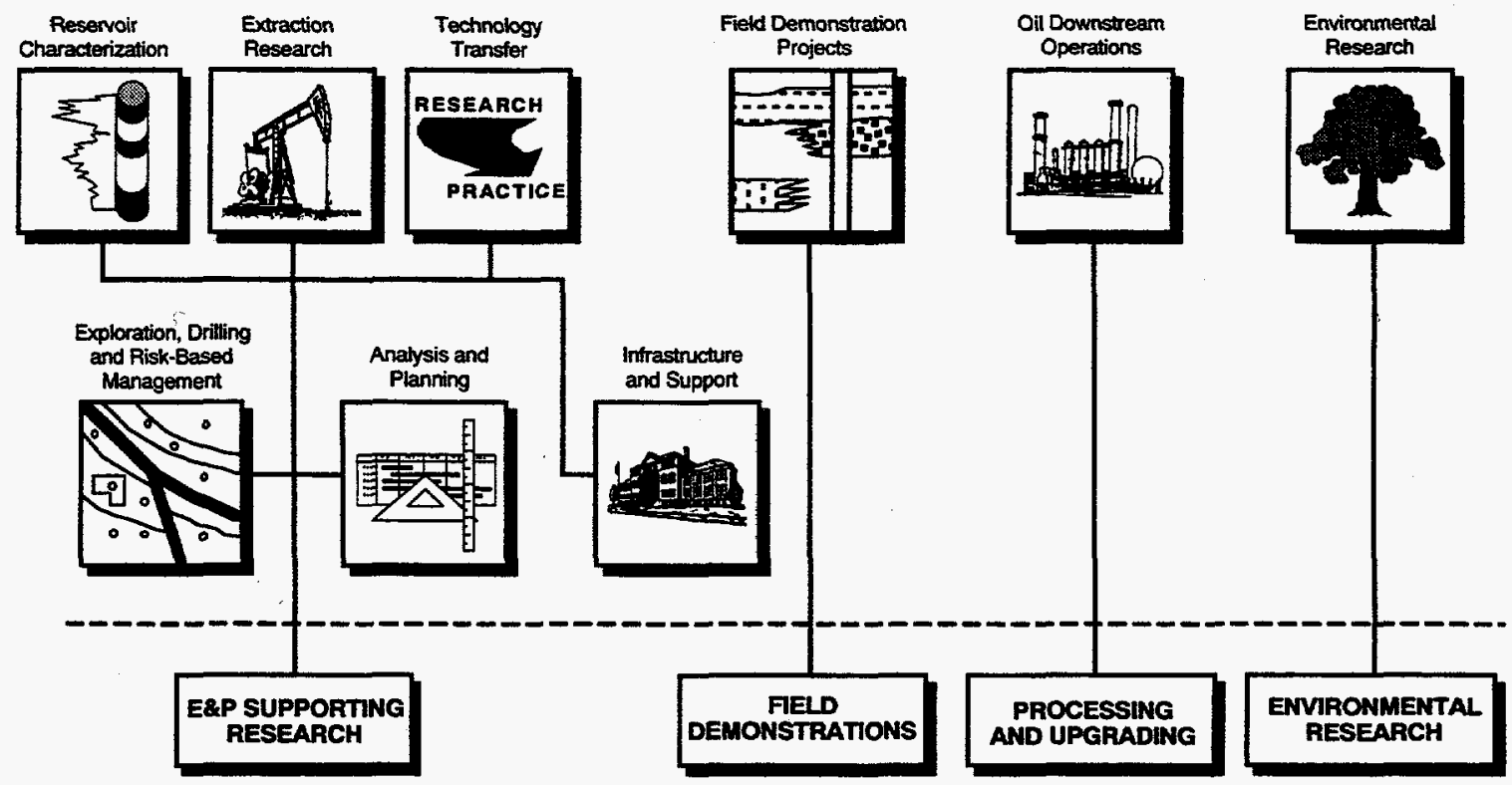

BUDGET AREAS

Figure 1.5.2 Relation of the Nine Program Areas to the Four Budget Areas

Table 1.5.1 Budget and Funding Plan

\begin{tabular}{lcc}
\hline & $\begin{array}{c}\text { FY 1994 } \\
\text { Appropriated } \\
(\$ 1,000)\end{array}$ & $\begin{array}{c}\text { FY 1995 } \\
\text { Appropriated } \\
(\$ 1,000)\end{array}$ \\
\hline Elanning Unit & & \\
Reservoir Characterization & & \\
Extraction & 10,437 & 15,179 \\
Exploration \& Drilling & 6,965 & 9,184 \\
Analysis \& Planning & 2,669 & 4,162 \\
Technology Transfer & 3,089 & 4,420 \\
\hline E\&P Supporting Totals & 1,809 & 3,148 \\
Field Demonstration & $\mathbf{2 4 , 9 6 9}$ & $\mathbf{3 6 , 0 9 3}$ \\
Processing \& Upgrading & $\mathbf{4 1 , 4 2 0}$ & $\mathbf{3 4 , 9 1 1}$ \\
Environmental Research & $\mathbf{4 , 2 7 4}$ & $\mathbf{6 , 9 2 9}$ \\
\hline Oil Program Totals & $\mathbf{3 , 6 1 1}$ & $\mathbf{4 , 7 7 5}$ \\
\hline
\end{tabular}


Processing and Upgrading Research. Figure 1.5.2 shows the relationship of the nine program areas to the four budget areas.

\subsubsection{E\&P SupPorting ReSEARCH}

E\&P Supporting Research includes support and planning of light and heavy oil recovery technology, exploration and drilling research, risk management, and advanced extraction geoscience activities. In developing the implementation plan, three technology programs (Reservoir Characterization, Extraction, and Exploration and Drilling) as well as two crosscutting functional areas (Analysis and Planning and Technology Transfer) were identified as planning units. Additional budget detail as well as other information on these five planning units are included in Sections 2.1-2.5.

\subsubsection{Field Demonstrations}

This area involves support and planning of field demonstrations of recovery techniques for light and heavy oil. Although E\&P supporting research is the largest program area in the new FY 1996-2000 plan, field demonstrations continue as a key component of the new plan. Funding increases would be consistent with directives to accelerate the Class cost-shared program and to assist the independent in improved competitiveness.

\subsubsection{Processing \& Upgrading}

This area involves support and planning of advanced refining, heavy oil upgrading technology, and related environmental research. The scope of processing research is increasing beyond limited fundamental research to assist industry in effectively dealing with the trend toward heavier crude oil inputs and stricter and sometimes conflicting environmental regulations. The move toward heavier crudes will accelerate based on the success of portions of the advanced oil extraction in the E\&P supporting research program area.

\subsubsection{Environmental Research}

This area includes support and planning of environmental research for exploration, recovery, and production of crude oil. The major increase in environmental research funding reflects an increased effort to affect the increasing cost for producers to meet confusing and sometimes conflicting environmental regulations.

\subsubsection{Research Budget Request}

Table 1.5.1 illustrates appropriated funding for FY 1994 and FY 1995.

The FY 1996-2000 Oil Plan was developed for an unconstrained budget. The plan was bounded by the scope of the goals set by DNGOI and EPACT as well as the historic context of the program. This results in funding increases that might be inconsistent with other DOE or administration policy goals and competing programs. These requested amounts will be considered as DOE moves through FY 1996 and later budget cycles.

\subsubsection{DOE Budget Cycle}

The budget cycle begins about two years before the beginning of an implementation year. For example, strategic planning by DOE headquarters for FY 1996 began before the fall of 1993. The strategic guidance was used by the field office to develop a planned budget for FY 1996 and subsequent years by the spring of 1994 . The Deputy Assistant Secretary of Energy prepared another version of the FY 1996 budget based on the field office inputs, other information, and new budget guidance. The Deputy Assistant Secretary submitted this revision to the Secretary of Energy early in the summer of 1994. By late summer of 1994, the Secretary submitted another revision to the Office of Management and Budgets (OMB). By late winter 1995, OMB will prepare the President's request for FY 1996. During 1995, Congress will decide how much and what the FY 1996 program will be. First, the House and then the Senate prepare a markup of the 


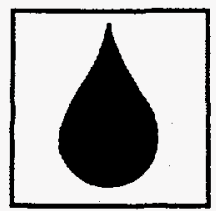

President's request for FY 1996. Finally, the differences between the Senate and the House markups are resolved in conference, and the final appropriation is made by fall of 1995. During this cycle, projects and program areas are adjusted, cut, added, deleted, and restored. 


\subsection{IMPROVING INDUSTRY \& STAKEHOLDER ACCEPTANCE}

This administration is focused on improving the government's responsiveness to its stakeholders. Our stakeholders are those people that have a direct or indirect interest in the success and failure of the Oil Program.

\subsubsection{Stakeholders}

The development of the Oil Plan is driven by the concerns of and consideration for our stakeholders. The following stakeholders were identified and their needs analyzed as part of the planning process.

- The U.S. taxpayer: mainly the petroleum consumer and future generations who will benefit from a stable, affordable petroleumbased energy supply for future consumption and a minimally affected environment

- The oil and gas industry: the petroleum explorationist, producer, refiner, and consultant; the petroleum and related environmental regulator, and the investor

- The businesses and facilities that conduct the research for the Oil Program: Bartlesville Project Office, Metairie Site Office, Morgantown Energy Technology Center, Fossil Energy (FE) Headquarters, National Institute for Petroleum and Energy Research (NIPER), universities, independent and major producers, national laboratories, and contractors

- State, local, and Native American governments

- Federal government: agencies, Congress, the President, and the administration

- Trade and professional interest groups

\subsubsection{STAKeholder INVOLVEMENT}

During the planning process, stakeholders from within DOE and other federal agencies were involved in refining the goals and objectives for each of nine planning sections. The inclusion of federal agency stakeholders has added new perspective to the program, reducing redundancy within the federal government as well as identifying areas for joint working efforts that will result in better products at lower cost to the taxpayer. In addition, industry perception was captured by including selected retired industry executives in several of the planning units. These individuals assisted in identifying the needs of all of the stakeholders and in developing the suite of projects addressing those needs within the context of the Oil Program's mission.

Additional input from outside stakeholders was the final step of the planning process. Industry and academia (over 300 participants) reviewed the description of this plan. A summary of their comments, as well as most of the detail, is included in the appendix. Where possible, comments and suggestions were included in the final description of the plan. The remainder of the comments and suggestions will be used as guidance and input into the FY 1997-2001 planning cycle.

An expanded role for stakeholders in future planning efforts is under consideration. Identification of needs and the appropriate response to those needs are facilitated by personal involvement. When industry and government share the responsibility for the success of a research plan, the plan is sharply focused towards removing impediments to the evolving technologies. Removing perceived risks will result in greater technology implementation.

\subsubsection{Stakeholder Partnerships}

One of the important tools used to implement the Oil Program is industry-government partnerships. Financial risk is considered a major impediment to technology implementation, 


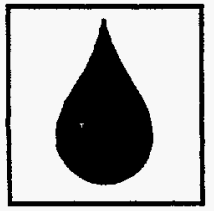

but the partnership approach serves to reduce this burden and also brings government and industry researchers together.

Cooperative Research and Development Agreements (CRADAs) are a method for industry to conduct joint research with NIPER and the national laboratories. NIPER and the national laboratories have assembled the manpower and created the infrastructure for highly sophisticated research. With a change in focus away from nuclear weapons research, the national laboratories are more available to assist in solving complex industrial problems. CRADAs have been and will continue to be used for cost-shared, industry-directed research. DOE is refining this instrument to be responsive to requests by industry for joint research. This program specifically targets reducing the technical risk of the industry user such as the major oil companies and service companies while making maximum use of the specialized resources assembled at NIPER and the national laboratories.

Another partnership program, Advanced Computational Technology Initiative (ACTI), uses input from industry to drive specific research projects. Advances in computing hardware should allow development of software that can assist in solving complex problems thought impossible only a few years ago. A series of conferences announcing this new program was well attended, and valuable input into the direction of this research is expected.

In the Field Demonstration Program, industry and industry/academia teams share the costs of near- and mid-term demonstration projects targeted toward a specific type (class) of geologic reservoir. The reservoir classes were identified and prioritized on the benefit from improved production technology and the danger of premature abandonment. This program was the guiding focus of the 1990 Oil Research Program Implementation Plan. Twenty-four projects have been awarded or initiated in Classes 1 and 2. Be- cause these project ideas came from industry, they focus on opportunities that have immediate payoffs, as well as potential for wide application. This popular program has been targeted for acceleration by Congress in EPACT and the President's DNGOI. The Oil Plan advocates increasing this program from one class procurement cycle per year to two classes per year.

In the petroleum industry's efforts to survive and be competitive, companies are shedding assets to reduce costs. Rock cores and bulky reservoir data such as well logs, core analysis, seismic, and other domestic reservoir data are being discarded as a result of bankruptcies, property abandonments, and cost-saving efforts. These cores and data were expensive to acquire, and they continue to have value for the petroleum resource's ultimate recovery. The United States Geological Survey is accepting donations of cores for the national repository with some limiting conditions, but there are no provisions for a central data repository. A nonprofit industry group has proposed a DOE cost-shared data repository with appropriate retrieval systems. The plan suggests joint development and management of the system with industry in order to maintain infrastructure in the face of the rapid shifting of properties between operators. Integration of this effort with the United States Geological Survey core repository could add additional value as well as reduce the overall costs. This will be an industry cost-shared program that will go as far as funding will allow.

The concept of a regionally based technology transfer network for the petroleum production industry has been in discussion and development for years. A cost-shared arrangement with a newly formed nonprofit industry organization will begin operation in FY 1995. This organization will provide feedback to the planning effort on the needs and reactions of its end users. Many of the tools and technology products generated by the Oil Plan are targeted to this set of end users. 


\subsection{MEASURES OF EFFECTIVENESS}

The success of the Oil Program will be measured by the program areas reaching their goals and objectives internally and by industry's acceptance and implementation of technological advances. The measures of effectiveness are highlighted in four ways within each program area individually and in the Oil Program as a whole. The four measures are:

- Comparison to current baseline technology

- Commitments made

- New processes and procedures

- Industry participation, acceptance, and application

Each program area has measurable criteria that relate to its success. Table 1.7 .1 summarizes this criteria for each of the four budget areas.

\subsubsection{Current Baseline Technology}

In order to establish a real measure of effectiveness, a current baseline will be established to judge progress in each working area of the Oil Program. Baselines will consist of current research projects, project man-hours committed, budgets and DOE Fossil Energy priorities, along with administration and congressional priorities. Any change in these areas and the impact of the change will be noted.

\subsubsection{Commitments MAde}

Commitments made will be the next step in measuring the effectiveness of the Oil Program.
As in the establishment of a baseline, the projects, man-hours, time frames, requested budgets, and the subsequent budgets approved and applied will be established. Once established, a tracking system will be set in place, thereby allowing all involved to follow the progress made in each area.

\subsubsection{New Processes and Procedures}

Each area of the Oil Program offers benefits to the program stakeholders. Any new processes or procedures developed as a result of the implementation of the plan and adopted or used by any of the stakeholders will be a direct measure of program success. Every process or procedure which increases stakeholder efficiency, causes more oil to be produced or refined, or helps maintain environmental quality will be a measure of success of this oil program.

\subsubsection{Industry Participation, ACCEPTANCE, AND Application}

The ultimate measure of effectiveness of this program will be its acceptance by the domestic oil industry, the industry's participation in the program, and the application of the processes and procedures developed. Because these criteria will be measured not only domestically but worldwide, success of this program will be measured ultimately on a global scale. 
Table 1.7.1 Measures of Effectiveness

Area

E\&P Supporting Research

\section{Metric}

- Improved seismic resolution \& decreased cost

- Advances in interpreting old logs

- Improved reservoir model \& characterization methods that increase recovery

- Reduction in dry hole risk

- Increased discoveries

- Reduce rate of well abandonment

- Increased production

- Increased recovery

- Reduced drilling risk

- Reduced cost of exploration and drilling

- Application of new technology

- Increased technology transfer

- Cost reduction

- Increased education outreach

- Increased export of goods \& U.S. technology

- Increased patents at the National Institute for Petroleum and Energy Research

- Quantity of technology documents distributed

- Number of conferences conducted

- Use of regional technology transfer centers

Field Demonstration

- Slowed abandonment rate

- Increased incremental production

- Increased active rig count

- Increased enhanced oil recovery \& advanced secondary recovery project starts

- Increased proposals received \& contracts awarded

Oil Downstream Processing

Environmental Research

- Number of Area of Review variances for wells

- Number of regulations modified based on DOE research

- Cost reduction for regulatory compliance 


\subsection{SUMMARY OF PROGRAM BENEFITS}

Historically the benefits of the oil economy have been a critical part of the growth and success of the United States. Oil will remain a critical component of the U.S. energy supply, as well as all countries of the world, for the foreseeable future. The oil supply and demand relationships that affect the U.S. economy are worldwide in nature. The United States is currently importing more than one-half of its oil at a direct cost of over $\$ 1$ billion/ week. Over the past 20 years, costs for imported oil have amounted to more than $60 \%$ of our trade deficit. The Oil Program's research and development projects are designed to support this important source of capital formation, technological development, and employment in the U.S. economy.

\subsubsection{Assessing the Magnitude of BENEFITS}

Clearly the oil economy is large. The amount of money spent on oil in this country is staggering.
This does not include the hidden cost of energy (e.g., defense expenditures to safeguard oil supplies in the Persian Gulf, tax credits, environmental degradation, increased health care expenditures). The expenditures and employment of each sector of the oil economy are shown in Table 1.8.1.

Quantitative estimates of the potential benefit of research products that have been commercialized and introduced into the market place require extensive modeling capabilities. Models need to consider the resource, technology introduced, timing parameters, economics, and market parameters. Using the models and databases available in the Tertiary Oil Recovery Information System (TORIS) and EIA, the Oil Program is able to project production, reserves, and economic benefits for various enhanced oil recovery techniques. The $\mathrm{Oil}$ Program is currently developing additional models to assess potential benefits/impacts of other program areas including: new exploration

Table 1.8.1 Oil Economy Expenditures and Employment by Sector

\begin{tabular}{lcc}
\hline \multicolumn{1}{c}{ Sector } & Employment as of $\mathbf{9 / 9 3}$ & $\begin{array}{c}\text { 1992 U.S. capital } \\
\text { spending (\$ millions) }\end{array}$ \\
\hline $\begin{array}{l}\text { Oil \& Gas extraction } \\
\quad \begin{array}{l}\text { Drilling \& Exploration } \\
\quad \text { Production }\end{array}\end{array}$ & 351,300 & 12,154 \\
$\quad$ OCS Lease Bonus & & 2,431 \\
Total Oil \& Gas extraction & 351,300 & 96 \\
& 17,600 & 14,681 \\
Crude \& Products Pipelines & & 779 \\
Refining \& Petrochemicals & 114,600 & \\
Marketing & 179,600 & 9,282 \\
Retail & 619,200 & 2,544 \\
Total & $1,282,300$ & 27,286 \\
\hline
\end{tabular}

Sources: "Employment," API Data Book 1994; "U.S. Capital Spending," Oil Industry Outlook, PennWell 1994 


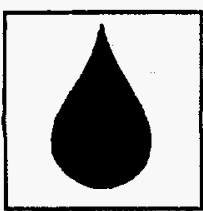

techniques, drilling methods and tools, riskreduction techniques, refinery methods, and reservoir characterization techniques. These models will help evaluate the progress of the program and assure the highest return on the research investment.

\subsubsection{Benefits by Program}

Oil Program products will have a positive impact in domestic production; employment; the U.S. trade balance; and federal, state, and local tax revenues. These benefits of the Oil Program will be seen in five areas:

- Improved exploration techniques to find domestic oil resources

- Improved technology to maximize domestic oil production

- Improved techniques to refine as much high quality fuel and lubricants as possible

- Assured protection of the environment

- Maintenance of U.S. leadership in oil and gas technology

\subsubsection{Finding OIL Resources}

There are over 350 thousand oil and gas extraction jobs and more than $\$ 12$ billion in capital expenditures currently involved in exploring and drilling for oil and gas in the United States (API 1994, Beck 1994). Domestic companies are also using sophisticated high-technology methods in the search for oil and gas. These activities are not only important for their impacts on jobs and economic activity, but also in their contribution to the public sector through taxes, lease payments, and reduced amounts of imported oil. The Exploration, Drilling, and Risk-Based Decision Management Program will provide improved geologic data and models, better drilling techniques, and better risk analysis to support domestic exploration.

\subsubsection{Maximizing Oil Production}

DOE programs are focused on maximizing the recovery of the remaining 351 billion barrels of known oil in place. Increased domestic production will contribute to the public sector through increased taxes and by reducing the amount of imported oil. The Reservoir Characterization Program will increase the recovery efficiency of existing domestic oil fields by as much as $20 \%$. The Extraction Program and Field Demonstration Projects also have the potential to increase ultimate recovery by promoting wider application of IOR and $A O R$.

\subsubsection{Refining OIL Resources}

The refining and petrochemical industry in the United States employs over 110 thousand people and spends more than $\$ 9$ billion on capital expenditures (API 1994, Beck 1994). The Oil Downstream Operations Program is designed to provide technological improvements necessary to maintain U.S. world-class refineries. U.S. refineries are becoming safer, more modern, and are reducing environment impacts. Results of research should result in reduced refinery emissions and waste streams, increased processing of heavy crude oils, and maintain refining cost.

\subsubsection{Protecting the Environment}

The Environmental Research Program goals are to reduce environmental cost to operators while improving environmental performance and to assure that sound regulatory decisions are made by state, tribal, and federal government officials. The five principle components of the Environmental Research Program are:

- Area of Review variance

- Streamlining regulations

- Gulf of Mexico discharges

- Environmental outreach and program planning

- Environmental technologies and practices

\subsubsection{U.S. Leadership IN OIL \& Gas Technology}

As the domestic oil and gas industry has downsized, there have been significant losses of skilled technical staff. R\&D technologists have left the industry. The Oil Program research is focused on discovering, developing, and transferring technologies that will keep the United States on the leading edge in the oil and gas marketplace. 


\subsection{REFERENCES}

American Petroleum Institute. 1994. Basic Petroleum Data Book: Petroleum Industry Statistics. Vol. 14:2.

American Petroleum Institute. 1985. Environmental Expenditures of the United States Petroleum Industry 1975-1984, Publication No. 4404.

Beck, Robert J., ed. 1994. 10th Oil Industry Outlook 1994-1998 with Projections to 2002. Tulsa: PennWell Books.

Beck, Robert J. 1994. Economic Growth Lifts Oil Demand Projections for 1994. Oil and Gas Journal. 92(30):53-75.

Energy Information Administration. 1994. Monthly Energy Review June 1994. Office of Energy Markets and End Use, U.S. Department of Energy.

Energy Information Administration. 1994. Monthly Energy Review August 1994. Office of Energy Markets and End Use, U.S. Department of Energy.

Energy Information Administration. 1994. Annual Energy Outlook 1994 with Projections to 2010. Office of Integrated Analysis and Forecasting, U.S. Department of Energy.

Energy Information Administration. 1993. Natural Gas 1992: Issues and Trends. Office of Oil and Gas, U.S. Department of Energy.

Energy Information Administration. 1993. Petroleum Marketing Annual 1992. Office of Oil and Gas, U.S. Department of Energy.

Energy Information Administration. 1994. Petroleum Supply Monthly June 1994. Office of Oil and Gas, U.S. Department of Energy.
Energy Information Administration. 1994. Petroleum Marketing Monthly July 1994. Office of Oil and Gas, U.S. Department of Energy.

Energy Information Administration. 1994. Petroleum Supply Annual 1993, Vol. 1 \& 2. Office of Oil and Gas, U.S. Department of Energy.

Fisher, W. L., et al. 1992. An Assessment of the Oil Resource Base of the United States/Oil Resource Panel. U.S. Department of Energy Report No. DOE/BC-93/1/SP.

Godec, M.L., et al. 1993. The Potential Role of Future Environmental Regulations on the Domestic Petroleum Industry. SPE 25833 presented at Soc. of Petro. Eng. Hydrocarbon Economics \& Evaluation Symposium, March 1993.

International Energy Agency. 1993. World Energy Outlook to the Year 2010. Paris.

International Petroleum Encyclopedia 1993. 1993. PennWell Books.

Interstate Oil and Gas Compact Commission. 1994. Marginal Oil: Fuel for Economic Growth.

Mast, R. F., et al. U.S. Geological Survey, and Martin, P. E., et al. Minerals Management Service. 1989. Estimates of Undiscovered Conventional Oil and Gas Resources in the United States-A Part of the Nation's Energy Endowment. U.S. Government Printing Office.

Moritis, G. 1992. EOR Increases 24\% Worldwide; Claims $10 \%$ of U.S. Production. Oil and Gas Journal 90 (16):51-79.

National Petroleum Council. 1992. The Potential of Natural Gas in the United States. 


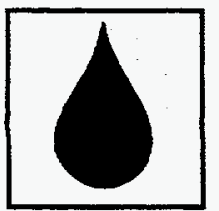

National Petroleum Council. 1993. U.S. Petroleum Refining.

National Petroleum Council. 1994. Marginal Well Study. In press.

Oil and Gas Journal Databook, 1994 Edition. 1994. Tulsa: PennWell Books.

Oil and Gas Journal. 1991. Energy Database. 6th Edition of Energy Statistics Sourcebook Incorporating Data Through 1990.

Pautz, J. F., et al. 1992. Enhanced Oil Recovery Projects Database, U.S. Department of Energy Report No. NIPER-583.

Society of Exploration Geophysicists (SEG). 1993. Special Report: Geophysical Activity of 1991. Geophysics: The Leading Edge of Exploration 12(11):1094-117
Statistical Abstract of the United States. 1993. The National Data Book. U.S. Department of Commerce, Economics and Statistics Administration Bureau of the Census, 41920.

U.S. Department of Commerce. 1992. Regional Multipliers; $A$ User Handbook for the Regional Input-Output Modeling System (RIMS II). U.S. Government Printing Office ISBM 0-16037944-X.

U.S. Department of Energy. 1990. Oil Research Program Implementation Plan. U.S. Department of Energy Report No. DOE/FE-0188P.

U.S. Department of Energy. 1991. National Energy Strategy: Powerful Ideas for America.

World Oil. 1994. Statistics. 215 (7):15. 


\subsection{RESERVOIR CHARACTERIZATION}

\subsubsection{Program Overview}

The reservoir characterization area of the Oil Program directly supports the goals of DOE's Fueling a Competitive Economy Strategic Plan, the Energy Policy Act of 1992 (EPACT), and the Domestic Natural Gas and Oil Initiative (DNGOI). These initiatives seek to maximize oil recovery in an environmentally sound manner, reduce dependence on imported oil, and strengthen national security. The specific strategies within these initiatives addressed by the reservoir characterization area are summarized in Table 2.1.1.

Reservoir characterization pursues the goals outlined in the initiatives by enhancing the ability to define and describe fluid-flow paths and barriers to fluid movement within reservoirs. This increased understanding enables more effective production and management strategies and slows the rate of resource abandonment. Reservoir model development; drilling; development of the oil field; and design of primary, secondary, and tertiary recovery processes all require ongoing reservoir characterization efforts.

Reservoir characterization efforts begin with the discovery of an oil field and continue through reservoir development and management phases. It encompasses primary, secondary, enhanced (EOR), and improved (IOR) oil recovery. A conceptual logic flow scheme depicting fundamental steps and iterations involved in characterization of a reservoir is illustrated in Figure 2.1.1. Every oil company uses (and emphasizes) some aspects of this logic flow scheme based on its own field development strategies and associated economic considerations.

Reservoir characterization provides an understanding of architecture, geometry dimensions, boundaries, fluid-rock properties, and fluid-flow characteristics. Characterization and quantification of the reservoir are the crucial steps in the process of efficient reservoir development and reservoir management. The success of infill drilling and other EOR and IOR recovery programs depends on precise, accurate reservoir data. Properly conducted reservoir characterization programs strongly influence the economic and development success of an oil field by increasing the ultimate oil recovery and slowing field abandonment. Stabilizing domestic supply reduces the nation's dependence on foreign oil and increases national security.

The process begins with the collection and management of geological, petrophysical, and geophysical data at a variety of scales, as shown in the first box of Figure 2.1.1. The amounts and variety of these data grow through time as an oil field progresses from an exploration prospect through to mature field development. The previous data are then geostatistically integrated with additional engineering and production information. Interpreting the data and interpolating the results enables model and relationship development, as shown in the second box of Figure 2.1.1. Both "hard" and "soft" data are integrated. 


\section{Table 2.1.1 Reservoir Characterization Drivers and Initiatives}

\begin{tabular}{|c|c|}
\hline Drivers & Initiatives \\
\hline $\begin{array}{l}\text { - Energy Policy Act of } \\
1992\end{array}$ & $\begin{array}{l}\text { - Improve reservoir characterization. } \\
\text { - Improve analysis and field verification. } \\
\text { - Identify and develop new recovery technology. } \\
\text { from porous media. } \\
\text { - Improve databases of reservoir and environment conditions. }\end{array}$ \\
\hline $\begin{array}{l}\text { - Domestic Natural Gas } \\
\text { and Oil Initiative }\end{array}$ & $\begin{array}{l}\text { - Develop an advanced computational technology initiative. } \\
\text { - Tund expanded industry-driven R\&D. } \\
\text { small producers. } \\
\text { - Use Naval Petroleum Reserves for advanced technology } \\
\text { testing, evaluation, and training. }\end{array}$ \\
\hline $\begin{array}{l}\text { - Fueling a Competitive } \\
\text { Economy Strategic Plan }\end{array}$ & $\begin{array}{l}\text { - Programs that establish the United States as a world leader } \\
\text { in developing energy technologies. } \\
\text { - Promote flexibility in the energy sector. } \\
\text { - Assist in mitigating severe impacts of oil price and supply } \\
\text { disruptions. } \\
\text { - Maintain a balance in basic and applied science that } \\
\text { supports energy and industrial competitiveness. }\end{array}$ \\
\hline
\end{tabular}

Hard data includes:

- Direct measurements on whole cores (from wells)

- Production information

- Indirect measurements from well logs, seismic, and production tests

Examples of soft data are:

- Geological depositional model analogs

- Interpolation in the interwell region

- Interpolation of field scales

The development of relationships among these data form the basis for prediction of reservoir architecture and flow unit distribution, as shown in the third box of Figure 2.1.1. This is achieved by describing the spatial arrangement of depositional facies within the reservoir units, estimating the effect of lithological variations on various scales of heterogeneity, and then identifying flow units within the reservoir. Quantitative reservoir models and simulations are used to develop reservoir management strategies, to design improved recovery schemes, and to predict resultant recovery efficiencies, as shown in the fourth box of Figure 2.1.1. Further refinement is attained by using advanced simulation technologies, improving the prediction of relationships derived from the data, or collecting additional data. Hence the feedback loop is completed.

The cost-effectiveness of collecting additional data becomes progressively important as the recovery process approaches tertiary recovery because increasingly finer scaled data are needed 


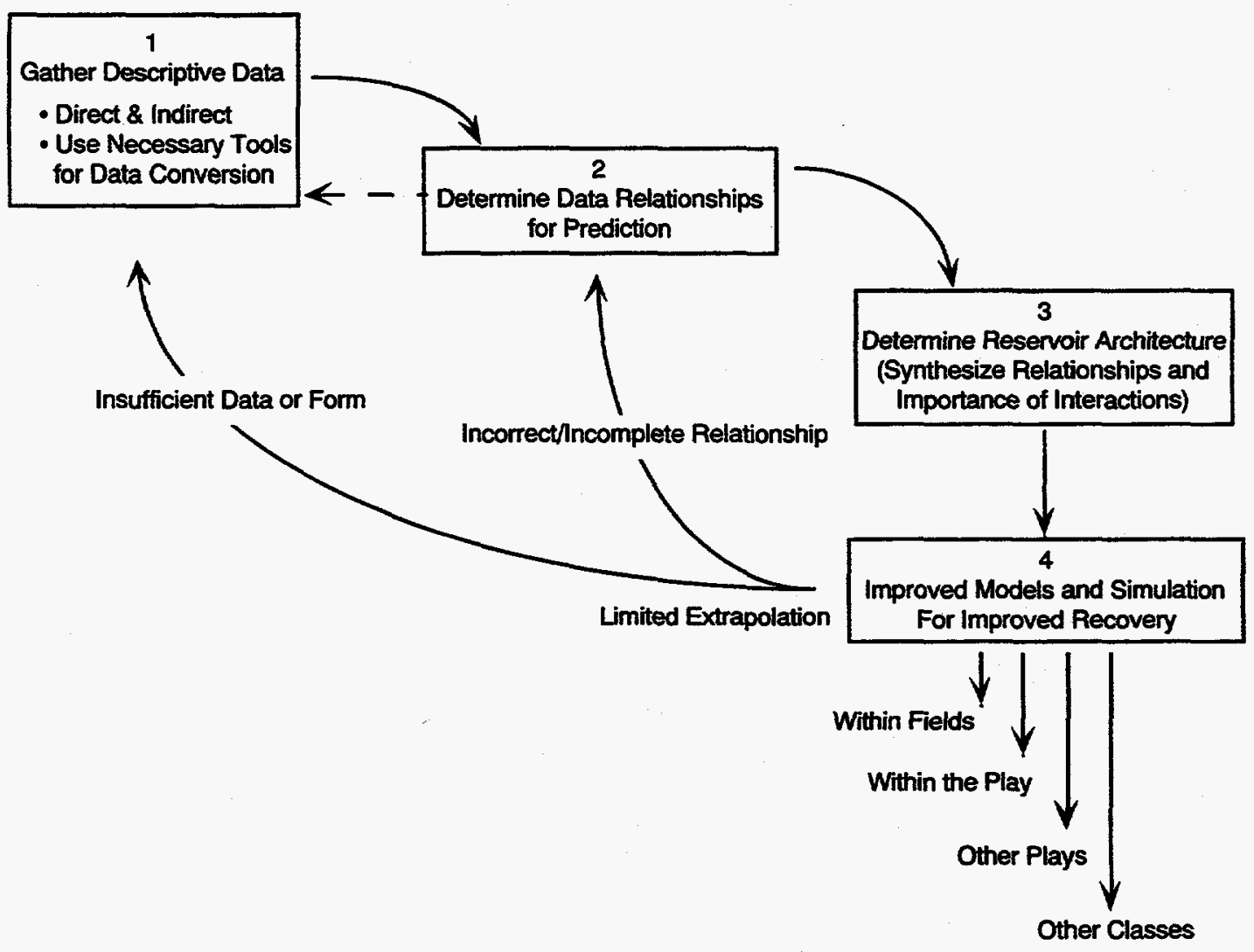

Figure 2.1.1 Steps in Characterizing a Reservoir

to quantify reservoir heterogeneities. These costs must be weighed against estimates of the remaining recoverable resources to decide whether to continue the feedback loop. Stochastic simulations are usually performed to include the effect of any uncertainties of data in the reservoir management decision-making process.

Based on the conceptual scheme outlined previously, the Reservoir Characterization Program has been designed to be interactively involved with other areas of the Oil Program. Reservoir characterization tools and methodology needs will be addressed. As near-term and mid-term products evolve out of research and development in the Reservoir Characterization Program area, these will be targeted for rapid transfer to oilfield use through integration with the Extraction and Field Demonstration Program areas discussed in
Sections 2.2 and 2.6, respectively. Near-term and mid-term technologies and methodologies will be identified and packaged for rapid dispersal and adaptation in the oil patch by targeting the midsized and large independent operators, consultants for small independents, and industry service contractors. This will be accomplished by close coordination with organizations currently being set up in the Technology Transfer area (see Section 2.5). A proactive role and interactive effort will develop and use pertinent databases to quantify and offer cost benefit input to proposed environmental regulations affecting the upstream aspects of the oil industry.

\subsubsection{Goals and Objectives}

Goal 1: Support development of technology needed to provide sufficient technical detail in 


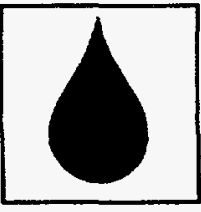

terms of reservoir architecture, rock and fluid distribution, and fluid-flow characterization to maximize production from existing fields.

\section{Objectives of Goal 1:}

- Advance measurement quality and resolution of rock and fluid properties from cores to interwell scales.

- Develop cost-effective technology for a more quantitative evaluation of reservoir architecture.

- Use advanced reservoir modeling and simulation for high potential, hard-toproduce reservoir fluids.

- Accurately describe the fluid-rock system and fluid movement to help develop strategies for maximum petroleum recovery.

- Advance technology and tools required for characterization of ultradeep reservoirs, both onshore and offshore.

Goal 2: Foster the use of appropriate data collection and analysis techniques for characterization, and integrate these data with information to facilitate sound production practices in order to maximize ultimate recovery and to prove additional potential.

\section{Objectives of Goal 2:}

- Develop methodologies to determine critical amounts and types of data to optimally exploit reservoirs through time.

- Determine the effects of various development strategies on controlling fluid movement within reservoirs in the context of advanced characterization techniques.

- Focus on methodologies that can be effectively transferred to medium-to-large independents and the consultants for small independents.

Goal 3: Support the development of technically sound and cost-effective environmental regulation efforts that affect domestic petroleum production by furnishing reservoir characterization data and expertise to state and federal regulatory agencies.

Goal 4: Package appropriate reservoir characterization technologies for technology transfer to independent operators.

These packages include both near-term and mid-term deliverables. Frequent topical area assessments and reviews are built into the program to allow flexibility and responsiveness to promising new technical initiatives and near-term needs as identified through other areas of the Oil Program.

To achieve these goals and objectives, the Reservoir Characterization Program has been divided into four main components, illustrated in Figure 2.1.2, in accordance with the conceptual scheme outlined previously:

- Geoscientific measurement

- Interdisciplinary reservoir geometry description and related reservoir fluid flow

- Reservoir modeling and simulation

- Advanced Computational Technology Initiative

\subsubsection{Geoscientific Measurement}

Having sufficient high-quality data is critical for a successful reservoir characterization program. The Geoscientific Measurement category is designed to address the need for high-quality, high-resolution data. Topical technology areas addressed in this program include:

- Seismic

- Wireline logging

- Well testing/tracer surveys

- Petrophysics - core analysis

- Electromagnetic/electrical technologies for crosswell imaging

- Surface and subsurface geochemical technologies

- Rock mechanics

- Remote sensing 

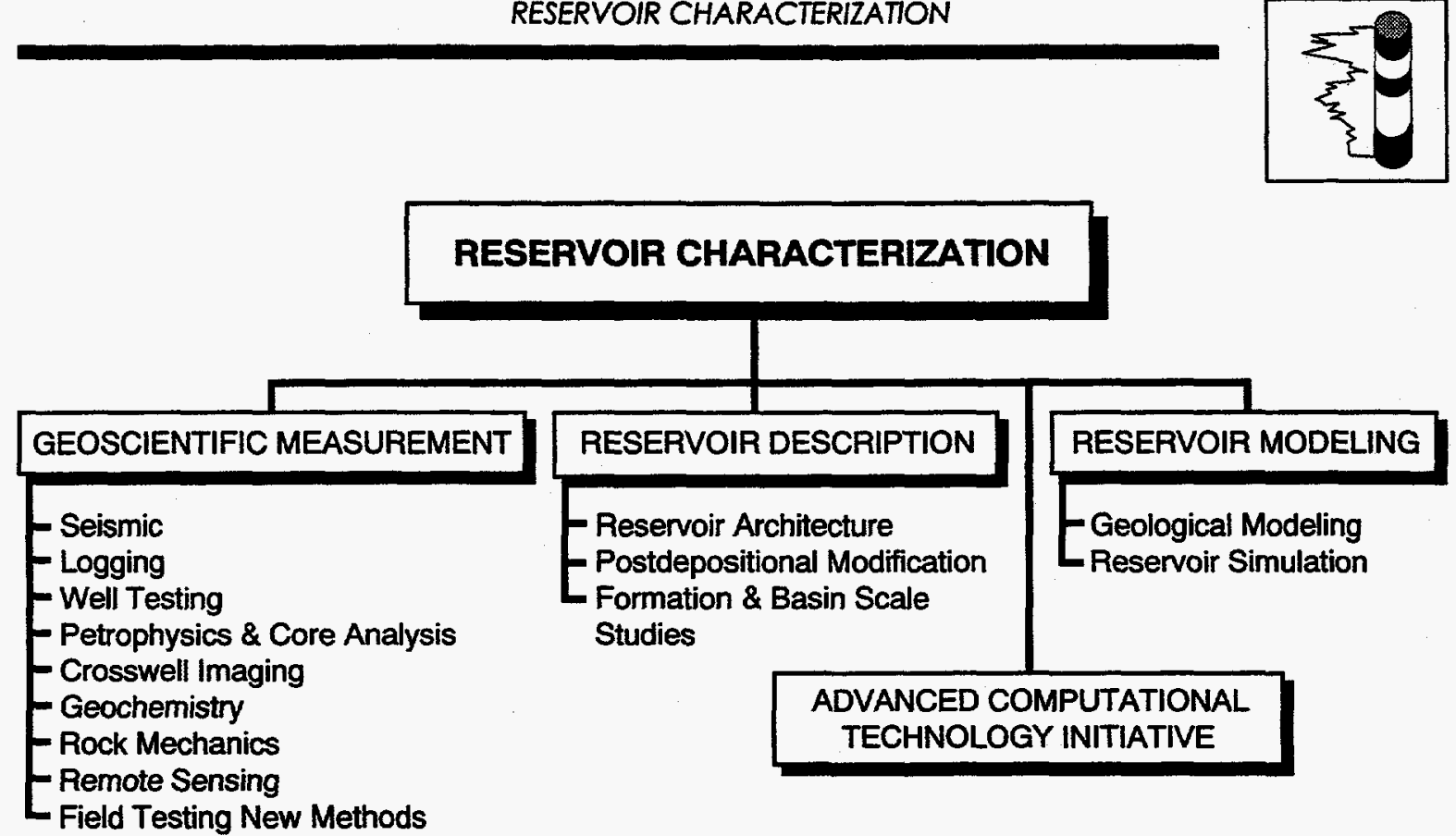

\section{Figure 2.1.2 Reservoir Characterization Program Work Breakdown Structure}

- Field testing new reservoir characterization tools and methods

A series of individual project areas has been developed under each technology area. These are generally organized by (1) tool development; (2) data processing; and (3) data interpretation, visualization, and presentation. This organization addresses the reality that all three aspects of a specific technology must be developed in parallel because each acts as a driver to accelerate the other two areas. As an example, advances in high resolution seismic tools development will generate greater quantities of data, thus driving the advancement in data processing and interpretation. Also affecting all three areas of seismic advancement is the development of related technologies such as parallel computing. Improvements in this area ensures that sufficient high-quality, cost-effective data can be collected to allow for determination of reservoir architecture and flow unit distribution.

\subsubsection{RESERVOIR DESCRIPTION}

Critical components of interdisciplinary reservoir geometry description and related reservoir fluid flow are:
- Improved understanding of reservoir architecture by using surface and reservoir data

- Improved understanding of impacts of postdepositional modification on the reservoir and the effects on the flow units

- Formation scale to basin scale studies that more accurately characterize and predict reservoir architecture and the migration of hydrocarbons into the reservoir

Project areas listed under these topics address the second and third boxes of the conceptual scheme (Fig. 2.1.1). Improvements in this area will more closely define the distribution of heterogeneities within complex reservoirs and delimit the relationships among reservoir data sets that lead to improved models, thus addressing the objectives under the first program goal.

\subsubsection{Reservolr Modeing and Simulation}

Critical components of reservoir modeling and simulation include:

- Advanced modeling of reservoir architecture and flow unit distribution to represent reservoir heterogeneity more accurately

- Reservoir simulation 


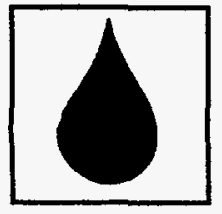

Included in project areas listed under these topics (fourth box, Fig. 2.1.1) are the quantification of flow unit distribution and reservoir heterogeneity at various scales, adapting existing simulators to be used on desktop personal computers, and advancing the state of the art in simulating difficult problems. Advances in these areas will help stimulate quantification of reservoir models for improved recovery. Geological modeling and reservoir simulation advances made in the Reservoir Characterization Program can be integrated with the numerical simulation of recovery processes developed in the Extraction Program, leading to better production and reservoir management strategies and the evaluation of field demonstration projects.

\subsubsection{Advanced Computational TECHNOLOGY INITIATIVE}

The Advanced Computational Technology Initiative (ACTI) is a new DOE-directed initiative that brings industrially focused and cosponsored research ideas together with DOE national laboratories' expertise and facilities to leverage defense-related computational technologies. The purpose is to foster a closer working relationship between industrial $R \& D$ efforts and national laboratory staffs, to adapt technologies and methodologies developed at the national laboratories to commercial use, and to accelerate the transfer of technology and usage of the resulting products. The exact topical areas for R\&D efforts are yet to be identified; however, research will most likely fall within all four blocks outlined under the reservoir characterization conceptual scheme (Fig. 2.1.1).

\subsubsection{Stakeholders}

The Oil Plan is driven by the concerns and consideration for key customers and stakeholders. For the Reservoir Characterization Program, these key people include:

- Small, medium, and large independent oil production companies

- Major integrated petroleum companies
- Petroleum and related environmental regulators

- Organizations that sponsor and conduct research in the Oil Program, including Department of Energy, Bartlesville Project Office; Department of Energy Fossil Energy Headquarters; NIPER; universities; research institutes; and national laboratories

- Federal agencies such as United States Geological Survey, Minerals Management Service, Bureau of Land Management, and United States Forest Service

- State, local, and Native American governments

- Trade and professional associations

- Investors

- Consultants

- Petroleum service companies

\subsubsection{IMPACTS}

A successful program of reservoir characterization projects will strongly affect industry jobs, affect oil discovery and recovery, and have an important impact on reducing well abandonments. Packaged and transferred technology derived from reservoir characterization projects alone could increase recovery efficiency in already discovered domestic oil fields by $20 \%$, from $33 \%$ to approximately $40 \%$ by the year 2000 .

\subsubsection{BUDGet}

The Reservoir Characterization budget is shown in Table 2.1.2 and Figure 2.1.3. As stated in Section 1, this Oil Plan is developed for an unconstrained budget that is bounded by the scope of goals set by Congress, the President, and the Secretary of Energy.

\subsubsection{Schedule}

Figure 2.1.4 shows key activities and their timing in the Reservoir Characterization Program area.

\subsubsection{Measures of Effectiveness}

End points of the program are shown in Table 2.1.3. 
Table 2.1.2 Budget for Reservoir Characterization

\begin{tabular}{lcc}
\hline Functions & $\begin{array}{c}\text { FY 1994 } \\
\text { Appropriated } \\
(\$ 1,000)\end{array}$ & $\begin{array}{c}\text { FY 1995 } \\
\text { Appropriated } \\
(\$ 1,000)\end{array}$ \\
\hline Geoscientific Measurements & 2,447 & 2,105 \\
Reservoir Description & 5,735 & 4,095 \\
Reservoir Modeling & 0 & 0 \\
ACTI \& Partnerships & 2,255 & 8,979 \\
\hline Totals for Reservoir Characterization & 10,437 & 15,179 \\
\hline
\end{tabular}

1994

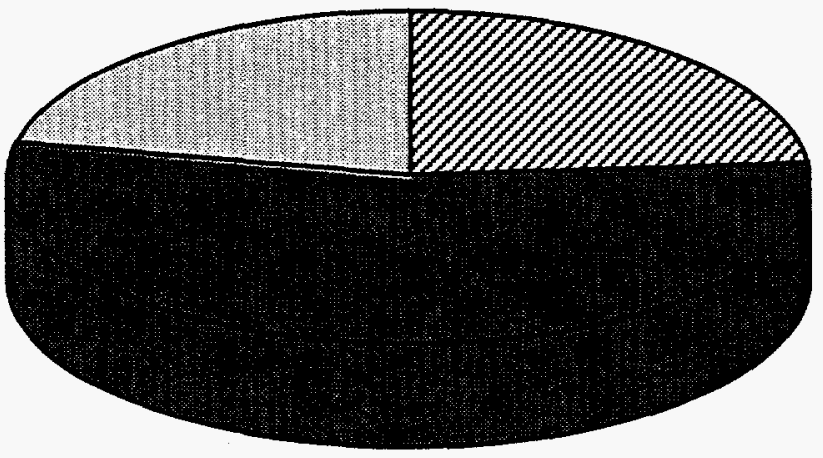

$\square$ Geoscientific Measurements

Reservoir Description

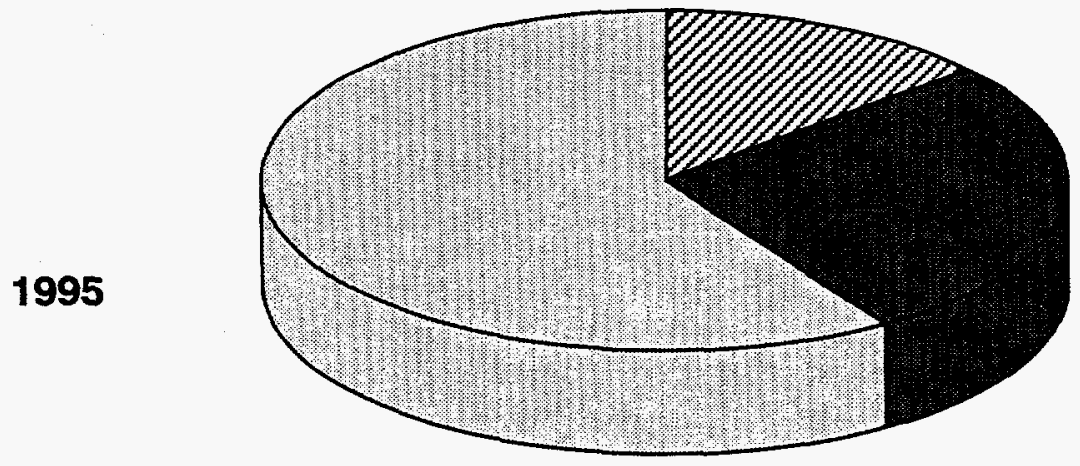

Reservoir Modeling

$\square \mathrm{ACTI} \&$

Partnerships

Figure 2.1.3 Reservoir Characterization Budget 
Figure 2.1.4 Key Activities and Timing for the Reservoir Characterization Program

\begin{tabular}{|c|c|c|c|c|c|c|c|}
\hline Schedule for & Reservoi & Cha & racteriz & ation & & & \\
\hline Name & \begin{tabular}{|l|l|l|l|}
\multicolumn{3}{|c|}{1994} \\
$Q^{1}$ & $Q^{2}$ & $Q^{3}$ & $Q^{4}$ \\
\end{tabular} & \begin{tabular}{|l|l|l|l|}
\multicolumn{3}{|c|}{1995} \\
$Q^{2}$ & $Q^{2}$ & $Q^{23}$ & $Q^{4}$ \\
\end{tabular} & \begin{tabular}{|l|l|l|l|}
\multicolumn{3}{|c|}{1996} \\
$Q^{2}$ & $Q^{2}$ & $Q^{3}$ & $Q^{4}$ \\
\end{tabular} & \begin{tabular}{|l|l|l|l|}
\multicolumn{3}{|c|}{1997} \\
Q1 & $Q^{2}$ & $Q^{2}$ & $Q^{2}$ \\
\end{tabular} & \begin{tabular}{|l|l|l|}
\multicolumn{3}{|c|}{1998} \\
$Q_{1}$ & $Q^{2}$ & $Q^{3}$ \\
\end{tabular} & \begin{tabular}{|l|c|}
\multicolumn{2}{|c|}{1999} \\
Q1 $\left|Q^{2}\right| Q_{3} \mid Q^{24}$ \\
\end{tabular} & 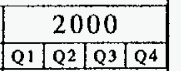 \\
\hline \multicolumn{8}{|l|}{ Geoscientific Measurement } \\
\hline \multicolumn{8}{|l|}{ Seismic tool development } \\
\hline \multicolumn{8}{|l|}{ Seismic processing development } \\
\hline \multicolumn{8}{|l|}{ Seismic interpretation development } \\
\hline \multicolumn{8}{|l|}{ Field test seismic tool } \\
\hline \multicolumn{8}{|l|}{ Wireline logging tool development } \\
\hline \multicolumn{8}{|l|}{ Wireline interpretation development } \\
\hline \multicolumn{8}{|l|}{ Field testing to wireline logging tools } \\
\hline \multicolumn{8}{|l|}{ Advanced well testing techniques } \\
\hline \multicolumn{8}{|l|}{ Advanced tracer testing techniques } \\
\hline \multicolumn{8}{|l|}{ Advanced coring techniques } \\
\hline \multicolumn{8}{|l|}{ Rel. permeability from drill cuttings \& rock fragm'ts } \\
\hline \multicolumn{8}{|l|}{ Adv imaging techniques appl. to scale-up from core to block scale } \\
\hline \multicolumn{8}{|l|}{ Field testing of petrophysics/core analysis techniques } \\
\hline \multicolumn{8}{|l|}{ Multifrequency electromagnetic source } \\
\hline \multicolumn{8}{|l|}{ Adv electromagnetic/data processing, interpretation technology } \\
\hline \multicolumn{8}{|l|}{ Field testing electromagnetic technology } \\
\hline \multicolumn{8}{|l|}{ Assess state of the art of electromagnetic technology } \\
\hline \multicolumn{8}{|l|}{ Advance geochemical methods to identify heterogeneities } \\
\hline \multicolumn{8}{|l|}{ Field test geochemical techniques } \\
\hline \multicolumn{8}{|l|}{ Assess in-situ stress relationship to rock/fluid properties } \\
\hline \multicolumn{8}{|l|}{ Develop sound reservoir management practices using geomechanics } \\
\hline \multicolumn{8}{|l|}{ Package for tech transfer-effect of in-situ stress on reservoir mgmt. } \\
\hline \multicolumn{8}{|l|}{ Advance remote sensing techniques for shallow reservoirs } \\
\hline \multicolumn{8}{|l|}{ Use Surface \& Subsurf. Data to Understand Res. Architecture } \\
\hline \multicolumn{8}{|l|}{ Heterogeneous reservoir performance definition } \\
\hline \multicolumn{8}{|l|}{ Stratigraphic and chronographic correlation } \\
\hline Advanced reservoir characterization & & & & & & & \\
\hline Advanced heterogeneity characterization & & & & 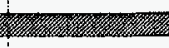 & 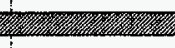 & & tris \\
\hline Improve reservoir properties prediction & & & 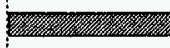 & & & & 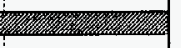 \\
\hline Research on fractured petroleum reservoirs & & & & & & & \\
\hline Fundamental geoscience research & & & & 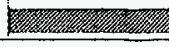 & & 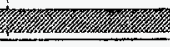 & 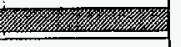 \\
\hline
\end{tabular}




\section{Figure 2.1.4 Key Activities and Timing for the Reservoir Characterization Program (continued)}

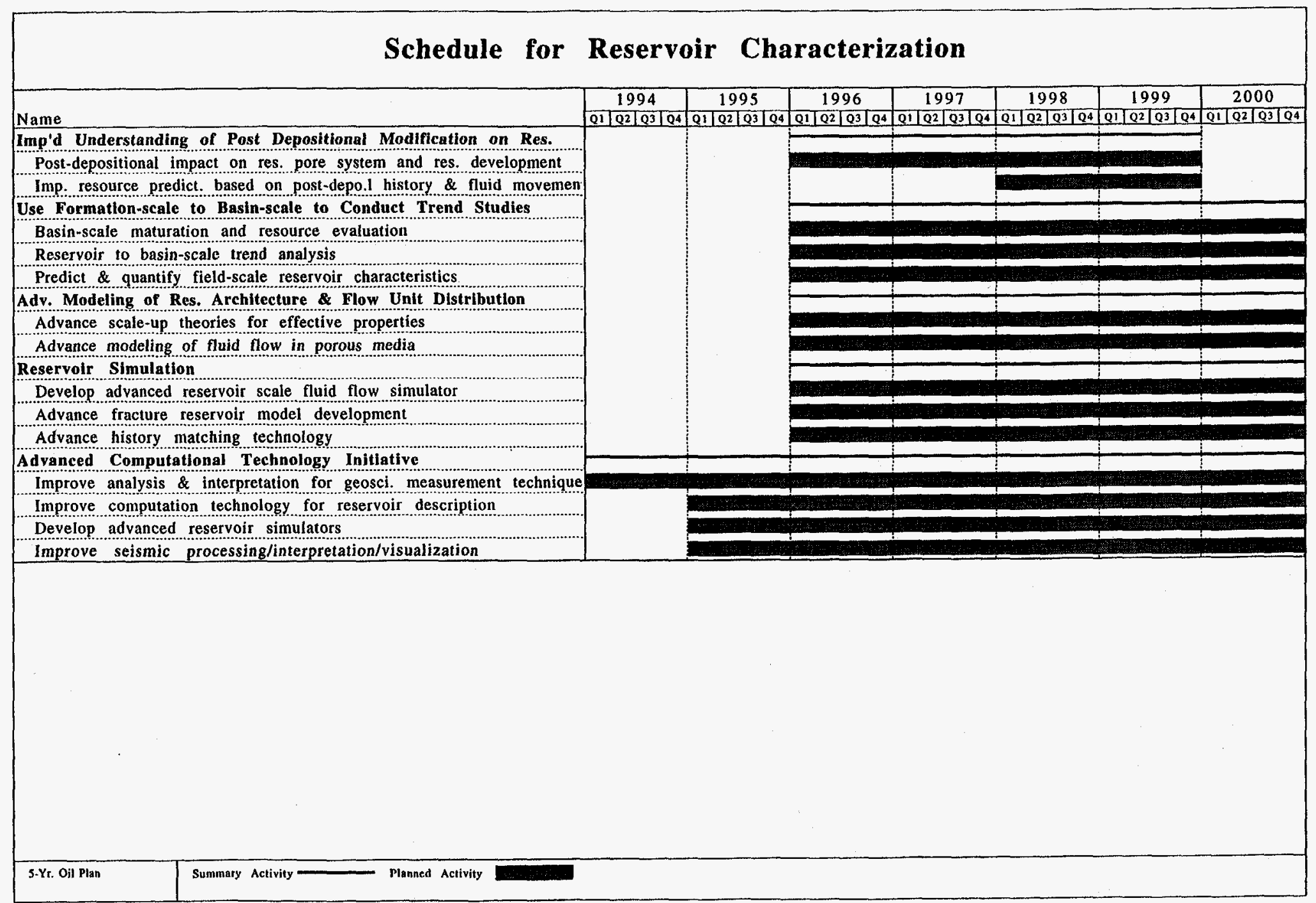




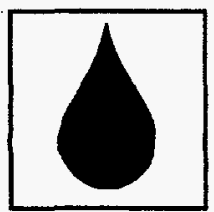

Table 2.1.3 Measures of Effectiveness for Reservoir Characterization

Reservoir Characterization Activities

- Geoscientific measurements

- Interdisciplinary reservoir geometry description and related reservoir fluid flow

- Reservoir modeling and simulation
Metrics

- Increase seismic data transmission by two orders of magnitude, increase vertical seismic resolution to the scale of depositional facies or by at least $50 \%$ in complex geologic terrains, and decrease seismic fielding cost by $25 \%$.

- Validate through casing resistivity logging.

- Develop electromagnetic multifrequency tools and the technology to routinely implement if used in oilfield monitoring.

- Significantly advance techniques for interpreting older logs.

- Reduce special core analysis costs by $50 \%$.

- Develop methodology for characterizing damaged formations and those that are prone to damage during exploitation.

- Improve capability to detect fingering, bypass zones, and degradation of flood front in AOR projects to allow adjustment of recovery strategy.

- Develop tracer programs that can be easily used by independent producers to detect thief zones, bypassed oil, and barriers to fluid flow to allow them to improve reservoir management.

- Improve reservoir modeling and characterization methodology for highpotential plays that can be used by independent operators to find bypassed oil and increase recovery efficiency at a minimum additional cost.

- Develop user-friendly public domain reservoir simulators for advanced personal computers and workstations for various IOR processes and reservoir architectures.

- Advance simulators for use in modeling high-potential, hard-to-produce reservoirs.

- Foster a working relationship between industry and national laboratory $R \& D$.

- Adapt technologies and methodologies developed at national labs to commercial use.

- Accelerate technology transfer. 


\subsection{EXTRACTION RESEARCH}

\subsubsection{Program Overview}

The mission of the Extraction Research Program is to provide vital technical assistance, laboratory support, and field support for DOE's Oil Program. This will be accomplished by developing both improved and advanced oil recovery methods and by providing the necessary vehicle to transfer the developed technology to stakeholders. Paramount to this task is the need for environmentally acceptable and economically attractiveoil extraction methods.

The focus of the program is maximizing the recovery of the remaining 351 billion barrels of known domestic oil in place. Figure 2.2.1 shows the chart of the remaining oil resource in known domestic reservoirs. Current U.S. proved reserves of 25 billion barrels (Beck 1994) would be doubled or even quadrupled by successful reserves growth in known fields, depending on the level of technology that is available and applied. New mechanisms for technology transfer will be established through joint programs with oilfield operators, especially by means of field laboratory pilot tests.

DOE research programs in the last two decades concentrated on basic work and on providing monetary incentives for enhanced oil recovery (EOR) programs. This program redirects DOE's efforts and has as its goal the wider application of improved and advanced oil recovery technologies to increase the ultimate oil recovery and to reduce significantly the volume of discovered oil left in the reservoirs. Field laboratory pilot test programs will be implemented as a means of demonstrating the benefits of these technologies and of transferring the technologies to the petroleum industry. Computer models will be developed that, in conjunction with the field pilot test programs, will allow even the smaller independents to self-assess the economics of oil recovery from existing reservoirs and to plan, as well as to implement, field tests.

\section{The mission is to provide vital technical assistance, laboratory \\ 2.2.1.1 Goals and Objectives} support, and field support for DOE's Oil Program.
The goal of the Extraction Program is the economic recovery of oil remaining in known reservoirs. Objectives include:

- Develop improved oil recovery (IOR) that advances waterflooding, pressure maintenance, sweep improvement, completions, stimulations, infill drilling, horizontal wells, and monitoring.

- Develop advanced oil recovery (AOR) methods based on chemical flooding, gas flooding, microbial, thermal, and other innovative methods.

- Undertake field pilot tests to demonstrate the benefits of both improved and advanced oil recovery.

- Promote wider acceptance and application of the developed technologies and models by the petroleum industry through technology transfer vehicles.

- Promote extraction simulation by developing process models, reservoir models, economic models, and tracer models suitable for independent oil companies.

Figure 2.2.2 outlines the work structure for the Extraction Research Program area. The primary areas are Improved Oil Recovery, Advanced Oil 


\section{NEARLY TWO-THIRDS OF THE U.S. OIL RESOURCE WILL REMAIN} AFTER CONVENTIONAL RECOVERY

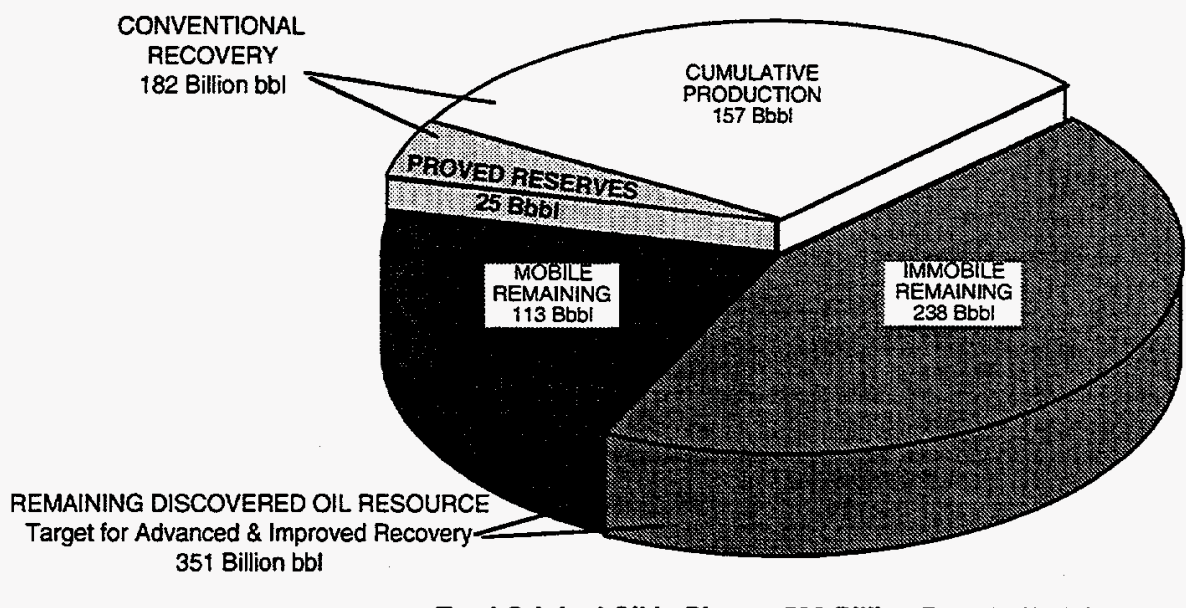

Total Original Oil In Place $=\mathbf{5 3 3}$ Billion Barrels $(\mathrm{Bbbi})$

Source: API 1980; EIA 1992; BPO 1992.

\section{Figure 2.2.1 Known Domestic Oil Resource as of 12/31/92}

Recovery, and Simulation of Extraction Processes. Field pilot tests are included under both IOR and AOR. These pilots will have a significant impact on DOE's effort to provide means of technology transfer to the industry. The following discussion deals with the field pilot test component as a new initiative and major undertaking for the program.

\subsubsection{IMPROVED OIL ReCOVERY}

DOE's program efforts will concentrate on providing an enhancement of IOR methods, including the integration of valuable information from detailed reservoir characterization. Specific areas include:

- Waterflooding design improvements

- Reservoir pressure maintenance

- Sweep improvement

- Better completion and stimulation techniques

- Selective infill drilling

- Using horizontal well technology

- Better means of monitoring treatments and responding (as needed)
- Developing and issuing corrective modifications to active treatments

Applications in these areas would contribute to increased recovery of the known mobile oil in existing reservoirs, which is estimated at 113 billion barrels. A slower rate of well abandonment would result.

Inadequate understanding of reservoir characteristics is a common barrier to effective application of current technology. Many of the past failures in field tests of oil recovery processes have been directly attributed to limited information on the reservoirs' characteristics. Knowledge of the existence and relative location of high-permeability channels and thief zones can be used to implement a strategy to improve sweep efficiency by blocking these channels or zones with foams, polymer gels, emulsions, or other innovative techniques. They are by far the simplest methods to apply to existing waterfloods and can be readily adopted by independents. Prospects are equally attractive for other production-related IOR processes, such as pressure maintenance, completions, 


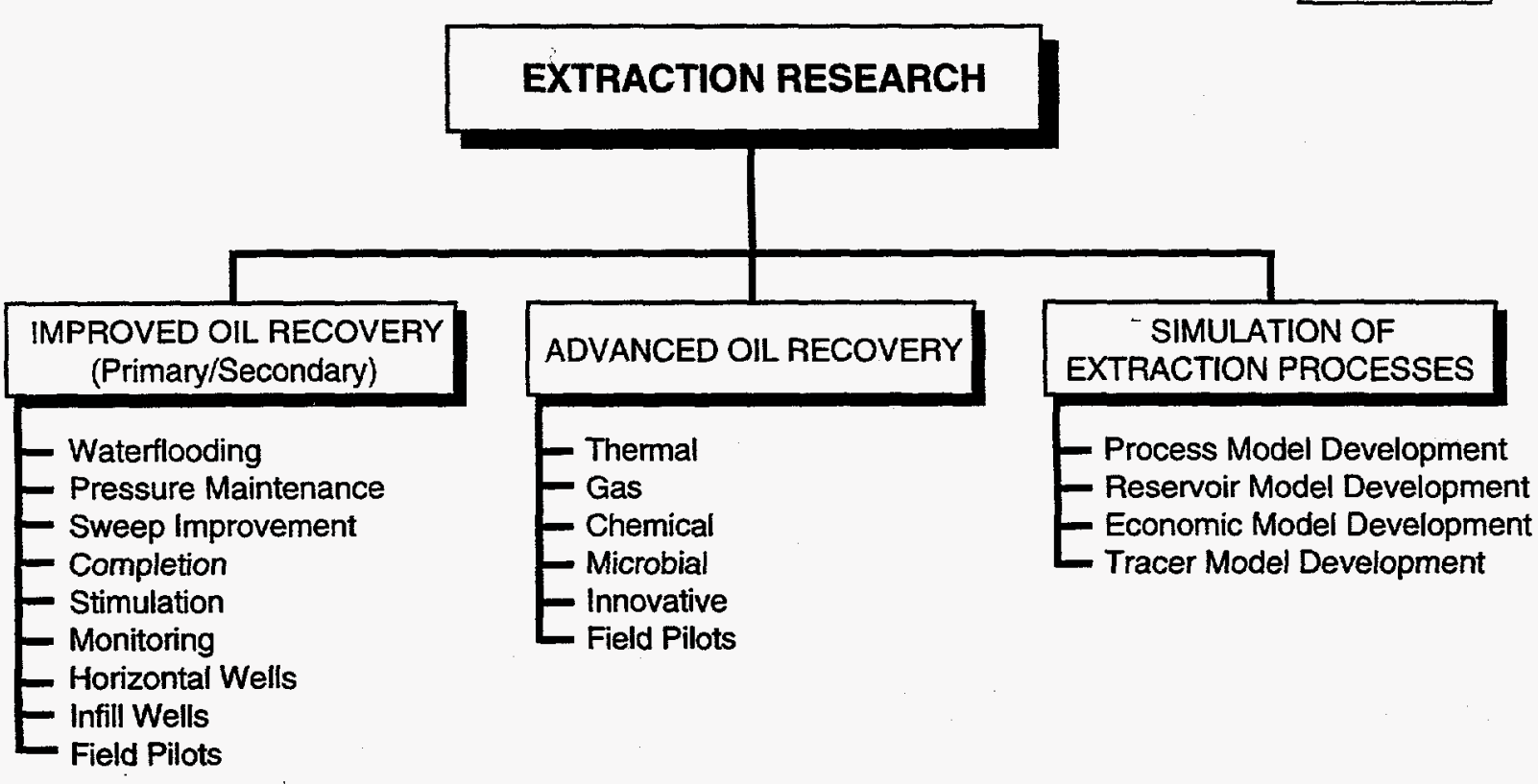

Figure 2.2.2 Extraction Research Program Work Breakdown Structure

stimulations, infill drilling, horizontal wells, and improved treatment monitoring.

Field pilot tests will demonstrate methods for specific reservoirs. Some of these pilot tests are planned to be initiated as early as FY 1997. An example of this work is the application of innovative methods of conformance control. Research and development work in FY 1994-96 will provide some of the input for this pilot. Another task planned is developing an IOR handbook series, with the first of the series expected in FY 1996. This handbook will be devoted to waterflooding and will be specifically geared for petroleum independents that target certain geographic regions.

Program Objectives for Improved Oil Recovery Activities:

- Develop and support improved waterflooding, pressure maintenance, completion and stimulation methods for effective application by the petroleum industry.

- Apply known and develop new and innovative methods of sweeping oil from reservoirs to increase economically oil recovery, thereby arresting the rate of well abandonments.

- Support the use of horizontal and infill drilling practices for IOR processes.

- Support field laboratory pilot tests to demonstrate IOR techniques.

- Provide supporting information and background for the simulation work on extraction processes, the advanced oil recovery laboratory, and field activities.

\subsubsection{Advanced Oll Recovery}

Immobile oil, oil that is not producible using standard recovery technologies, is the primary target for developing advanced oil recovery technologies. There are about 238 billion barrels of immobile oil in the known oil reservoirs. Incrementally recovering only $5 \%$ of this oil would amount to over 11 billion barrels of additional recovery. The problem is that currently no known recovery technology exists that can recover this oil. 


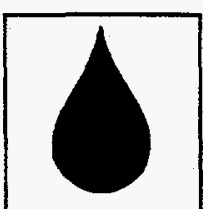

There are two-parts to solving the immobile oil recovery problem. The first, covered in the Reservoir Characterization Program area, addresses locating the oil and identifying the conditions under which it exists. The second is defining the recovery technology that would be required to produce the oil under the then-known reservoir, environmental, and economic conditions.

Transferring the technology to the end user is also equally important. Convincing petroleum operators to commit resources to conduct these methods early in the life of their field would be extremely favorable towards the successful application of these oil recovery efforts. Five main AOR program areas are considered, and each area contains elements that support the field laboratory pilot testing of promising recovery methods.

Thermal Recovery. Thermal recovery methods have been successfully applied in the United States since the 1960 s and remain viable; current production by this method is 530,000 barrels per day. However, while the recovery efficiencies in principle can be as high as $85 \%-90 \%$, field projects usually recover no more than $50 \%-60 \%$ of the remaining oil resource before the process is discontinued (Pautz 1992). Incomplete sweep, due to reservoir heterogeneity and gravity override effects, is a common reason for the lower efficiency. In addition, this technology is underutilized because of the economic entry barriers.

To mitigate these difficulties, much of the research program will be focused on developing improved methods to increase sweep efficiencies in steamflooding, studying mechanisms leading to oil recovery (especially in fractured and heterogeneous reservoirs), and providing more accurate predictive tools to model the performance of the improved recovery methods, as well as to reduce project startup risks (an economic entry barrier). New initiatives are also proposed to address improving the efficiency of field steam distribution network, developing more economic methods for recovering heavy oil in thin sands (common in the Gulf of Mexico Region), improving the technology for recovering oil from deep reservoirs using in situ combustion, and evaluating the potential for recovery of mediumgravity oils with thermal methods (a case of potential underutilization).

Gas Flooding. Gas flooding includes both miscible and immiscible methods. In reservoirs suitable for miscible gas recovery (reservoir pressure exceeding miscible pressure), displacement efficiencies can approach $100 \%$. Flow barriers prevent uniform sweep of a reservoir, limiting most field recovery efficiencies to less than $25 \%$.

Much of the research program will be focused on developing improved methods to increase sweep efficiencies of injected gases and providing more accurate predictive tools to reduce project startup risks (an economic entry barrier). New initiatives will address asphaltene deposition and near-miscible three-phase gas flooding systems.

Chemical Flooding. For many U.S. domestic oil reservoirs, chemical flooding may be the only viable means of enhancing crude oil recovery. It has the potential of recovering more residual oil than other available methods.

Research work will be directed toward several fronts. One major area of consideration is the development of chemical systems that are effective over a broad range of conditions, e.g., temperature, salinity, and hardness. Harsh reservoir conditions have severely limited the application potential of most chemical flooding processes. Recent advances in the development of synergistic combinations of processes, such as low-tension alkaline flooding used with a surfactant and polymer injectant, are promising. Field pilot testing of this method is slated in FY 1995. Further developments to extend the application range of these processes are necessary. In addition, this program offers support for the development and synthesis of new and advanced surfactant and polymer systems that provide a vital influx for future generation chemical systems. 
Another key emphasis is reducing the cost associated with the use of these chemical systems. The development of advanced chemical systems that minimize retention under reservoir conditions would have significant impact on costreduction efforts. Some of the development work crosscuts other advanced oil recovery areas. Efforts to develop conformance control systems for harsh and restrictive conditions will benefit other technical areas where sweep improvement is necessary to improve oil recovery.

Microbial Recovery. Microbial advanced oil recovery technology has progressed from laboratory-based evaluation to international field applications. The successful application of microbial processes for marginally producing wells has been shown; now the feasibility of microbial advanced oil recovery in wells with higher oil saturations should be demonstrated to stimulate widespread use of the technology.

Areas that require more research emphasis include cost-effective nutrients for microbial-based advanced oil recovery processes and adaptation or selection of microorganisms for reservoirs with extreme environmental conditions. It has been documented that there are microorganisms that can exist at temperatures and salinities over much greater limits. What has not been documented is the ability of these microorganisms to grow under reservoir conditions and to mobilize oil.

In order to adequately develop microbial techniques for $A O R$ processes, numerical simulation must be improved to accurately predict the performance of the process from the laboratory to the field.

Innovative Recovery. The Extraction Program's overall objective is to recover economically both mobile and immobile oil remaining in known reservoirs. Innovative recovery supports the development of the combination of advanced oil recovery processes. Many chemical, gas, and microbial advanced oil recovery technologies have demonstrated synergistic capabilities. An example is the adaptation of advanced oil recovery techniques for horizontal wells.

Program Objectives for Advanced Oil Recovery Activities:

- Develop AOR processes based on chemical flooding, gas flooding, microbial, and thermal methods for effective application by the petroleum industry.

- Develop and support innovative processes using unconventional methods that have cost-effective and environmental advantages for oil recovery.

- Develop advanced methods of sweep improvement in reservoirs to support the application of developed oil recovery processes.

- As early as FY 1994, undertake field pilot tests to demonstrate promising AOR methods.

- Provide supporting information and background for simulation, laboratory, and field activities.

\subsubsection{FieLd PILOTS}

The field pilots will provide the means to test and to document promising oil recovery processes at the pilot scale. This will occur at the site most appropriate for the technology and research partners. Research efforts in IOR and AOR will be evaluated in these field tests. These tests would serve as the vital link to tie in all the other elements of the Extraction Research Program. The results from these pilots will provide answers to important questions that can not be directly addressed in the laboratory, as well as help identify technical issues and contingencies that could not have been anticipated. They provide the necessary feedback to the process development aspects of the program. Any unforeseen shortcomings detected during the pilot tests will be clearly obvious to the laboratory researcher participating in the field laboratory pilot tests. The research program will benefit from such close interaction, resulting in accelerated development in each recovery method. The success of 
these pilot tests will lead to expanded field demonstrations and eventually commercialization. This process feedback loop provides the necessary information exchange cycle to test and to demonstrate the most promising, cost-effective emerging technologies.

Figure 2.2.3 shows the logical flowchart for the field application of developed extraction methods. The figure illustrates the following proposed steps:

1. The R\&D input for the selection and application of the appropriate oil recovery process

2. Laboratory testing and process optimization for selected sites

3. Field monitoring and pilot design

4. Pilot testing and postmortem evaluation

5. Feasibility evaluation and project expansion to field demonstration/commercialization level

Efforts to provide components of technology transfer to the industry are also factored into the program.

Program Objectives for Field Pilot Activities:

- Test the viability of developed technologies from other elements of the program to recover the remaining crude oil in known reservoirs. Plans for field testing of low-tension alkaline process are slated as early as FY 1995.

- Provide supporting information and background for research and simulator development activities.

- Promote wider acceptance and application of the developed technologies and models by the petroleum industry through technology transfer vehicles.

\subsubsection{Simulation Of Extraction Processes}

DOE's program can benefit the independent producer by providing computer models that can easily be used to evaluate and to plan field operations. These operations will include: (1) characterizing the reservoir by interpretation of field tests, (2) investigating the feasibility of IOR and AOR methods, ( 3 ) determining the economics of the proposed operations, and (4) evaluating risk associated with recovery processes.

Several computer models developed by DOEfunded research in the public domain include BOAST-II, BOAST-VHS, UTCHEM; PC-GEL, MASTER, PC-SITS, and $\mathrm{CO}_{2}$ PROPHET. Some of these computer models have been widely adopted by the petroleum industry, as in the case of BOAST-II and BOAST-VHS. Many of the existing second generation specialized commercial simulators find their roots in the Black Oil Model. These models need to evolve into a more userfriendly form capable of being run on entry-level personal computers. A default data system to be used in conjunction with these modified simulators is also required to routinely select representative values for respective domestic reservoir and economic properties. This will result in a much broader acceptance and application by the independents. The capability to conduct simple simulation runs and obtain access to these results will provide them with the necessary tools to select better prospects and to assess different strategies for economically recovering their oil. Furthermore, this additional background and knowledge empowers them to be full participants in planning any field project implementation with expert consultants and service companies. The net result would be more oil production (less resource abandoned) and more jobs.

Program Objectives for Extraction Simulation Activities:

- Develop computer models that use field data and minimal available reservoir information to reasonably predict fluid and front movement.

- Develop reasonable estimates of reservoir properties for use in computer models that use minimal available data to predict economic possibilities for improved oil recovery techniques.

- Develop enhanced computer models that 


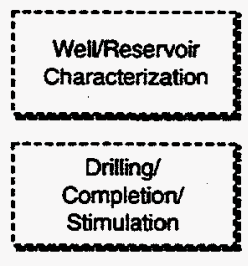

Environmental
Damage Prevention
\& Cleanup

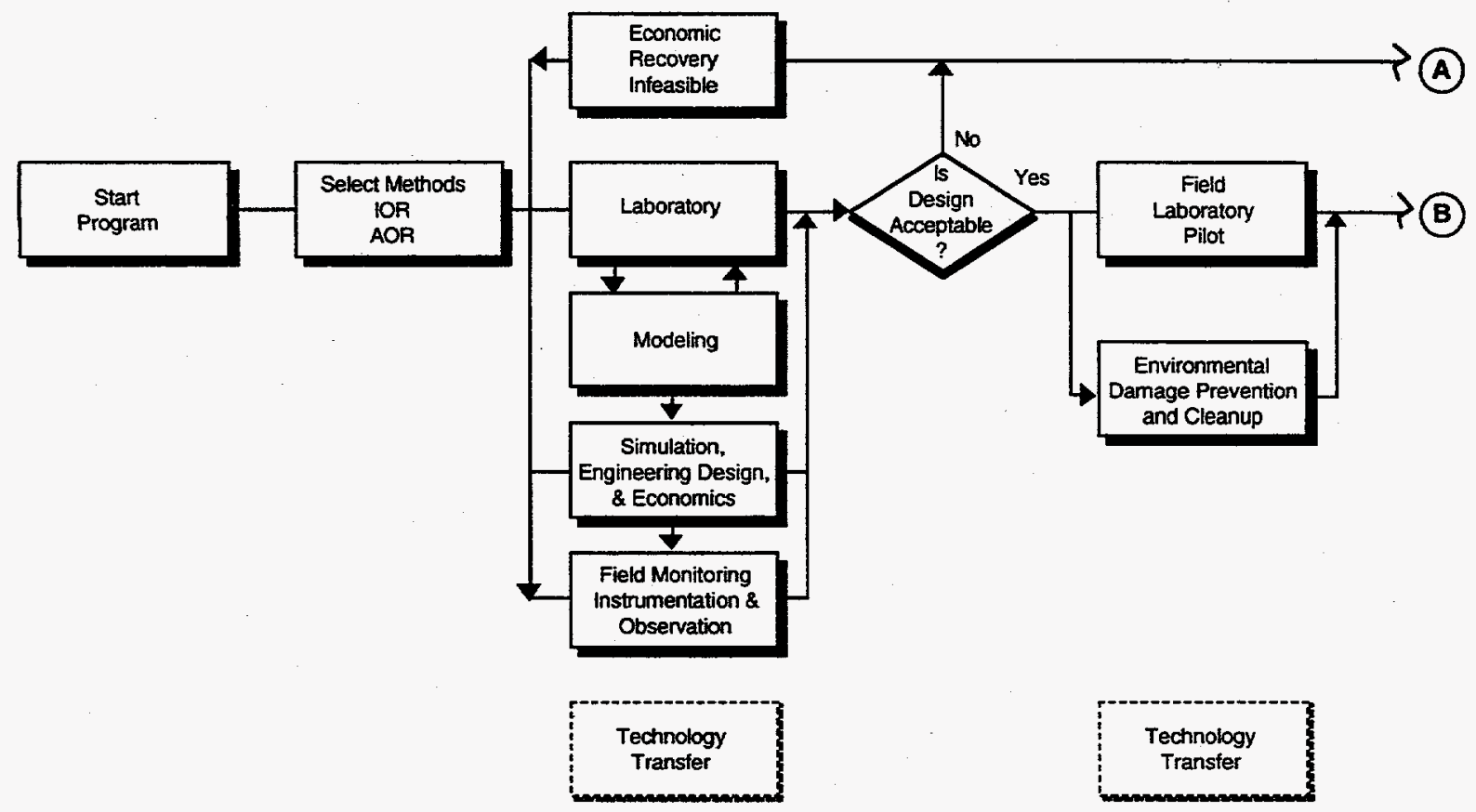

(A)
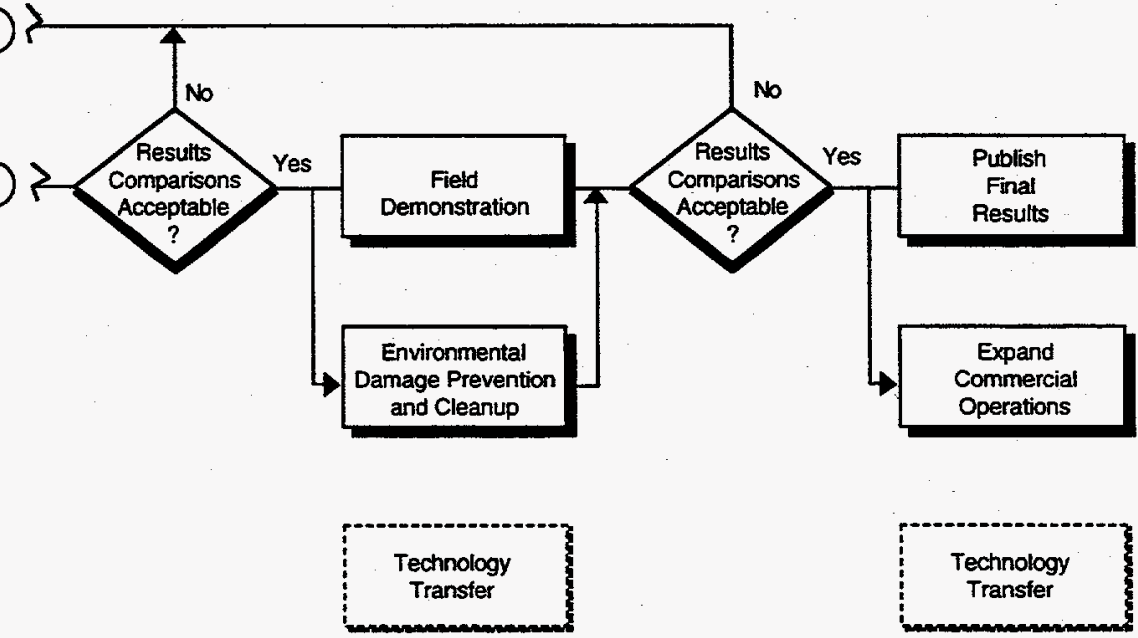

Figure 2.2.3 Field Laboratory Pilot Activities 


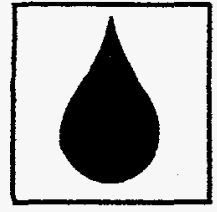

reasonably predict oil recovery for extraction processes available for use by the petroleum industry.

- Provide support for improved and advanced oil recovery laboratory and field activities.

- Develop computer models that use minimal available economic data to predict future possibilities for improved oil recovery for specific reservoirs.

\subsubsection{StAKEHOLDERS}

The development of the program plan is driven by the concerns and consideration for key customers and stakeholders. For the Extraction Research Program, these include:

- The U.S. taxpayer: the petroleum consumer, the petroleum producer, the petroleum and related environmental regulator, consultant, and the investor

- The businesses and facilities that conduct the research in the Oil Program: DOE's Bartlesville Project Office, Morgantown Energy Technology Center, Fossil Energy Headquarters, NIPER, universities, independent and major producers, national laboratories, contractors

- State, local, and Native American governments

- Federal government: agencies, Congress, the President and the administration

- Trade and professional interest groups

- Future generations who will benefit from a stable domestic oil reserve for future consumption

\subsubsection{IMPACTS}

A significant increase in domestic crude oil recovery will supply an important product and will result in more jobs and increased tax revenues. A further benefit arises because every barrel of domestic crude oil produced offsets an imported barrel of oil. To the extent this occurs, increased oil recovery will improve the nation's energy security.
Briefly, those areas that will benefit from the Extraction Research Program are:

Increased Reserves. Ultimate recovery from known reservoirs will be substantially augmented by the successful application of technologies advanced through the R\&D Program. As well abandonments are reduced after the arrival of advanced technology, the percentage of the remaining proved oil in place being abandoned drops. The wider application of improved oil recovery and advanced oil recovery technologies will increase the ultimate oil recovery, significantly reducing the volume of discovered oil left in the ground.

Impact on Industry. Improved oil recovery and advanced oil recovery activities require more engineering, monitoring, and oversight than conventional production methods. Oil operations and service companies will increase employment. Suppliers (e.g., chemicals) also will benefit from the additional activities. Investment opportunities will arise to finance operators for improving ultimate oil recovery from reservoirs. American companies will also use these new tools to improve competitiveness in the world.

Revenues. Increases in domestic oil production will have a wide-ranging ripple effect in the U.S. economy. Increased federal and state revenues are expected from production taxes on incremental oil and employee income taxes.

National Security. Increases in domestic oil production will reduce foreign import requirements and decrease balance of payment deficits. Reducing dependence on imported oil would make the United States more secure from the disruptive effects of another embargo.

\subsubsection{BUDGet}

The budget for the Extraction Research Program is summarized in Table 2.2.1 and Figure 2.2.4. As stated in Section 1, this Oil Plan is developed for an unconstrained budget that is 


\section{Table 2.2.1 Budget for Extraction Program}

\begin{tabular}{lcc}
\hline Functions & $\begin{array}{c}\text { FY 1994 } \\
\text { Appropriated } \\
(\$ 1,000)\end{array}$ & $\begin{array}{c}\text { FY 1995 } \\
\text { Appropriated } \\
(\$ 1,000)\end{array}$ \\
\hline Improved Oil Recovery & 2,589 & 2,038 \\
Advanced Oil Recovery & 4,376 & 4,628 \\
Extraction Simulation & 0 & 2,518 \\
\hline Totals for Extraction & 6,965 & 9,184 \\
\hline
\end{tabular}

1994

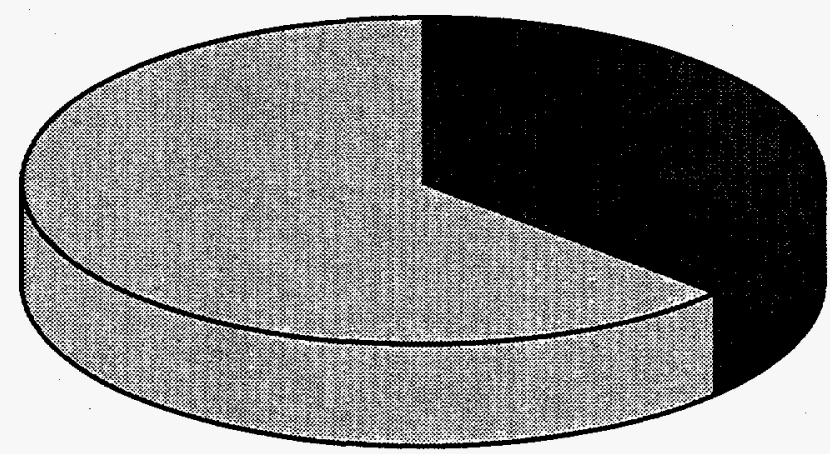

1995

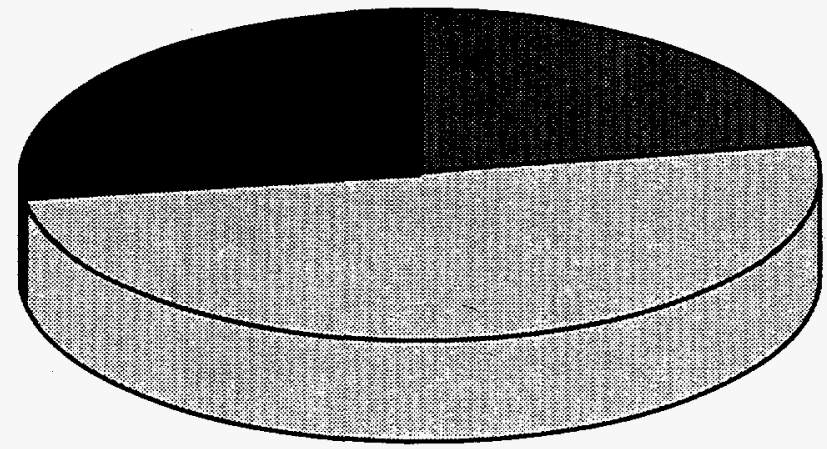

Improved Oil Recovery

Advanced Oil Recovery

Extraction

Simulation

Figure 2.2.4 Extraction Program Budget 


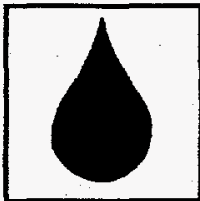

bounded by the scope of goals set by Congress, the President, and the Secretary of Energy.

\subsubsection{SCHEDULE}

Figures $2.2 .5-7$ show key activities and their timing in the Improved Oil Recovery, Advanced Oil Recovery, and Simulation of Extraction Process areas of the Extraction Research Program.

\subsubsection{Measures of Effectiveness}

The success of the Extraction Research Program can be gauged by several indicators. They include the rate of well abandonment, IOR/AOR starts, IOR/AOR crude oil production, and total domestic crude oil production. Table 2.2.2 provides a detailed listing of the measures of effectiveness of the different activities undertaken by the program. 
Figure 2.2.5 Key Activities and Timing for Improved Oll Recovery

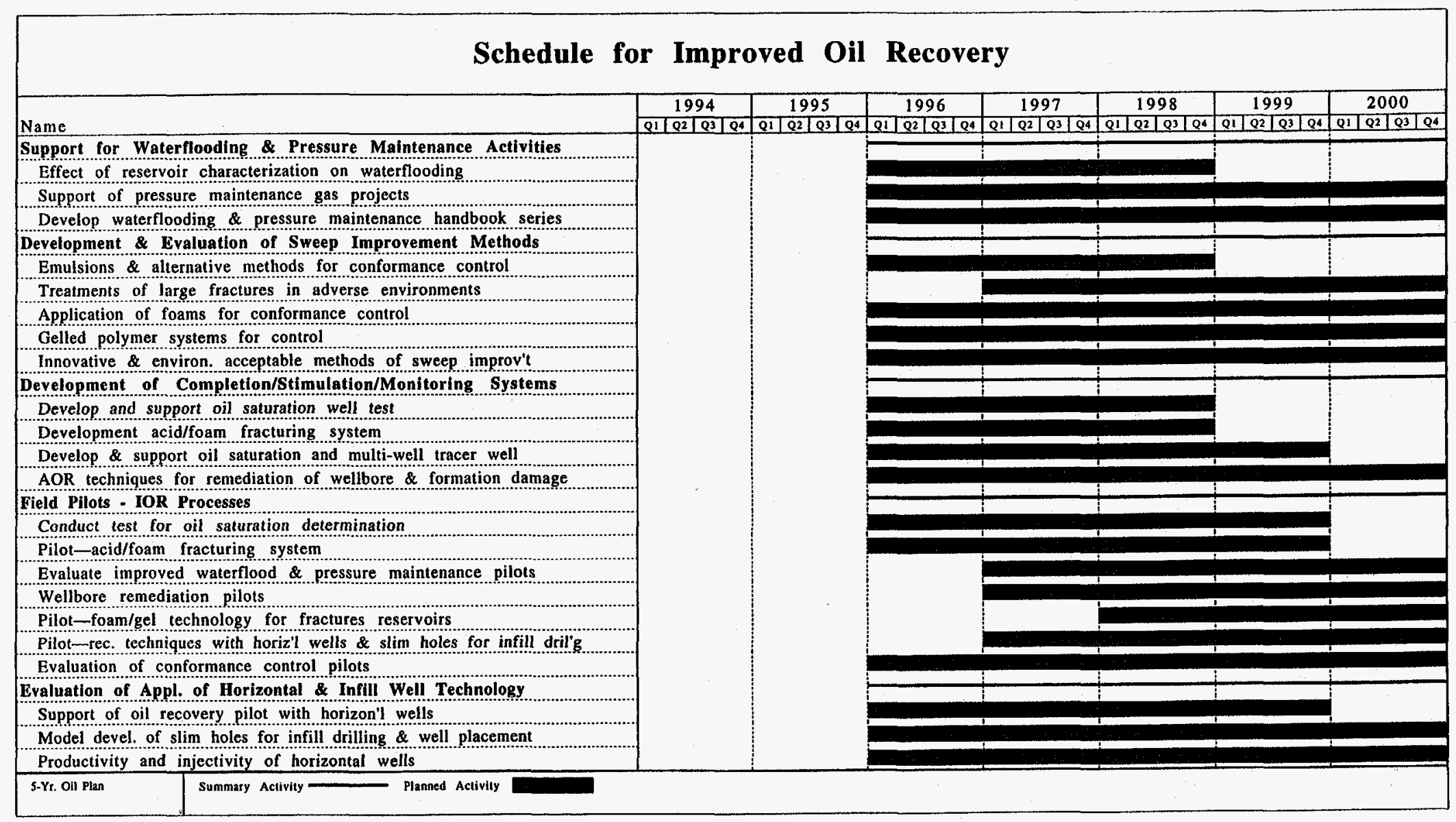

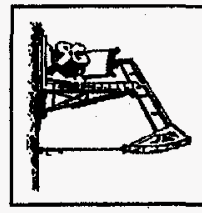


Figure 2.2.6 Key Activifies and Timing for Advanced Oil Recovery

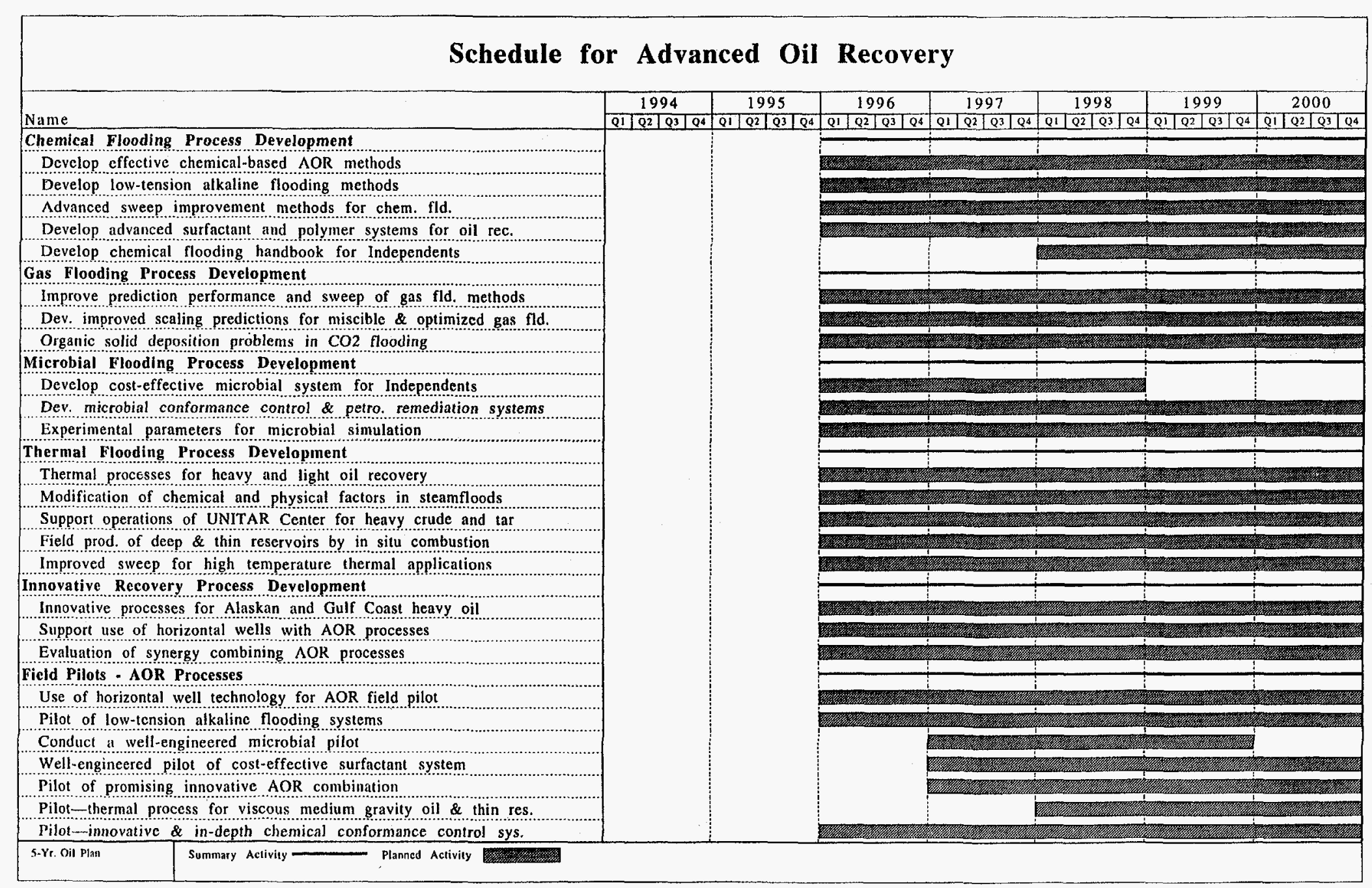
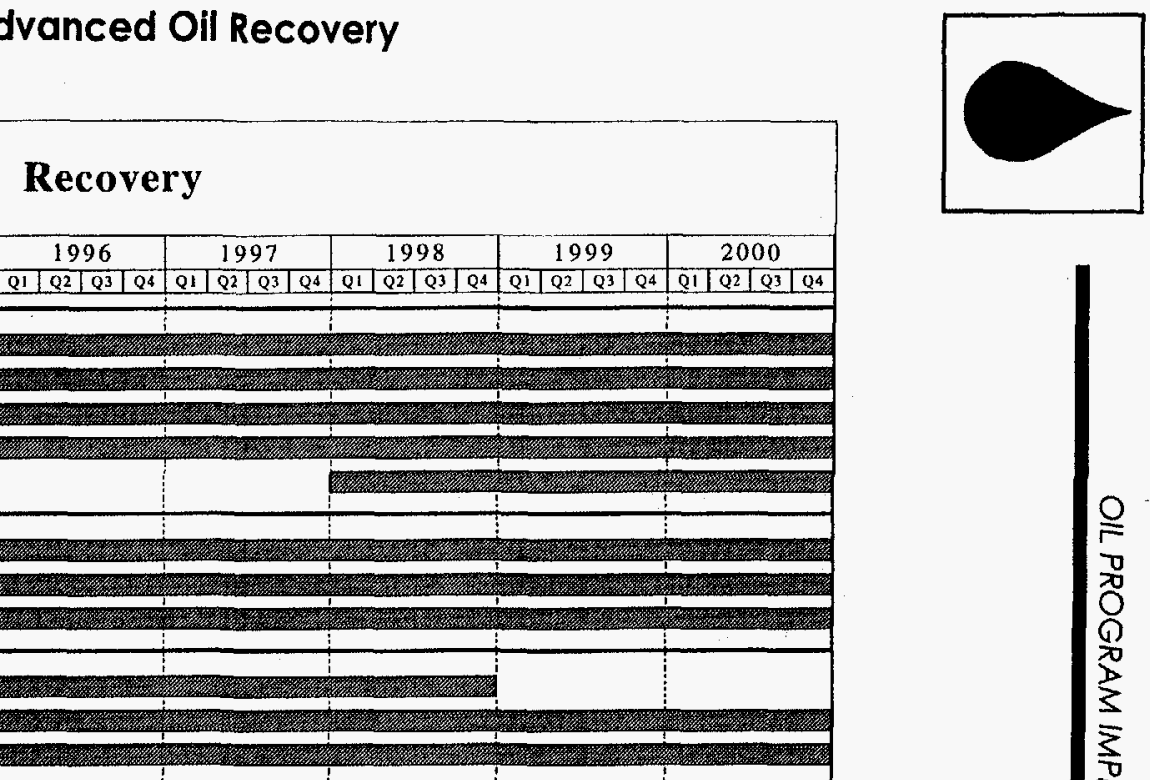

1.

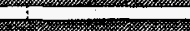

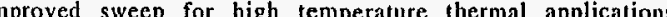

ion of synergy combining $\triangle O R$ processes

Pilot of low-tension alkaline flooding system

\begin{tabular}{|l|l}
\hline 5-Yrr. Oil Plan & Summary Activity — Planned Activity
\end{tabular} 
Figure 2.2.7 Key Activities and Timing for Simulation Extraction Process
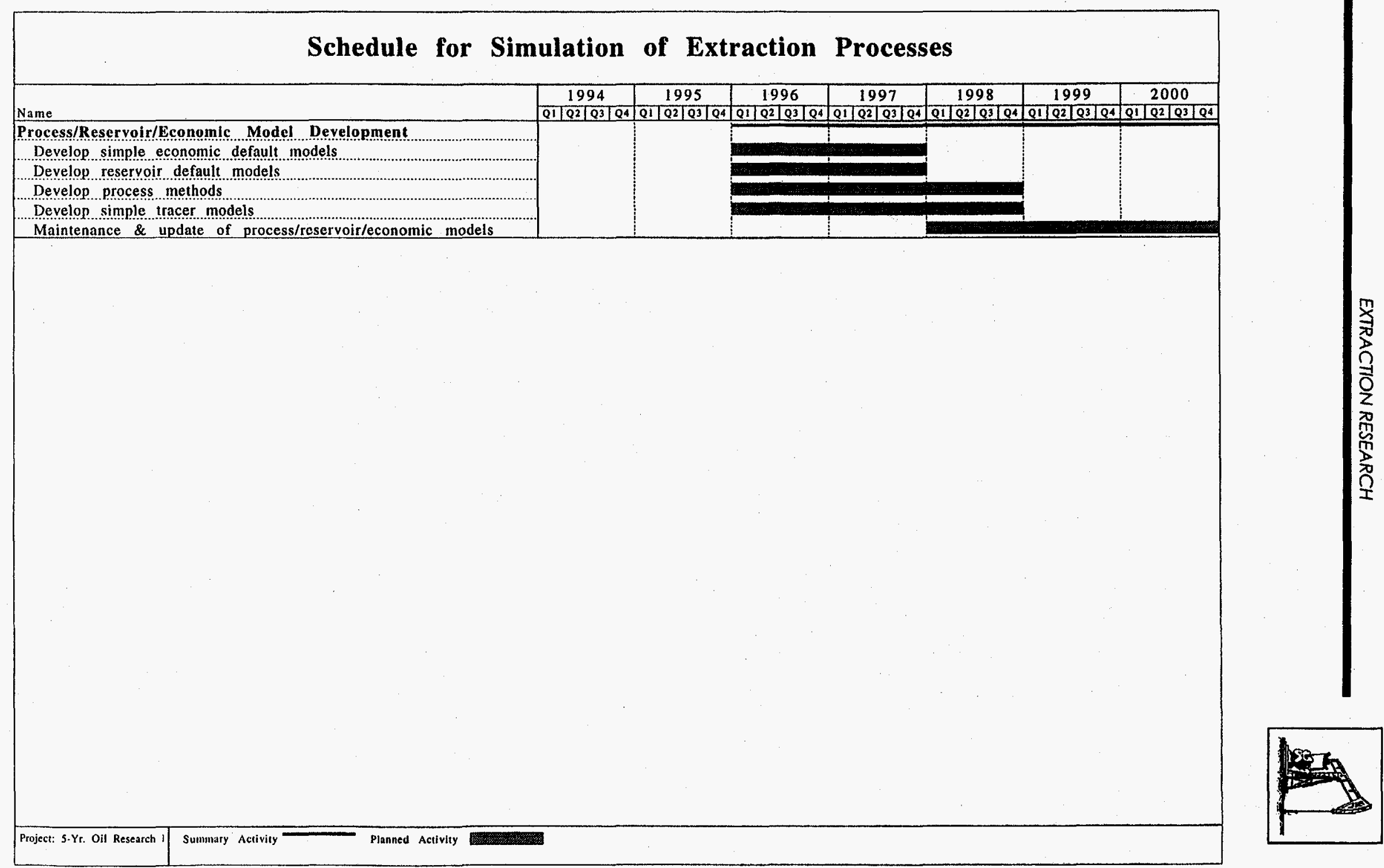


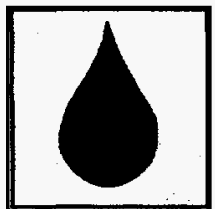

\section{Table 2.2.2 Measures of Effectiveness for the Extraction Research Program}

\section{Extraction Research Activities}

- Process development efforts: Improved Oil Recovery and Advanced Oil Recovery

- Process Simulator development

- Field pilots testing

- Participation in Department of Energy Field Laboratory

- Technology transfer and information dissemination activities

\section{Metrics}

- Improved technologies/products that reduce operating costs, defer abandonments, increase success of production activities, and protects environment

- Increase in the number of improved oil recovery/advanced oil recovery initiatives implemented in high potential reservoirs

- Decrease in rate of well abandonment

- Increase in number of inactive wells returned to production

- Number of jobs created

- Number of independents with increased awareness, interest, and participation in pilot projects

- Number of requests for software tools

- Number of contacts for information

- Number of technical publications disseminated

- Number of Cooperative Research and Development Agreements generated per year

- Number of companies contacted for potential Cooperative Research and Development Agreements

- Number of technical assistance requests by the industry directed towards National Institute for Petroleum and Energy Research

- Copies of publications requested; i.e., IOR handbook

- Number of patent awards granted and licensed

- Foreign oil importation level

- Reduced perception of risk 


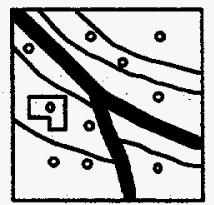

\subsection{EXPLORATION, DRILLING, AND RISK- BASED DECISION MANAGEMENT}

\subsubsection{Program Overview}

The modern world oil industry was founded in the United States, and this country has become the most heavily explored area in the world. The major U.S. onshore basins have been widely explored for shallow, conventional reservoirs and obvious traps. Many giant fields have been discovered using the older tried-and-true methodologies. Today, however, the petroleum industry is being subjected to new stresses and pricing pressures. Conventional geologic and geophysical procedures have led to fewer major finds in the United States onshore in recent years, and even offshore prospecting has turned up many smaller finds, but few large field discoveries. As a result, the U.S. petroleum industry has been looking more and more to foreign sources for its necessary increases in reserves. This increased reliance on foreign oil has serious strategic implications for the nation as a whole, as witnessed by the war for the liberation of Kuwait.

Economic considerations have forced the U.S. petroleum industry to change during the last decade. Drops in the world price for oil have had a significantly negative impact on the state of the U.S. oil and gas industry and on exploration in this country. Trends in seismic crew activity peaked in 1981, but then the crew count dropped rapidly until 1983. It stabilized briefly in 1984, then dropped again dramatically in 1985 and 1986 (SEG 1993). The seismic crew count is a leading indicator for the oil and gas industry. Companies planning exploration and development operations frequently precede their drilling with seismic work. Figure 2.3.1 shows the decrease in the U.S. rig count and production that occurred in the mid-1980s. Projections show if current trends continue, the United States will be able to supply only $30 \%$ of its own domestic requirements by the year 2000 , making the country even more dependent on foreign energy supplies for its needs and more vulnerable to supply disruptions that can cause economic downturns.

As the size of the average new field discovery has been dropping in this country, large and small oil companies alike have been searching for ways to increase productivity and to reduce costs. For this reason, DOE has been looking for ways to stimulate the search for the subtle trap and the unconventional resource that may yield significant reserve increases for the nation. A program strategy is being designed that will emphasize the application of new and innovative concepts in the fields of geology, geochemistry, and geophysics. These disciplines will be used to determine how, where, and when oil and/or natural gas may have formed in various basins of the United States, what has happened in these and surrounding areas that could have led to the accumulation and concentration of these hydrocarbons, and if satisfactory conditions have existed there for trapping the resource in sufficiently large pools to be economically viable at realistic oil prices. This part of the program will be evaluating broad regions, with the objective of reducing exploration risks by providing reliable information on the general subsurface geology of regions. Companies using this information will be able to focus their efforts on the best general targets within a region. 

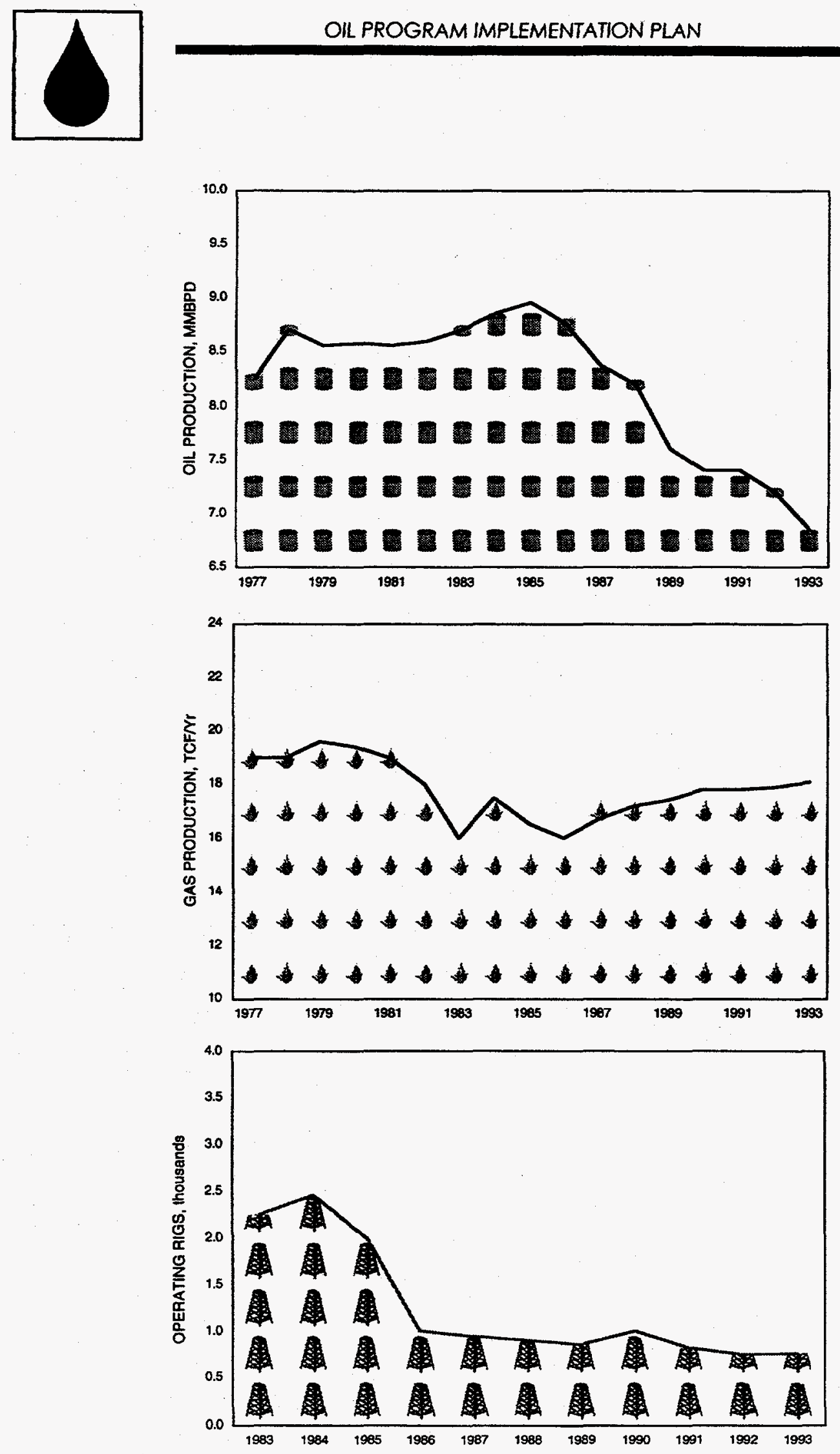

Figure 2.3.1 U.S. Production and Rig Count 


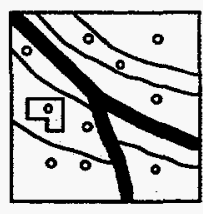

In addition to the regional studies, the program will include a description of innovations and current state-of-the-art advances in drilling technology. Individual states have adopted a number of new drilling rules and regulations that must be considered if drilling is to continue in these basins. Improved drilling systems and methodologies are constantly being introduced that optimize recovery in environmentally safe manners. The program will focus on these techniques for the drilling of new wells and on the reworking and recompletion of older existing wells to improve recovery and the economics.

Finally, the program will include a review of processes and computerized programs for risk analysis in the oil industry. Various improved management concepts and systems will be evaluated, and methods will be reviewed for determining the economics of various exploration and development strategies in the current industry. Technological advances, environmental regulations and up-to-date economic analysis will all be included in the evaluation.

\subsubsection{Goals and Objectives}

The mission of the Exploration, Drilling, and Risk-Based Decision Management Program is to provide technical and informational support for DOE's Oil Program component directed towards efficient discovery of our remaining undiscovered oil resource. This will be accomplished through research and development efforts in the following areas: exploration, drilling, and riskbased decision management.

\section{Objectives for the Program:}

- Update and increase the amount of publicly available information on the regional geology and hydrocarbon prospects of toppriority basins, with the prime directive of improving the success rate for U.S. wildcat drilling.

- Stimulate environmentally safe exploration work in currently underexplored areas and in untested formations within older producing fields.

- Develop improved, more cost-effective scientific and engineering methodologies and/or equipment for environmentally sound, operationally safe drilling and completion technologies.

- Reduce engineering and exploration costs, and thus improve economics and stimulate increased drilling in the United States.

- Improve confidence in the economic analysis of domestic oil and natural gas exploration and production by developing and disseminating improved, risk-based, decision management concepts for the oil field.

- Provide the necessary technology transfer to the petroleum industry of developed and identified successful methodologies.

Figure 2.3.2 outlines the work breakdown structure for this research program.

\subsubsection{EXPLORATION}

The exploration research phase of this program will focus the efforts to update and to increase the amount of publicly available information on the regional geology and hydrocarbon prospects of the top-priority basins, with the objective of improving the $20 \%$ success rate for U.S. wildcat drilling. This ratio must rise significantly if new exploratory drilling is to be costeffective and to continue in these regions. This work, in tandem with the engineering phase of the project, will be geared to stimulate environmentally safe exploration work in currently underdrilled areas and in untested formations within older producing fields.

This part of the program will use a multidisciplinary geoscience approach to basin analysis. Geological, geophysical, geochemical, and engineering input will be coordinated synergistically, using such tools as remote sensing and some of the new geophysical/geochemicalsurvey techniques, as well as computerized data management, analysis, and computer-assisted 


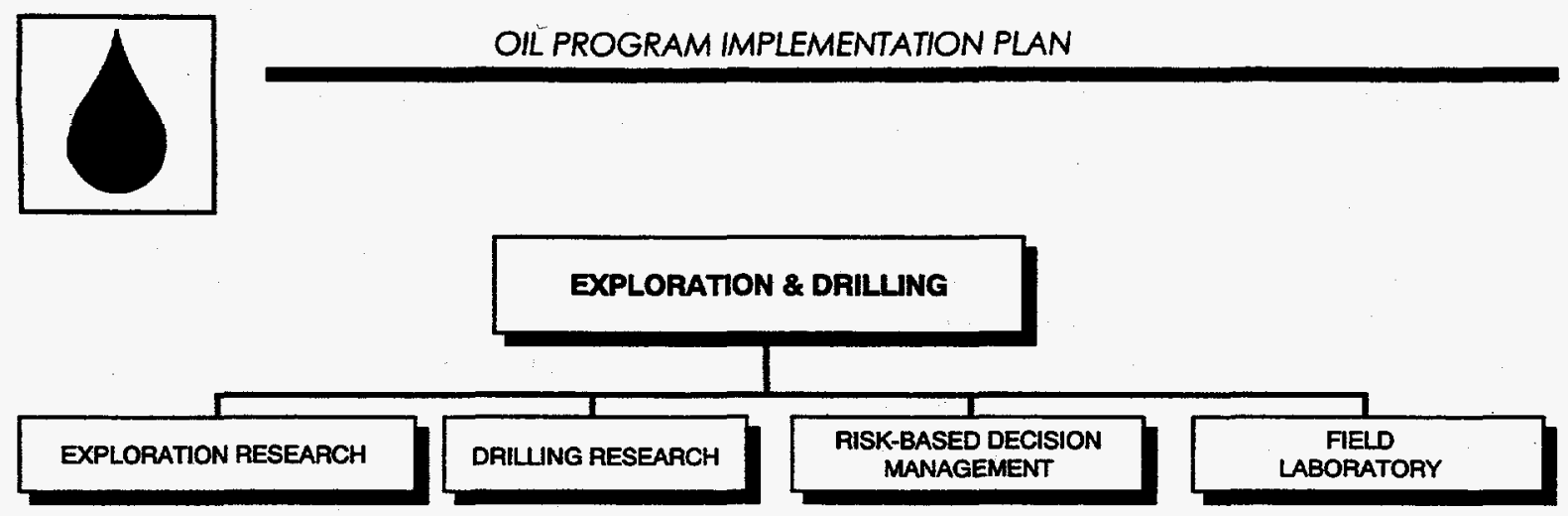

\section{Figure 2.3.2 Exploration and Drilling Work Breakdown Structure}

design. The exploration research part of this project is geared toward quickly and costeffectively identifying underexplored, highpotential regions and formations in U.S. basins.

An overview survey of sedimentary basins was initiated in FY 1994, with the objective of identifying five to seven basins for more detailed multidisciplinary study and evaluation. A detailed analysis will begin for the highest priority basin in FY 1995. Figure 2.3.3 outlines the workplan for the exploration research phase of the project. The geology and hydrocarbon prospects of additional basins will be studied at the rate of two each year from FY 1996 to FY 1998.

The studies will begin with a review of basin tectonic history, internal structural features, and stratigraphic framework. Modern concepts of sequence stratigraphy will be applied, based on outcrop descriptions, well logs, and advanced seismic-sequence concepts. A synthesis of the geologic history of each basin will be formulated. Finally, cap rocks and trapping mechanisms will be reviewed to see if seals were present at key times in key areas during the basin's evolution.

Data will be acquired to assemble geochemical and geophysical descriptions of the study areas. Newer, high-resolution satellite imagery, gravity, magnetic, magnetotelluric, and regional seismic data will be used to identify previously overlooked or neglected features of potential interest. Computerized model studies, lineament analyses, desktop seismic reprocessing, well-towell seismic imaging and tomography, amplitude variation with offset (AVO) technologies, and other similar innovative techniques will be investigated and applied where appropriate and cost-effective. Additional data will be integrated into the interpretations as they are acquired.

There will be a steady stream of products for our customers distributed through the technology transfer function of the Oil Program. These products will be in the form of reports, publications, and workshops and symposia. Feedback will also come from field pilot tests, industry partners, and data sources. An effort will be made to preserve data from older fields that might otherwise be destroyed as operations are abandoned. The geologic information gathered will be fed to the drilling and risk analysis phases of the project. Varying geologic characteristics of target formations will lend themselves to different drilling technologies and engineering innovations. Risk analysis will likewise be highly dependent on the geology of the study areas.

Objectives for Exploration Research Activities:

- Select five to seven basins with a high potential for untapped hydrocarbon resources and increased industry activity, and initiate the integrated, multidisciplinary exploration research effort in FY 1995.

- Collect, collate, and analyze available data and models to identify targets for the primary focus for further research in the various basins.

- Issue refined geologic and engineering models of the first basin by the end of FY 1999.

- Sponsor seminars, workshops, and symposia for industry and other interested personnel. 

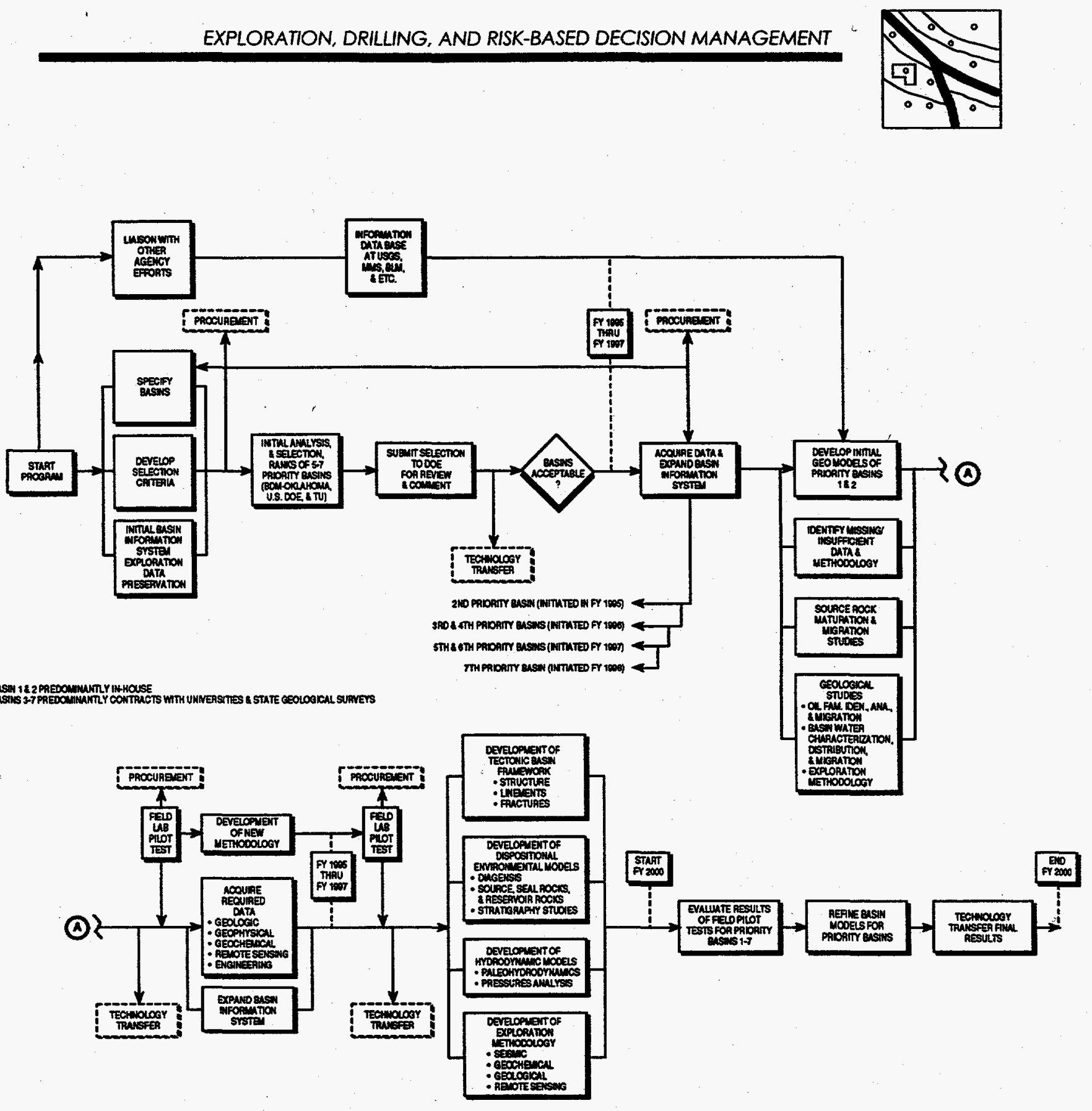

Figure 2.3.3 Workplan for Exploration Research 


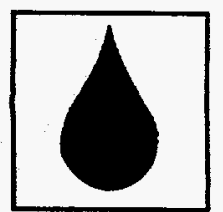

- Conduct cost-shared field pilot projects under real-world conditions to test exploration and geoanalytical techniques.

- Integrate project work with other government and nongovernment programs such as National Advanced Drilling and Energy Technology (NADET), the Morgantown Energy Technology Center (METC) Natural Gas Program, the National Gas and Oil Partnership, and university and industry programs.

\subsubsection{DrILING}

The drilling research part of this program is intended to develop improved, more cost-effective engineering methodologies and/or equipment. These are intended to optimize environmentally sound, operationally safe drilling and completion technologies. The objective is to reduce engineering and operating costs, and thus improve economics and stimulate increased drilling in the United States. The work will encompass research on vertical, slant, horizontal, and slimhole wells.

A preliminary study began in FY 1994 to determine technological needs in the engineering area of the drilling industry. Current research projects will be identified, with the emphasis on drilling systems design and strategies, drilling tools and fluids, wellbore and formation integrity and stability, and openhole techniques, including logging, well testing, and completion/ recompletion technologies. This phase of the project will be completed in FY 1995. Figure 2.3.4 outlines the work plan for the drilling research part of the program. Technology transfer and industry outreach/interaction will receive heavy emphasis throughout the duration of the program. Figure 2.3.4 also includes regular technology transfer, which includes the field work, pilot tests, workshops, symposia, forums, and constant feedback from industry cost-shared partnerships.
Projects will be identified in the preliminary phase of the program where DOE and industry will be able to share research costs. The program will enlist universities for research activities through program research and development announcements. DOE has ongoing jointly funded research with industry for the development of drilling tool technologies. This type of research will continue and expand under this program. In addition, DOE will perform drilling research that is not currently conducted by industry.

This drilling research phase of the program will be closely coordinated with the exploration and risk analysis phases. Basin-specific drilling research needs will be identified in the exploration research effort with work started in FY 1994. Results from the assessments and analyses will be fed to the risk-based decision management research as shown in Figure 2.3.5.

\section{Objectives for Drilling Research Activities:}

- Identify potential target areas for study where modifications and innovations in engineering may improve well drilling and completion/recompletion economics, operational safety, and/or environmental impacts.

- Develop innovative strategies, technologies, and equipment for exploration and well drilling to the point where field testing can begin.

- Sponsor seminars, workshops, and symposia for industry and other interested personnel and conduct cost-shared field pilot projects under real-world conditions to test new drilling and completion/recompletion technologies.

- Integrate project work with other government and nongovernment programs such as National Advanced Drilling and Energy Technology, the Morgantown Energy Technology Center Natural Gas Program, the National Gas and Oil Partnership, and university and industry programs. 

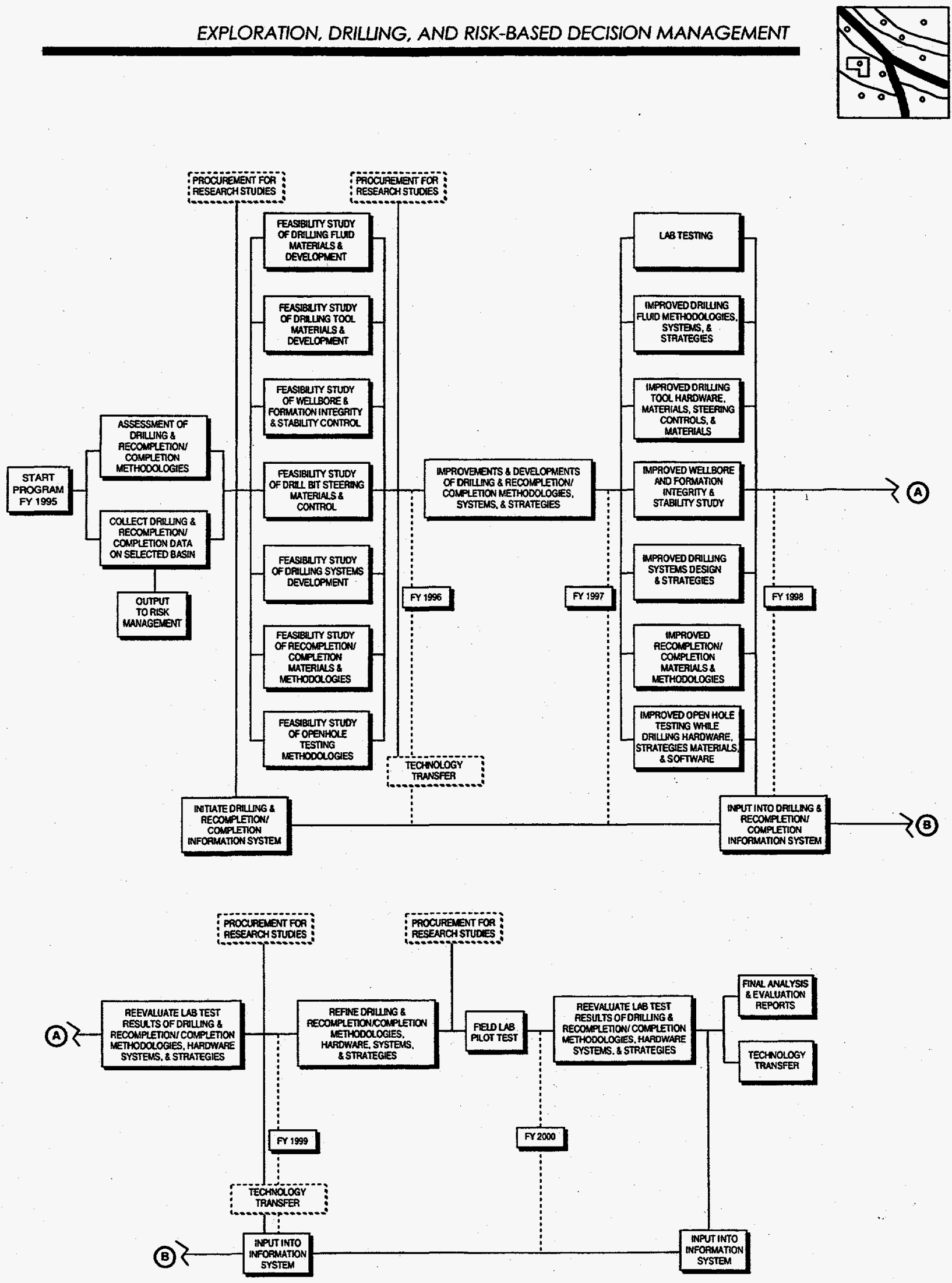

Figure 2.3.4 Workplan for Drilling Research 

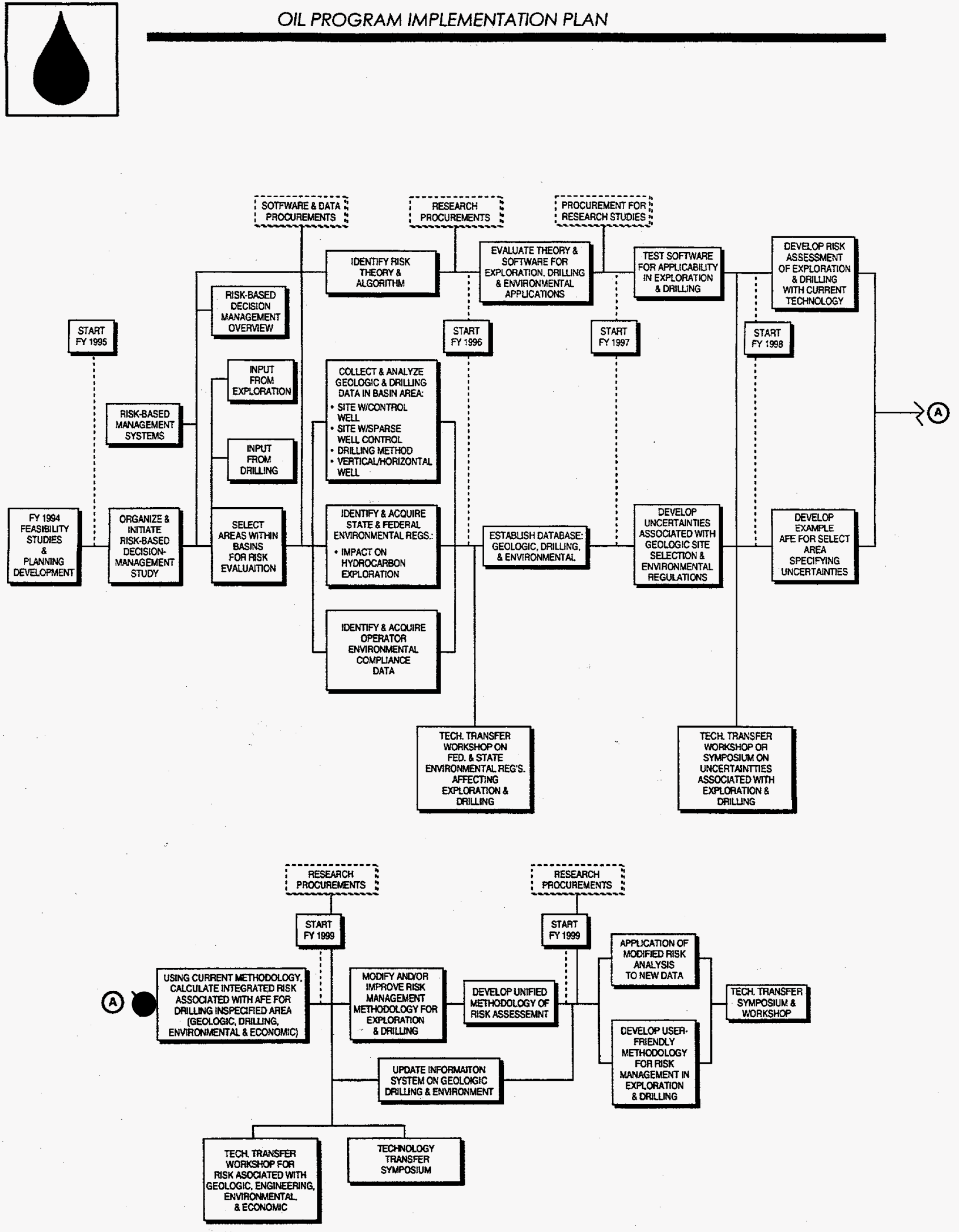

Figure 2.3.5 Workplan for Risk-Based Decision Managemenf 


\subsubsection{Risk-Based Decision Management}

This part of the program is intended to improve the economics of domestic oil and natural gas exploration and production by developing and disseminating improved, risk-based, decision management concepts for the oil field. These systems will evaluate technological, environmental, and economic information associated with the typical drilling program.

The U.S. petroleum industry today is drilling in the face of low prices, while having to minimize the impact of well activity on the environment. Industry economic analysts and decision makers are generally faced with fragmentary information and conflicting interpretations regarding geologic data, engineering options, and the environmental impacts of their activities, largely because the risks involved and the time scale of their effects are difficult to quantify. The riskbased decision management research conducted in this program will provide baseline information that will allow managers to better evaluate their options and reduce the numbers of unquantified risks in drilling and environmental activity.

Figure 2.3.5 is a workplan that outlines the risk-based decision management part of the program. It tracks the various inputs from operations in the field, software and data procurements. and evaluations, governmental agencies, and environmental monitoring. This information will be merged and modified to develop and improve risk theory approaches, algorithms, and methodologies. The goal will be to better identify and quantify uncertainties and risks associated with typical petroleum industry processes and decision management such as geologic risk, environmental risk, economic risk, and drilling risk.

As the program continues, there will be continuing interaction with and feedback from industry through a series of workshops and symposia. The program direction will be proactive, responding to actual field examples and experiences, as determined through these meetings with industry operators.

\section{Objectives for Risk-Based Decision Manage- ment Activities:}

- Develop and test an integrated, state-of-theart risk-based decision management model using currently available operational data.

- Modify and improve the theories and algorithms used to specify and minimize the risk associated with hydrocarbon exploration and drilling.

- Hold seminars, workshops, and symposia for industry and other interested individuals, with demonstrations of risk and decision strategies using real-world case studies.

- Integrate project work with other government and nongovernment programs such as National Advanced Drilling and Energy Technology, the Morgantown Energy Technology Center Natural Gas Program, the National Gas and Oil Partnership, and industry and university programs.

\subsubsection{Field Laboratory}

An important component of the program is the establishment of an operational field laboratory. The field laboratory will provide the means to test promising technologies on the pilot scale. The technologies include areas of exploration, drilling, reservoir characterization, environmental research, and petroleum production. Research and development in improved oil recovery and advanced oil recovery are the primary processes to be evaluated in the field laboratory. The availability of the field facility would provide the means to tie in all the other elements of the Oil Program.

An ideal field laboratory would be close to NIPER and in an area where a large number of companies are actively recovering crude oil. Such an area has been located in Osage County, Oklahoma. It is on Native American (Osage Nation) land, and most of the leases are farmed out to 


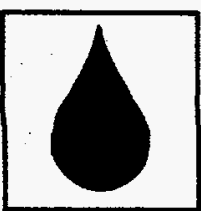

independent operators. Members of the Osage Tribal Council have expressed keen interest in pursuing a cooperative effort with DOE. Other fields will be chosen to test emerging technologies not suited for Osage County. There is expressed interest in pursuing similar cooperation in other locations, such as the Naval Petroleum Reserve No. 3 in Teapot Dome Field, Wyoming.

\section{Objectives for Establishing a Field Laboratory:}

- Test the viability of developed technologies from other elements of the Oil Program in the areas of exploration, drilling, reservoir characterization, environmental research, and petroleum production.

- Promote wider acceptance and application of the developed technologies and risk-based models by the petroleum industry through technology transfer vehicles.

\subsubsection{StaKeholders}

The Exploration, Drilling, and Risk-Based Decision Management Program is driven by the concerns and consideration for key customers and stakeholders. These include:

- U.S. taxpayers: the petroleum consumer, the petroleum producer, the petroleum service companies, the petroleum and related environmental regulator, consultants, and the investor

- Businesses and facilities that conduct the research in the Oil Program: Bartlesville Project Office, Metairie Site Office, Morgantown Energy Technology Center, Fossil Energy headquarters, NIPER, universities, national laboratories, independent and major producers, contractors

- State, local, and Native American governments

- Federal government: Agencies including United States Geological Survey, Bureau of Indian Affairs, United States Forest Service, Bureau of Land Management, Minerals Management Service, Congress, the President, and the administration

- Trade and professional interest groups

\subsubsection{IMPACTS}

The following impacts can be expected from this program:

- Improved availability of geological data and interpretations in the study basins

- Increased drilling in areas covered by the studies included in this project

- Higher success ratios for exploratory and development drilling in the mapped areas

- Better recovery rates for wells using advanced drilling/engineering technologies

- More efficient planning and economics for wells using advanced risk analysis

- More economically recoverable oil discovered and lower finding costs

- Increase in jobs related to program

\subsubsection{BUDGET}

The budget for the Exploration, Drilling, and Risk-Based Management Program is summarized in Table 2.3.1 and Figure 2.3.6. As stated in Section 1, this Oil Plan is developed for an unconstrained budget that is bounded by the scope of goals set by Congress, the President, and the Secretary of Energy.

\subsubsection{SCHEDULE}

Figures 2.3.7-9 show key activities and their timing in the Exploration, Drilling, and RiskBased Decision Management Program.

\subsubsection{Measures of Effectiveness}

The first measure of the effectiveness of this program will be an account of the drilling activity in the study areas adjusted for trends in the oil price. Accurate basin analysis and improved geologic interpretations will lead to increased local drilling and higher oil and gas discovery ratios.

The effectiveness of the engineering technology transfer and risk analysis aspects of the 


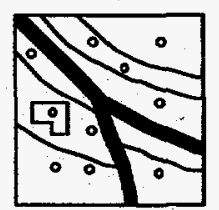

Table 2.3.1 Budget for Exploration, Drilling, and Risk-Based Decision Management

\begin{tabular}{lcc}
\hline Functions & $\begin{array}{c}\text { FY 1994 } \\
\text { Appropriated } \\
(\$ 1,000)\end{array}$ & $\begin{array}{c}\text { FY 1995 } \\
\text { Appropriated } \\
(\$ 1,000)\end{array}$ \\
\hline Exploration Research & 2,043 & 1,107 \\
Drilling Research & 626 & 2,190 \\
Risk-Based Decision Management & 0 & 542 \\
Field Laboratory & 0 & 323 \\
\hline Totals for Exploration \& Drilling & 2,669 & 4,162 \\
\hline
\end{tabular}

1994

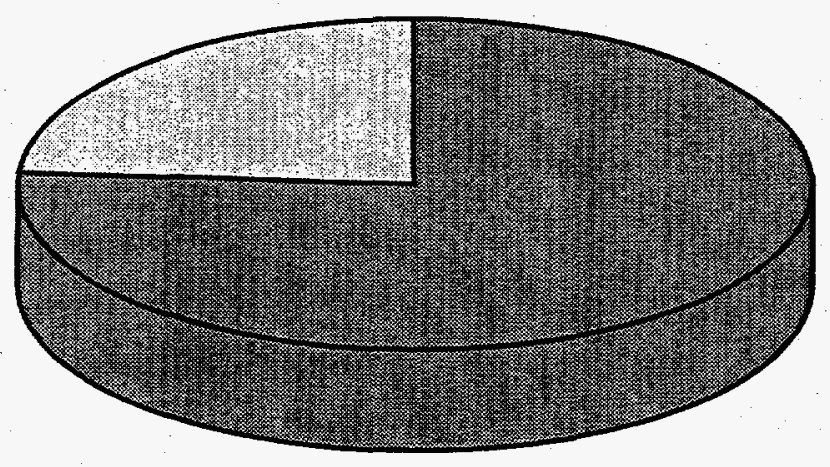

Exploration

Research

$\square$ Drilling

Research

Risk-Based

Decision

Management

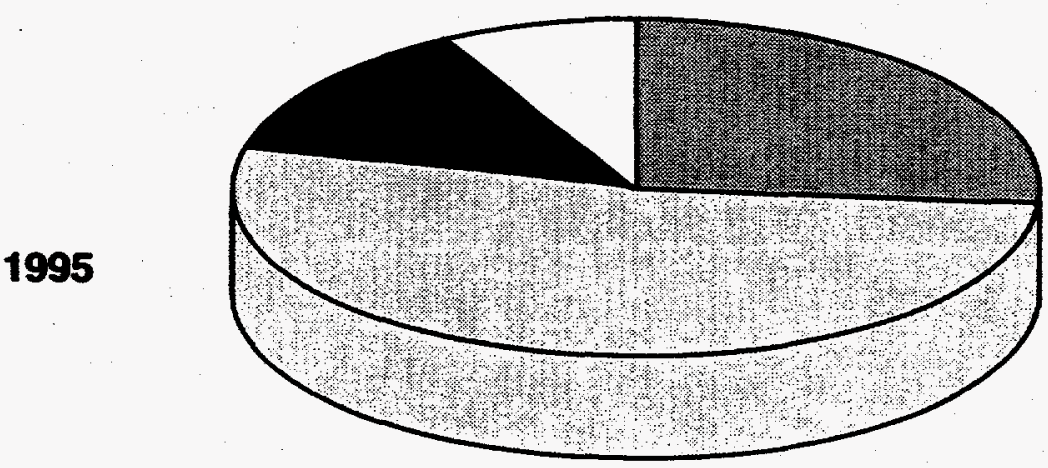

Field

Laboratory

Figure 2.3.6 Exploration, Drilling, and Risk-Based Decision Management Budget 


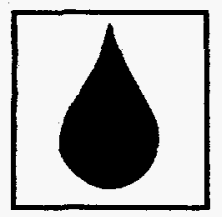

project will be more subtle and harder to measure. Engineering innovations and new business analysis programs will have broad application over many geographic areas. Success in those fields will be seen well beyond the study regions. Engineering and economic advances from this program may spread rapidly, but go largely uncredited. New measurement methods will be designed for this area.

A major goal of the Oil Program is to establish or support a national data center and source for geoscience information and expertise for the petroleum industry. Activities and materials provided by this repository will include comprehensive energy resource information, reports and maps, interpretations, and educational materials, as well as technology transfer documents. This material will be available for individuals and companies, as well as for educational institutions and federal and state agencies. Energy data maintained in the facility will include such information as well cutting samples, digi- tized logs, descriptive and analytical data, and environmental assessments and investigations. Use of this center will provide a measure of effectiveness of this program.

The project also aims to establish an outreach program that will attempt to reach industry through publications, public forums, and jointparticipation partnerships with public and private companies and institutions. Attendance at workshops, forums, and symposia will help gauge the success of the project, as will the number of requests for project reports and updates.

Reports on progress in this program will be publicized in prominent industry and public media outlets that can be expected to reach most large and small oil and gas producers. Successes in exploration and drilling will be the best publicity for the program.

Table 2.3.2 summarizes the measures of effectiveness of the program's different activities. 


\section{Figure 2.3.7 Key Aclivities and Timing for Exploration Research}

\begin{tabular}{|c|c|c|c|c|c|c|c|}
\hline \multirow[b]{2}{*}{ Name } & \multicolumn{3}{|c|}{ Exploration Research } & \\
\hline & 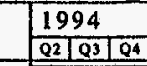 & \begin{tabular}{|l|l|}
1995 \\
$Q 1$ & 02103 \\
\end{tabular} & \begin{tabular}{|l|l|}
\multicolumn{2}{|c|}{1996} \\
$01|02| 03 \mid 0^{2}$ \\
\end{tabular} & 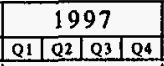 & 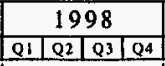 & 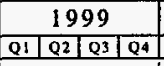 & 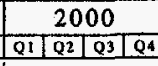 \\
\hline \multicolumn{8}{|l|}{ Identify Key Basins with Potential for Underexploited Hydrocarbon Plays } \\
\hline \multirow{2}{*}{\multicolumn{2}{|c|}{ Basin 1 - Review/refine regional studies of structure, tectonics lithologies, etc. }} & & & & & & \\
\hline & \multicolumn{7}{|c|}{ Basin 2 - source, reservoir, and cap rock for key areas in each study basin } \\
\hline \multicolumn{8}{|l|}{ Basin $3 \& 4$ - procurement contracts with Universities and State Geol. Surveys } \\
\hline \multicolumn{8}{|l|}{ Basin $5 \& 6$ - procurement contracts with Universities and State Geol. Surveys } \\
\hline \multicolumn{8}{|l|}{ Basin $7 \& 8$-procurement contracts with Universities and State Geol. Surveys } \\
\hline \multirow{2}{*}{\multicolumn{8}{|c|}{$\begin{array}{l}\text { Refine Hydrocarbon Exploration Methodologies, Strategies, and Concepts } \\
\text { Basin 1 - Review/refine geochemical, geophysical, remote-sensing tech. }\end{array}$}} \\
\hline & & & & & & & \\
\hline \multicolumn{8}{|l|}{$\begin{array}{l}\text { Basin } 2 \text { - analyze hydrodynamics and fluid-mitigation histories in each basin } \\
\text { Bun }\end{array}$} \\
\hline \multicolumn{8}{|l|}{ Basin $3 \& 4$ - procurement contracts with Universities and State Geol Surveys } \\
\hline \multicolumn{8}{|l|}{ Basin $5 \& 6$ - procurement contracts with Universities and State Geol surveys } \\
\hline \multicolumn{8}{|l|}{ Basin 7 \& 8 - procurement contracts with Universities and State Geol. Surveys } \\
\hline \multirow{2}{*}{\multicolumn{8}{|c|}{$\begin{array}{l}\text { Re-evaluate Basin Stratigraphy } \\
\text { Basin 1 - Review/refine regional and local sequence stratigraphy for each }\end{array}$}} \\
\hline & & & & & & & \\
\hline \multicolumn{8}{|l|}{ Basin 2 - basin and develop predictive techniques to identify potential reservoirs } \\
\hline \multicolumn{8}{|l|}{ Basin $3 \& 4$ - procurement contracts with Universities and State Geol. Surveys } \\
\hline \multicolumn{8}{|l|}{ Basin $5 \& 6$ - procurement contracts with Universities and State Geol Surveys } \\
\hline \multicolumn{8}{|l|}{ Basin 7 \& 8 - procurement contracts with Universities and State Geol Surveys } \\
\hline \multicolumn{8}{|l|}{ Identify Hydrocarbon Sources, Generation, Stability and Surviva! } \\
\hline \multicolumn{8}{|l|}{ Basin 1 - Identify potential source rocks and model thermal histories of each } \\
\hline \multicolumn{8}{|l|}{ Basin 2 - basin conduct field tests/collect samples to verify history and maturity } \\
\hline \multicolumn{8}{|l|}{ Basin $3 \& 4$ - procurement contracts with Universitics and State Geol. Surveys } \\
\hline \multicolumn{8}{|l|}{ Basin 5 \& 6 - procurement contracts with Universities and State Geol. Surveys } \\
\hline Basin 7 \& 8 - procurement contracts with Universities and State Geol. Surveys & & & & & & & \\
\hline Fluid Mitigation and Accumulation in Basins & & & & & & & \\
\hline Basin 1 - Identify hydrocarbon mitigation histories for regions and areas & & & & & & & \\
\hline Basin 2 - conduct ficld tests/collect samples to verify mitigation pathways/patter & & & & & & & \\
\hline Basin 3 \& 4 - procurement contracts with Universities and State Geol. Surveys & & & & & & & \\
\hline Basin 5 \& 6 - procurement contracts with Universities and State Geol. Surveys & & & & & & & \\
\hline Basin 7 \& 8 - procurement contracts with Universities and State Geol. Surveys & & & & & & & \\
\hline Identification of Regional Alterations (Non-structural) & & & & & & & \\
\hline Basin 1 - Identify diagenetic history and alteration for regions and areas & & & & & & & \\
\hline Basin 2 - conduct field tests/collect samples to verify concepts of diagenesis & & & & & & & \\
\hline Basin $3 \& 4$ - procurement contracts with Universities and State Geol. Surveys & & & & & & & \\
\hline Basin $5 \& 6$ - procurement contracts with Universities and State Geol. Surveys & & & & & & & \\
\hline Basin $7 \& 8$ - procurement contracts with Universities and State Geol. Surveys & & & & & & & \\
\hline Technology Transfer - conduct Workshops, Seminars, Symposia & & & & & & & \\
\hline Summary Activity $\longrightarrow$ Planned Activity & & & & & & & \\
\hline
\end{tabular}


Figure 2.3.8 Key Activities and Timing for Drilling Research

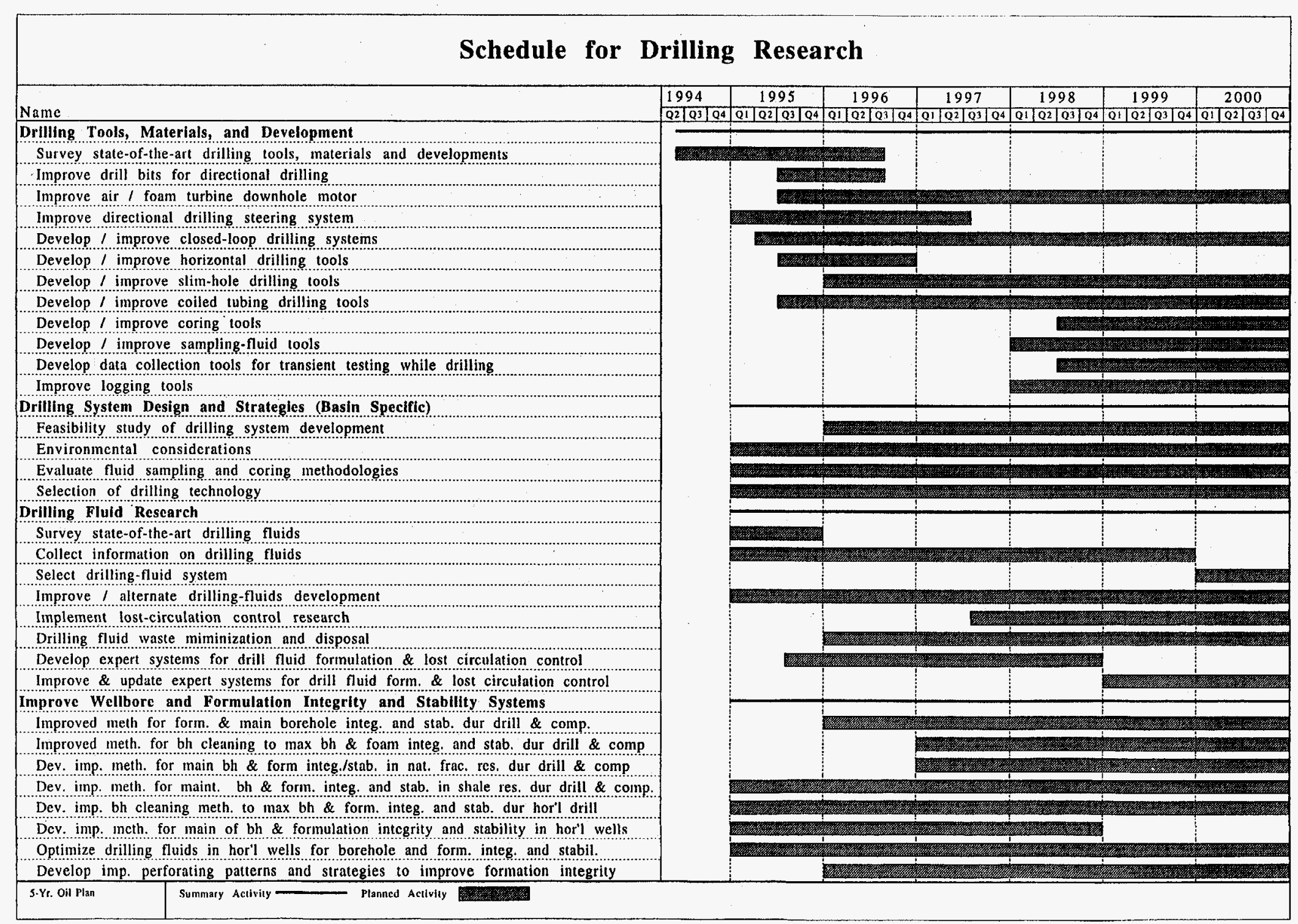


Figure 2.3.8 Key Activities and Timing for Drilling Research (continued)

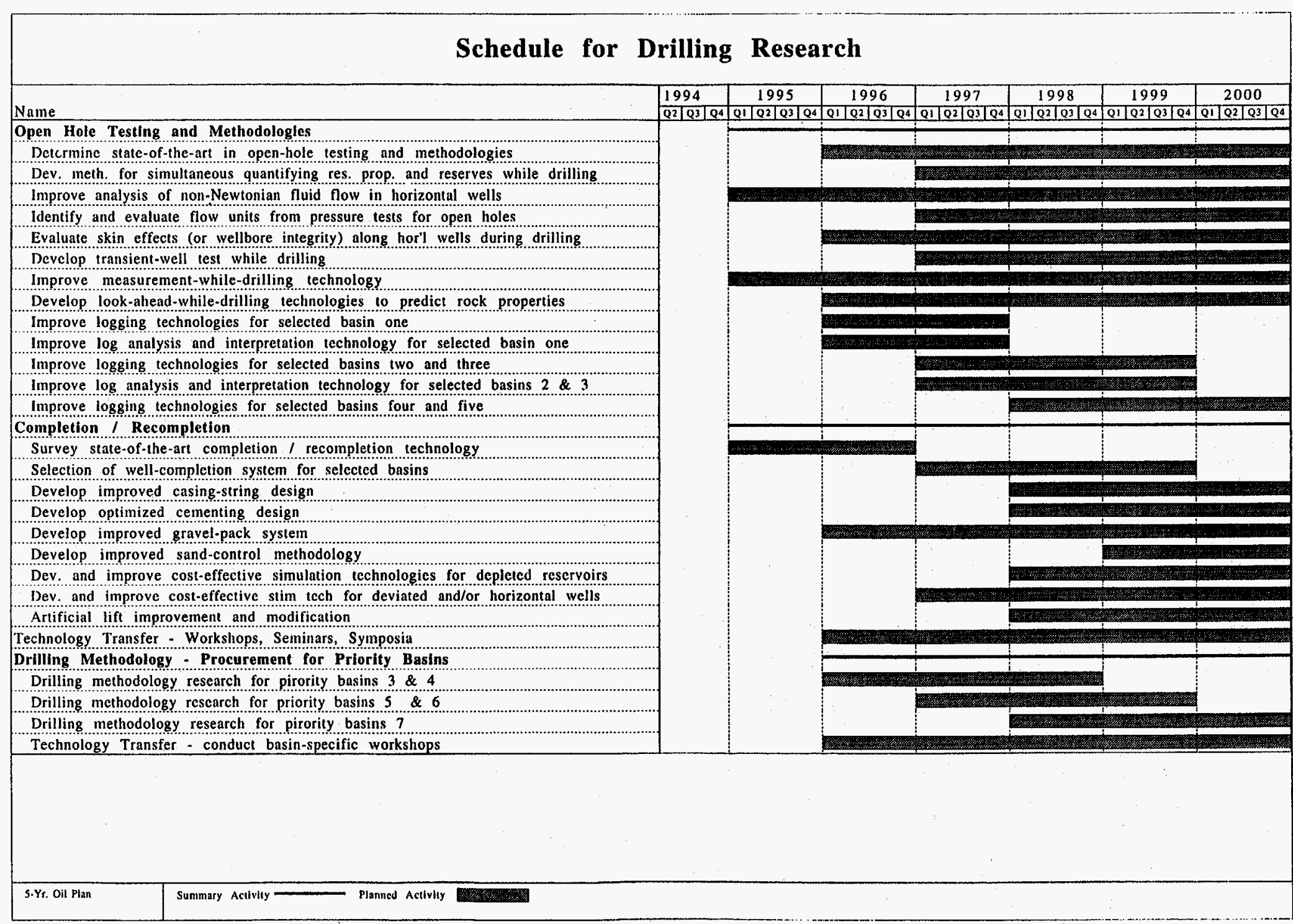


Figure 2.3.9 Key Actlvilles and Timing for Risk-Based Decision Management

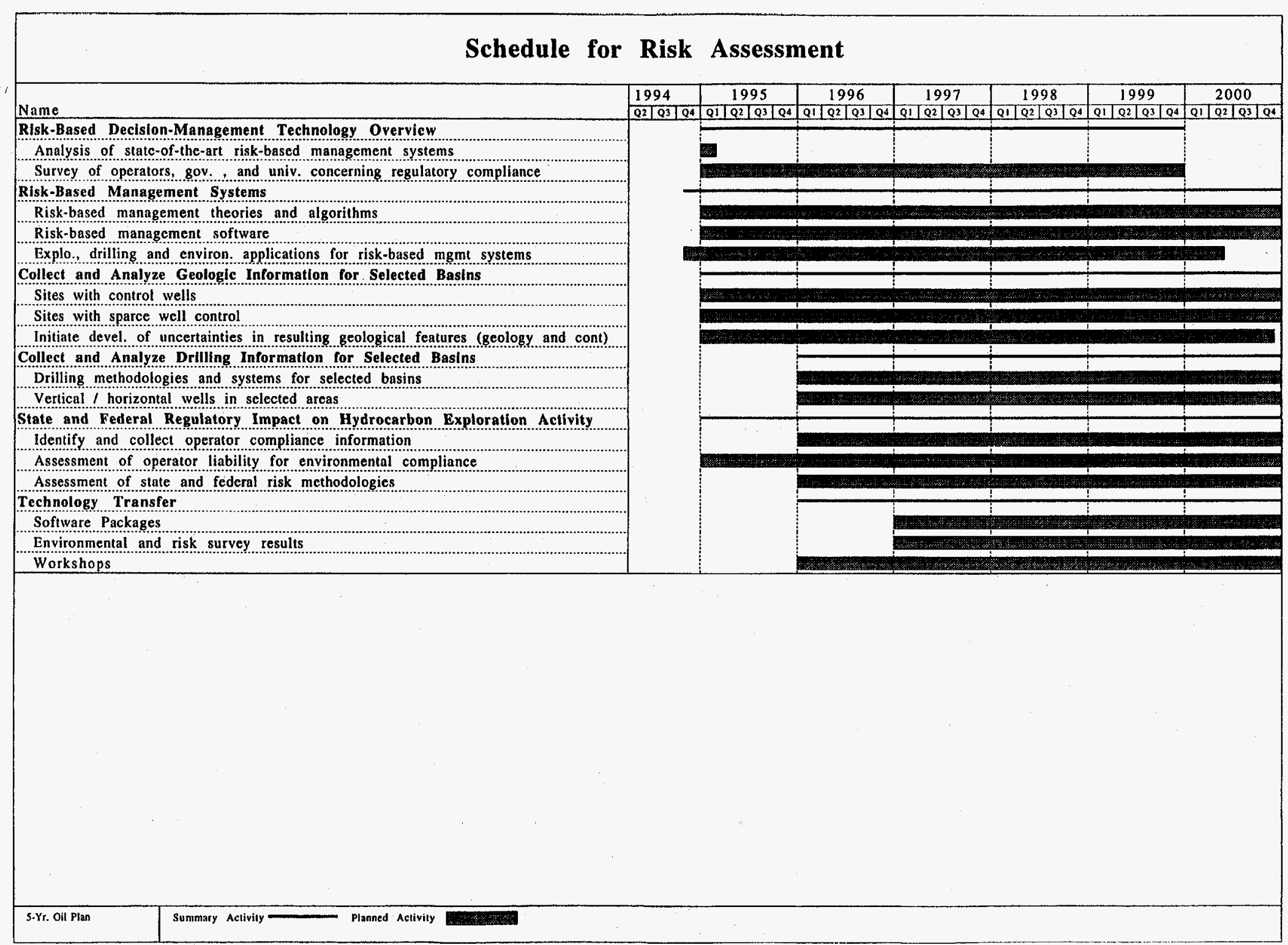




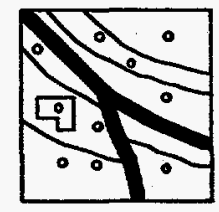

Table 2.3.2 Measures of Effectiveness

\begin{tabular}{|c|c|}
\hline Planned Research Activities & Metrics \\
\hline $\begin{array}{l}\text { - Basin analysis } \\
\text { - Refined geologic and engineering model } \\
\text { - Completion engineering } \\
\text { - Developmentetion strategies } \\
\text { models } \\
\text { - Theories and algorithms for risk analysis } \\
\text { - Risk analysis of environmental factors } \\
\text { related to exploration, drilling, production }\end{array}$ & $\begin{array}{l}\text { - Improved technologies/products that } \\
\text { reduce exploration and drilling costs, } \\
\text { defer abandonments, increase success of } \\
\text { exploration and drilling activities, } \\
\text { improved risk analysis of projects and } \\
\text { protects environment } \\
\text { - Number of completed basin analyses } \\
\text { - Success ratio for exploration wildcat wells } \\
\text { in mapped areas } \\
\text { - Success ratio for development wells in } \\
\text { mapped areas } \\
\text { - Increase in drilling activities in mapped } \\
\text { areas } \\
\text { - Recovery rates in new wells } \\
\text { - Improved drilling rates (feet per day) } \\
\text { - } \text { Decress ratio for exploration wells } \\
\text { costs } \\
\text { - Additional reserves from new discoveries } \\
\text { in mapped areas } \\
\text { - Environmental impacts of new wells } \\
\text { Domestic oil and gas production } \\
\text { - Number of jobs created in oilfield-related } \\
\text { areas } \\
\text { Number of independents with increased } \\
\text { awareness, interest, and participation in } \\
\text { pilot projects } \\
\text { - Number of requests for software tools } \\
\text { - Number of contacts for information about } \\
\text { the program } \\
\text { - Number of technical publications } \\
\text { disseminated } \\
\text { Number of cooperative research and } \\
\text { development agreements generated per } \\
\text { year } \\
\text { cooper of companies contacting the } \\
\text { agreements } \\
\text { bumber of technical assistance requests } \\
\text { Institute for Petroleum and Energy } \\
\text { Research }\end{array}$ \\
\hline
\end{tabular}




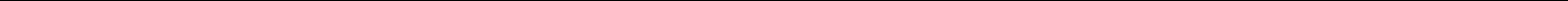




\subsection{ANALYSIS \& PLANNING}

\subsubsection{Program Overview}

The mission of Analysis and Planning is to support prudent, cost-effective management of the Oil Program through four functions: planning, evaluation, analysis, and quality assurance. The planning function includes defining priorities, developing strategic and implementation plans, and establishing reasonable measures of effectiveness. The evaluation function encompasses developing and implementing monitoring systems, reporting relevant discrepancies, and collecting data to measure the program's effectiveness. The analysis function includes developing and maintaining a comprehensive analytical capability to provide information to internal and external clients. Quality Assurance is a nonprogram function that seeks to maintain a well-coordinated staff and satisfied clients. As a crosscutting, tightly integrated network of functions, this area of the program is supported by expertise from all of the program's research areas, and its products reflect the perspective of the entire program. Figure 2.4.1 shows the work breakdown structure for Analysis and Planning.

\subsubsection{Goals and Objectives}

\section{Goals for Planning Activities:}

- Develop an implementation plan that improves effectiveness and responsiveness to stakeholders.
- Add customer input that includes independents and $\mathrm{Na}$ tive Americans (FY 1996).

- Integrate the planning information system with the program monitoring system and make both systems online at Fossil Energy headquarters (FY 1997).

- Integrate evaluation results into the planning cycle (FY 1998).

\section{Goals for Evaluation Activities:}

- Develop a system of metrics for each area that identifies measures of effectiveness and the processes for collecting information (FY 1997).

- Develop external indices, surveys, and state-of-the-art studies that describe the baseline of technologies targeted by the program (FY 1997).

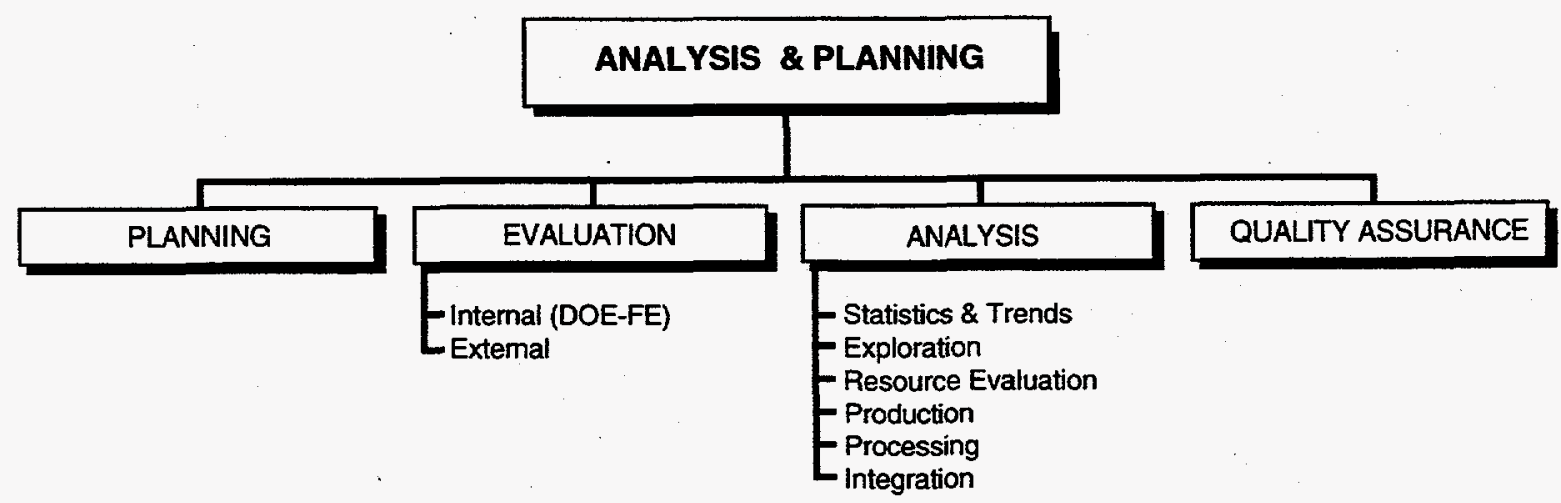

Figure 2.4.1 Analysis and Planning Work Breakdown Structure 


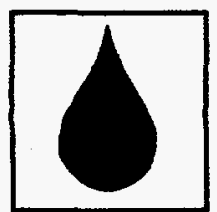

- Measure the impact the program has on its customers and feedback the information into program management and planning.

- Organize annual meetings of the program researchers to facilitate technical exchange as well as to evaluate progress.

\section{Goals for Analysis Activities:}

- Improve the resource database to include information representing $75 \%$ of domestic oil in place (FY 2000).

- Have analytical models for all the technology areas and geographic areas (FY 1998).

- Major update and expansion of software tools for independents (FY 1998).

- Develop data repository for oilfield information that would otherwise be discarded (FY 1997).

- Satisfy our customers by using analytical tools and data to analyze policy, program, technology, and development alternatives.

\subsubsection{Planning}

The last published strategy for the Oil Program was in 1990, the Oil Research Program Implementation Plan. The strategy has now been revised to meet the expanded roles indicated by Congress in the Energy Policy Act of 1992 (EPACT), the President in the Domestic Natural Gas and Oil Initiative (DNGOI), and the Secretary of Energy in Fueling a Competitive Economy Strategic Plan. The new strategy has expanded the scope of the program to include exploration, drilling, risk assessment, oil processing, and international activities, as well as expansion and acceleration of the technical areas and crosscutting areas previously included in the oil program. This Oil Plan is one of the tasks of the planning function. The expanded program envisions an annual update of the Oil Plan. An important new task for the planning function is specifying measurement criteria for the impact on the customers of the program, linking external factors to program activities and products.

\subsubsection{Evaluation}

The evaluation function is concerned with monitoring both internal and external achievements of the program. Although this function has been accomplished for internal progress, FY 1996 is the first year this function will be funded to monitor and to estimate the impact the program has on its customers. Systems will be developed and used to monitor the application of resources (time, money, and personnel) for project activities. A new internal monitoring system upgrades the current financial monitoring system to integrate with the planning systems. For external monitoring, the function is concerned with comparing changes to well-established baselines and relating those changes to program products. Although internal monitoring of financial resources has been a priority in the past, assessing the impact of the program and meeting strategic goals and objectives has been limited. External evaluation will require new methods, data, and models. Although the goal is to quantify the effects, a qualitative measurement may be all that can be obtained for many of the technological areas.

\subsubsection{Analysis}

A comprehensive analytical capability to provide sound, objective information on the potential impact of the technologies in the program is needed to consider choices that determine the success of the program. This capability is addressed by six areas:

- Statistics and trends

- Exploration

- Oil production

- Resource evaluation

- Processing

- Program integration

Environmental regulations is a crosscutting factor involved in all these areas. Figure 2.4.2 shows the interrelations of all these components. 


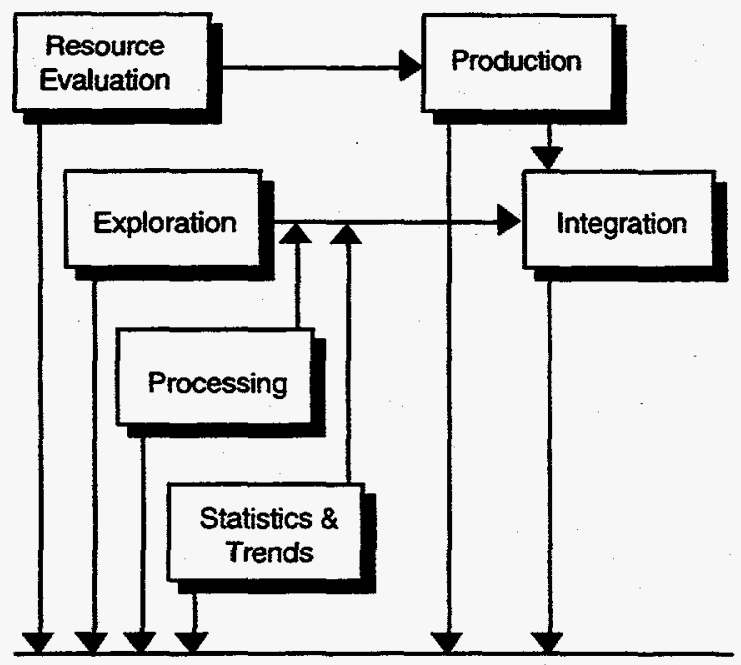

Outputs:

Production Potential Policy Impacts

Revenue Estimates

Employment; Estimates Refinery Capacity \& Utilization Potential Impact of Technologies

\section{Figure 2.4.2 Analytical Tools Working Together or Individually}

Statistics and Trends. Information on the aspects of the industry will be obtained and made available to all Oil Program areas. Continuing analysis of the industry statistics and the technological development will identify trends that affect the technology areas of the Oil Program. Selected statistics will be online in the future.

Information on petroleum fields is being lost as companies downsize. A major initiative will be to save this information from destruction by instituting a national petroleum data repository. This will be a joint project with industry to maintain the infrastructure of the industry in the face of the rapid shifting of properties between operators.

Resource Evaluation. An important portion of the current analytical capability is the reservoir database. Although this database is the most complete and well researched of its kind for the United States, it was intended for use with enhanced oil recovery predictive models to assess enhanced oil recovery potential. The information in the database represents less than $70 \%$ of the known oil resource, so improvements in the number of reservoirs and the depth of the information in the database is desirable. The range of the current data indicates improved data is needed for offshore areas, Louisiana, Oklahoma, Arkansas, Kansas, California, Missouri, and areas that are currently under review, such as the Appalachia area. The direct analysis of these data identifies the appropriate priority for the geologic and geographic targets for research. When used with models, estimates are made of the potential recovery from the defined resource.

Exploration. Discovering more oil is a new goal for the Oil Program. A new methodology will be developed for assessing the potential of this program initiative and the sensitivity to alternative technical solutions for reaching this goal.

Production. Process-predictive models are used to estimate the potential of enhanced oil recovery and advanced secondary recovery (ASR) under varying economic and technological assumptions. The enhanced oil recovery models were developed in the late 1970s and early 1980 s and are in need of technical review and revisions. The technologies covered by the models need to be broadened as well. Although the advanced secondary recovery models are more recent, they also need to be reviewed, revised, and broadened. DOE has made most of these models available to the public in a version designed for mainframe computers and modified versions for DOS-based microcomputers. The interface limits the use of the public domain models to those users knowledgeable in these computer systems. New releases of the models will update the technology and target less sophisticated users with an improved user interface as well.

DOE has a successful suite of public domain simulators, such as BOAST, that have been widely used in academia and industry to model 


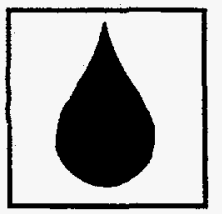

oil production. Supporting, updating, and expanding these simulators to meet the needs of independent petroleum producers will be accomplished during the planning period. Public domain engineering software that can assist independent producers in solving production, completion, and other field-related problems will be collected and integrated into a easy-to-use suite.

Processing. The Oil Program now emphasizes processing, refining, and upgrading portions of the petroleum industry. This adds the requirement of analyzing the technical areas. The development of an analytical model that differentiates outputs related to environmental factors and oil gravity inputs is a specific objective during the period.

Integration. Combining the models and statistics into an integrated system yields a useful policy analysis tool. Using this tool for internal clients as well as external clients has provided and will continue to provide insight into the development of the technologies in the Oil Program as well as policy alternatives affecting the petroleum industry. Currently, the system considers interrelations, economics, resource assignment, process assignment, and project timing. Integrating exploration, conventional production, processing, environmental, and offshore data into the system will be a challenge. Reviewing and upgrading the interactions of the existing components will allow reasonable analysis of the interdependencies of the factors affecting the petroleum industry.

\subsubsection{Quauty Assurance}

Although assuring that a program runs efficiently and that high-quality products are generated is a normal management goal, the complexity of the program and the relationship between product quality and program effectiveness justifies specific inclusion of this function in the Oil Plan.

A continuing survey of products and services will be combined with a benchmarking process to determine the trend of quality. A customer focus and satisfaction program will be developed and implemented with the necessary feedback to management. A process quality program will also be developed.

\subsubsection{Stakeholders}

The Oil Plan is driven by the concerns and consideration for key customers and stakeholders. For Analysis and Planning, these key people include:

- U.S. taxpayers: the petroleum consumer, the petroleum producer, the petroleum refiner, the petroleum and related environmental regulator, and the investor

- Businesses and facilities that conduct the research in the Oil Program: Bartlesville Project Office, Metairie Site Office, Fossil Energy headquarters, National Institute for Petroleum and Energy Research, universities, independent and major producers, contractors

- Federal agencies: United States Geological Survey, Energy Information Administration, Minerals Management Service, Bureau of Land Management, Treasury, United States Forest Service, Environmental Protection Agency and others

- State, local, and Native American governments

- Congress: House and Senate Energy Committees, key staff, and members of Congress who initiate petroleum-related legislation

- The President and the administration

- Trade and professional interest groups

\subsubsection{IMPACTS}

Analysis and Planning affects the entire Oil Program by setting the course of action for all areas in service to all customers, internal and external.

Planning Impact. While implementing the program drivers (presidential, congressional, and departmental strategies and goals), the planning function provides the framework and guidelines throughout the planning cycle. The intended 
impact is a plan that targets research efforts to areas where the federal government can encourage the production, discovery, and refining of more oil while improving or at least maintaining the environment in a cost-effective manner.

Evaluation Impact. This part of the program establishes discrepancy analysis (program vs. plan) and a monitoring system for both internal and external clients. The desired impact is a more effective program that improves on successes and corrects its failures.

Analysis Impact. The analysis functions will provide industry with data and software tools to make cost-effective decisions that improve operations and recover more oil. Extensive analyses sharpen the focus of the Oil Program and assist in setting priorities that accomplish the Oil Program's mission. Through models and expertise, the analysis function continues to affect the development of policies that relate to the nation's oil resource.

Quality Assurance Impact. Quality assurance strengthens management support, increases data reliability, and promotes Total Quality Management (TQM), which creates strategic quality planning, training and recognition, employee empowerment and teamwork, improved products and services, and exceeds customer requirements and expectations.

\subsubsection{BUDGet}

The budget for the Analysis and Planning area is summarized in Table 2.4.1 and Figure 2.4.3. As stated in Section 1, this Oil Plan is developed for an unconstrained budget that is bounded by the scope of goals set by Congress, the President, and the Secretary of Energy.

\subsubsection{SCHEDULE}

Figure 2.4.4 shows key activities and their timing in the Analysis and Planning area.

\subsubsection{Measures of Effectiveness}

Table 2.4.2 is a summary of the activities in the Analysis and Planning Program and the metrics for evaluating these activities.

Planning Measures. The effectiveness of the planning effort is shown by the success of the Oil Program in achieving its objectives and goals. A second measure is meeting the internal requirements of the government budget and planning deadlines. Another measure is whether the industry accepts the plan as beneficial and whether Congress is willing to fully fund the Oil Program. Industry attitudes will be determined by a customer survey administered by the Quality Assurance area.

Evaluation Measures. One key to this function will be identifying a baseline for the various technologies within the Oil Program and then monitoring the deviation from those baselines. The measure is the number of technologies tracked and the quality of the measurements. Also, a customer survey will measure how the industry perceives the benefits of the research conducted by the Oil Program.

Analysis Measures. The effectiveness the analytical function is more complex than other Analysis and Planning functions. A majority of the requested funds are for a data repository that captures oilfield information (logs, core analysis, maps, well tests, etc.) that are being lost due to changing ownership and downsizing within the industry. A measure of the effectiveness of the program is the volume of data collected and the volume of information that is being requested and disseminated by this repository. This measure is also appropriate for other DOE public databases such as the field demonstration, enhanced oil recovery project, and Crude Oil Analyses Databases.

The public domain software tools developed and supported by the analysis function are effective when their use is broad and appreciated. 
Table 2.4.1 Budget for Analysis \& Planning

\begin{tabular}{lcc}
\hline & $\begin{array}{c}\text { FY 1994 } \\
\text { Appropriated } \\
(\$ 1,000)\end{array}$ & $\begin{array}{c}\text { FY 1995 } \\
\text { Appropriated } \\
(\$ 1,000)\end{array}$ \\
\hline Functions & 550 & 505 \\
Planning & 0 & 0 \\
Evaluation & 2,539 & 3,915 \\
Qualysis & 0 & 0 \\
\hline Totals for Analysis \& Planning & 3,089 & 4,420 \\
\hline
\end{tabular}

1994

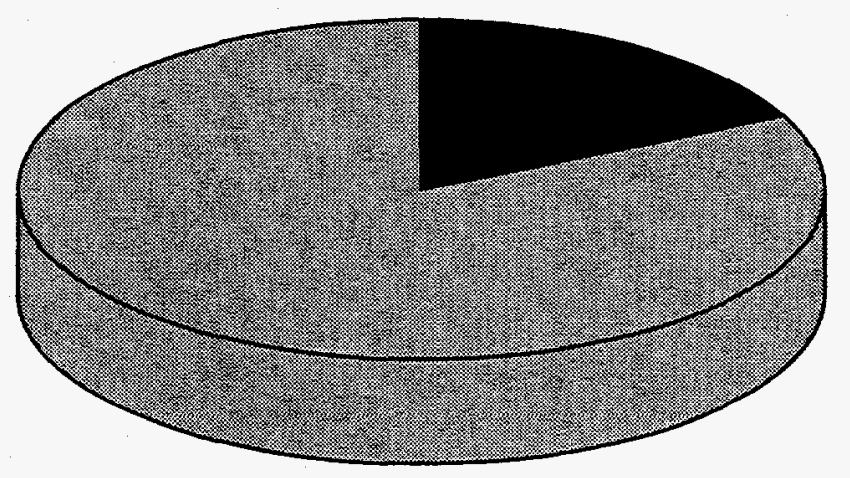

1995

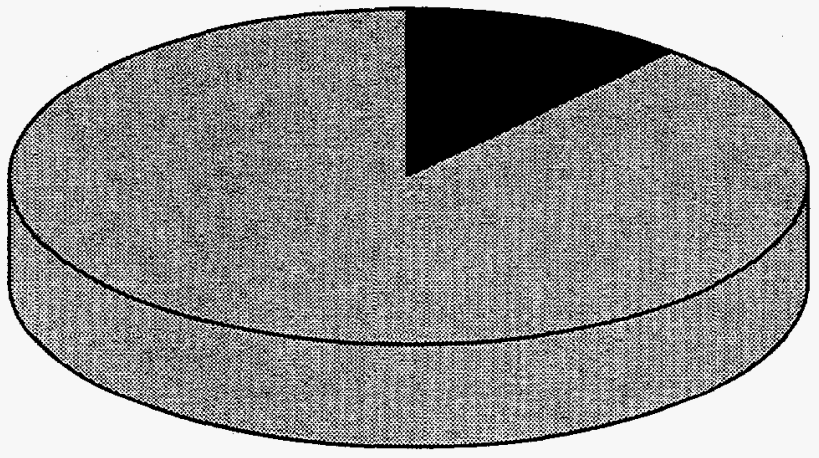

Figure 2.4.3 Analysis \& Planning Budget
Planning

日 Evaluation

Analysis

Quality Assurance

(Nonprogram

Funding) 
Requests for developed software tools is an appropriate measure.

The number of requests for the tools to perform studies beyond the oil programmatic studies is an excellent measure of the effectiveness and reputation of the tools. The reputation within the petroleum industry is measured by the number of times the results are referenced, the number of copies of studies requested, and the general reliance of industry and government of the studies to set strategy-most major oil companies made enhanced oil recovery a central part of their strategy after the 1984 National Petroleum Council enhanced oil recovery study.

Quality Assurance. Since the focus of this function is streamlined communication and good management, measures of success in the other program areas will determine the effectiveness of this function. Also, a customer survey will be administered in order to ensure that the work products and services (research) conform to our customers' requirements. 
Figure 2.4.4 Key Activities for the Analysis \& Planning Program

\section{Schedule for Analysis and Planning}

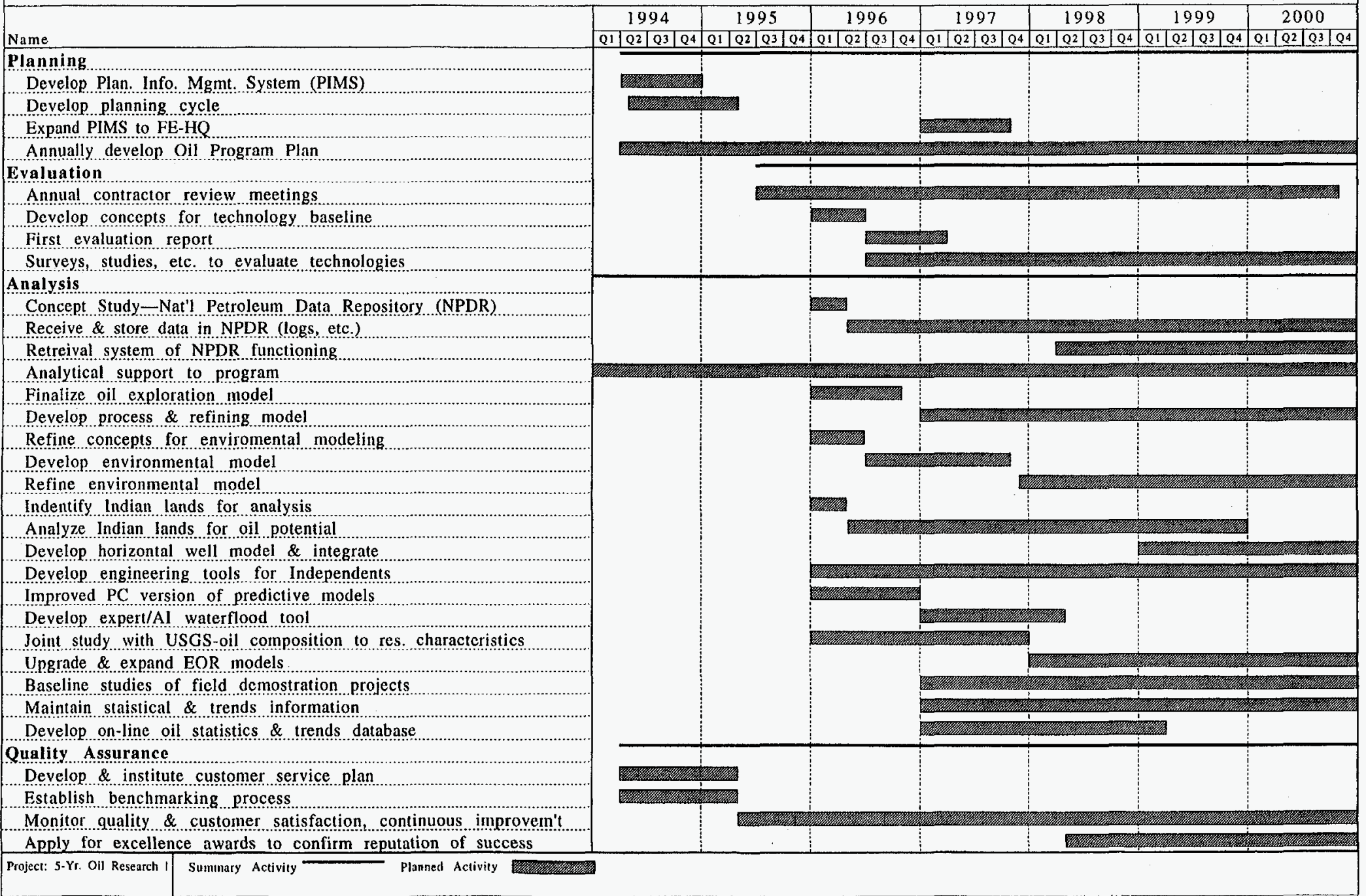




\section{Table 2.4.2 Measures of Effectiveness for the Analysis \& Planning Program}

\begin{tabular}{|c|c|}
\hline Analysis \& Planning Activities & Metrics \\
\hline \multicolumn{2}{|c|}{ Planning } \\
\hline $\begin{array}{l}\text { - Oil Plan } \\
\text { - Internal planning cycle } \\
\text { - Internal inputs } \\
\text { Internal planning information system }\end{array}$ & $\begin{array}{l}\text { - Technologies/products that reduce costs, defer } \\
\text { abandonments, increase success of E\&P } \\
\text { activities, improve processing and utilization, } \\
\text { and protect environment in accordance with } \\
\text { customer priorities } \\
\text { - Plan timed to meet the requirements of the } \\
\text { congressional budget and planning cycle } \\
\text { - Customer awareness of the plan } \\
\text { - Customer agreement with the goals and } \\
\text { intended impacts } \\
\text { - Internal availability of information on the } \\
\text { program plan }\end{array}$ \\
\hline
\end{tabular}

\section{Evaluation}

- Contractor review meetings to evaluate program progress and develop synergy within the program

- Development of metrics that measure targeted impacts above a baseline

- Measure program impacts on industry, Native Americans, and other customers

- Feedback to improve plan and implementation
- Program contractors working toward program goals, minimizing duplicate efforts, and supporting each others' research

- Acceptable estimates of the baseline for desired impacts

- Incremental improvement above the baseline that can be attributed to the Oil Research Program

- Deficiencies and successes of the program are identified

- Deficiencies minimized, successes leveraged

Analysis

- Acquire and develop data on oil resource

- Develop and maintain analytical tools to analyze the domestic oil resource under different technology, economic and policy alternatives

- Expand analytical tools for direct application by oil program customers

- Conduct studies for internal use to analyze program and policy alternatives

- Analyze Native American lands for potential and best application of technology

- Cooperative analytical work with other agencies

- Data contributed by the oil industry to National Petroleum Data Repository
- Estimated improvement in the coverage of the resource by the oil resource database

- Degree of coverage of the analytical tools in modeling the key components of the oil program

- Satisfaction of internal and external customers with the quality of the analytical work

- Number of requests for software tools

- Number of technical assistance requests by industry and other government agencies for use of the analytical tools

- Amount and quality of data in the National Petroleum Data Repository as well as the amount of information disseminated 


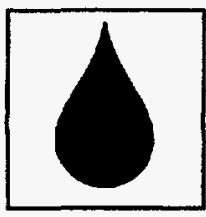

\section{Table 2.4.2 Measures of Effectiveness for the Analysis \& Planning Program (continued)}
Analysis \& Planning Activities
Metrics

Quality Assurance

- Survey quality operational results

- Develop and implement Customer Focus and Satisfaction Program
- Dollars saved per employee due to new ideas \& methods

- Number of problems identified in process and corrected

- Number of employees participating in cost effectiveness

- Percentage of corrective action requests not completed vs. completed

- Number of customer complaints

- Rework costs

- Percentage of outputs delivered on schedule

- Customer Satisfaction Survey showing trends in awareness of the program and the quality of its products 


\subsection{TECHNOLOGY TRANSFER}

\subsubsection{Program Overview}

As DOE's Oil Technology Transfer Program has expanded and altered its approach to address program and operational changes, priorities have been identified. Internal priorities are improved document control, electronic publication capability, and maintenance of up-to-date stakeholder contact and program information databases. External priorities include expanded contact with the petroleum community, particularly operators and independents, and improved domestic and international outreach.

The mission of the technology transfer program is to deliver the products of the oil program to our customers and stakeholders. This will be done through a comprehensive and effective program that:

- Accelerates the application of existing and new technologies and information to increase environmentally acceptable production and processing of U.S. oil resources

- Expands exports of U.S. petroleum exploration, production, processing, and environmental technologies, equipment, and services

- Improves public understanding of the roles of DOE in achieving energy security

An aggressive Technology Transfer Program is being implemented to achieve these goals. The Technology Transfer Program is divided into four major areas:

- Support for dissemination of information
- Stakeholder outreach to transfer technologies to the petroleum industry from $\mathrm{DOE}$ and other programs

- International activities involving conferences and oil and gas technology centers

- Educational efforts supporting enhanced science and technical education at all levels.

Figure 2.5.1 shows this work breakdown structure.

\subsubsection{Oll Program Imformation SUPPORT}

Oil research information has been a basic function of the Bartlesville Project Office since 1918. Technical project reports are published and disseminated to a wide audience of researchers, producers, and other interested stakeholders. Beginning in 1994, improvements were made in publication and dissemination of information.

\section{Goals for Technology Transfer Support:}

- Improve the document control system.

- Develop a more efficient system and improve methods of tracking, retrieval, and dissemination of documents.

- Convert printed publications to electronic form to provide access to online searches and print-on-demand systems that will eliminate the need for storing multiple report copies.

- Compile a comprehensive database of information on U.S. independent oil producers to facilitate contact, needs analysis, and other tasks.

- Compile a database of contract information, current status, and progress on all DOE 


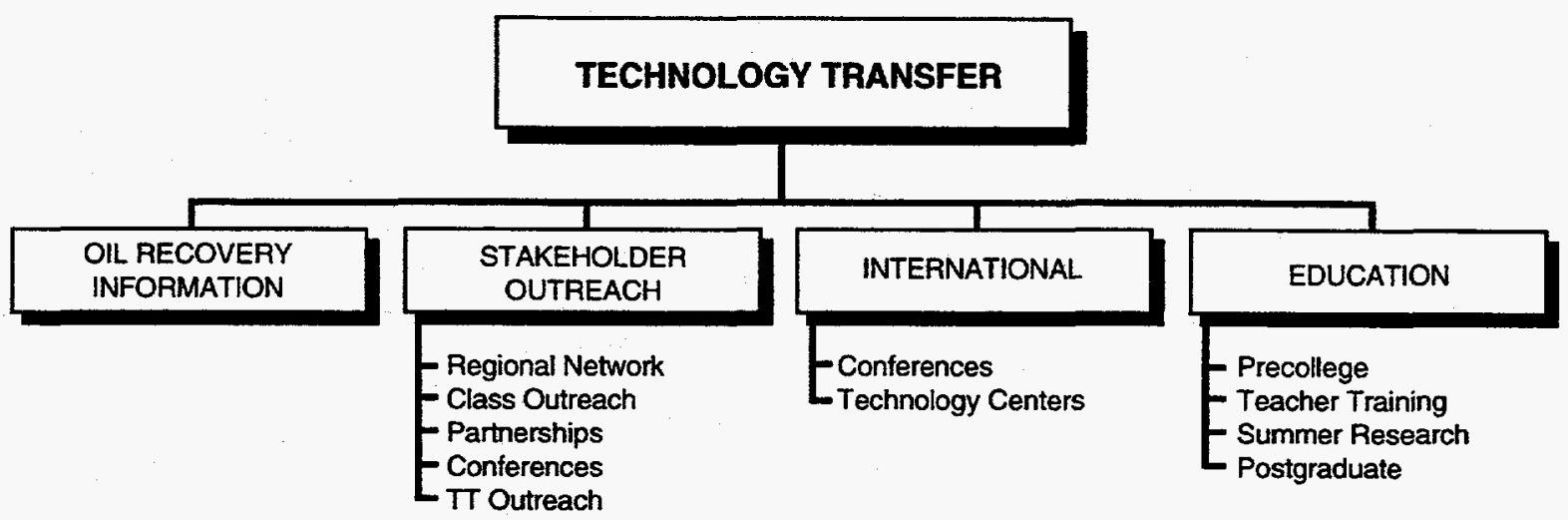

Figure 2.5.1 Technology Transfer Work Breakdown Structure

projects, with topical information for immediate retrieval to expedite requests from Headquarters and other offices and agencies.

- Develop capability for document preparation that reduces the time required to publish.

- Develop information products such as video tapes, newsletters, and electronic bulletin boards.

\subsubsection{Stakeholder Outreach}

The success of the DOE Oil Program will depend on effectively moving the products of the program to customers. More than any other function, outreach to stakeholders will provide the mechanism for transfer (Fig. 2.5.2). Technologies developed by DOE and other programs are transferred to end users with appropriate backup information to facilitate and to encourage their application. Successful transfer will result in an increased supply of improved domestically produced and refined oil products for the nation.

Class Program Outreach. The Technology Transfer Program will augment the existing activities required for each Reservoir Class project.

\section{Goals of Class Program Outreach}

- Develop outreach campaign, including brochures, a newsletter, presentations, and other multimedia tools promoting application of Class Program technologies.

- Establish a technology transfer agent to facilitate these activities.

- Develop and conduct workshops and field trips on technical subjects appropriate to the reservoir class, with the cooperation of project contractors as available.

- Develop a video to describe the activities of the Class Program. Develop a comprehensive database of Class Program operators.

National Technology Transfer Network. A national network connecting regional centers will provide oil operators, particularly independents, with technologies keyed to the specific needs of their region. Funding for these activities will be cost shared by DOE, the Gas Research Institute, industries, associations, and state agencies.

\section{Goals of National Technology Transfer Network:}

- Implement National Technology Transfer Network. 

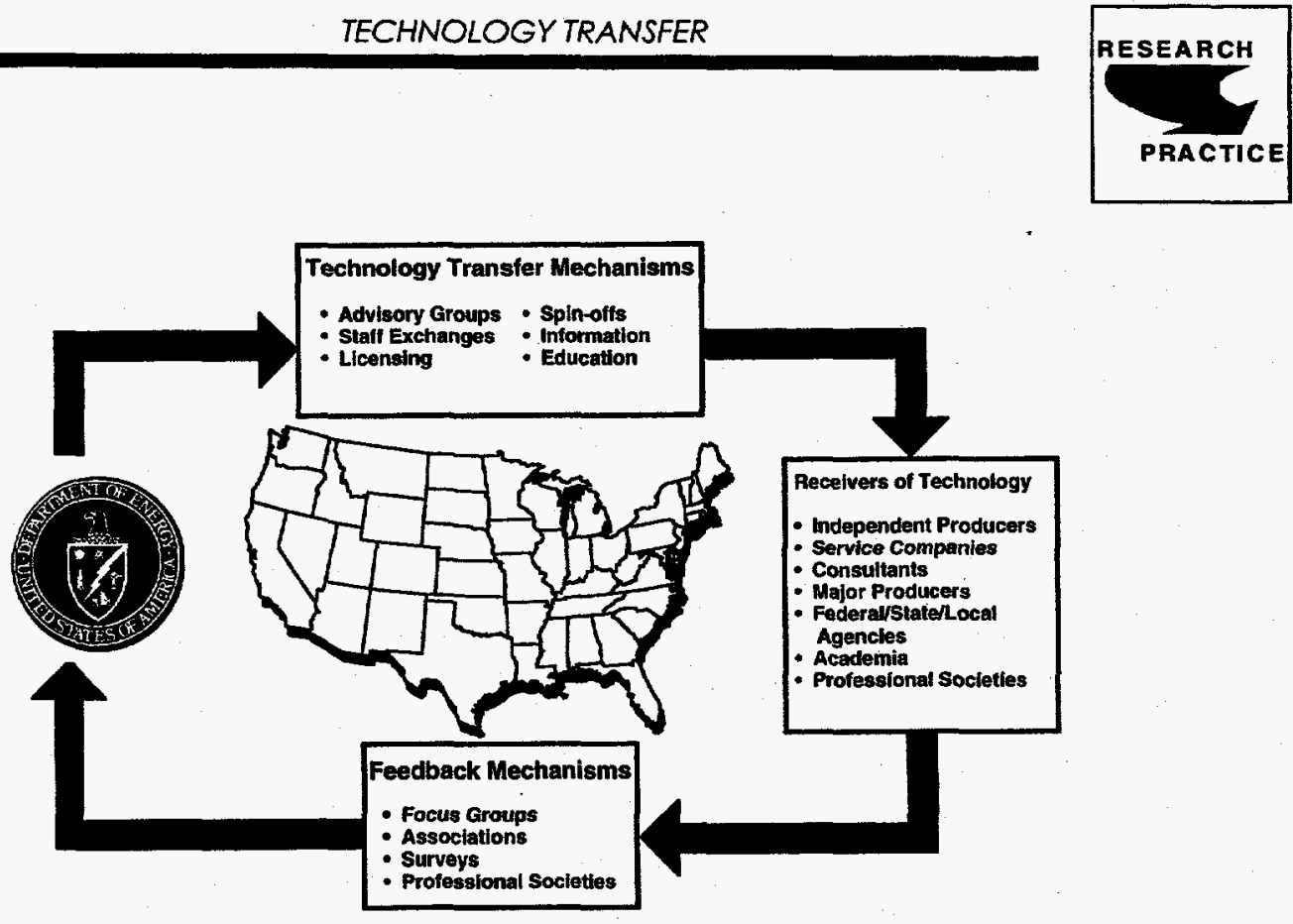

Figure 2.5.2 Technology Transfer, the Pipeline to Key Stakeholders

- Support National Technology Transfer Network in the implementation of technology transfer activities.

Technology Transfer Outreach. This outreach effort will focus on identifying and serving the needs of those stakeholders not directly targeted by other DOE technology transfer programs, including Native American tribes, oil operators not affiliated with industry associations, and small business researchers.

\section{Goals of Technology Transfer Outreach}

- Establish a stakeholder review panel to facilitate communication with other technology transfer networks.

- Complete a stakeholder market research study to identify high-priority technology transfer needs.

- Develop a database of contacts in the heavy oil refining industry to facilitate the transfer of heavy oil and residuum processing technologies.

- Complete a study to determine ways to accelerate the development of oil resources on Native American tribal lands.
- Develop a methodology to measure the effectiveness of the Technology Transfer Program.

Natural Gas and Oil Partnership. The Natural Gas and Oil Technology Partnership facilitates the development and transfer of technology to the petroleum industry through cooperation with national laboratories. Cooperation between the national laboratories and NIPER will be expanded to enhance technology transfer and support initiatives such as the Advanced Computational Technology Initiative (ACTI).

\section{Goals of Natural Gas and Oil Partnership}

- Augment technology transfer efforts of the partnership through wider distribution and notification of technology results, publications and meetings, using industry databases and contact lists.

- Support transfer of technologies developed as part of ACTI.

Conferences. DOE's conference activities will be expanded to include meetings that are opportunities to promote the DOE Oil Program, 


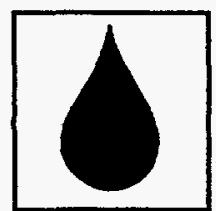

to increase dissemination of material, and to solicit input from the production and research communities. Topical exhibits will be targeted to key stakeholders.

\section{Goals of Conferences:}

- Support conferences and symposia on reservoir characterization, microbial enhanced oil recovery, petroleum engineering education, and improved oil recovery.

- Support other conferences as appropriate.

\subsubsection{InTERnATIONAL}

The movement of U.S. major oil company activities overseas presents an opportunity to create jobs and to increase U.S. competitiveness internationally. The Oil Program will include three projects that will foster international partnerships, promote international awareness of U.S. competitive interests, and create opportunities for U.S. industry to provide services and equipment.

U.S.-Russian O\&G Technology Center. DOE will provide administrative, procurement, and legal support to help the Russian oil industry establish and operate an Oil and Gas (O\&G) Technology Center in Tyumen City. Assistance will be provided to assess the needs of the Russian petroleum industry and to coordinate delegate visits. This is a cooperative effort between DOE and the U.S. Agency for International Development.

\section{Goal of U.S.-Russian OEG Technology Center:}

Establish a Russian-American Oil and Gas Technology Center to serve as a focal point for identifying U.S. technologies and services that are potentially applicable for export to the Russian federation and Russian technologies suitable for transfer to U.S. industry.

International Conferences. DOE will assist in organizing and sponsoring international conferences to increase awareness of U.S. technologies and research in foreign countries and to facilitate international cooperation on gas and oil technology development.

\section{Goal of International Conferences:}

Organize international conferences addressing gas and oil issues in key producing countries.

Support for International Activities. Various international activities will be conducted to facilitate international exchange of data and technology, to increase international collaboration, and to support international agreements.

\section{Goals of Support for International Activities:}

- Support American Geological Institute's Russian Student Exchange Program by coordinating internships at NIPER.

- Support activities related to bilateral and multilateral agreements

\subsubsection{Educational EfForts}

As part of the commitment to improved science and technical education, DOE will pursue several avenues to enhance education at the elementary, high school, and university levels.

Education Outreach. DOE will assist public education by sponsoring teacher training in innovative science curricula, organizing DOE's annual Oklahoma Science Bowl, and fostering partnerships with industry, scientific and professional associations, and civic organizations to support science education.

\section{Goals of Education Outreach:}

- Conduct teacher training sessions.

- Conduct three Earth Science Leadership Institutes (FY 1994-96), featuring "Train the Trainer" teacher workshops.

- Cooperate with Associated Western Universities to provide summer research internships for teachers and students selected from a national pool. 


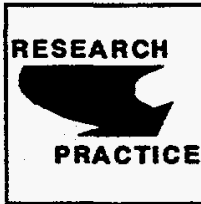

- Conduct theDOE Science Bowl competition at the state level and support the winning teams in the national contest.

- Develop a new Native American education initiative, a long-term project supported by supplemental funds that will employ innovative science and environmental curricula to enhance the education of tribal youth, to support energy and environmental education, and to accelerate the development of tribal oil resources.

Summer Student Program. This program provides career-enhancing summer research experience for undergraduate university science and engineering majors through internships at NIPER.

\section{Goal of Summer Student Program:}

Conduct a summer student program at NIPER.

Personnel Exchange Program. The purpose of this new project is to seek out candidates in industry, academia, and government to participate in exchange internships with Bartlesville Project Office/NIPER in areas related to petroleum technology and their work specialty.

\section{Goal of Personnel Exchange Program:}

Establish a Personnel Exchange Program that fosters mutual learning experiences in petroleum technologies.

\subsubsection{Work for Others, CRADAs, AND LICENSING}

Additional technology transfer mechanisms used by DOE include conducting work for industry and other government agencies, implementing joint projects through Cooperative Research and Development Agreements (CRADAs), and licensing technologies developed under DOE's programs. Industrial partners can gain access to the specialized capabilities and expertise at DOE's laboratories through the Work for Others and CRADA programs. These programs directly affect the petroleum industry by supporting projects driven by industry's needs. Licensing stimulates application of technologies developed under DOE research programs.

\subsubsection{StaKehOLDERS}

Technology Transfer concentrates on delivering to key customers the technology to discover, to produce, and to effectively refine more domestic oil with a less detrimental effect on the environment. Successful implementation will maintain high-wage jobs that might be exported without this program. The key stakeholders for Technology Transfer include:

- U.S. taxpayers: petroleum producers, petroleum refiners, consultants, petroleum and related environmental regulators, and oil and gas investors

- Businesses and facilities that conduct research funded under DOE's Oil Program: Bartlesville Project Office, Metairie Site Office, Fossil Energy headquarters, NIPER, universities, independent and major producers, contractors

- State, local, Native American, and foreign governments

- Congress, the President, and the administration

- Trade and professional interest groups

- Most importantly, future generations

\subsubsection{IMPACTS}

The Technology Transfer Program crosscuts every element of DOE's National Oil Program. The outputs derived from these activities result in impacts to the domestic natural gas and oil industry, which then provides feedback for Analysis and Planning.

Among the outputs resulting from the Domestic Natural Gas \& Oil Initiative and Office of Gas and Petroleum Technology Programs and the EPACT requirements are analysis of the existing technology transfer program, a comprehensive oil technology transfer plan, and technology transfer guidance at every level of management. The impacts of these activities 


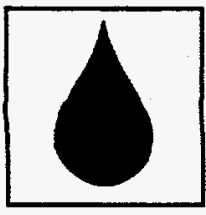

are useful $R \& D$ and analytical products packaged for the appropriate audience to accelerate and to expand the use of DOE products.

Technology Transfer Support Impacts. The outputs are reports, proceedings, publications, databases, software, and analytical tools that result in acceptance of products and materials in greater numbers by a more diverse client base. The impact of client application of technologies is:

- Reduced oil production costs

- Deferred abandonments

- Increased exploration activity

- Increased production, and processing

- Environmental protection

Class Program Outreach Impacts. The outputs are demonstration projects, databases, field trips, project reports, brochures, newsletters, presentations, and multimedia tools. The impact of these activities results in:

- Increased awareness, interest, and participation of producers in demonstration projects

- Reduced risk

- Increased interest in applying technologies

- Increased application of existing state-ofthe-art technologies and combinations of technologies to increase exploration, production, and environmental protection

National Technology Transfer Network Impacts. The outputs include case studies, reports, guidelines for effective consortia, problem identification, needs analysis, site visits, workshops, information, technological and analytical resources, technology assistance, and unbiased referrals. The impacts of these activities are:

- Increased consortia activity involving independents and intermediaries in R\&D and technology transfer

- Improved input to identify and prioritize $R \& D$ and technology transfer requirements and increased operator awareness of access to technology
- Faster, greater use of existing and emerging technology

Technology Transfer Outreach Impacts. The outputs include a stakeholder review panel to improve contact with Native American tribes, oil operators not affiliated with associations, and small business researchers. A database of contacts in heavy oil refining will facilitate the transfer of heavy oil and residuum processing technologies. The impact of these and other outreach activities will accelerate the development of oil resources on tribal lands, and promote greater use of existing and emerging technology.

Conferences Impacts. Participation in conferences, meetings, workshops, symposia, and colloquia present opportunities to transfer information and promote DOE's Oil Program to very targeted audiences. The impact of this activity results in increased awareness and interest in the program and application of technologies.

International Activities Impacts. These activities will establish a U.S. mechanism for transferring information, technical and instructional materials, and personnel exchanges. The impact of international conferences and the Russian Oil and Gas Center will enhance U.S. competitiveness in international markets and create jobs.

Education Initiative Impacts. These activities will broaden the science education base in the United States through summer intern programs, personnel exchanges, and education outreach. The impact of this stronger scientific foundation is to improve the competitive technological edge of U.S. businesses worldwide.

\subsubsection{BUDGET}

The budget for the Technology Transfer Program is summarized in Table 2.5.1 and Figure 2.5.3. As stated in Section 1, this Oil Plan is developed for an unconstrained budget that is bounded by the scope of goals set by Congress, the President, and the Secretary of Energy. 


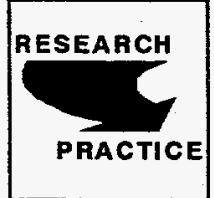

Table 2.5.1 Budget for Technology Transfer

\begin{tabular}{lcc}
\hline & $\begin{array}{c}\text { FY 1994 } \\
\text { Appropriated } \\
(\$ 1,000)\end{array}$ & $\begin{array}{c}\text { FY 1995 } \\
\text { Appropriated } \\
(\$ 1,000)\end{array}$ \\
\hline Functions & 1,308 & 2,799 \\
International & 300 & 0 \\
Education Efforts & 201 & 349 \\
\hline Totals for Technology Transfer & 1,809 & 3,148 \\
\hline
\end{tabular}

1994

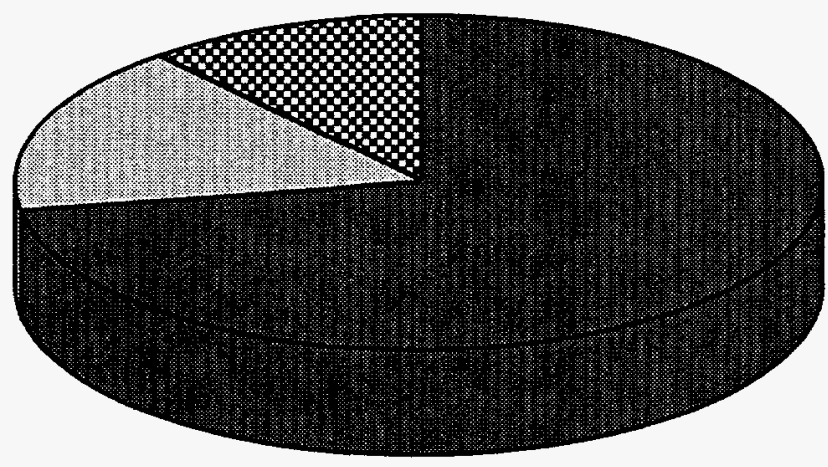

Stakeholder

Outreach

International

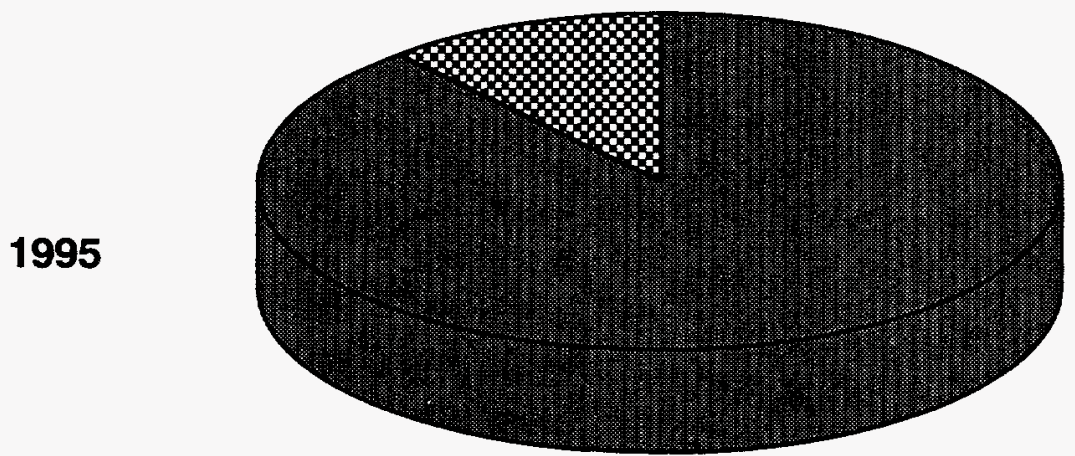

Education

Efforts

Figure 2.5.3 Technology Transfer Budget 


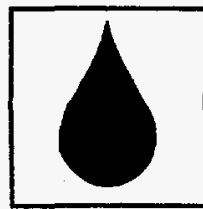

\subsubsection{SCHEdule}

Figure 2.5.4 describes key Technology Transfer Program activities and their timing.

\subsubsection{Measures of Effectiveness}

The ultimate success of DOE's National Oil Program depends on the effectiveness of the Technology Transfer Program. The goal of the program is to ensure that producers apply technologies to increase domestic oil production and reduce the rate of abandonment of our petroleum resources. Table 2.5.2 is a summary of the Technology Transfer Program activities and the metrics for evaluating these activities.

Information Support Measures. Success of information support activities will be measured by the efficiency of disseminating information to end users. Stakeholders will be surveyed to develop databases to target specific information to them to assess the effectiveness of the information distribution methods. The number of requests for information, reports, and software are a measure of effectiveness of the program.

Stakeholder Outreach Measures. The major component of the Technology Transfer Program is outreach to stakeholders -DOE's ultimate clients. Success of outreach efforts will depend on how well technology is delivered to end users by using new and existing networks of organizations, people, and computers. Effectiveness of the Class Outreach Program will be assessed by the number of producers who receive information, attend workshops, symposia, and field trips, and ultimately apply the new technologies in their own fields. Similar measures will be used to determine the effectiveness of other outreach efforts of the National Oil Program. Success of the nationwide technology transfer network will be measured by the number of producers who attend the problem identification workshops and focused technology seminars and information that is disseminated.

Measures of International Efforts. Success of international efforts will be determined by the number of people who attend international conferences, opportunities created for U.S. businesses in the international marketplace, and personnel exchanges. It is often difficult to measure the degree to which efforts by the federal government can increase competitiveness of U.S. businesses in foreign markets. The ultimate indicators will be the number of new business opportunities and domestic jobs created.

Measures of Educational Efforts. Efforts to educate students, teachers, and the public are an investment in our country's future that will produce both short-term and long-term benefits. While the success of efforts in education can be measured by the number of teachers who receive specialized training and students who gain knowledge about petroleum and environmental technologies through hands on experience, the ultimate measure will be the increased strength and diversity of the U.S. work force and increased public awareness of petroleum energy issues.

Ultimate success of DOE's Technology Transfer Program will be measured by its impact on increasing domestic production and jobs. The program must provide products to oil producers that help them apply the most effective methods to produce oil, opportunities to researchers to develop efficient technologies, and information to legislators and the public so they make informed decisions regarding our energy future. 
Figure 2.5.4 Key Activilies and Timing for Technology Transfer

\begin{tabular}{|c|c|c|c|c|c|c|c|}
\hline \multicolumn{8}{|c|}{ Schedule for Technology } \\
\hline Name & \begin{tabular}{|l|}
\multicolumn{1}{|c|}{1994} \\
$0102] 03184$ \\
\end{tabular} & \begin{tabular}{|l|l|}
1995 \\
010203104 \\
\end{tabular} & \begin{tabular}{|l|l|}
\multicolumn{1}{|c|}{1996} \\
$Q 102103104$ \\
\end{tabular} & \begin{tabular}{|l|l|}
\multicolumn{1}{|c|}{1997} \\
$Q 1\left[Q_{2}\left[Q_{3}\right] Q^{4}\right.$ \\
\end{tabular} & \begin{tabular}{|l|l|}
\multicolumn{2}{|c|}{1998} \\
01
\end{tabular} & 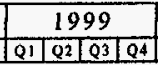 & 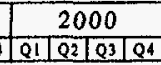 \\
\hline \multicolumn{8}{|l|}{ OIL PROGRAM INFORMATION SYSTEM } \\
\hline \multicolumn{8}{|l|}{ Develop a more efficient storage method for BPO publications } \\
\hline \multicolumn{8}{|l|}{ Develop improved process of issuance of BPO Progress Review } \\
\hline \multicolumn{8}{|l|}{ Convert Pprinted DoE Pubs to electronic format for storage/retrieval } \\
\hline \multicolumn{8}{|l|}{ Develop new lech transfer products for the industry (video newsleter, BBS, etc) } \\
\hline \multicolumn{8}{|l|}{ STAKEHOLDER OUTREACH PROGRAM } \\
\hline \multirow{2}{*}{\multicolumn{8}{|c|}{$\begin{array}{l}\text { Class out Reach Program } \\
\text { Develop outreach canpaign to promote application of class prog. techno }\end{array}$}} \\
\hline & & & & & & & \\
\hline \multicolumn{8}{|l|}{ Establish a tech transfer agen! to facilitate class outreach activities } \\
\hline \multicolumn{8}{|l|}{ Develop and conduct yorkshops and field trips on technichl subjects } \\
\hline \multicolumn{8}{|l|}{ Develop video series describing class program activities } \\
\hline \multicolumn{8}{|l|}{ Develop comprehensive database of operators } \\
\hline \multirow{2}{*}{\multicolumn{8}{|c|}{$\begin{array}{l}\text { National Technology Transfer Network } \\
\text { Implement national technology transfer network }\end{array}$}} \\
\hline & & & & & & & \\
\hline \multicolumn{8}{|l|}{$\begin{array}{l}\text { Inplement national technology transfer network } \\
\text { Support implementation of technology transfer activities }\end{array}$} \\
\hline \multicolumn{8}{|l|}{ Technology Transfer ontreach } \\
\hline \multicolumn{8}{|l|}{ Establish a stakeholder review panel } \\
\hline \multicolumn{8}{|l|}{ Conduct market resegrch study to identify high-priority technology necds } \\
\hline \multicolumn{8}{|l|}{ Develop Ddatabase of coptacts in the heavy oil refining industry } \\
\hline \multicolumn{8}{|l|}{ Conduct study to determine ways to accelerate development in tribal lands } \\
\hline \multicolumn{8}{|l|}{ Develop methodologies to measure effectiveness of tech transfer program } \\
\hline \multicolumn{8}{|l|}{ Support technology transfer outreach } \\
\hline \multirow{2}{*}{\multicolumn{8}{|c|}{ Nattral Gas \& on Partnership }} \\
\hline & & & & & \\
\hline \multirow{2}{*}{\multicolumn{8}{|c|}{$\begin{array}{l}\text { Conferences } \\
\text { Support the SPE/DOE } 10 \text { th IOR Symposium }\end{array}$}} \\
\hline & & & 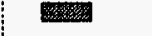 & & & & \\
\hline Support the SPE /DOE 1 lth IOR Symposium & & & & & & & \\
\hline Support conferences and symposig as required & & & & & & & \\
\hline INTERNATIONAL PROGRAM & & & & & & & \\
\hline Reevaluate opportunities for exporting domestic technologies \& serrices. & & & & & & & \\
\hline Support Russian oil \& gas technology center & & & & & & & \\
\hline Conduct oil \& gas international conferences & & & & & & & \\
\hline Suppor other DOE international petroleum activities & & & & & & & \\
\hline Assess export opportunities for U.S petroleum technologies & & & & & & & \\
\hline EDUCATION OUTREACH PROGRAM & & & & & & & \\
\hline Conduct annug DoE Science Bowl competition in oklahoma & & & & & & & \\
\hline Conduct teacher intern program & & & & & & & \\
\hline Conduct Earth Science Teacher Institute & & & & & & & \\
\hline Native American teacher training & & & & & & & \\
\hline Coordinate TRAC Teacher Program & & & & & & & \\
\hline Conduct teacher training for Oklahoma teachers & & & & & & & \\
\hline
\end{tabular}


Table 2.5.2 Measures of Effectiveness

Transfer Activities

Metrics

National Technology Transfer Network

- Technical assistance provided

- Outreach

- Formal and informal information dissemination

- Focused workshops and problemidentification seminars
- Technologies/products that reduce costs, defer abandonments, increase success of exploration and production activities, improve processing and utilization, and protect environment

- Number of jobs created

\section{Class Outreach Program}

- Outreach

- Field trips

- Workshops

- Formal and informal information dissemination
- Number of producers with increased awareness, interest and participation in demonstration projects

- Application of existing state-of-the-art technologies and combinations of technologies to increase exploration, production, and environmental protection

\section{Technology Transfer Outreach}

- Technical assistance

- Outreach

- Formal and informal information dissemination

- Consulting

- Work for others and contract research

- Use of facilities
- Number of times outside organization contracted with lab for "Use of Facilities"

- Number of times lab personnel provided consulting services to private sector

- Number of visitors to lab

- Number of technical assistance requests by industry directly to National Institute for Petroleum and Energy Research

\section{Technology Transfer Support}

- Formal and informal information dissemination
- Number of technical publications disseminated

- Number of contacts for information

- Number of copies of software distributed

\section{Technology Transfer Conferences}

- Outreach

- Formal information dissemination
- Number of attendees at conferences sponsored by DOE

- Number of requests for technical information

- Number of requests for technical assistance

- Number of trade shows participated in that resulted in technology transfer

- Number of scientists participated in meetings 
Table 2.5.2 Measures of Effectiveness (continued)

\begin{tabular}{|c|c|}
\hline Transfer Activities & Metrics \\
\hline \multicolumn{2}{|c|}{ Education Outreach } \\
\hline $\begin{array}{l}\text { - Outreach } \\
\text { - Formal information dissemination }\end{array}$ & $\begin{array}{l}\text { - Number of teachers trained in "train-the- } \\
\text { trainer" program } \\
\text { - Number of teachers trained by "teacher } \\
\text { trainers" } \\
\text { - Number of students exposed to curriculum } \\
\text { - Distribution (by state) of teachers trained } \\
\text { - Demographics of students reached } \\
\text { - Number and demographics of teacher } \\
\text { interns } \\
\text { - Number of students participated in science } \\
\text { bowl, science fair, and other education } \\
\text { activities }\end{array}$ \\
\hline
\end{tabular}

Summer Intern Program

- Outreach

- Formal information dissemination
- Number of student interns

- Demographics of student interns

- Number of students choosing a career in the petroleum industry

\section{Russian-American Oil and Gas Technology Center}

- Outreach

- Formal and informal information dissemination

- Personnel exchanges

- Technical assistance
- Number of technical assistance requests received

- Number of technical publications disseminated

- Number of personnel exchanges that resulted in technology transfer

- Number of opportunities to enhance U.S. competitiveness by promoting the acceptance of federal lab or U.S. industry technologies

\section{International Oil and Gas Conferences}

- Outreach

- Formal information dissemination
- Number of attendees with interest in U.S. technologies, products, or services

- Number of requests for technical information and software

- Number of companies exporting goods and services as a result of the conferences 


\section{Table 2.5.2 Measures of Effectiveness (continued)}

\begin{tabular}{|c|c|}
\hline Transfer Activities & Metrics \\
\hline \multicolumn{2}{|c|}{ Oversight and Assistance for International Activities } \\
\hline $\begin{array}{l}\text { - Outreach } \\
\text { - Formal information dissemination }\end{array}$ & $\begin{array}{l}\text { - Number of international personnel } \\
\text { exchanges }\end{array}$ \\
\hline \multicolumn{2}{|c|}{ Cooperative Research and Development Agreements Program } \\
\hline $\begin{array}{l}\text { - Formal and informal discussions with } \\
\text { companies on cooperative research and } \\
\text { development agreements program }\end{array}$ & $\begin{array}{l}\text { - Number of cooperative research and } \\
\text { development agreements generated each } \\
\text { year } \\
\text { - Number of companies contacted for } \\
\text { potential cooperative research and } \\
\text { development agreements }\end{array}$ \\
\hline \multicolumn{2}{|c|}{ Licensing Program } \\
\hline $\begin{array}{l}\text { - Commercialization studies of patents } \\
\text { developed under DOE program }\end{array}$ & $\begin{array}{l}\text { - Number of patents issued each year at } \\
\text { National Institute for Petroleum and Energy } \\
\text { Research } \\
\text { - Number of patents licensed each year }\end{array}$ \\
\hline
\end{tabular}




\subsection{FIELD DEMONSTRATION PROJECTS}

\subsubsection{Program Overview}

The Field Demonstration Program was initiated in FY 1992 in response to rapidly declining domestic production and the realization that huge volumes of oil are being abandoned in reservoirs because of uneconomic production techniques. Since then, the program has been refined in response to:

- DOE's Fueling a Competitive Economy Strategic Plan

- The Energy Policy Act of 1992 (EPACT)

- The Domestic Natural Gas and Oil Initiative (DNGOI)

- Industry input from the completed Class 1 and Class 2 competitive solicitations

The Field Demonstration Program is just one of the critical elements of the Oil Program necessary to move improved oil recovery (IOR) technology from the conceptual stage through research, pilot scale field experiments, and fullscale field demonstrations to industry acceptance and commercialization. Both successful results and failures of the field demonstrations will provide focus to concurrent research programs. Elements of the field demonstrations that are suitable for broad industry application will be communicated to the industry through the oil program's technology transfer effort. Interrelationship among the Field Demonstration projects and other Oil Program elements is shown in Figure 2.6.1.

\subsubsection{Goals and Objectives}

The Field Demonstration Program, in support of the Reservoir Characterization Program mission to stimulate the maximum economically sound recovery of crude oil from known domestic reservoirs, has established the following four goals, each with a series of operational objectives:

Goal 1: Extend the economic production of domestic fields by (1) slowing the rate of well abandonments and (2) preserving industry infrastructure (including facilities, wells, operating units, data, and expertise).

Goal 2: Increase ultimate recovery in known fields by demonstrating (1) better methods of reservoir characterization (both rock and fluid), (2) advanced oil recovery and production technologies, (3) advanced environmental compliance technologies, and (4) improved reservoir management techniques.

Goal 3: Use field demonstrations to broaden information exchange and technology application among customers by (1) expanding participation in DOE projects to include both traditional and nontraditional participants, (2) increasing third-party participation and interaction throughout the life of DOE-sponsored projects, and (3) making technology transfer products user-friendly. Customers include oil producers, researchers, Native American tribes, service companies, consultants, regulators, state legislators, 


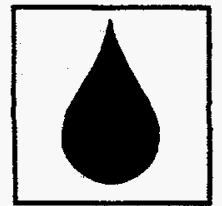

Congress, financial community, environmentalists, and equipment suppliers.

Goal 4: Integrate Field Demonstration activities with activities of other areas of the advanced oil recovery program by (1) actively pursuing demonstration activities from work developed in other program areas, (2) assessing Field Demonstration efforts regarding future directions and research needs, and (3) informing the research community of research needs and opportunities identified in demonstration projects.

The objectives will be accomplished through a set of projects as described that are designed to address critical elements of DNGOI.

The Field Demonstration Program will continue to emphasize industry-driven projects. It will attempt to obtain more industry input regarding program directions through public meetings, industry participation on planning teams, and feedback from industry participants working on DOE grants or contracts.

The work breakdown structure is shown in Figure 2.6.2.

\subsubsection{Near-term and Mid-term technologies for Class Demonstrations}

Class 1 Fluvial-Dominated Deltaic Reservoirs. Four mid-term and 10 near-term projects were selected and awarded in FY 1992 and FY 1993. DOE will monitor contractual performance and fund the second budget period of each demonstration as appropriate, that is, for technologies proved technically and economically feasible in the first budget period. Projects will be completed between FY 1994 and FY 2000.

Class 2 Shallow Shelf Carbonate Reservoirs. Three mid-term and seven near-term field demonstrations in shallow-shelf carbonate reservoirs have been selected. Award of the cooperative agreements occured in FY 1994. DOE will monitor the contractual performance and fund the second budget period as necessary.
Class 3 Slope and Basin Clastic Reservoirs. DOE received and evaluated proposals in FY 1994 and will award cooperative agreements to industry participants in FY 1995. DOE will then monitor the contractual performance and fund the second budget period as necessary.

DOE intends to select industry cost-shared projects for both advanced and underutilized conventional technologies in the following proposed reservoir classes:

- Class 4 in FY 1995

- Class 5 in FY 1996

- Class 6 in FY 1997

- Class 7 in FY 1998

Class Gulf Coast Heavy Oil Reserooirs. Gulf Coast heavy oil reservoirs represent a special reservoir class with unique production constraints: the region lacks infrastructure, and a majority of the fields are operated by small producers that lack the research and capital resources to develop the infrastructure alone. Based on reservoir characterization in progress, DOE intends to request industry proposals in FY 1996.

\subsubsection{Advanced Class Work}

Field-based reservoir characterization and recovery process experiments will be conducted, starting with the highest priority classes, to refine advanced technologies that were demonstrated or shown to be needed in the Class demonstration projects. In addition, technologies shown to be promising in laboratory research and development efforts-improved recovery methods and reservoir characterization technologies - will be considered for demonstration in Advanced Class Work activities.

\subsubsection{Analysis}

Technical and Economic Analysis of Field Demonstration Projects. The purpose of this project is to assess areas for focused research and development activities in the Advanced Class Work area and to enhance technology transfer from DOEindustry cost-shared field demonstration projects. 


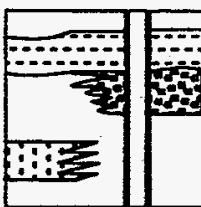

GOALS

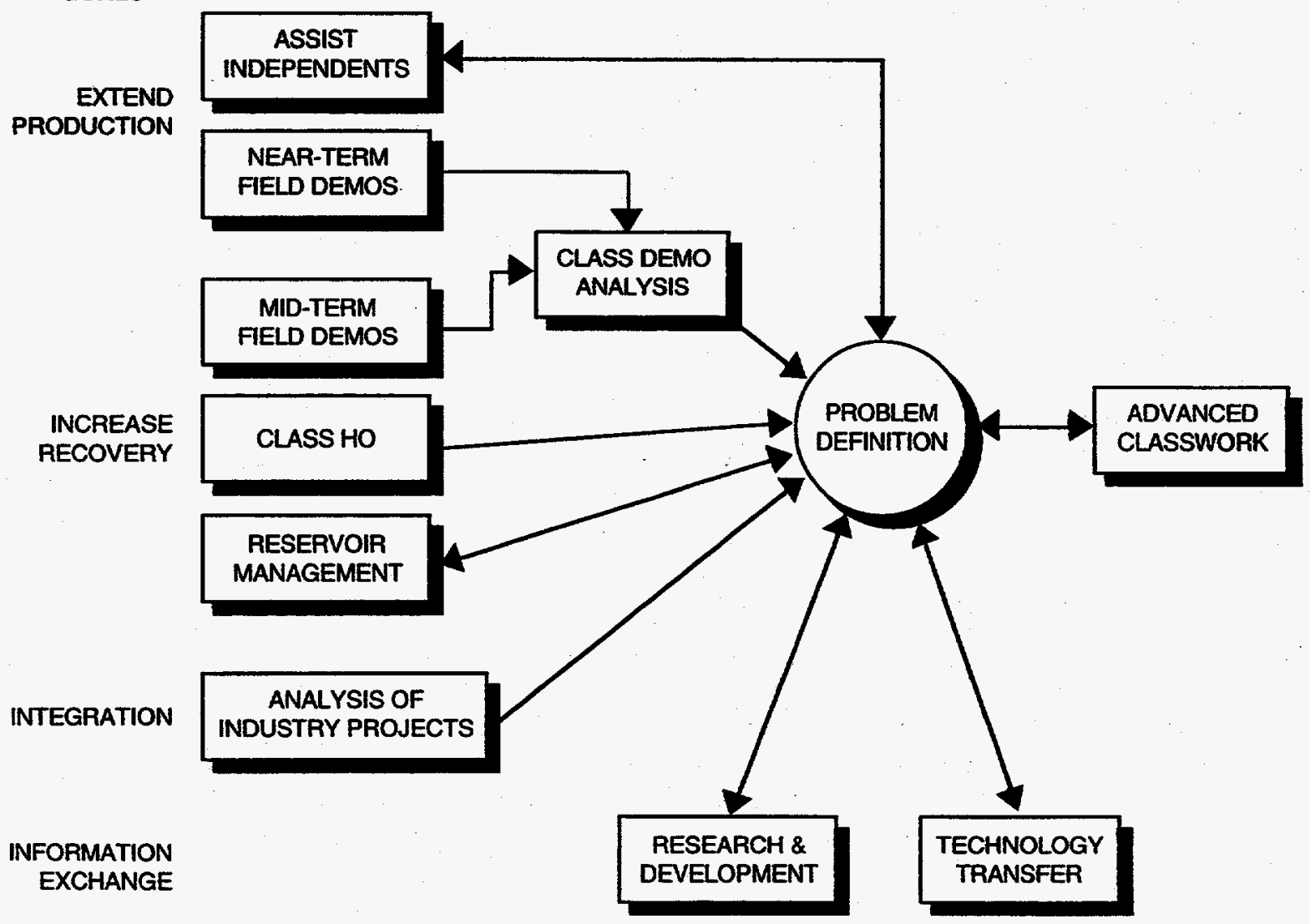

Figure 2.6.1 Relationships Between Field Demonstration Projects and Other Oil Program Elements

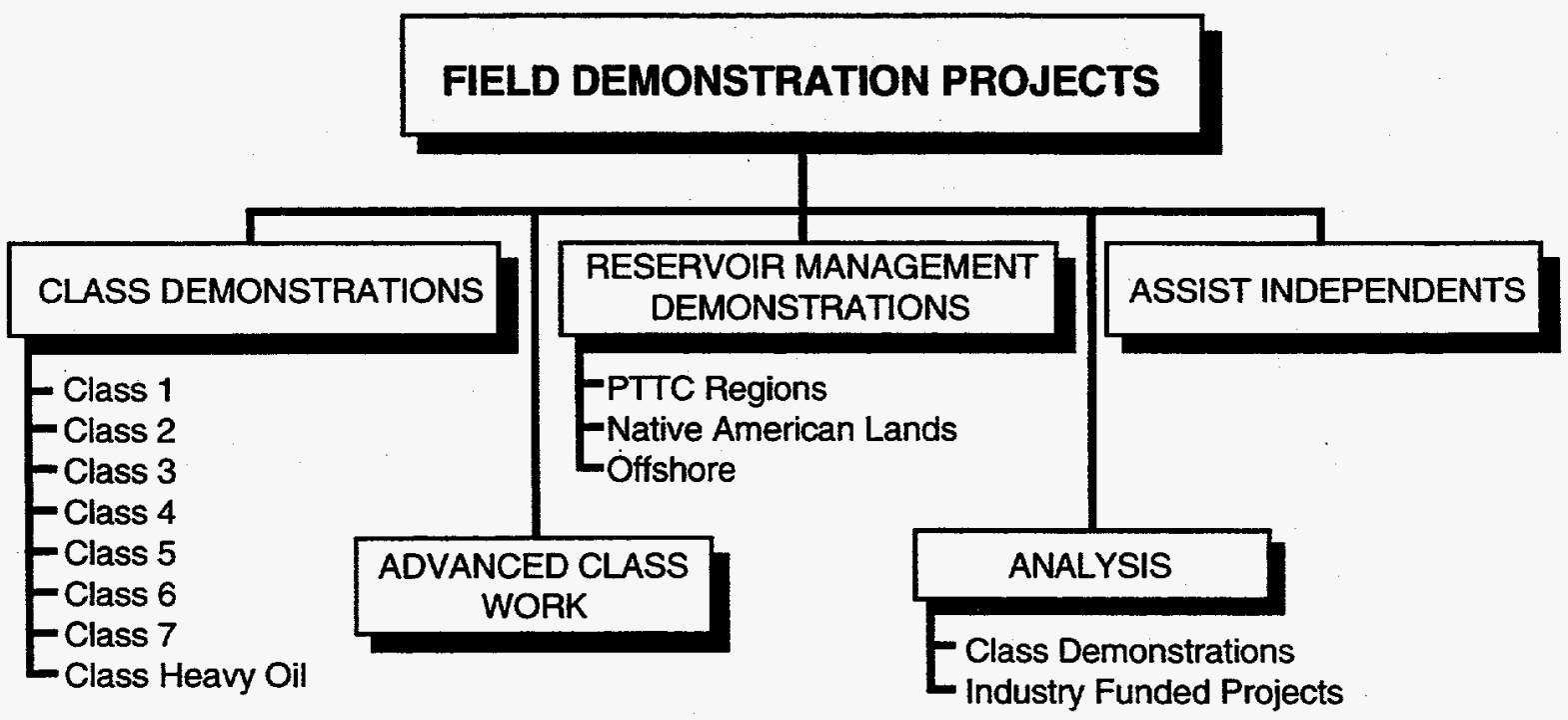

Figure 2.6.2 Field Demonstration Work Breakdown Structure 


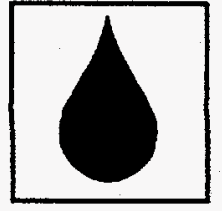

IORProject Analysis and Technology Assessment. This project will conduct a large number of indepth assessments of past and ongoing improved oil recovery projects conducted by industry. Projects for study will be selected based on reservoir class, industry activity, technology applied, and regional significance of the project. Studies will compare preproduction expectations against actual behavior. The results of this project will be combined with results of the analyses of DOE field demonstration projects to guide the Advanced Class Work and other research and development programs. Industry will be informed of the results of the analyses.

\subsubsection{Assist InDEPENDENTS WITH URGeNT Production Constraints}

The oil price in 1993 severely affected domestic independent operators that were already operating near the economic limit. Recognition of worsening industry conditions justifies additional DOE effort to assist domestic operators to adopt more efficient and effective production technologies. Another consideration in refocusing the Field Demonstration Program is the perception of many small operators that the current Field Demonstration solicitation process is too slow and cumbersome. This project, which targets the basic operating issues of small oil producers, will support qualifying proposals for cost-shared demonstrations of technologies that will increase production, improve efficiency, or increase ultimate recovery. In addition, through the Wells of Opportunity Program, technology developed through DOE sponsorship, either at NIPER or national laboratories, will be demonstrated by operators who agree to apply it on appropriate wells. Results of the projects will be made available to other operators.

\subsubsection{Reservoir Management Demonstrations}

In order to promote the use of innovative reservoir management techniques to optimize oil and gas operations, this project will conduct reservoir management demonstrations using teams that include BDM-Oklahoma, NIPER, operators, consultants, and the National Technology Transfer Network regional resource centers. The network is discussed in more depth in Chapter 2.5. In addition to projects in the 10 regions, several projects will target fields on Native American tribal lands, and two are planned in offshore fields.

The Field Demonstration Program contains elements that address several special issues critical to large subsets of the domestic oil industry, such as operators, Native American lands, offshore areas, Naval Petroleum Reserves (NPR), and analogous reservoirs. Native American tribes own significant oil reserves in the central and western United States. Because many of these mature oil reservoirs are at risk of abandonment, the oil program proposes elements that will assist the tribes and the independent operators that produce most of the oil on tribal lands. The approach will be to target components of two projects, Analysis of Industry Projects and Reservoir Management Demonstrations, to tribal lands. In addition, producers on tribal lands are expected to continue to be participants in the class demonstrations.

The oil program has traditionally worked with NPR in both California and the Rocky Mountains to provide research support for improved field operations. Several Field Demonstration projects will specifically target NPR because of the excellent availability of field and recovery process data, the fact that the reservoirs are in highpriority reservoir classes, and the ease of conducting field operations in NPR fields.

Oil program support of offshore technology development and demonstration will be expanded in response to the increased abandonment threat and the shift of offshore operations from large oil companies to smaller operators that lack in-house research capability. This will be accomplished by targeting components of three projects to the special recovery constraints of offshore operations, Reservoir Management Demonstration, Advanced Class Research, and Analysis of Industry Projects. 


\subsubsection{STAKEHOLDERS}

The program implementation plan is driven by the concerns and consideration for key customers and stakeholders. For Field Demonstration, these key people include:

- Independent oil companies

- Major oil companies

- Consultants

- Academic institutions

- Research and development organizations

- Service companies

- Equipment manufacturers

- State agencies

- Congress

\subsubsection{IMPACTS}

The Field Demonstration Program is expected to yield the following benefits to the domestic oil industry and more generally to the entire U.S. economy (listed in order of importance):

- Decrease in the rate of well abandonments

- Recovery and production of more domestic oil

- Preserve jobs in the oil production industry

- Increase the total volume of domestic oil ultimately produced

- Increase teaming efforts by industry for projects of mutual benefit

\subsubsection{BUDGE}

The budget for the Field Demonstration Program is summarized in Table 2.6.1 and Figure
2.6.3. As stated in Section 1, this Oil Plan is developed for an unconstrained budget that is bounded by the scope of goals set by Congress, the President, and the Secretary of Energy.

\subsubsection{SCMEdule}

Figure 2.6.4 shows key activities and their timing in the Field Demonstration area.

\subsubsection{Measures of Effectiveness}

Measuring the effectiveness of the Field Demonstration Program is best done by using both industry and oil program indicators (see Table 2.6.2). Industry indicators include slowing the rate of abandonment, enhanced oil recovery and advanced secondary recovery project starts, incremental production, and an increase in the active drilling rig count. Program indicators include the number and value of proposals received, number of contract awards, percent of proposed industry cost sharing, peer reviews, and modeling analysis. It is expected that the Field Demonstration Program will allow industry to develop about 1.5 billion barrels of incremental production by the year 2020 at a daily average rate of 170,000 barrels of oil. This incremental oil will result in the direct addition of 3,600 jobs and upwards of 7,800 jobs due to indirect or ripple effects. Increased oil production revenues to federal and state treasuries could amount to $\$ 390$ and $\$ 100$ million/year, respectively. 
Table 2.6.1 Budget for Field Demonstration Program

\begin{tabular}{lcc}
\hline Functions & $\begin{array}{c}\text { FY 1994 } \\
\text { Appropriated } \\
(\mathbf{\$ 1 , 0 0 0 )}\end{array}$ & $\begin{array}{c}\text { FY 1995 } \\
\text { Appropriated } \\
\mathbf{( \$ 1 , 0 0 0 )}\end{array}$ \\
\hline Class Demonstration & 40,314 & 34,316 \\
Analysis & 256 & 0 \\
Assist Independents & 235 & 595 \\
Advanced Class Work & 0 & 0 \\
Reservoir Management Demonstrations & 615 & 0 \\
\hline Totals for Field Demonstration & 41,420 & 34,911 \\
\hline
\end{tabular}

1994

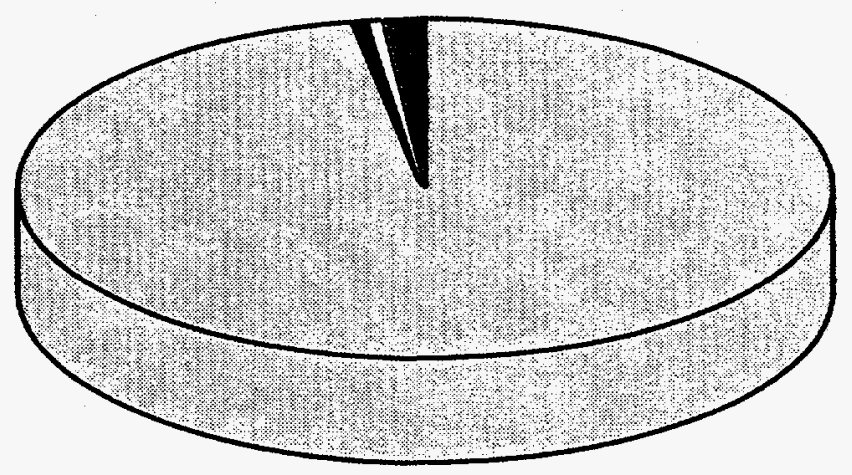

$\square$ Class

Demonstration

Analysis

$\square$ Assist Independents

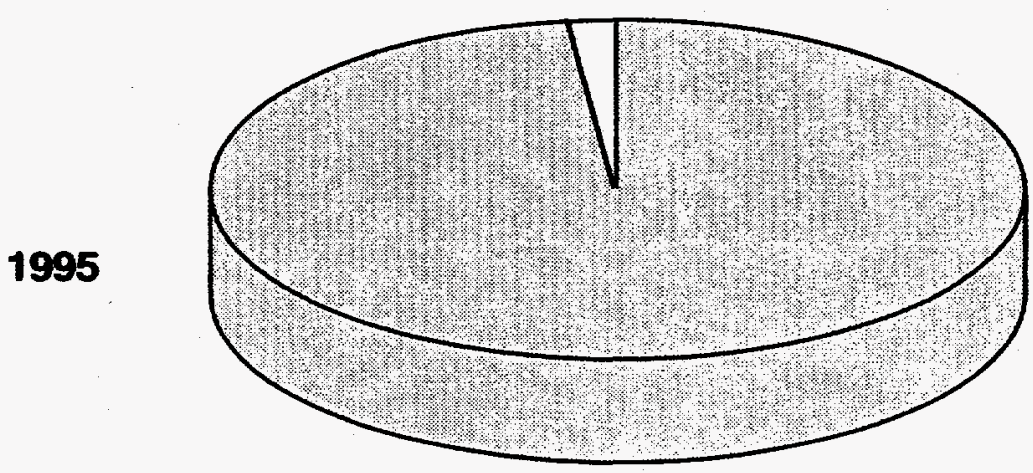

Advanced Class Work

Reservoir Management

Figure 2.6.3 Field Demonstration Program Budget 
Figure 2.6.4 Key Activities and Timing for Field Demonstration Program

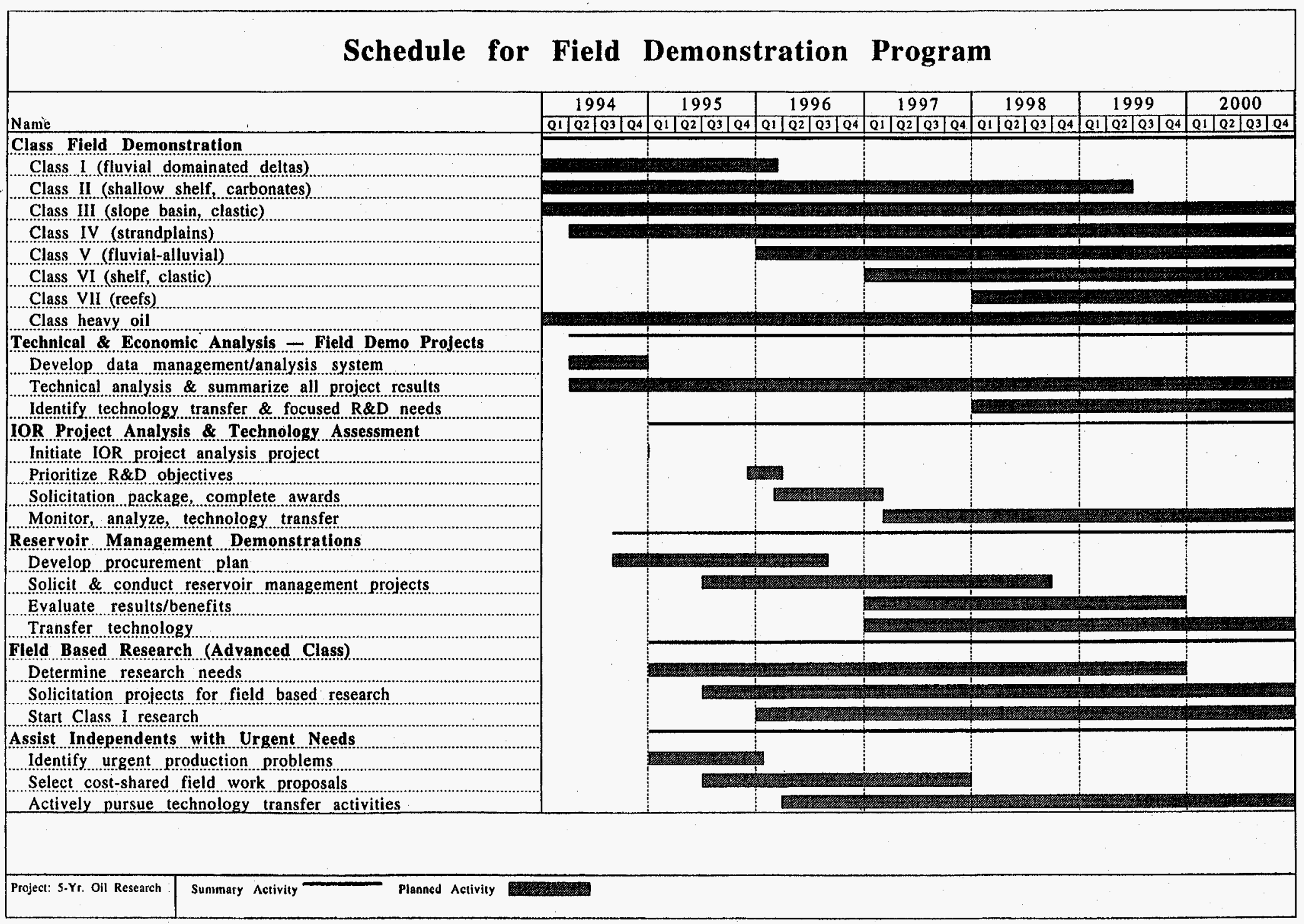




\section{Table 2.6.2 Measures of Effectiveness}

\section{Field Demonstration Activities}

- Demonstrations in Classes 1 through 7

- Demonstration in Gulf Coast heavy oil reservoir

- Advanced class demonstrations

- Analysis of class demonstrations

- Analysis of industry projects

- Reservoir management demonstrations

- Assist independents

\section{Metrics}

- Number and value of proposals received

- Number of contracts awarded

- Percent of proposed industry cost sharing

- Increased number of field applications of demonstrated technologies by domestic oil industry

- Incremental production of 1.5 billion barrels by 2020

- Daily average production rate of 170,000 barrels

- Direct addition of 3,600 jobs and upwards of 7,800 jobs due to indirect effects

- Increased oil production revenues to federal and state treasuries of $\$ 390$ million/year and $\$ 100$ million/year, respectively

- Slowing the rate of abandonment

- Increased rate of EOR and ASR starts

- Better understanding of successful measures to mitigate production constraints

- Number and value of proposals received

- Number of contracts awarded

- Percent of proposed industry cost sharing

- Slowing the rate of abandonment

- Increased use of advanced reservoir management technology

- Number and value of proposals received

- Number of contracts awarded

- Slowing the rate of abandonment

- Increased utilization of advanced production and management technology by independents 


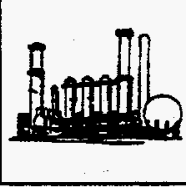

\subsection{OIL DOWNSTREAM OPERATIONS}

\subsubsection{Program Overview}

The mission of the Oil Downstream Operations Program is to help the petroleum industry maintain viable domestic refineries by:

- Assisting the industry to increase the efficiency and effectiveness of its environmental programs

- Assisting the industry to develop costeffective and environmentally acceptable domestic heavy oil and residua upgrading and processing technologies to maximize the output of transportation fuels

- Communicating with all clients so as to understand their needs and then planning activities to address those needs, consistent with national priorities

This Oil Program is a complementary effort to the studies as described by the Offices of Fossil Energy (FE) and Energy Efficiency and Renewable Energy (EERE) Refinery of the Future Program. Refineries now and in the future are a strategic domestic industry that create jobs while becoming increasingly more environmentally acceptable. It is imperative that research programs be supported that will improve the long-term vitality of refineries in the United States. Without a strong refining industry, other strategic industries will also be placed in jeopardy.

Assisting the industry remains the ultimate objective of this program. To accomplish this, we must communicate with all clients to understand their needs and concerns and plan activities to address them that are consistent with national goals. Technology transfer efforts must be made with individual refiners, consortia, and industry organizations to define the direction, the priorities, and the activities for the program. Based on these studies, critical research and development needs can be identified, and prioritized research and development areas can be determined to achieve the program's goals. The research and development capabilities of NIPER, the national laboratories, and universities can then be used to accomplish these goals. Many of the problems facing the U.S. refining industry are common to refineries worldwide. The global nature of the refining industry should be used to foster a national and international exchange of information through a multifaceted educational program. The Fossil Energy Oil Downstream Operations Program can provide the foundation for a new educational initiative enhancing efforts with North American Free Trade Agreement (NAFTA), Russian developments, and other governments.

These research and development efforts address a number of DOE programs and strategic plans and include the end goals of the Domestic Natural Gas and Oil Initiative (DNGOI). Our strategy must meet the needs for energy supply and environmental preservation and demonstrate that they are compatible with oil processing and marketing. The research and development efforts affecting energy issues will help implement EPACT and many other new programs that affect oil production and utilization. These studies all relate to the identification and implementation of the administration's stated environmental objectives.

\subsubsection{Situation Analysis}

Commercial petroleum refineries will be the primary source of transportation and other fuels for decades to come. However, the overall economic health of the domestic petroleum industry has 
declined dramatically during the last few years because of lower crude oil prices, reduced profitability in the refining operations, and increased expenses in complying with environmental regulations and meeting increasingly strict environmentally driven fuel specifications. The industry has lost hundreds of thousands of jobs over the last decade; industry-sponsored research and development activities, in particular, have been downsized or eliminated.

Global integration and high dependence on technology have been the hallmark of the refining industry. Because refined products move freely among countries and refinery processes are international in character, technological advances become available worldwide relatively quickly. Our domestic petroleum industry has led the rest of the world in technology developments and, as a whole, remains the most sophisticated. However, the economic health of the U.S. downstream operations must improve if we are to maintain world leadership. At the last peak of the refining industry capacity in the 1970 s, there were over 300 processing sites in the United States. At the close of 1993, only 171 sites remained. United States dominance endures because these refineries account for approximately $21 \%$ of the worldwide crude processing capacity.

Projected product slate mandates will result in higher storage and transportation costs, added capital expenditures, product exchange complications, and potential product degradation problems. This, in part, relates to the problems of fungibility, and a recent Wright Killen analysis suggests that the result could be another $10 \%$ (1.5 million barrels per day) of refinery capacity being closed. The past closures were mostly smaller plants that could not afford capital investments to comply with environmental regulations; unfortunately, a significant number of jobs were lost, both directly and in the community infrastructure services. Refineries are vital to the U.S. economy in direct employment and to the array of independent oil producers who supply domestic crude feedstocks.
Around the world, the 1970s perception of an oil shortage has changed to one of ample world reserves. Producers and consumers have a twoway relationship driven by economic factors in which neither availability of supply at low cost nor increasing demand for refined products can be predetermined with confidence. Worldwide coordination and communication are increasingly important as the petroleum industry has changed from a closed market to a commodity exchange traded in markets that rapidly adjust to supply and demand changes.

Changing lifestyles and practices have yielded an ethic of efficiency in the industry, and many past inefficiencies in energy uses have been eradicated. As a result, energy intensity (thousand Btu consumed per dollar of gross domestic product) has declined markedly over the last few years and should continue to decline into the future. Despite the improved efficiencies, the Energy Information Administration has recently projected that America's improving economy will cause crude oil demand to increase, resulting in about 1 million barrels per day of additional domestic consumption of refined products by the year 2000. Environmental concerns must also be met. These are now a major factor in oil demand and the growth of U.S. energy consumption.

Globally, environmental awareness is increasing the responsibilities of the refining industry. This is particularly true at present in the United States since we remain the leader in new pollution prevention technologies for manufacturing quality products. Based on a recent National Petroleum Council (NPC) study, the refining industry's cost of compliance with environmental regulations between 1991 and 2010 will be in excess of $\$ 150$ billion, with the capital component of that cost being $\$ 36$ billion. The main impact areas that were addressed in the study were safety and health, air control emissions, wastewater, and solid wastes, including coke.

American leadership of the global petroleum industry in preventing pollution and protecting 
the environment will drive much of the downstream's activities. Because of this global view, the efforts must be cost competitive and provide improved efficiency and performance. All of the elements of the program must be directed towards pollution prevention, waste minimization, and economic savings so that pollutants are eliminated, quality and service are improved, and the public perception of a company and its products is enhanced. Thus a key objective for the FE/DOE program is to assist industry in increasing the efficiency and effectiveness of the industrial environmental efforts in site restoration, waste management, and pollutant prevention. DOE should assist industry by conducting research aimed at new practical technologies to minimize pollution production and to reduce or to eliminate the incremental operating and capital costs identified by the NPC study.

Crude oil feedstocks supplied to U.S. refineries from domestic and imported sources have become increasingly heavier with higher levels of sulfur and heavy metals. In contrast, U.S. finished product demand continues to shift to lighter, high-value products, such as gasoline, diesel, and petrochemical feedstocks that must conform to specified environmental standards. The continued decline in domestic crude oil production is increasingly evident. EIA recently forecast that U.S. dependency on foreign oil will rise to $60 \%$ of consumption by 2000 , up from $38 \%$ in 1992. U.S. refineries must achieve a new level of technological excellence in producing superior transportation fuels at necessarily high efficiencies with reduced quantities of residual oils and coke byproducts. The competitive difference is not in deciding what to do, but in how to do it with regard to technology, business processes, company organizational structures, and dealing effectively and positively with the government. A total quality execution concept will become paramount.
Environmental requirements pose a number of challenges to refiners' future strategies. The primary focus will be progressively towards different and continuously changing standards for transportation fuels to decrease emissions and toward requiring bottom-of-the-barrel conversion to minimize lowvalue byproducts and wastes. U.S. crude production continues to decline, but the one noteworthy area of possible increased production is in heavy crude oil. Abundant domestic sources of heavy crude oil are available in California, North Slope Alaska, the Gulf Coast, and areas of the Rockies. The potential for large-scale production from all these sources exists, but the market for this crude is not now robust. $A$ primary objective of these FE/DOE programs must be to assist the industry to develop cost-effective and environmentally acceptable domestic heary oil and residua upgrading and processing technologies.

\subsubsection{Strategic Goals}

The program has three strategic goals, as illustrated by Figure 2.7.1.

\section{Environmental Compliance}

Develop environmental data and technologies in collaboration with industry to provide superior environmental compliance by downstream operations.

\section{Pollution Prevention}

Help provide the technologies to prevent the formation of pollutants by process modifications and/or unit changes in the refineries.

\section{Heavy Oil Upgrading}

Assist the industry in increasing the yields of environmentally acceptable, cost-competitive, 


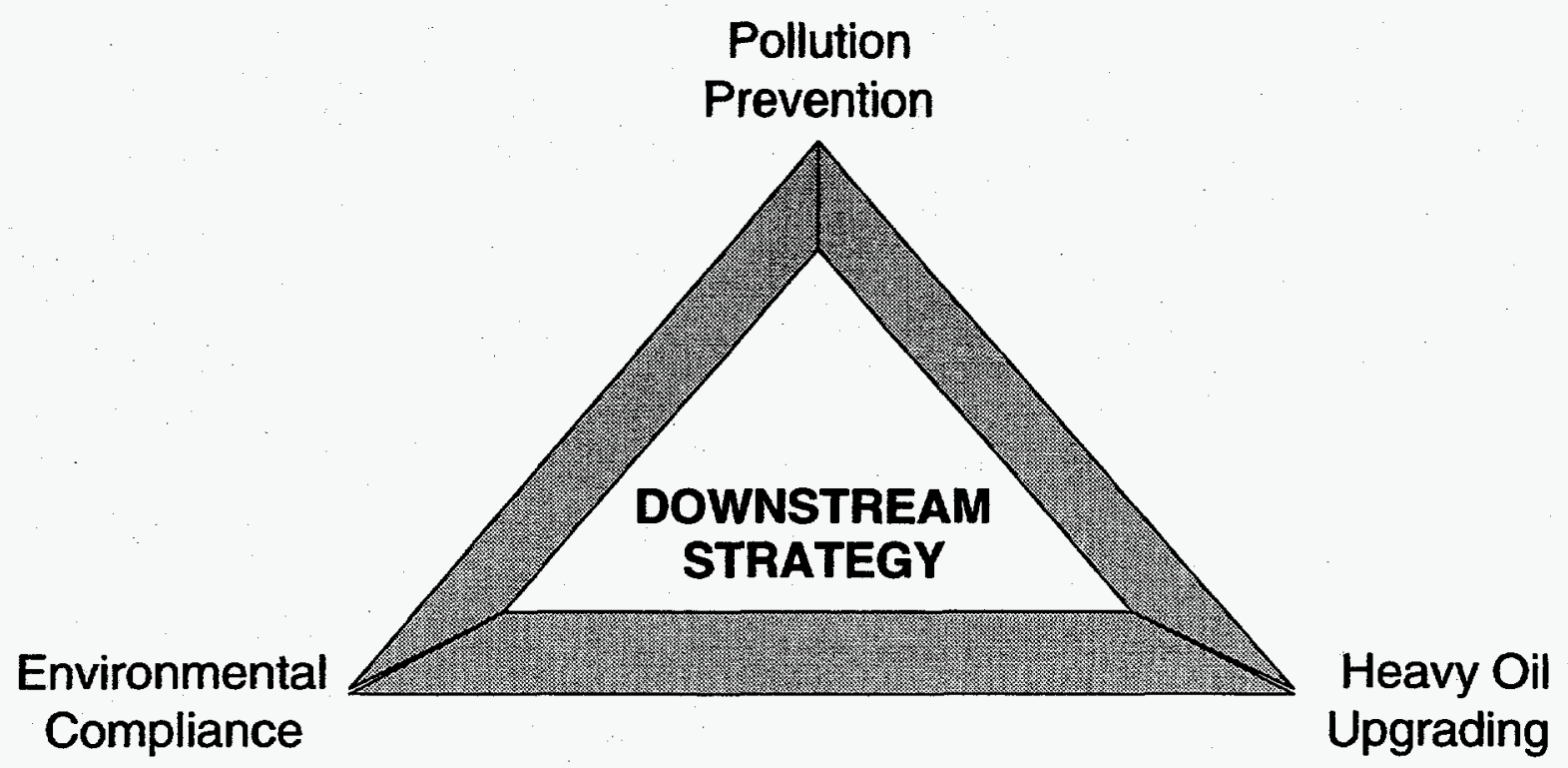

Figure 2.7.1 Cornerstones of Downstream Strategy

high-value transportation fuels and petrochemicals from heavy oils and residua while reducing the quantities of low-value byproducts.

\subsubsection{Implementation Strategies}

The Oil Downstream Operations Program consists of a number of strategies to achieve the three strategic goals.

\section{Environmental Compliance}

- Conduct studies in cooperation with a number of refinery groups to collect and to document basic emission, waste, and similar data through agreements with the industry.

- Help develop advanced measurement instrumentation for collecting complex emission data, particularly with regard to air toxins.

- Work with industry; environmental groups; and federal, state, and local regulators to improve the availability of scientifically based information accepted by all parties and to enhance cost-effective and riskbased regulatory development.
- Jointly support research and development with business and government organizations on innovative approaches and technologies for remediation, wastewater treatment, waste disposal and similar environmental efforts.

- Work with regulators to move beyond command and control procedures to allow industry to develop the necessary environmental programs in a more cost-effective manner for their particular situation.

\section{Pollution Prevention}

- Work with refiners and various organizations to identify the various pollutants and the levels that result from specific downstream operations.

- Help evaluate new and promising technologies or modified processes that show the greatest reduction in pollutants.

- Work to increase understanding of the importance of process changes to pollution levels and fund those processes with the greatest apparent cost-effectiveness in lab tests, possibly up through the pilot scale. 
- Target the technology developments specifically at pollutants, such as air emission toxics, wastewater, refractory hydrocarbon residues, coke, and spent catalysts.

- Work with regulators to expedite installation of pollution prevention processes in the refineries.

\section{Heavy Oil Upgrading}

- Continue to develop fundamental chemical and thermodynamic data on heavy crude oil and residua components.

- Facilitate distribution of useful information by improving the understanding of domestic clients' processes, needs, and regulatory requirements.

- Work with industry to discover the appropriate program areas to increase the yield of environmentally acceptable, costcompetitive, high-value transportation fuels and petrochemicals from each barrel of crude oil refined, while particularly reducing low-value products and residua.

- Support industrial partners to undertake research and development for promising new upgrading/processing technologies and for improvements to existing technologies.

- Promote commencialization of new technology.

- Aggressively search for and support with industry those emerging technologies that will cost-effectively upgrade domestic heavy crudes.

- Aggressively support programs consistent with the first two goals, resulting in the development of minimum discharge refineries.

\subsubsection{Stakeholders}

The Oil Plan is targeted at the individuals, groups, and companies who are the key beneficiaries. For the Oil Downstream Operations Program, these stakeholders include:

- U.S. consumers, whose lifestyle and livelihood depend upon a reliable source of high quality, environmentally friendly, and reasonably priced fuel for transportation and heating.
- The refiners, who must be able to produce the required slate of products in a manner consistent with all regulatory constraints. They must produce a product that can be afforded by the consumer, while still producing an acceptable rate of return for the stockholders.

- The upstream crude oil producers, who would fail without a market for their products. Unless a viable domestic refining industry is maintained, there will be no market for their crude oil at an acceptable price. Their crude oil-particularly the heavy crudes-will not be able to compete in world markets.

- The Congress, state, and local governments, the President and the administration, and the nation as a whole, because without a viable domestic refining industry, the United States will be at the mercy of foreign suppliers and the disruptions in trade and commerce caused by even occasional shortages. The health of this nation depends on a sustained supply of reasonably priced energy and refined products.

\subsubsection{IMPACTS}

It is evident that many refineries will remain viable in the United States because crude oil is more easily transportable than the large variety of finished products produced by refining. America's refining industry will provide the United States with economic fuels for many years to come. Furthermore, the refineries are becoming safer, more modern, and more environmentally benign. Because of the scope and volume of fuels, no foreseeable major moves are being made to build competing capacity offshore. Without question, DOE's major challenges for FY 19962000 will be in working with industry to create innovation and industry leadership, to develop organization and refining strategies, to deal with environmental concerns and satisfy external groups, and to develop positive governmental relationships.

New technology is the key on which the future of the American refining industry depends 
for its world class position. Because many of its research and development programs have suffered because of poor industry economics and (in part) to the consequences of takeovers, it is urgent for DOE to conduct research and development programs that satisfy the most important research and development needs. DOE programs must be of a fundamental nature that will provide timely and reliable technology to help the industry use the available resources to develop commercial products. Because the domestic oil and gas industry remains of strategic importance to the nation, this effort must be directed to help improve the industry's vitality and its ability to create jobs and environmentally acceptable products.

\subsubsection{BUDGet}

The downstream operations budget has been developed to conform to strategic goals and to support goals consistent with DNGOI. The proposed budget for FE's downstream operations for the area is summarized in Table 2.7.1 and in Figure 2.7.2. As stated in Section 1, this Oil Plan is developed for an unconstrained budget that is bounded by the scope of goals set by Congress, the President, and the Secretary of Energy.

\subsubsection{SCHEDULE}

Figure 2.7.3 shows key activities and their timing in the Oil Downstream area. These key activities represent a balanced program to achieve the three strategic goals, environmental compliance, pollution prevention, and heavy oil upgrading. Some of the activities are crosscutting; these are presented under the most relevant goal. The activities in the later years will build upon the findings from the earlier year programs. These later year activities are designed with flexibility to take advantage of these early year findings. Most of the key activities have as a common theme consideration of the existing technology base and allow for input from industry in setting the key objectives.

\subsubsection{Measures of Effectiveness}

The effectiveness of the oil downstream operations research can be assessed by comparing both short-term and long-term performance based upon the outputs from the various elements of this plan. Evaluations should center on the impacts on the petroleum industry between the desired efforts and the actual ones that address areas of improvement. The ultimate impact of this DOE program compared to the current baseline should be:

- More stable and risk-based refinery environmental regulations

- Reduced refinery emissions and waste streams at acceptable costs

- Increased processing of domestic heavy crude oils leading to greater domestic production

- Increased production of transportation fuels and a reduction in environmentally adverse products, such as residual fuel oil, residua, and coke

- Lower refining costs by development of more efficient technologies

- U.S. refining industry remaining competitive in the global market, maintaining its technological edge, and retaining its foremost role in environmental leadership

Without question, these measures of effectiveness will depend on the actions of the petroleum industry refiners-to assist in the technology developments and to make the commitments to install the new processes or procedures. 


\section{Table 2.7.1 Budget for Oil Downstream Operations}

\begin{tabular}{lcc}
\hline Functions & $\begin{array}{c}\text { FY 1994 } \\
\text { Appropriated } \\
(\$ 1,000)\end{array}$ & $\begin{array}{c}\text { FY 1995 } \\
\text { Appropriated } \\
(\$ 1,000)\end{array}$ \\
\hline Environmental Compliance & 767 & 1,132 \\
Pollution Prevention & 1,605 & 1,883 \\
Heavy Oil Upgrading & 1,902 & 3,914 \\
\hline Totals for Oil Downstream Operations & 4,274 & 6,929 \\
\hline
\end{tabular}

1994
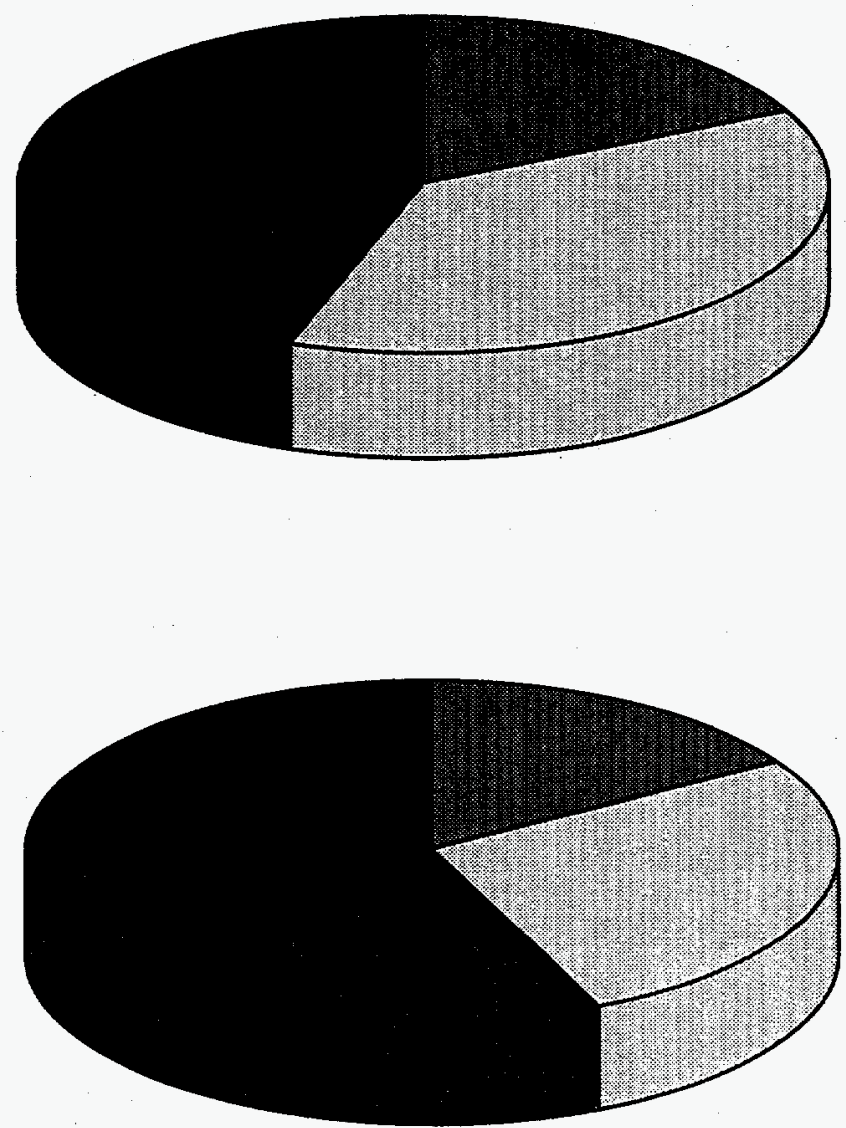

Environmental Compliance

Pollution Prevention

Heavy Oil Upgrading

Figure 2.7.2 Oil Downstream Operations Budgef 
Figure 2.7.3 Key Activities and Timing for Oil Downstream Operations

\section{Schedule for Processing Operations}

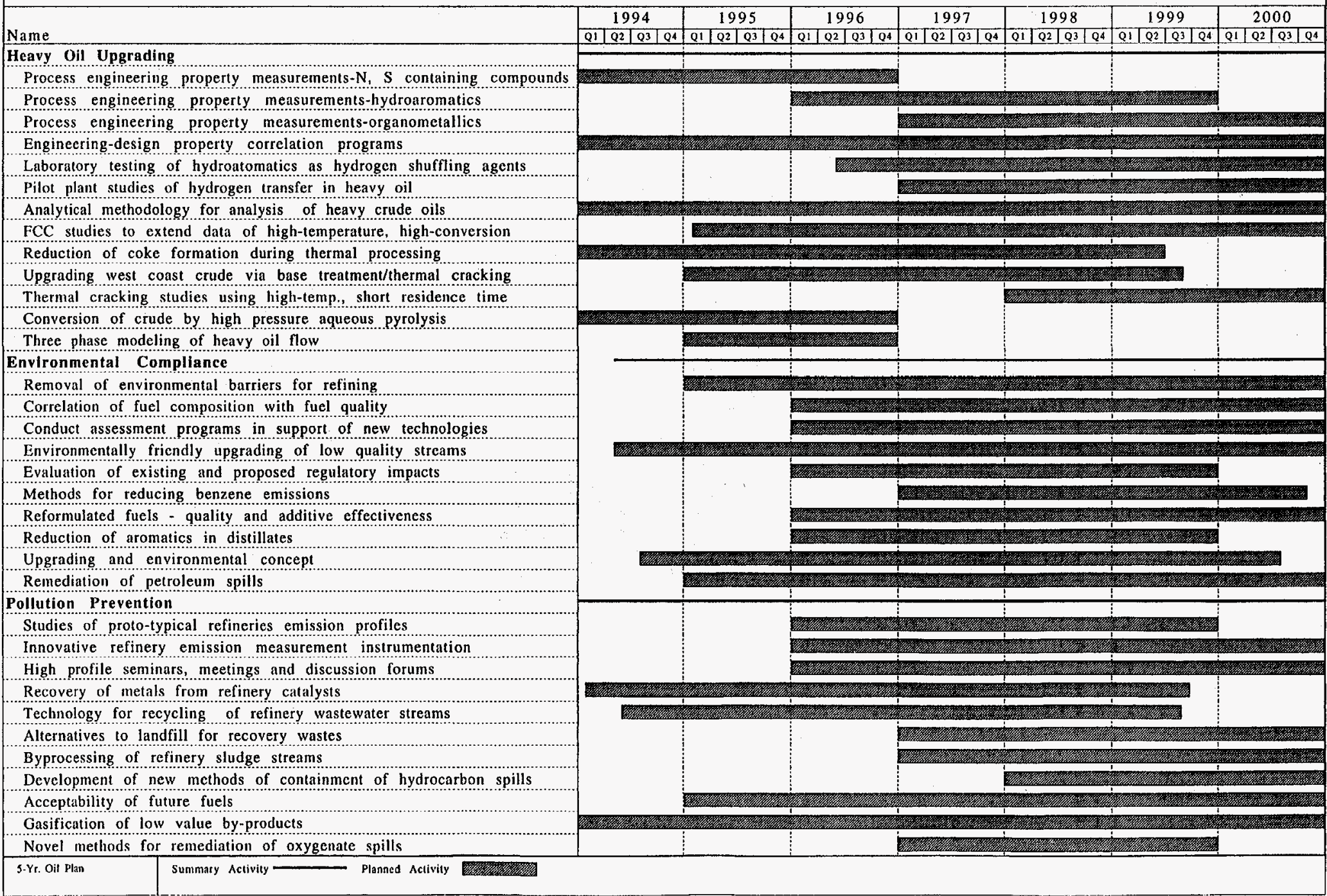




\subsection{ENVIRONMENTAL RESEARCH}

\subsubsection{Program Overview}

Implementation of the Environmental Research Program is the responsibility of DOE's Metairie Site Office (MSO) in New Orleans, LA. The MSO mission is to maximize the production and ultimate recovery of U.S. oil and gas resources by reducing the cost of effective environmental protection. This program is designed to implement EPACT, DNGOI, and DOE's Strategic Plan.

\subsubsection{Goals and Objectives}

\section{Goals of Environmental Research:}

- Reduce environmental costs to operators while improving their environmental performance.

- Support state, tribal, and federal government officials in making sound regulatory decisions.

- Promote better communications with producers in order to assist them in environmental and regulatory problem solving.

Five principal research areas form the basis of the Environmental Research Program: Area of Review variance, streamlining regulations, Gulf of Mexico discharges, environmental technologies and practices, and environmental outreach and program planning. Figure 2.8.1 shows the work breakdown structure for the Environmental Research Program.

\subsubsection{Area of Review Variance}

This research area involves expanded data acquisition, data analysis, and improved data management to support risk-based regulatory decisions related to Area of Review requirements for Class 2 (oil and gas) injection wells under state Underground Injection Control programs. A variance methodology has been developed by the University of Missouri through the American Petroleum Institute (API) and the Groundwater Protection Council (GWPC).

This project will provide states with the capabilities to support the acquisition of variances to forthcoming Environmental Protection Agency (EPA) Area of Review requirements. These requirements relate to risks posed to groundwater from injecting produced water for disposal and enhanced oil recovery. These requirements are expected to include Area of Review analyses for pre-1982 injection wells that had previously been grandfathered. The risk-based decision-making process should provide savings for the oil and gas industry and regulatory bodies by providing variances to wells not representing a significant environmental threat. The proposed regulation provides the potential for exemption through area-specific variance plans submitted by the states and approved by the EPA. The results of this project, including guidance in preparing Area of Review reports where required, will be transferred to oil and gas operators. 


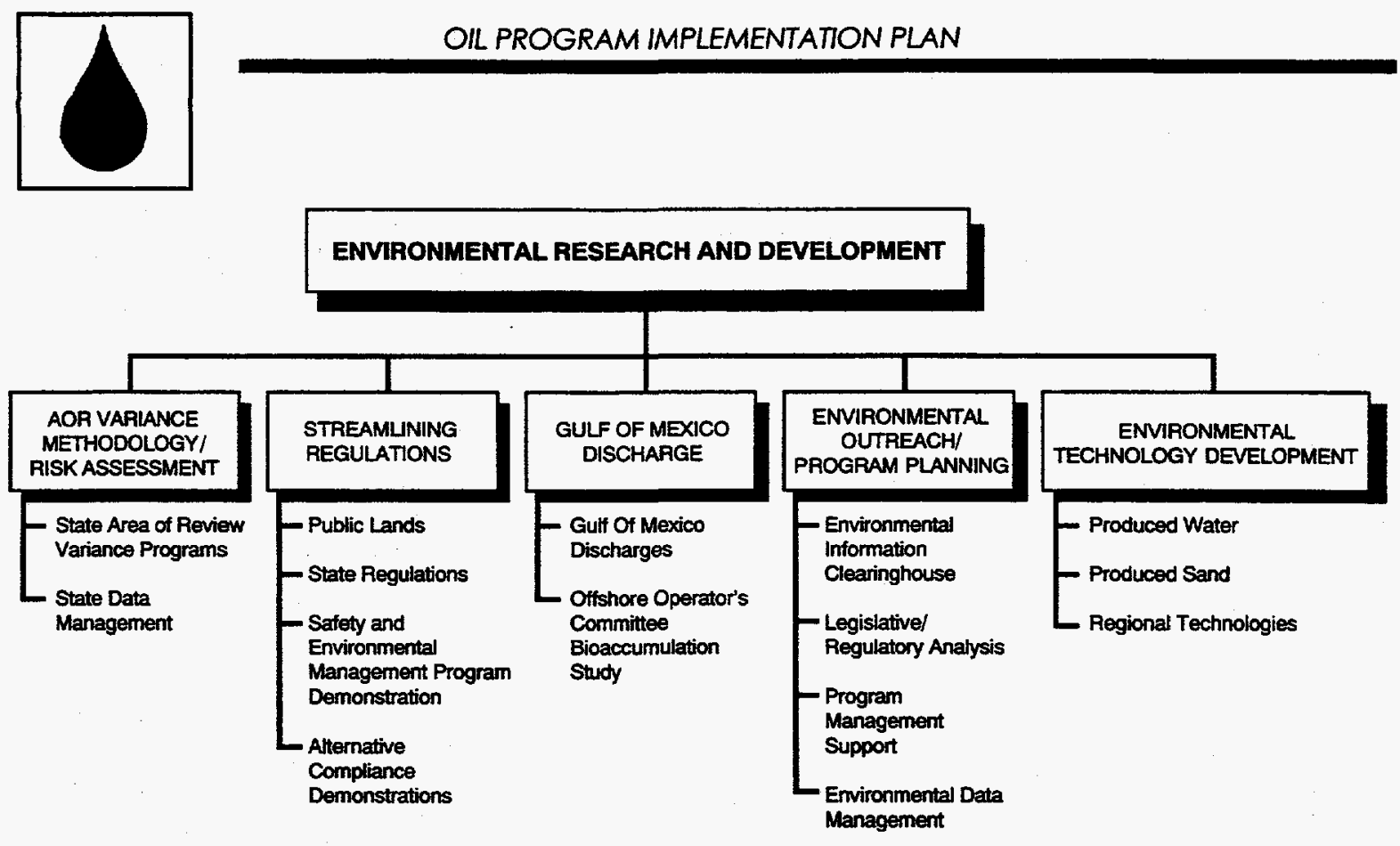

Figure 2.8.1 Environmental Research Program Work Breakdown Structure

If DOE successfully coordinates and adequately supplements the available resources, savings from avoiding maximum Area of Review requirements costs would reach as high as $\$ 340,000,000$ for pre-1982 wells. Savings from corrective actions could also be achieved. Savings for newly drilled wells and the states who will have to process the actions are significant but have not been estimated.

Ultimate Project Objective: To cause all primacy states (which have the most resource at risk) to submit by early 1998 their Area of Review Variance Plans under the Safe Drinking Water Act in order to provide variances for all wells not representing a significant environmental threat.

\subsubsection{Streamuining Regulations}

One of the objectives of DNGOI is to streamline and improve environmental regulations. If accomplished, this should reduce costs to oil and gas operators. Streamlining will simplify regulations without compromising environmental protection. One sample project is the Safety and
Environmental Management Program (SEMP) alternative regulatory compliance demonstration project. This work is a joint pilot project of DOE, Department of the Interior, and the offshore oil and gas industry. It will demonstrate the feasibility of voluntary SEMP plans for small operators on the Outer Continental Shelf as an alternative to new regulations.

A second example involves work with states, tribes, and federal agencies to enhance the efficiency and effectiveness of regulatory programs and to reduce undue burdens on the oil and gas industry by improving coordination among regulatory agencies. Strategies include promoting dialogue and building partnerships among industry, states, the public, and other interested parties. Specific activities include a public lands project and a state regulatory streamlining project. The first activity focuses on streamlining regulations in western states having a large area of federal lands with petroleum potential. The second focuses on developing cost-effective, risk-based approaches to state oil and gas exploration and production regulations and regulatory permitting processes. 


\section{Objectives of Streamlining Regulations:}

- By 1995 initiate the SEMP alternative regulatory compliance demonstration project (as an alternative to regulations).

- By 1995 initiate a public lands project focusing on regulations in western states having a large area of federal lands with petroleum potential.

- By 1996 initiate a state regulatory streamlining project involving environmental regulations in a minimum of two states.

- By 1997 initiate a second alternative compliance demonstration project, designed to show a process which will lead to regulatory simplification.

\subsubsection{Gulf of Mexico Discharges}

The assessment of environmental and human health risks associated with produced water and sand discharges from offshore and coastal oil and gas operations in the Gulf of Mexico (GOM) region is a subject of great significance to the domestic oil and gas industry. This research area will add to scientific knowledge concerning:

- The fate of organics, trace metals, and naturally occurring radioactive material (NORM) in water, sediment, and biota

- Chemical characteristics of produced water and sand discharges

- Environmental recovery of four former produced-water discharge sites in wetlands and open bays

- Economic and energy supply impacts of existing and anticipated federal and state offshore and coastal discharge regulations

- Catch, consumption, and human use patterns of seafood species collected from coastal and offshore waters

- Laboratory analysis methods for NORM

- Human health and environmental risks associated with the ingestion of radium in fish and shellfish harvested near offshore produced-water discharges
- Bioaccumulation of organics and inorganics in resident fish and invertebrates in the immediate vicinity of representative GOM offshore platforms

- Investigating the applicability of lower cost produced water-treatment technologies for Louisiana and Texas open bays

The results of these studies will assist regulatory agencies to develop technically sound and justifiable regulations based on scientific data.

\section{GOM Discharge Project Objectives:}

- If scientifically justifiable, affect regulatory decision making that would allow industry to continue produced-water surface discharges in coastal Texas and Louisiana open bays through at least January 1, 1997.

- If scientifically justifiable, affect regulatory decision making that would allow industry to continue produced-water surface discharges on the Outer Continental Shelf.

- If scientifically justifiable, affect regulatory decision making that would allow produced-sand discharges on the Outer Continental Shelf.

\subsubsection{Environmental Outreach and Program Planning}

This research and analysis area seeks: (1) to conduct analyses of industry and environmental trends and to maintain performance measure data for program planning, program evaluation, and technology transfer; (2) to conduct environmental outreach efforts to oil and gas producers and regulators; (3) to support program management; (4) to conduct regulatory and legislative impact analysis.

\section{Outreach Goals and Objectives:}

- Maintain performance measure data for program planning, program evaluation, and technology transfer. 


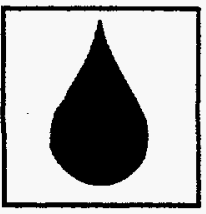

- By 1997 initiate environmental information clearinghouses and assistance centers for independent operators.

- Assist producers with risk-based environmental decision making through better communications.

- Assist state and federal regulatory bodies with environmental data management for risk-based decision making.

- Maintain program management support for the MSO.

\subsubsection{Environmental Technology DeVELOPMENT}

Another major research area is the research, development, demonstration, and transfer of environmental compliance technologies and practices to oil and gas operators, thereby improving environmental performance and lowering costs for producers. A project is planned to investigate lower cost produced-water treatment and disposal in the following area: (1) Appalachian region, (2) Rocky Mountain region, and (3) California. The project includes developing three lower-cost (20\% lower) produced-water treatment technologies suitable for small operators and marginal well producers, and delivery to key producers in each major producing region using commercial scale demonstrations.

\section{Project Goals and Objectives:}

- Reduce costs of produced water treatment.

- Improve/reduce costs for produced water injection.

- If scientifically justified, continue offshore produced water discharges.

- If scientifically justified, continue producedwater surface discharges for beneficial use in the Rocky Mountain region.

- If scientifically justified, continue produced-water surface discharges in the Appalachian region.

- By the end of 1998 , have at least five candidate treatment technologies in testing or demonstration.
- By the end of 1998 , initiate commercialization plans.

\subsubsection{StAKehOLDERS}

The Environmental Research Program is driven by concern and consideration for key customers and stakeholders, including:

- The producer, the refiner, the environmental regulator, and the investor

- Federal agencies: EPA, Minerals Management Service, Bureau of Land Management, U.S. Geological Survey, Treasury, and U.S. Fish and Wildlife Service

- State, local, and Native American governments

- Organizations of state governments (such as the Interstate Oil and Gas Compact Commission and GWPC)

- Congress: House and Senate Energy Committee, key staff, and Congress members

- The President and the administration

- Trade and professional interest groups (such as API, Gas Research Institute, Independent Producers Association of America, and Petroleum Technology Transfer Council)

\subsubsection{IMPACTS}

Potential impacts of the Environmental Research Program include:

- Reducing the cost of compliance and improving environmental performance with better operating procedures, equipment modifications, and new equipment

- Promulgation of rules and regulations by state and federal regulatory agencies based on sound science and risk analysis

- Streamlining and simplification of multijurisdictional, multilayer, and overly complex regulatory processes

- Increased availability of information and improved coordination concerning the environmental aspects of gas and oil exploration and production 
- Industry, government, and the public working together as partners to resolve regional environmental issues, unnecessary delays in the regulatory permitting process, and outstanding disputes concerning natural gas and oil development.

\subsubsection{BUDget}

The Environmental Research budget focuses on those areas where the most benefit is likely to be obtained for the investment: new costeffective technologies, streamlined approaches to complying with multiple regulations, and rational risk-based decision making in developing regulations. The budget is summarized in Table 2.8.1 and Figure 2.8.2. As stated in Section 1, this
Oil Plan is developed for an unconstrained budget that is bounded by the scope of goals set by Congress, the President, and the Secretary of Energy.

\subsubsection{SCHEDULE}

Figure 2.8.3 shows key activities and their timing in the Environmental Research Program.

\subsubsection{Measures of Effectiveness}

The success of the Environmental Research Program will be determined by using a number of performance indicators. Table 2.8.2 summarizes the key activities in the Environmental Research Program along with the measures of effectiveness. 


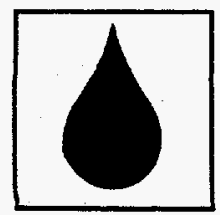

Table 2.8.1 Budget for Environmental Research and Development Program

\begin{tabular}{lcc}
\hline Functions & $\begin{array}{c}\text { FY 1994 } \\
\text { Appropriated } \\
(\$ 1,000)\end{array}$ & $\begin{array}{c}\text { FY 1995 } \\
\text { Appropriated } \\
(\$ 1,000)\end{array}$ \\
\hline Risk Assessment & 1,690 & 2,114 \\
Streamline Regulations & 440 & 605 \\
Produced Water Research & 820 & 1,065 \\
Program Planning & 254 & 250 \\
Program Management & 132 & 641 \\
Heavy Oil* & 275 & 100 \\
\hline Totals for Environmental Research & 3,611 & 4,775 \\
\hline
\end{tabular}

* Activities relevant to heavy oil are considered with other functions after FY 1995.

1994

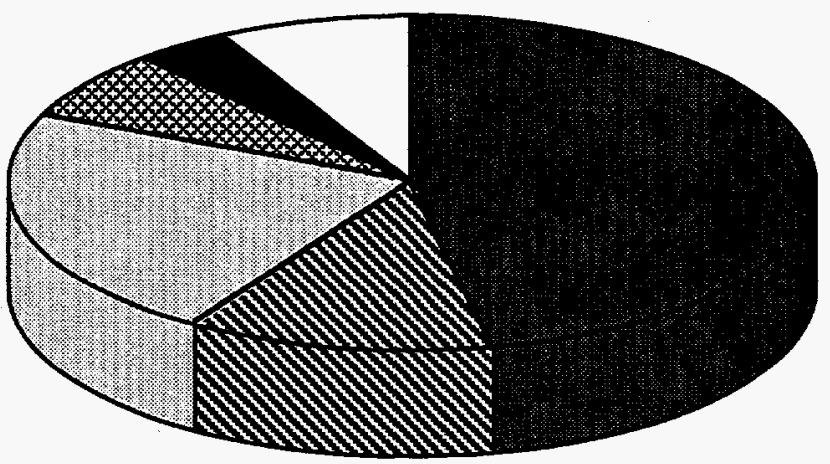

1995

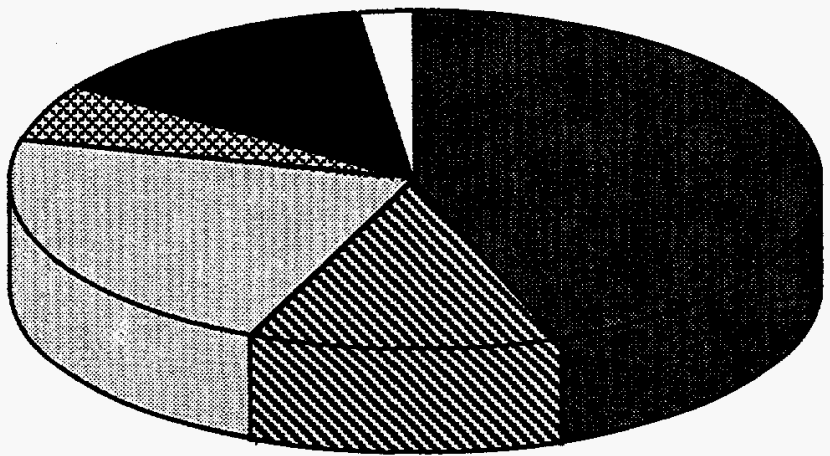

Figure 2.8.2 Environmental Research Budget
Risk Assessment

Streamline

Regulations

Produced Water

Research

Program Planning

Program

Management

Heavy Oil 
Figure 2.8.3 Key Activities and Timing for Environmental Research and Development
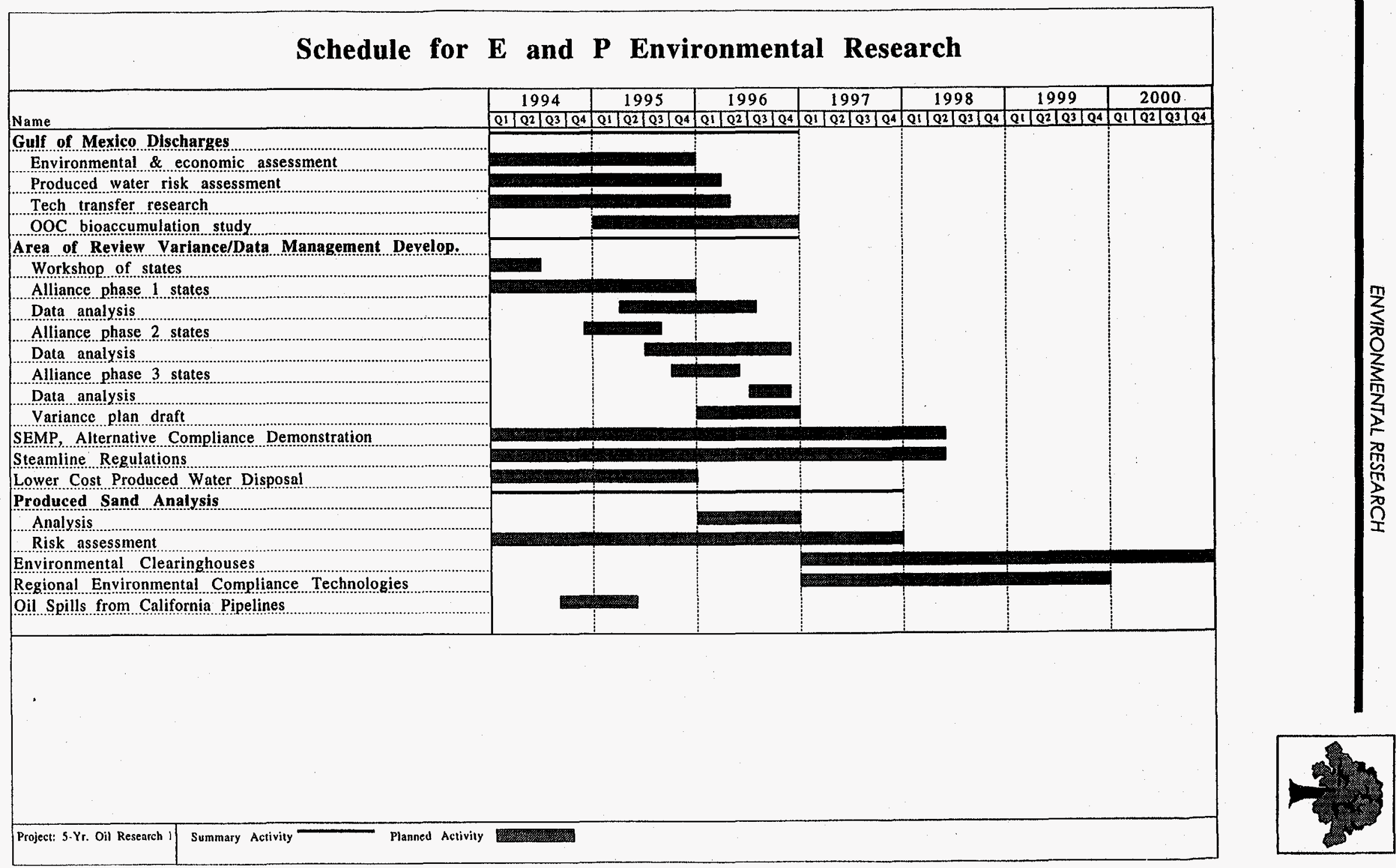


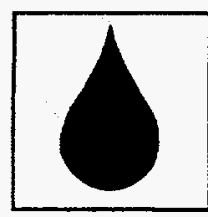

Table 2.8.2 Measures of Effectiveness for the Environmental Research Program

Environmental Research Activities

- Area of Review variance

- Streamlining regulations

- Gulf of Mexico discharges

- Environmental technologies and practices

- Environmental outreach and program planning

\section{Metrics}

- Number of variances for wells not representing a significant environmental threat, included in approved state and Environmental Protection Agency Variance Plans

- Number of environmental regulations avoided

- Number of regulations simplified

- Technically sound and justifiable federal/state produced water/produced sand regulations as a result of DOE research and analyses

- Cost reduction for environmental compliance through technically effective environmental technologies and practices

- Numbers of producers/operators that have received and applied environmental information as a result of DOE activities

- Ability to evaluate program effectiveness through tracking of environmental trend data. 


\subsubsection{Program Overview}

Program Support Infrastructure is comprised of three working areas: Quality Assurance (QA); Environment, Safety and Health (ES\&H), and Facilities Management. The mission of these areas is to work as an interdisciplinary team to assure minimal contract delays and to promote smooth operations at NIPER in Bartlesville, Oklahoma. This goal is accomplished by meeting ES\&H requirements, complying with all QA standards, and attending to all Facilities Management needs. The team goal is to ensure that the Oil Program proceeds as planned and on schedule. Figure 2.9.1 shows the work breakdown structure of the program area.

\subsubsection{Quautr Assurance}

As part of the Oil Program, QA plans, develops, and monitors the standards necessary to ensure that all program activities meet the appropriate quality standards.
QA strengthens the standards of excellence affecting all parties and improves facility performance by ensuring that performance plans are met.
The mission...is to assure minimal contract delays and promote smooth operations.

\subsubsection{ENVIRONMENT, Safety \& Health}

ES\&H is a crosscutting area responsible for oversight, complying with regulatory requirements, and obtaining permits. The ES\&H goal is to assure continuous improvement in meeting appropriate contract requirements, to take appropriate corrective actions, to promote interactive decision making, and to implement effective measures of performance.

\subsubsection{FACILIIES Management}

The Facilities Management team establishes a site master plan, provides real property support, and provides operational management. The Facilities Management goal is to ensure that program needs are considered in site development planning so that growth is not needlessly

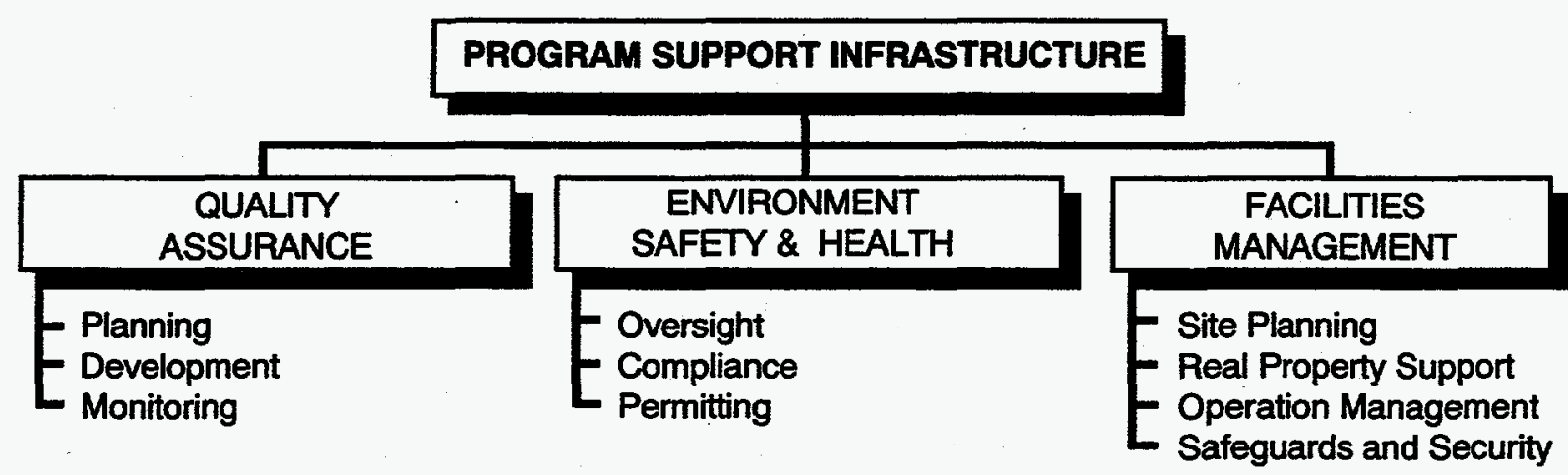

Figure 2.9.1 Program Support Infrastructure Work Breakdown Structure 


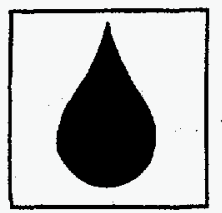

constrained by facilities. Delays would therefore be reduced. Facilities Management is essential to the smooth operation of the projects at NIPER. The Safeguard and Security program acts to protect research facilities as well as proprietary and intellectual information.

\subsubsection{StaKeholders}

As with all other areas in the program implementation plan, the drivers of Program Support Infrastructure are the plan stakeholders and customers. Although the stakeholders ultimately include the U.S. taxpayer, Secretary of Energy, and President, the primary stakeholders are the Oil Plan, Bartlesville Project Office, and the Office of Fossil Energy.

\subsubsection{IMPACTS}

Program Support Infrastructure is a nonprogram, nonbudget area. Independently or in concert, the three work areas will reduce liability, maintain safety and health, and benefit the environment in operating the NIPER facility.

\subsubsection{BUDGET}

Since Program Support Infrastructure is a nonbudget area, it is not included in the Oil Plan budget.

\subsubsection{SCHEDULE}

Figure 2.9.2 shows key activities and their timing in the Program Support Infrastructure area.

\subsubsection{Measures of Effectiveness}

Table 2.9.1 provides a summary of the activities in the Program Support Infrastructure function and the metrics for evaluating these activities. 
Figure 2.9.2 Key Activities and Timing for Program Support Infrastructure

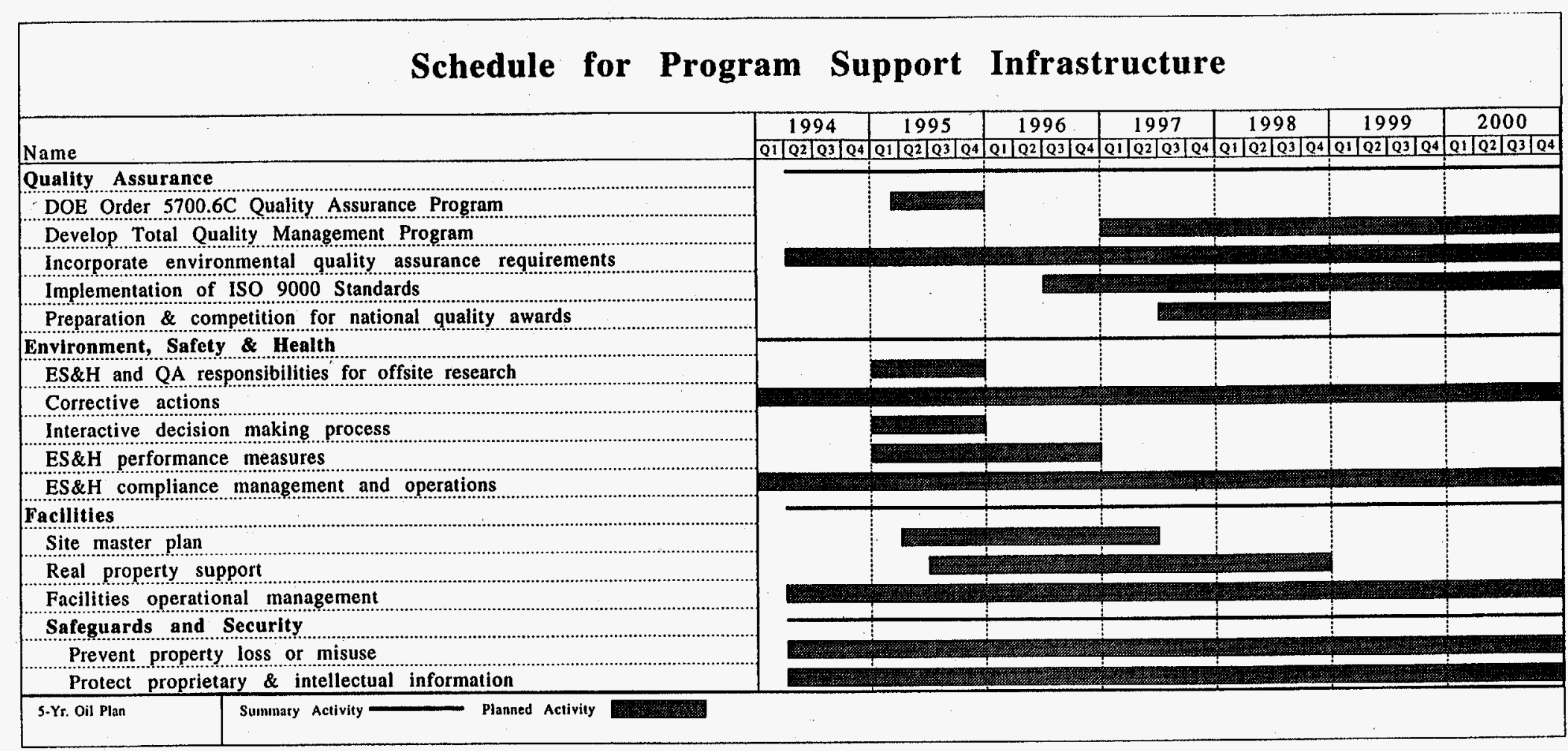




\section{Table 2.9.1 Measures of Effectiveness for Program Infrastructure}

\begin{tabular}{|c|c|}
\hline Activities & Metrics \\
\hline \multicolumn{2}{|c|}{ Quality Assurance } \\
\hline $\begin{array}{l}\text { Develop and promote continuous } \\
\text { improvement } \\
\text { - Survey quality operational results } \\
\text { Develop and implement Customer Focus } \\
\text { and Satisfaction Program }\end{array}$ & $\begin{array}{l}\text { - Reduced number of customer complaints } \\
\text { - } \text { Rework costs } \\
\text { schedule } \\
\text { - Customer Satisfaction Survey showing } \\
\text { improving trends in awareness of the } \\
\text { program and the quality of its products }\end{array}$ \\
\hline \multicolumn{2}{|c|}{ Environment, Health \& Safety } \\
\hline $\begin{array}{l}\text { - } \text { Compliance } \\
\text { - Regulatory requirements } \\
\text { Permitting }\end{array}$ & $\begin{array}{l}\text { - } \text { Absence of fines } \\
\text { - } \quad \text { Lack of project interruptions } \\
\text { - Safety record improvement }\end{array}$ \\
\hline \multicolumn{2}{|c|}{ Facilities Management } \\
\hline $\begin{array}{l}\text { - Site master plan } \\
\text { - Real property support } \\
\text { - Operational management }\end{array}$ & $\begin{array}{l}\text { - Project delays reduced } \\
\text { - Lack of project interruptions }\end{array}$ \\
\hline
\end{tabular}




\section{APPENDIX}

An earlier draft of this report was distributed to over 330 representatives of the oil industry for their review and comments. The content of the responses from this industry review follows.
Editorial comments were included when appropriate, and the other comments will be considered during the development of future planning and implementation efforts. 



\section{GENERAL COMMENTS}

- I find the plan to be very comprehensive in scope, very well organized, and possibly very beneficial to companies of our size and position within the oil and gas industry.

- It is an excellent document.

- I think it [the plan] is a very informative and useful work. The DOE is right on in their assessments and likewise in their identified targets for solutions. It is a good piece of work. Unfortunately, it seems to be counter to the Administration's assessment of the situation facing our industry, and particularly that of the Secretary of Energy. This document professes encouragement and support, but in fact, I don't see much support from the Administration...Maybe it would be something that Senator Boren's group could take on.

- The plan seems to be complete and well conceived.

- Based on my observations and general understanding of various proposed programs, DRAFT 10-19-94 adequately represents our needs as a major independent producer.

- A couple of general criticisms have been voiced. First, there is some concern that the plan may be too fragmented; i.e., it addresses too many separate issues rather than applying a critical mass to a select few. Second, there is concern whether the key issues facing industry and our society have been properly prioritized. For example, in some cases it is questioned whether programs are designed to match capabilities rather than needs. (ACTI is cited an example)

- The document is an excellent job of "wordsmithing" but it is much too much. The plan would have far more impact if it were reduced by a half to two-thirds.

- I do not mean to be negative, but I believe the U.S. oil crisis is a major problem that without a major successful national effort will get worse and destroy the U.S. economy. I can remember when the government atomic energy program was going to give the U.S. nearly free energy. The oil crisis deserves a national effort at least the size of the Manhattan Project. The oil crisis is more important than the Space Program, the Space Station, and most military fiascos in progress or to come. Documents that promise a solution with a small effort divert attention from the real problem. 


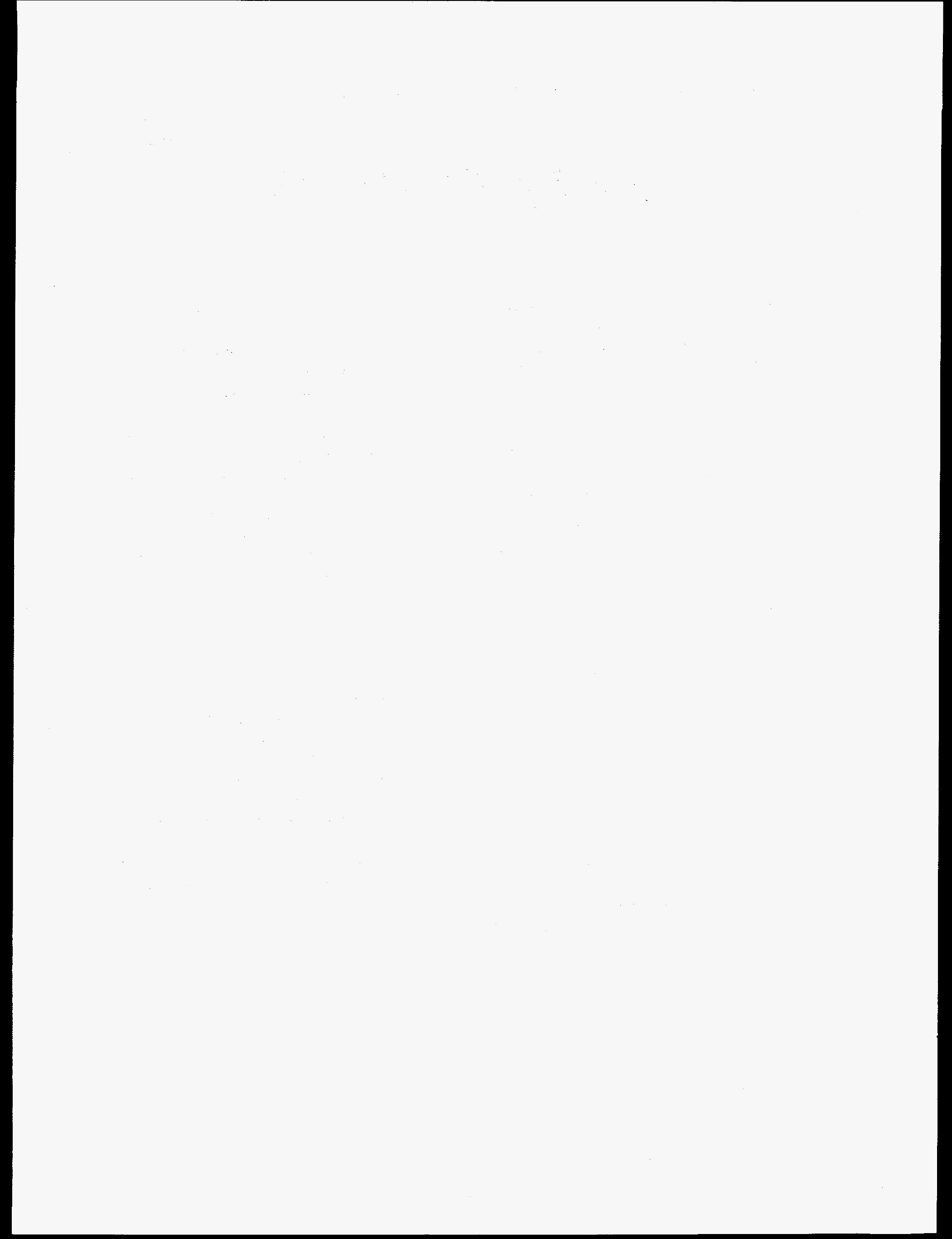




\section{SECTION 1 COMMENTS}

\section{SECTION 1.1 VISION, MLSSION, \& Goals}

- Restrictions on drilling of federal lands need to be removed. All of the technology in the world will not help if there is no place to drill.

- Are all of the research efforts going into the oil side of the industry? Natural gas, which often occurs in association with oil, should also be targeted (particularly re: exploration, reservoir analysis and management, production techniques and practices.

- DOE is to be commended for keeping the focus on the "stakeholder" in the DOE partnership.

- What I believe we need to do is to find out what each sector in our domestic oil industry needs, weld these together, and come up with a Save Our Domestic Industry First (SODIF) program.

- Each region of the country has unique economic, geologic, refining, transportation, and marketing problems. The plan seems to be attempting to solve world energy and environmental problems rather than to help the domestic energy industry and the U.S. economy.

- We believe the plan will contribute significantly to DOE's goal to better manage the nation's oil resources by providing assistance to industry, particularly independent companies.

- I find the plan to be internally inconsistent; i.e., the unbridled optimism of "Visions, Missions and Goals" is in direct contradiction to the real facts, trends, and history in "Issues \& Trends."

- The stated Department of Energy's Oil Program goal is to better manage our nation's oil resources by helping the industry more efficiently and effectively find, develop, and process oil into the desired energy products. We believe that a major part of the develop is not addressed by this plan.

\section{SECTION 1.1.1 VISION}

- What is adverse about "adverse products such as residual fuel oil?" Perhaps "low value products" would describe these materials more accurately.

- Is oil part of the Secretary of Energy's vision?

\section{SECTION 1.1.2 MISSION}

- It is especially important to emphasize the economic/technological implications of the plan. The value of the program goes beyond domestic energy production alone.

- Why do we want to export U.S. oil-related technology and services? It looks like this would increase competition for the domestic oil and gas industry. It doesn't fit with "Policy Drivers."

\section{Section 1.1.4 Poulcy Drivers}

- Again, this goes back to educating the investment community. Outside capital is vitally needed to promote active exploration, which will lead to the discovery of new oil and gas reserves. Anything DOE can do 


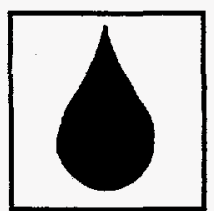

to educate the investment community will ultimately benefit the domestic industry.

\section{Section 1.1.4.3 DOe Strategic Plan}

- A chart or table of DOE's budget with the amount for this program highlighted would be interesting. How committed is DOE? Are we subgovernment workers for [or] oil and gas employees?

\section{TABLE 1.1.2 DNGOI DIRECTIVES}

- DOE should encourage the release of much presently inaccessible federal, state, and Indian lands to leasing for exploration. Educate the public and governments as to the advantages of such lands being available for exploration.

- "Increase oil production and environmental protection on Native American tribal lands" should include all federal lands.

\section{Section 1.2 Issues \& Trends}

- The major factor in the relatively low consumer cost of gasoline in the United States vs. that of other $O E C D$ countries is the very high excise taxes on gasoline in those countries, not the "efficiency in producing, refining, and distributing petroleum" in the United States.

- Overall, I believe that the plan does an excellent job of identifying upstream and to some degree, downstream needs of the petroleum industry, especially the independent sector.

- The foreword and other sections (p. xv, xix) mention the goals set by the President, Secretary of Energy, and Congress and their commitment to these goals. However, the funding levels for FY 1994-95 do not indicate a strong commitment. Our industry must have a more serious commitment of funds.
- I think the bottom line is that we have to get some help through taxes and incentives in order to enable us to get on with the extraction of hydrocarbons. We have the potential, we have the reserves in recoverable oil, but industry has, as you well know, an expensive marginal resource. Compounding this fact is that we are now being bombarded with many environmental regulations that, in my opinion, are not totally necessary.

- In final analysis, the U.S. oil crisis is not a technical problem but an economic problem. Any new technology developed will have to be low cost and very effective. The independents can not afford the technology they have now and the majors are leaving because of poor economics. Oil prices will increase but foreign producers with large easy to produce oil will have access to any U.S. developments and the gap remains.

- "The federal government can affect this rate of decline with its policies and oil research products." These policies and R\&D must have producer input.

- There is plenty of technology available to get secondary and tertiary oil out of the ground now. The problem is lack of profit. Since nothing can be done about the price of oil, perhaps the tax structure can be changed to increase profit on such projects.

- It is important to demonstrate the linkage between each individual component of the program and its value. It is important to the technical staff as well as the stakeholder. Having a specific client and user in mind from the beginning of a project stimulates and anchors the researcher and the program segment.

- Our interest in commenting is to maximize the opportunity to realize value to the oil industry from the national labs. What can 
we learn from the big three automakers or from the NSF R\&D franchise system?

- The plan looks like a plan to create government research for the oil industry and work for the labs rather than using more of the R\&D knowledge already gathered by the industry (major oil companies, service companies, and independents), much of which could be used now if it is disseminated.

- If our main objective is to help the domestic oil industry, we need to fast track the program in the United States and put less emphasis on foreign oil and gas projects for now.

- I think the DOE efforts are commendable. I can summarize my comments that most of the programs that have been presented are not possible under today's oil price schedule... The efforts of the DOE and others are important because increased prices will occur at some future date, so we can assume that a foundation is being established that will bear fruit at that time.

\section{Figure 1.2.1 U.S. Petroleum Industry Employment and Oll Production}

- It is equally important to address the issues of governmental agencies working together. Small operators cannot survive under the current environmental compliance levels from state and federal governments. A $43 \%$ increase in operating costs will require already marginal wells to be plugged and abandoned. What can we do to protect the industry from unreasonable regulations? There must be emphasis placed upon this so that enhanced oil recovery technology is feasible and government agencies are on the same page.

- It would be useful to show this information graphically over a period of 10 or more years to illustrate trends.

\section{Section 1.2.1.4 Marginal Wells and ABANDONMENT}

- Marginal wells account for approximately $75 \%$ of all domestic producing wells. They are more important than the $22 \%$ suggests because they help maintain the infrastructure needed to maintain even nonmarginal wells.

\section{Section 1.2.1.6 Exploration and Drilling}

- "These developments combined with promising estimates of significant undiscovered oil are creating excitement in the industry." (add) "but not enough in the absence of higher oil prices to stimulate drilling."

- Statistics on both wildcat and development drilling need to be documented, especially in light of the fact that some drilling statistics include a well once it is spud while others only include a well once it is completed. Also, seismic crew counts can be misleading. Data collection procedures are now much more efficient, especially with regards to 3-D seismic and, as a result, more data (it terms of both line-miles and square miles) are being collected even though the total number of seismic crew counts may have gone down.

\section{Section 1.2.1.7 Regulations}

- New environmental regulations may be the major reason for domestic-based production companies moving overseas (and this applies to other industries besides oil and gas).

- The rising costs associated with environmental regulations are why the industry is leaving.

- State regulations require plugging of SI wells or acquire TA permits. If there is no activity in time, the wells are required to be plugged. 


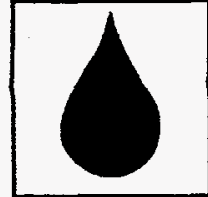

- In addition to over- and underregulation, double and triple regulation often occurs. Compliance would be easier if we [operators] had only one agency to deal with. Different agencies have different degrees of compliance.

\section{SeCtion 1.2.1.10 Decuning Industry R\&D EXPENDITURES}

- If R\&D trends are as stated, then where is all the new technology coming from.

- Perhaps this section would be better titled "Industry R\&D Expenditures," since that is what is being dicussed here. Governmental R\&D funding, I believe, has increased somewhat, as also indicated in Figure 1.5.1.

\section{Section 1.2.2.1 Demand, Price, \& Production}

- The discussion, based on Figure 1.2.7, uses inconsistent price and volume values. It appears to compare the high oil price $(\$ 30 / \mathrm{bbl})$ with the low production rate ( $<4$ million bbl/day) in 2010 .

\section{Figure 1.2.3 Product Demand}

- It would be instructive to include data from 1993 or 1994.

\section{SeCtion 1.3 DOE's Evolving Role}

- Government research can only speed up the implementation process if they can get small- to medium-sized producers involved in the program.

- The plan is correct about the increased role of government and academic research, but the plan seems to assume that most government activity is at the national level and state level participation is minimized.

\section{Section 1.4.1 Finding Domestic Oll Resources}

- Why should the establishment of a field laboratory be restricted to Native American lands? It should include all federal lands as well.

\section{Section 1.4.2 Maximizing Domestic Oll}

- Re: computer models. PC-based models would be most applicable.

\section{Section 1.4.4 Protecting the Environment}

- Under "Streamlining Regulations," we do not need another federal regulatory agency.

- Re: Area of Review Variance. They are proposing less than five-year MITs. Only a few wells now don't pass at five-year intervals.

\section{SECtION 1.4.5 U.S. LeAdership}

- "Over 350,000 oil and gas extraction jobs have been lost since 1982." (add) this amounts to almost a $50 \%$ decline.

- In Analysis and Planning, the industry should define the priorities.

- The third sentence of the middle paragraph should read: "Major oil and gas companies are leaving the United States by moving many of their operations overseas where cost are lower..."

\section{Section 1.5 Budget}

- Since FY 1996 and out-year budgets are not included in this draft of the plan, and since these are politically sensitive, it is difficult to make any thoughtful judgments about the reasonableness of the plan or whether it is internally consistent. 
- For the well-formulated goals of the Oil Program to be accomplished, two events must occur. First, the level of funding for FY 1996-2000 must be drastically increased over the 1995 level. Second, an additional budget category must be included in the funding mechanism. It is necessary to create a new budget category and associated selection process so that independent operators can submit projects as needs/opportunities arise. (For example, if Company had a Class 7 project in inventory, it would not be possible to delay the project until it would qualify for assistance in FY 1998.)

- The plan should include a total budget summarized in a final Section 3.1.

- DOE paints with a very broad brush. The plan indicates that DOE will spend 75-80 million dollars a year, about half for research and half for field demonstrations. There is no detail in the plan as to what will be researched and what will be demonstrated in the field. I would like some examples. There are a lot of nice sounding words like "stakeholder," but no specific about research projects or who will do the work. Will it be BDM, DOE itself, the national labs, or universities?

- I doubt that producers will get much benefit out of this 150-million-dollar two-year program.

- About 10 times as much money is budgeted for Extraction and Reservoir Characterization as for Exploration and Drilling. The problem with the industry today is that no new fields are being discovered because of a lack of exploration. The industry is buying and selling old fields and infield drilling instead of exploring.

- It appears as though commitment from the government is slow in coming. Is DOE still trying to judge industry support prior to inclusion in its budgets requests, or is it sim- ply that all of the work has so far predated the budgetary cycles?

\section{Figure 1.5.1 R\&D Funding 1973-94}

- It would be helpful to indicate whether the dollars are held constant or current and, if constant, the reference year.

- How does this compare to money spent in research of other energy supplies?

\section{SECTION 1.6 IMPROVING INDUSTRY \& STAKEHOLDER ACCEPTANCE}

\section{Section 1.6.3 Stakeholder Partnerships}

- It is unclear what is meant by "nuclear invasion." Half or more of the national labs have had little or no involvement with nuclear weapons for many years, hence their availability is not much related to the reduction in nuclear weapons programs.

\section{SeCtion 1.7 Measures of EfFECTIVENESS}

- Application of evaluation metrics in the $R \& D$ area is inherently difficult. Metrics should: be measurable, be understandably related to the program, mathematically manageable, and not introduce excessive lag time into the project.

- Internal program accomplishments (p. 33) is a bureaucratic strawman. The only real measures of the success are the bottom-line economics (which in turn fuel R\&D).

- I feel more work is need to be done on the metrics for measures of effectiveness; particularly for Reservoir Management Demonstrations. Better ways of measuring and reporting effectiveness would be important to DOE and NIPER for evaluating your program and to oil operators to learn quickly of new technology and judge its applicability. 


\section{SECTION 2 COMMENTS}

\section{Section 2.1 Reservoir Characterzation}

- "ACTI is part of a larger government/industry partnership to move defense technology from the national labs to other domestic applications." This statement is inconsistent with the ACTI plan document of May 1994, which says, "The Program has been formulated to enhance, apply, and transfer computational technologies ...developed within the National Laboratories in such areas as earth sciences...to the domestic natural gas and oil E\&P sector." This plan should be inclusive of organizations and technologies rather than exclusive.

- Industry may be better served by disbanding these partnerships and reducing taxes to the industry and letting them develop their own technology as in the past on a free market basis.

- All kinds of fancy programs and high-tech approaches are discussed. The most basic problem is not addressed. The detailed individual well data critical to any analysis of the reservoir containing this discovered, but unproduced, oil is being rapidly lost as major companies and larger independents sell or abandon oil fields and particularly large multiworking interest secondary recovery units. There is no easy way to convert this often ancient data to the electronic medium and storage of numerous hard copy files is impractical. These absolutely vital files are being junked and can never be replaced. It is my opinion that present data collecting and processing projects are a fine start, but will never enable geologists and engineers to accomplish the stated objective. We need to think about encouraging donations of this data to libraries/ institutions/geological societies/engineering societies/etc., and funding to maintain them.

- Under Reservoir Characterization, geostatistics should be included as an integral part of the overall program. I can not stress the importance of this tool for data integration and construction of reservoir models, enough. Geostatistics also fits nicely into the "Risk-Based Decision Management" under the Exploration, Drilling,... Program.

- I believe that technology transfer of the benefits of Reservoir Modeling is the most seriously neglected aspect of Reservoir Characterization. The economic benefit of small scale (three to five wells) reservoir simulation needs to be demonstrated to Independent operators. It would also be nice to have some larger scale reservoir simulations which have benefited from careful geoscience characterization available in the literature. I believe that the costs for this type of work are very high so it may need to be singled out for its own cost center.

\section{Section 2.1.1 Program Overview}

- Injection data is not listed under "hard" data. Is it assumed to be included under production data?

- Reservoir characterization efforts begin before the discovery of an oil field (p. 39, col. 1, par. 3).

\section{Section 2.1.1.1 Goals and Objectives}

- It is not clear how reservoir characterization data and expertise provided to state 


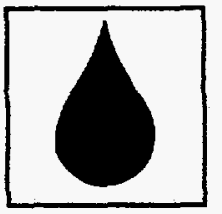

and federal regulatory agencies will support the development of technically sound and cost-effective environmental regulation efforts.

\section{Section 2.1.1.5 Reservolr Characterzation}

- To maximize this partnership, universities, state entities, etc., should be a part of the team because these state groups house much of the descriptive data required for reservoir characterization, have had vast experience determining reservoir architecture, and most importantly, have been interacting with industry for decades thereby providing a critical link between industry and the national laboratories.

- For the most part "national laboratories" do not have the technology development techniques to encourage industry application of their results. If funded they will not develop this overnight. Funding of \$6 million plus in this area is not warranted. This paragraph somewhat mixes up the chicken with the egg...Is this limited to "DOE national laboratories?" Somewhere else in the report NIPER excludes themselves from being a "national laboratory." I thought the idea was to bring some of the formerly defense supported laboratories into geoscience research; if that was the intention, par. 2.1.1.5 doesn't make that point.

\section{Figure 2.1.3 Work Breakdown Structure}

- Add "Fluid Properties/Phase Behavior" under "Geoscientific Measurement."

- The budget for 1995 for Geoscientific Measurements and Reservoir Description is so low that little can be expected in these categories. Much emphasis is given this area of research in introductory chapters funding here is so low as to negate any impact.

\section{Table 2.1.3 Measures of Effectiveness}

- A decrease in the cost of seismic fielding on the order of $50 \%$ would be much more desirable.

\section{Section 2.2 Extraction Research}

- In the figure on page xvi, "Extraction Research" should extend forward into "Find Domestic Oil Resource."

\section{Section 2.2.1 Program Overview}

- Investigate more efficient, less costly methods to artificially lift oil or to replace beam pumping units and downhole centrifugal pumps or greatly improve their efficiency and reduce costs of acquisition and operation.

- Study means to reduce fuel costs (electricity, natural gas, propane) utilized in lifting oil and associated liquids. Experiment on utilization of oilfield brines to extract usable products therefrom to make resulting water usable for agricultural purposes. Reduce cost of brine disposal, create usable products, provide water in semiarid regions where possible.

\section{Section 2.2.1.3 Advanced Oil Recovery}

- The Hepla Field Project has been shelved. The first project of this type was initiated in 1987. This field scale project produced $16 \%$ OOIP and was economically successful. A second project began in 1993. Several other will begin in 1995.

\section{Section 2.2.1.5 Simulation of Extraction}

- The computer models to which the plan refers are "expert systems." 


\section{Table 2.2.2 Measures of Effectiveness}

- "Foreign oil importation level," though commonly used, is closely related to other macroeconomic activity and may bear little relationship to the accomplishments, or lack thereof, of the program.

- "Increase in the number of IOR/AOR initiatives" is impacted by the price of oil, as shown in Figure 1.2.9, and may not be a good metric.

- There are numerous citations in the metrics and in the narrative to patents, technical information requests, etc., to NIPER. This is inconsistent with DOE's interest in seeking broad participation by industry, national labs, universities, and others. This plan should not connote itself as being a sales brochure for BDM-Oklahoma or any other specific party (reference pp. 34, 62; 79).

\section{Section 2.3 Exploration, Drilling, AND RISK-BASEd MANAGEMENT}

- Deepwater (GOM) drilling and production systems offer a significant opportunity to increase U.S. reserves and production. This will have a greater impact on G\&O business decisions, economics, and U.S. oil production than any other technology. Deepwater technology should be targeted and featured, not buried as an "also."

- The industry is driven by economics, but DOE is not. Consequently, DOE should take the leading role in researching and developing exploration technology. It is new exploration technology, not extraction, that will do more to arrest our domestic production decline and our growing balance of payment deficit.

- DOE should devote considerable research to new technologies applicable to exploration (i.e., geophysics, geochemistry, etc.) to increase discovery ratio and risks and cost of discovery. We need greatly improved drilling techniques to reduce costs. Cheaper, more effective downhole evaluation methods are needed.

- We need to educate the investment community to increase the flow of risk capital into the industry.

- Many of the technologies mentioned in the plan are being studied at...These include: 3D seismic, slimhole drilling, coiled tubing drilling, MWD, horizontal drilling, reservoir characterization, EOR, producer/injector profile modification.

- Rapid transfer of the benefits of 3-D seismic in field development context should also be given priority as well as development of screening processes for usefulness of horizontal wells.

\section{Section 2.3.1 Program Overview}

- I may have missed this, but I am not clear as to who does all of the work associated with each aspect [of the plan]. An example: on page 66 [Section 2.3.1.2] in discussing basin analysis (which is a great project), who does the work? It would seem that a task force of government, industry, and academia would be effective and then the data could be transferred... How the work gets done needs to be outlined in detail, perhaps before the plan is completed, so that industry can see where we fit.

\section{SECTION 2.3.1.2 EXPLORATION}

- A thorough review of the U.S. sedimentary basins prior to the selection of the priority basins for study is critical to the success of this initiative. State surveys and universities, in addition to federal agencies, should be queried as to available data on the nation's sedimentary basins. This is an initiative that can produce huge dividends by 


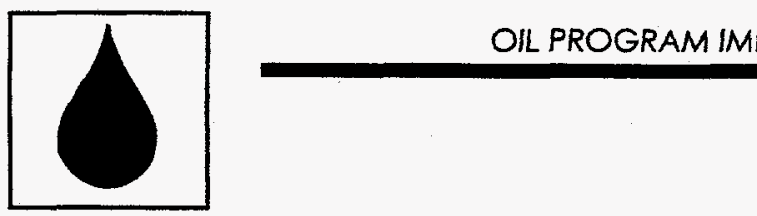

identifying untapped hydrocarbon resources.

\section{SECtion 2.3.1.5 Field Laboratory}

- Why locate the field laboratory in such an atypical area (Osage County, OK)?

\section{SECTION 2.3.3 IMPACTS}

- Again, why restrict the drilling areas covered in the project?

\section{Section 2.3.6 Measures of Effectiveness}

- Re: establishing a national data center and source for geoscientific information, much of the data is proprietary and probably will not be released to everyone.

- I doubt voluntary transfer of proprietary "research" information from within the industry is a viable concept. The reason industry does such research is to gain a competitive advantage, and no one gives up a competitive advantage.

\section{Section 2.4 Analysis \& Planning}

- I believe that data collection from downsized and bankrupt companies should not be added to the USGS Core Collection initiative. The organization of "oilfield data" so that it is available to independent operators will require quite a bit more sophistication than required to maintain a Core Research Library.

\section{Figure 2.4.2 Analytical ToOls}

- Drilling is now feeding back to exploration and influencing geophysical interpretation discovery economics (p. 83).

\section{Section 2.5 Technology Transfer}

- The ideas on Technology Transfer are a good start; however there is no way all these ideas can be implemented in the period prior to 2000. It would be helpful if some priorities or focuses were indicated. It would also be useful to say that a reprioritization would occur after three years of trying various methods. It is not clear in the Technology Transfer chapter that the statement on p. 41 "[transfer] will be accomplished by close coordination with organizations currently being set up in the Technology Transfer area (see Chapter 2.5)." There is barely any mention of "organizations" other than GRI in the Technology Transfer chapter. A 10\% Technology Transfer expense item should be included in all DOE funded proposals so that money could be applied as recommended by DOE to transfer of technology from individual projects.

- Significantly more funding than for FY 1995 for technology transfer will be required if that part of the program is to succeed.

- Regarding the PTTC. Industry-supported and government/industry imply that the organization will be cofunded. Is it envisioned that industry will cash up to be involved or is money "in-kind" envisioned?

- It is vitally important for DOE to understand industry needs and communicate frequently.

- Technology Transfer is not a separate topic (p. 91), but an individual part of each researcher's job.

- Hands-on, joint problem solving is the only technology transfer that matters. Traditional conferences, papers, etc., may serve record keeping, but not technology transfer.

- Innovative technology transfer tools must be imagined and experimented 
with. Differences between independents and majors may be shrinking, especially in the technology transfer area. If we keep doing things the same old way, we'll get the same old results.

- How does the independent sector access the ongoing work associated with the plan? Data must be made available as it is developed or it might be too late. As you know, in past DOE plans, participation by small companies did not occur to the degree needed primarily because of the complexity in getting projects on an agenda.

- Several states have Geological Surveys, Bureaus of Mines, etc., that have responsibilities to the petroleum industry. They should be included as an additional set of interested parties.

\section{Section 2.5.1.2 Stakeholder Outreach}

- We strongly encourage using the Petroleum Technology Transfer Council (PTTC) as the agent to facilitate technology transfer activities and increasing the proposed budget for technology transfer.

\section{SECtion 2.5.1.3 InTERnATONal}

- The Minerals Management Service (MMS) has recently established a Memorandum of Understanding (MOU) with Russia through the Committee of the Russian Federation on Geology and the Use of Underground Resources (ROSKOMNEDRA). This has included training sessions on resource evaluation procedures. The MMS may be able to assist DOE efforts through our MOU with ROSKOMNEDRA.

\section{Figure 2.5.2 Technology Transfer, the Pipeline to Key Stakeholders}

- The national technology transfer network should be at a very reasonable cost for licensing and use a PC modem format for the widest range of users.

\section{Section 2.6 Field Demonstration ProjeCts}

- In several places, you talk about assisting the independents. Where does assistance to major integrated oil companies come in?

- Based on the availability of adequate research facilities to do full scale Class 1 through 8 projects, allowing bids on two classes per year is one too many.

\section{Section 2.6.1.2 Near-Term and Mid-Term Technologies for Class Demonstramon}

- In indicating what classes of reservoirs will be selected in which years, either indicate what the classes are or reference Table 2.6.4.

\section{SECTION 2.6.1.5 Assist InDEPENDENTS}

- The perception that the current field demonstration process is too slow and cumbersome is shown under Section 2.6.1.2, which demonstrates that the process is slow and cumbersome as well as underfunded. Why only one reservoir class per year? Most independents rarely possess a project in the reservoir class being solicited at the appropriate time.

\section{Section 2.6.1.6 Reservoir Management DeMONSTRATIONS}

- Isn't BDM NIPER? (Reply: NIPER is the DOE research facility in Bartlesville, $O K$ )

- Please spell out NPR.

- We strongly encourage utilizing the PTTC as the vehicle to transfer effectively the knowledge gained from the field demonstration projects and increasing the budget for this activity. 


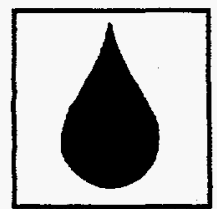

\section{Section 2.7 Oll Downstream Operations}

- For downstream processing, there are three areas that are not addressed. The first is process control technology and implementation. The second is modeling and the associated "real time" computer control. The third is a total process/product optimization model. These are capabilities that reside in DOE labs, and are more appropriate for government funded research than specific technologies for heavy oil processes.

- For some of your processing technologies, it would be useful to have an environmental component more explicitly added. (The focus right now is on environmental through the process side). For example, you might consider including a statement related to your desire to support R\&D that will help industry address environmental regulatory mandates in a cost-effective manner.

- There are three components in the processing side. First is the development of enabling technologies (or enabling data such as program in thermodynamics) that will support environmentally benign and economically competitive refining processes. Second is the support you will give to programs that investigate innovative refining processes. Third is your support of environmentally $R \& D$ related to oil processing.

The mechanism for doing the above can vary significantly. To support enabling technology or fundamental data acquisition, you don't need the direct cooperation of the industry. It may be worthwhile to work with industry consortia to develop the information, but it can be done by supporting programs at NIPER or national laboratories in these areas.

- The mechanism for developing innovative refining processes can be similar to the one you are already using; i.e., CRADAs with individual companies or groups of companies. However, as you realize, many companies feel that the government has little to offer in the process side. Yet, many would agree that only the government can support "far out" and truly innovative concepts.

\section{Section 2.7.1 Program Overview}

- No description is provided regarding the Refinery of the Future Program. Such a description should be provided to give the reader an understanding of how the elements of downstream R\&D fit together.

\section{SeCtion 2.8 Environmental Research}

- On environmental considerations, we do not need more governmental supervision in that area. What is needed is reasonable regulation and prompt decision making.

- I have a problem with your statement "to protect the environment." First of all, oil is a biodegradable substance. It cleans itself up. I think you will have to admit that what our industry has done in the last decade to alleviate the environmental problems associated with the production of hydrocarbons is significant.

- It is very important to have basic data to support or refute environmental regulations. Such R\&R should not be written without adequate background scientific and economic data. Research in these instances often proceeds in haste and after the fact.

- My final comment has to do with DOE's apparent obsession with the environment. I noticed that the word environment and environmentally, etc., were inserted into sentences and paragraphs where they were not appropriate. 
- It is in the environmental area that we see a really different way you can work with industry. Rather than work with individual companies, we would hope that the focus would be on working with industry groups. We see PERF being a possible forum for this type of interaction. We also would like to see the effort not be project based but program based. In other words, the DOE would participate in program planning meetings with industry to come up with solutions to key environmental issues. Initially, at least, it will be much easier to work in those areas in which information generated can be nonproprietary and shared with all of industry. I believe most industry representatives would also like to see a shift in funds away from process side to the environmental side. 


\section{OTHER PROGRAM IDEAS}

- "Neural Networks for Reservoir Management." This program has been proposed by Dr. Larry Lake of UT and Mr. Joe Brown of Electronics and Computer Technology Corporation. The program offers an Artificial Intelligence based solution to production forecasting. We suggest inclusion of this program in the DRAFT in an expanded form to cover Field Development Optimization and Forecasting.

- "Development of Techniques for Scale Up in Reservoir Definition"

- "Automatic History Matching"

- "Comprehensive Evaluation of In Situ Hydraulic Fracture Growth Behavior"

- "Composite Material for Offshore Application" (This program can be in corroboration with Offshore Technology Research Center@ Texas A\&M)

- "Risk Assessment of Structural Deformation Due to Environmental Overload"

- "Platform Removal"

- "Modeling Transient Multiphase Flow in Pipes"

- The document could use more input on how DOE plans to use the various selected research areas to produce more oil. The select research areas are not new and have been well researched by the oil companies for many years. Major new technical breakthroughs are needed to reduce even the slope of the oil decline curve. I would trade most of the document for four or five specific projects designed to produce economically new domestic oil.

- The part of the industry in which we participate, and where significant research and new technology are needed, is related to transportation of the crude oil from the well head to downstream processing plants. This need is particularly acute for oil produced offshore, as much of the oil that is yet to be discovered lies in deepwater reservoirs off the continental shelf. Bringing this oil to shore for downstream processing will require significant developments over current technology for economic development of these fields. We believe their economic development is essential if the United States is to maintain its role as a top petroleum producer.

- As part of the vision, the United States would be a worldwide leader in development of economically competitive energy systems and an exporter of oil-related technology and services. As a service company to the petroleum industry we also share this vision, but we are concerned. Most of the technology developed for the offshore industry has occurred in Europe, and much of it has been partially funded through European government agencies. For example, during the period of 1973-90, the European Economic Community (EEC), through the Directorate General for Energy, has funded almost 700 projects for offshorerelated activities with an overall financial support of about half billion ECU ( $\$ 676,000,000$ at current exchange rates). While this has served the European gas and oil industry well, it hurts U.S. industries like ours who would like to be a provider of 
these services. As itstands, we fear that we will not be the exporter of offshore-related products and services. In addition, we fear that without DOE support, the needed offshore technologies will be too costly for equipment suppliers and engineering firms to develop independently.

- Some critical areas where we would like to see the Department of Energy consider programs to meet the stated goals are:
- Subsea production systems including separation, pressure boosting, electrical power, and controls

- Composites for offshore structures

- Advanced pipeline and structure inspection \& monitoring

- Real-time corrosion monitoring of pipelines \& structures 